\author{
UNIVERSIDADE DE SÃO PAULO \\ ESCOLA DE ENGENHARIA DE SÃO CARLOS \\ DEPARTAMENTO DE ENGENHARIA DE PRODUÇÃO \\ PROGRAMA DE PÓS-GRADUAÇÃO EM ENGENHARIA DE PRODUÇÃO
}

SIMONE CRISTINA DE OLIVEIRA GOBBO

Aplicação da teoria de redes no contexto de uma rede de médicos com vínculos profissionais em unidades de saúde públicas e privadas 



\section{Aplicação da teoria de redes no contexto de uma rede de médicos com vínculos profissionais em unidades de saúde públicas e privadas}

Tese apresentada para defesa a Escola de Engenharia de São Carlos da Universidade de São Paulo para obtenção do título de Doutor em Engenharia de Produção

Área de Concentração: Processos e Gestão de Operações.

Orientador: Prof. Dr. Marcel Andreotti Musetti 


\section{AUTORIZO A REPRODUÇÃO TOTAL OU PARCIAL DESTE TRABALHO, POR QUALQUER MEIO CONVENCIONAL OU ELETRONNICO, PARA FINS DE ESTUDO E PESQUISA, DESDE QUE CITADA A FONTE.}

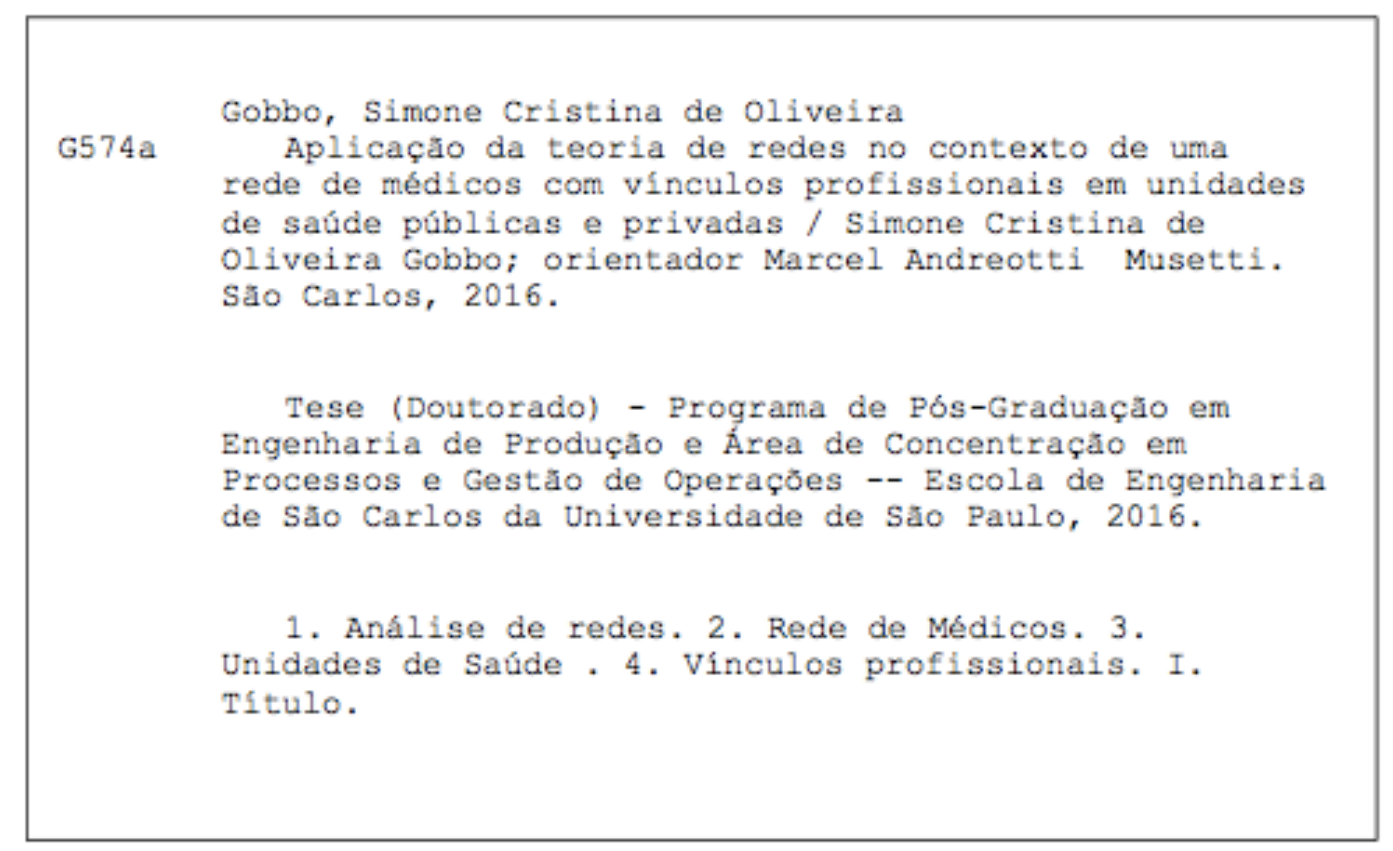


FOLHA DE JULGAMENTO

Candidata: Bacharel SIMONE CRISTINA DE OLIVEIRA GOBBO.

Título da tese: "Aplicação da teoria de redes no contexto de uma rede de médicos com vínculos profissionais em unidades de saúde públicas e privadas".

Data da defesa: 03/08/2016.

Comissão Julgadora:

Prof. Dr. Marcel Andreotti Musetti (Orientador)

(Escola de Engenharia de São Carlos/EESC)

Prof. Dr. Mário Sacomano Neto

(Universidade Federal de São Carlos/UFSCar)

Prof. Dr. Bernardino Geraldo Alves Souto

(Universidade Federal de São Carlos/UFSCar)

Prof. Associado André Lucirton Costa

(Faculdade de Economia, Administração e Contabilidade de Ribeirão Preto/FEAR-USP)

Prof. Dr. Luiz Ricardo Kabbach de Castro

(Escola de Engenharia de São Carlos/EESC)
Resultado:

APROVADE

APROVADA

LPRONADA 
Dedico este trabalho

Ao meu querido esposo, José Alcides.

À minha amada filha, Chiara.

Aos meus pais, Antenor e Antonia. 


\section{AGRADECIMENTOS}

Ao meu esposo, por me amar, respeitar e sempre me apoiar e incentivar pela busca de conhecimento. Ele carinhosamente nos ajudou, cuidando de nossa filha, nos momentos em que eu me dedicava a tese. Pacientemente ele ouviu as minhas queixas nos momentos de dificuldades e as minhas alegrias nos momentos de progressos deste trabalho.

Ao meu orientador, Prof. Dr. Marcel Andreotti Musetti, pelo carinho, apoio e incentivo à essa pesquisa.

A todos os professores e funcionários do Departamento de Engenharia de Produção da Escola de Engenharia de São Carlos, pelo aprendizado e pela cordialidade.

Aos membros do Grupo de Pesquisa Logística, Organização, Sistemas e Sociedade (LOGOSS) e colegas de doutorado, o meu agradecimento, em especial: Catarina Barbosa Careta, Luis Carlos de Marino Schiavon, Rodrigo Amâncio Briozo e Thomás Silva Oliveira.

A todos os professores e amigos do Departamento de Packaging Logistics da Lund University, Suécia, pelo provimento de um espaço de trabalho para realização de parte da revisão bibliográfica desta pesquisa. Em especial agradeço pela amizade, aprendizado e orientação desde a primeira visita em 2008: Annika Olsson, Helena Lindh, Maisam Abbasi, Gunilla Jönson, Daniel Hellström e Erik Andersson.

Aos professores da banca: Dr. André Lucirton Costa, Dr. Bernardino Geraldo Alves Souto, Dr. Luiz Ricardo Kabbach de Castro e Dr. Mário Sacomano Neto, pela participação nesse trabalho e pelas contribuições.

Ao Departamento de Engenharia de Produção, da UNESP de Bauru, pelo provimento de um espaço de trabalho, acesso ao Software NetMiner3, para realização desta pesquisa. Pela ajuda na elaboração das matrizes e planilhas agradeço especialmente: Profa. Gladys Barriga, Prof. Enzo Mariano, Prof. Manoel Henrique Salgado, Alexandre Benedetti e Marcelo Zanetti.

A todos os meus amigos, em especial: Ana Beatriz, Charbel, Daniel, Greice, Rosane e Rosani pelos conselhos, compreensão e amizade, que muito me estimularam ao enfrentamento deste 
desafio.

A toda equipe do Centro de Convivência Infantil "Gente Miúda" (CCI) pelos cuidados e pelo carinho com a minha filha Chiara, que me ajudou a focar no desenvolvimento desta tese de doutorado.

Aos médicos e amigos: Dr. Silvio, Dr. Itamar e Dr. Hilton pelas conversas que enriqueceram o entendimento das análises dos resultados.

A toda a minha família, pela companhia e apoio nos momentos difíceis.

A Deus, por me ter concedido saúde, coragem e fé, durante todo o percurso desta jornada. 


\section{RESUMO}

GOBBO, S.C.O. Aplicação da teoria de redes no contexto de uma rede de médicos com vínculos profissionais em unidades de saúde públicas e privadas. 2016. 193f. Tese (Doutorado) - Escola de Engenharia de São Carlos, Universidade de São Paulo, São Carlos, 2016.

Estudos de redes de médicos com vínculos profissionais no setor público e privado de saúde são praticamente inexistentes na literatura de saúde. Este trabalho objetiva desenvolver uma análise da rede de médicos com vínculos profissionais em unidades de saúde públicas e privadas. Adicionalmente, busca-se identificar os principais Hubs nas unidades de saúde no Município de Bauru e propor um esquema conceitual para análise da rede em estudo. A delimitação desse estudo foi feita a partir de unidades de saúde vinculadas ao Sistema Único de Saúde (SUS) no município sede de um Departamento Regional de Saúde (DRS) do Estado de São Paulo. A principal fonte de dados utilizados nesse trabalho foi o sistema de Cadastro Nacional dos Estabelecimentos de Saúde (CNES). O mapeamento dessa rede envolveu três níveis de análise: Unidades de Saúde (organização); Médicos (pessoas) e Ocupações (cargos). Desenvolveu-se uma pesquisa empírica, de cunho quantitativo, por meio do mapeamento da rede com o auxílio do software de análise de redes organizacionais. Adaptou-se a fórmula do modelo Hub and Spoke, proposta originalmente para a área de logística por Derudder et al. (2007), para avaliar o grau de Hubiness das unidades de saúde. Adicionalmente, foi proposto um esquema conceitual de análise da rede de médicos no SUS que auxiliou no entendimento dessa rede e ilustra os atores tipicamente encontrados nos diferentes níveis de atendimento do SUS. Os Hubs tipicamente encontrados foram atores que atuam nos níveis de Alta Complexidade (AC) e, usualmente compostos pelos hospitais gerais. Os médicos que declaram as ocupações Médico da Estratégia de Saúde da Família, Ginecologista e Pediatra são aqueles atores típicos que atendem no nível Atenção Básica (AB). Portanto, este trabalho contribui tanto para a teoria, com o estabelecimento de questões de pesquisa descritivas para serem refinadas na forma de hipóteses, passíveis de serem testadas em estudos futuros, quanto para a prática, com a proposição de um esquema conceitual de análise da rede de médicos no SUS, pela adaptação da fórmula do modelo $H u b$-and-Spoke para identificação das as unidades de saúde que atuam como $H u b$ e, finalmente, pela identificação da necessidade de políticas 
para a gestão dos vínculos profissionais médicos no SUS. As principais limitações do estudo envolvem, a delimitação da pesquisa em um município e do fato dos médicos vinculados ao Programa Mais Médicos não serem registrados nesse sistema.

Palavras chaves: Análise de redes; Rede de Médicos; Unidades de Saúde e Vínculos profissionais 


\begin{abstract}
GOBBO, S.C.O. Application of Network Theory in the context of a physician network with professional linkages in public and private healthcare units. 2016. 193f. Doctorate's Thesis (Production Engineering) - Engineering School of São Carlos, University of São Paulo, São Carlos, 2016.
\end{abstract}

Studies of physicians' networks with professional ties in the public and private healthcare sector are virtually non-existent in the healthcare literature. This study aims to develop a physician network analysis with professional links with public and private healthcare facilities. In addition, it seeks to identify the main "Hubs" in the healthcare sector in Bauru (Brazil), and to propose a conceptual framework for analysis of this network. The delimitation of this study was made from healthcare units linked to the Brazilian Unified Healthcare System (Sistema Único de Saúde - SUS) in a municipality that headquarters a Regional Healthcare Department (DRS).The main data source used in this work was the DATASUS/CNES system. The mapping of the network involved three levels of analysis: Healthcare Units (organization); Physicians (people) and Occupations (positions). An empirical research of quantitative nature was developed, through the healthcare network mapping with organizational networks analysis software. The Hubiness degree formula, originally proposed for the Hub-and-Spoke model of logistics sector for Derudder et al. (2007), was adapted to assess the degree of Hubiness of healthcare units. In addition, it was proposed a conceptual framework for the analysis of physician network in SUS that supported the understanding of that network, and illustrated the actors typically found in different SUS service levels. Hubs are typically composed by actors who act in the levels of High Complexity (AC) and usually consist of the general hospitals. Physicians that declare Medical occupations of the Family Healthcare Strategy, Gynaecologists and Paediatricians are those typical actors that meet the Primary level (AB). Therefore, this study contributes to both, theory, with the proposition of descriptive research questions to be refined in the form of hypotheses that can be tested in future research, and practice, with the proposition of a conceptual framework of the physicians network in SUS, the adaptation of the Hubiness degree formula for identification of healthcare units that act as Hubs and, finally by identifying the need for public policies for the management of physicians professional 
linkages in SUS. The main limitations of the study involve the delimitation of research in a municipality and the fact that physicians linked to the Program "More Physicians" are not registered in the system.

Keywords: Healthcare sector; SUS; physician's professional linkages; Network theory; networks analysis. 


\section{LISTA DE FIGURAS}

Figura 1 - Abordagem contextual para a análise da rede.................................................25

Figura 2 - Elementos morfológicos das redes..................................................................

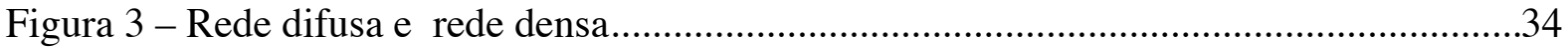

Figura 4 - Gráfico com 5 pontos e 5 arestas........................................................................

Figura 5 - Uma estrela ou roda com cinco pontos..............................................................42

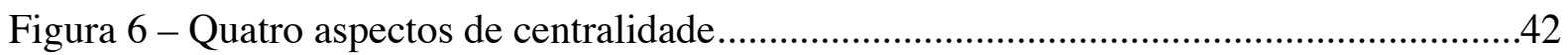

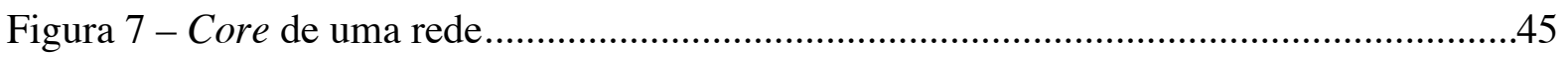

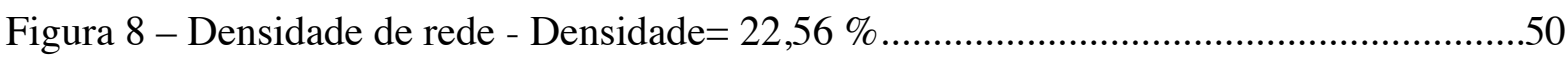

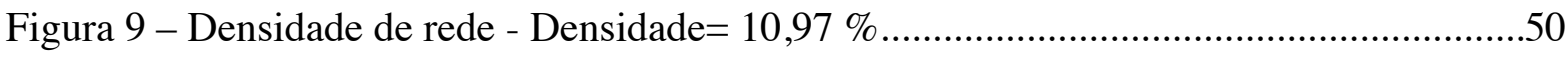

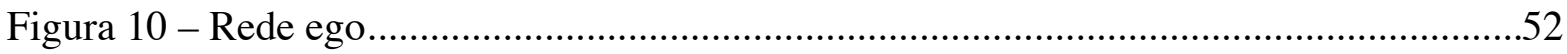

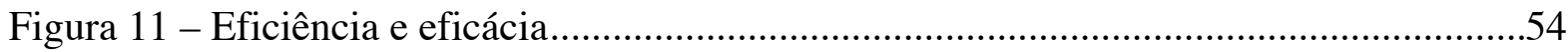

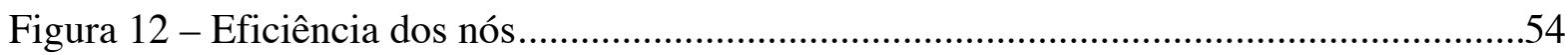

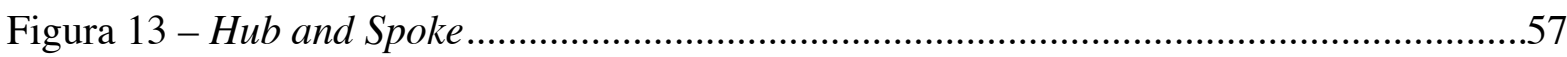

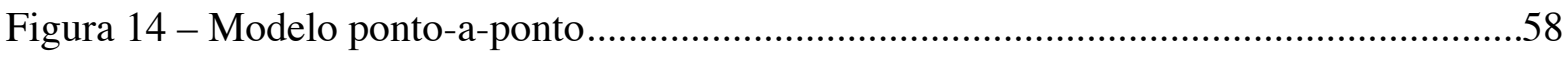

Figura 15 - Mapa com a divisão do Estado de São Paulo nos DRS .......................................75

Figura 16 - Ilustração da rede do DRS de Bauru.................................................................77

Figura 17 - Análise de centralidade (degree) - Nível de atendimento do SUS......................92

Figura 18 - Análise de centralidade (degree) - Nível de atendimento do SUS ......................92

Figura 19 - Análise de centralidade (degree) - Atendimento SUS versus Privado.................93

Figura 20 - Análise de centralidade (degree) - Atendimento SUS versus Privado................93

Figura 21 - Análise de centralidade (coreness) - Nível de atendimento no SUS...................96

Figura 22 - Análise de centralidade (closeness) - Nível de atendimento do SUS ..................98

Figura 23 - Análise de centralidade (betweenness node) - Nível de atendimento do SUS...101

Figura 24 - Análise do grau de centralidade por tipo de estabelecimento ............................104

Figura 25 - Análise do grau de centralidade por esferas de gestão ......................................105

Figura 26 - Mapa geral da rede por esferas de gestão..........................................................115

Figura 27 - Mapa geral da rede - Atendimento SUS versus Atendimento Privado..............116

Figura 28 - Mapa geral da rede - Nível de Atendimento do SUS ......................................118

Figura 29 - Visualização dos vizinhos do ator Hospital das Clínicas de SP ...........................118

Figura 30 - Visualização dos vizinhos do Hospital das Clínicas de Botucatu........................118

Figura 31 - Visualização dos vizinhos da Santa Casa de Pederneiras...................................119

Figura 32 - Análise de centralidade (degree) - Quantidade de ocupação dos médicos ........126 
Figura 33 - Análise de centralidade (degree) - Quantidade de vínculos dos médicos 128

Figura 34 - Análise de centralidade (degree) - Quantidade de carga horária semanal de trabalho dos médicos

Figura 35 - Análise de centralidade (coreness) - Quantidade de carga horária dos médicos 131

Figura 36 - Análise de centralidade (closeness) - Quantidade de carga horária semanal de trabalho dos médicos

Figura 37 - Análise de centralidade (Node Betweeness) - Quantidade de carga horária semanal de trabalho dos médicos

Figura 38 - Análise de centralidade (degree)

Figura 39 - Análise de centralidade (mapa do núcleo) 150

Figura 40 - Análise de centralidade (mapa completo) 150

Figura 41 - Análise de centralidade (Coreness). 152

Figura 42 - Análise de centralidade (Closeness).. .154

Figura 43 - Análise de centralidade ( betweenness - node) 156

Figura 44 - Mapa geral da rede de ocupações dos Médicos. 157

Figura 45 - Análise de hubs de saúde 168

Figura 46 - Esquema conceitual de análise da rede de médicos no SUS 175 


\section{LISTA DE GRÁFICOS}

Gráfico 1 - Unidades de saúde distribuídas por esferas de gestão.....................................113

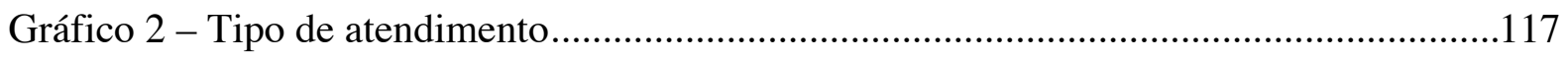

Gráfico 3 - Unidades de saúde por nível de atendimento no SUS ......................................119

Gráfico 4 - Quantidade de médicos por ocupação...............................................................126

Gráfico 5 - Quantidade de vínculos profissionais por médicos ...........................................128

Gráfico 6 - Ocupações com maiores média de carga horaria semanal..................................164 


\section{LISTA DE QUADROS}

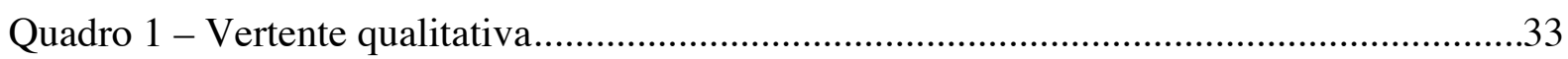

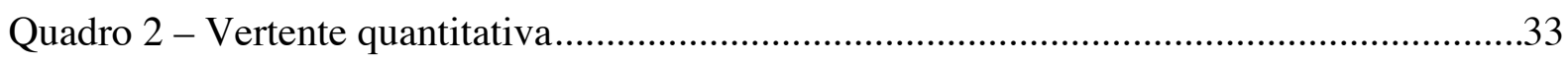

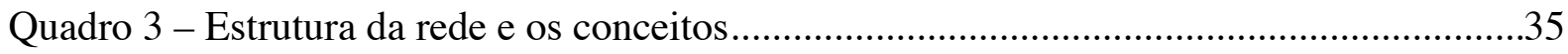

Quadro 4 - Principais conceitos sobre as formas de análise de redes ...................................40

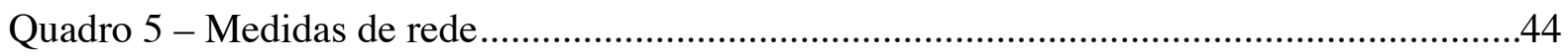

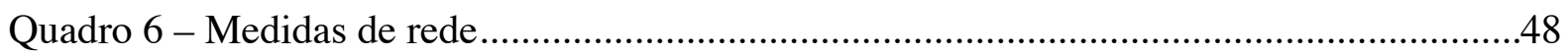

Quadro 7 - Medidas e formas de análise de redes...............................................................56

Quadro 8 - Pesquisas sobre redes do setor de saúde..........................................................60

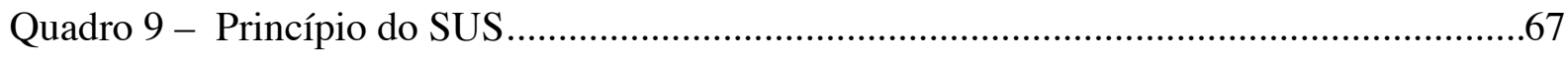

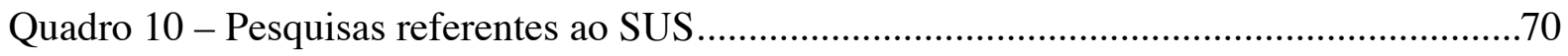

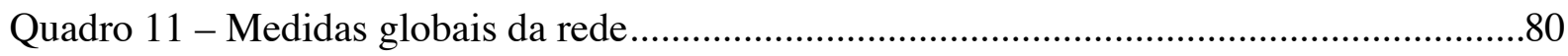

Quadro 12 - Medidas de análise - Nível de análise: unidades de saúde...............................87

Quadro 13 - Resumo das discussões sobre as medidas da rede das unidades de saúde........120

Quadro 14 - Medidas de análise - Nível de análise: médicos.............................................122

Quadro 15 - Resumo das discussões sobre as medidas da rede no nível de análise -

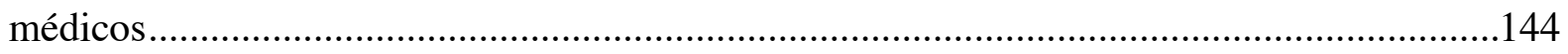

Quadro 16 - Medidas de análise - Nível de Análise: ocupações dos médicos......................146

Quadro 17 - Resumo das discussões sobre as medidas da rede no nível de análise - ocupações

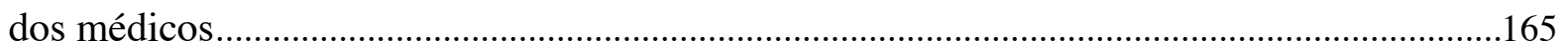

Quadro 18 - Quadro descritivo dos principais resultados sobre as medidas globais da rede e

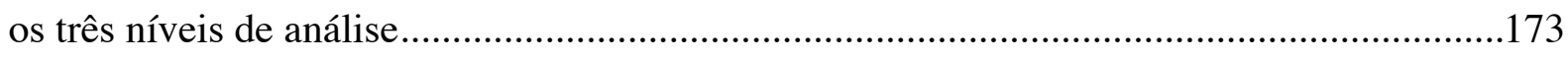

Quadro 19 - Os cinco atores com maior grau de centralidade nos três de níveis de análise de rede...

Quadro 20 - Os cinco atores com maior grau de betweenness nos três de níveis de análise de rede.

Quadro 21 - Os cinco atores com maior índice de buraco estrutural nos três de níveis de análise de rede. 


\section{LISTA DE TABELA}

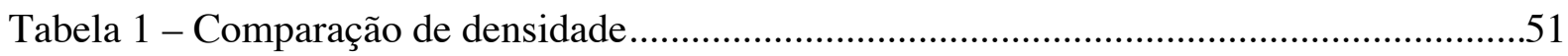

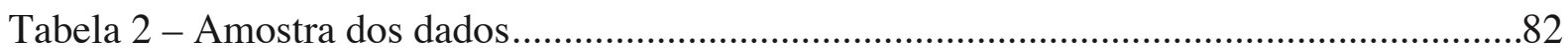

Tabela 3 - Relatório por unidade de saúde do Município de Bauru.........................................84

Tabela 4 - Parte da Matriz de 1 modo do mapeamento da rede de médicos com vínculos profissionais em unidades de saúde públicas e privadas.......................................................86

Tabela 5 - Distribuição do índice do grau de centralidade da rede.........................................88

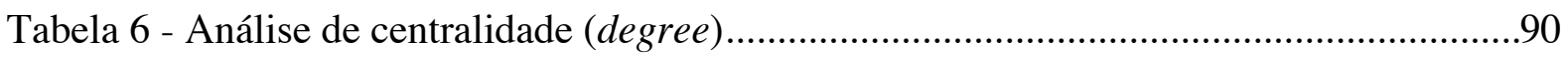

Tabela 7 - Análise de centralidade (coreness) ....................................................................95

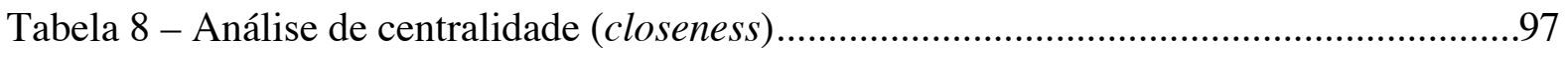

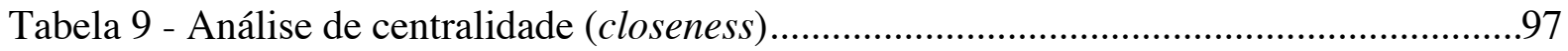

Tabela 10 - Análise de centralidade (betweenness - node)..................................................99

Tabela 11 - Análise de centralidade (betweenness - node) ...................................................100

Tabela 12 - Análise de centralidade (betweenness - link) ..................................................101

Tabela 13 - Centralidade por tipo de estabelecimento - Dados Box Plot ..............................103

Tabela 14 - Centralidade por esferas de gestão - Dados Box Plot .........................................105

Tabela 15 - Análise de centralidade (Neighbor - degree) ....................................................106

Tabela 16 - Número do tipo de nó (Neighbor - degree)......................................................107

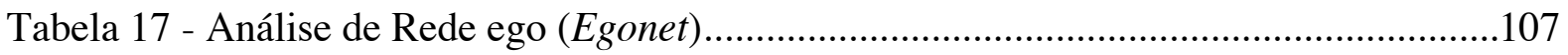

Tabela 18- Análise de Rede ego (Egonet) - tamanho.........................................................108

Tabela 19 - Análise de Rede ego (Egonet) - densidade.......................................................108

Tabela 20 - Distribuição de medidas de buraco estrutural...................................................110

Tabela 21 - Buraco estrutural - Medidas de limitação agregada e eficiência........................111

Tabela 22 - Buraco estrutural - Medidas de tamanho eficaz e hierarquia............................112

Tabela 23 - Parte da Matriz de 1 modo do mapeamento da rede de médicos com vínculos profissionais em unidades de saúde públicas e privadas - Unidade de análise Médicos.......121

Tabela 24 - Distribuição do índice do grau de centralidade...................................................124

Tabela 25 - Análise de centralidade (degree) ....................................................................125

Tabela 26 - Análise de centralidade (coreness) .................................................................130

Tabela 27 - Análise de centralidade (closeness) .................................................................132

Tabela 28 - Análise de centralidade (closeness) ..................................................................133

Tabela 29 - Análise de centralidade (betweenness - node) ....................................................135

Tabela 30 - Análise de centralidade (betweenness - node) ...................................................135 
Tabela 31 - Análise de centralidade (betweenness - link)................................................137

Tabela 32 - Análise de centralidade (neighbor - degree) ...................................................138

Tabela 33 - Número do tipo de nó (neighbor - degree) ........................................................138

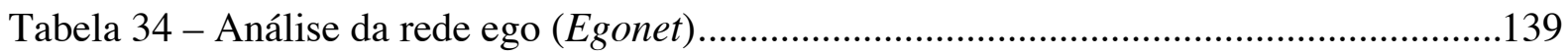

Tabela 35 - Análise da rede ego (Egonet) - tamanho.........................................................139

Tabela 36 - Análise da rede ego (Egonet) - densidade .......................................................140

Tabela 37 - Distribuição de medidas de buraco estrutural.....................................................141

Tabela 38 - Medidas de buraco estrutural.........................................................................142

Tabela 39 - Matriz (parte) da rede de ocupações dos médicos.............................................146

Tabela 40 - Distribuição do índice do grau de centralidade.................................................148

Tabela 41 - Análise de centralidade (degree) …..................................................................148

Tabela 42 - Análise de centralidade (coreness) ...................................................................151

Tabela 43 - Distribuição do índice do grau de centralidade (closeness) .................................153

Tabela 44 - Análise de centralidade (closeness) ....................................................................153

Tabela 45 - Análise de centralidade (betweenness - node) ...............................................155

Tabela 46 - Análise de centralidade (betweenness - node) ................................................155

Tabela 47 - Análise de centralidade (betweenness - link ....................................................157

Tabela 48 - Análise de centralidade (neighbor - degree) …................................................158

Tabela 49 - Número do tipo de nó (neighbor - degree) .....................................................158

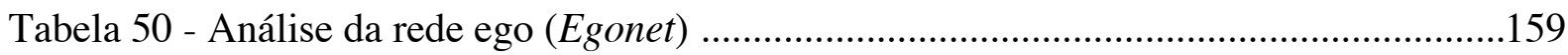

Tabela 51 - Análise de Rede Ego (Egonet) - tamanho.......................................................159

Tabela 52 - Análise da rede ego (Egonet) - densidade .....................................................160

Tabela 53 - Distribuição de medidas de buraco estrutural.....................................................161

Tabela 54 - Distribuição de medidas de buraco estrutural (limitação e eficiência).................162

Tabela 55 - Distribuição de medidas de buraco estrutural (tamanho e hierarquia)................163

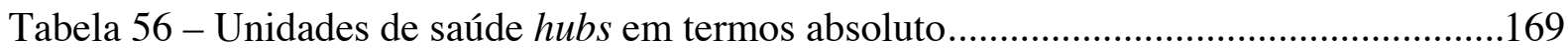

Tabela 57 - Unidades de saúde hubs em termos relativos....................................................170

Tabela 58 - Hubs de saúde mais importante em termos unidades de saúde conectadas.......171 


\section{LISTA DE SIGLAS E ABREVEATURAS}

AB Atenção Básica

AC Alta Complexidade

BDD Banco de Dados Detalhados

CBO Classificação Brasileira de Ocupações

CNES Cadastro Nacional dos Estabelecimentos de Saúde

CROSS Central de Regulação de Ofertas de Serviços de Saúde

DATASUS Departamento de Informática do SUS

DRS Departamento Regional de Saúde

HE Hospitais de Ensino (HE),

HS Hub and Spoke

MC Média Complexidade

ONA Organizational Network Analysis

SNA Social Network Analysis

SUS Sistema Único de Saúde

US Unidades de Saúde

VMED Vínculos Médicos 


\section{SUMÁRIO}

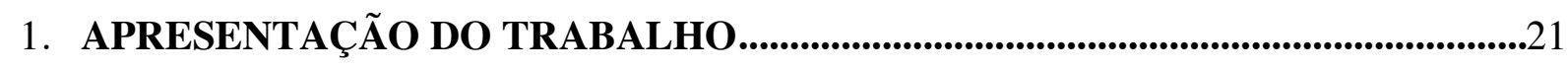

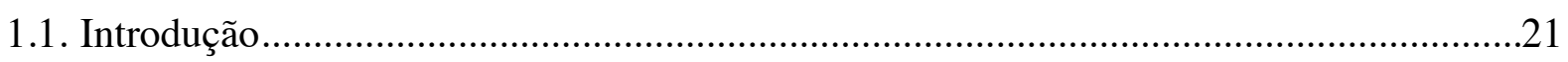

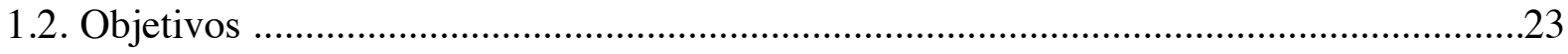

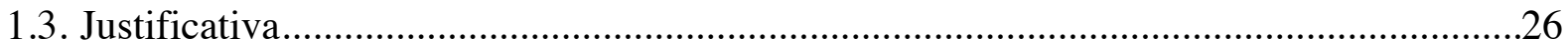

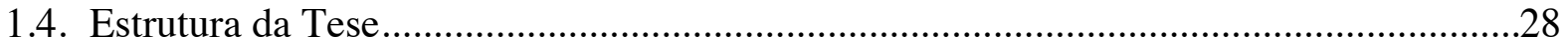

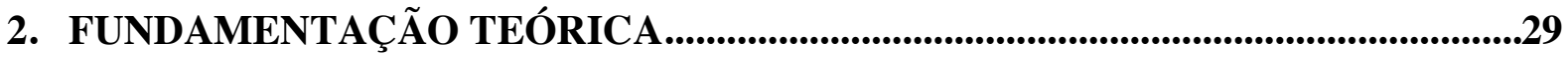

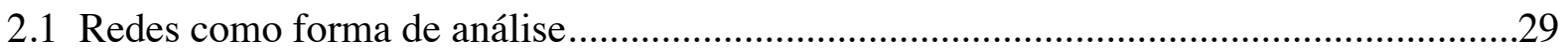

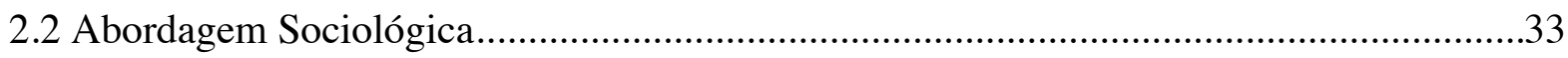

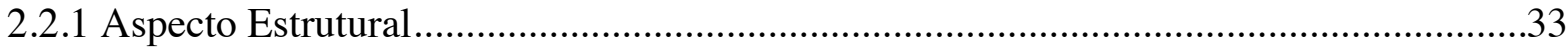

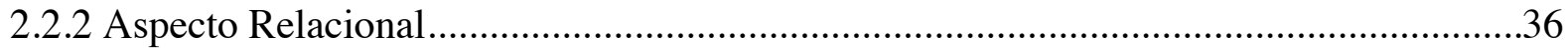

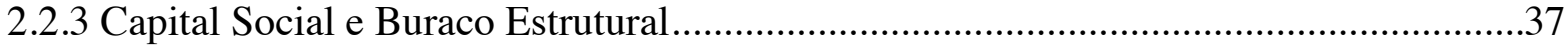

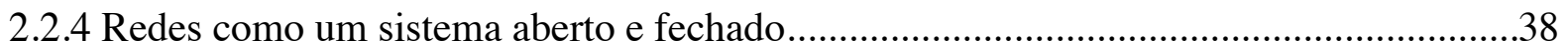

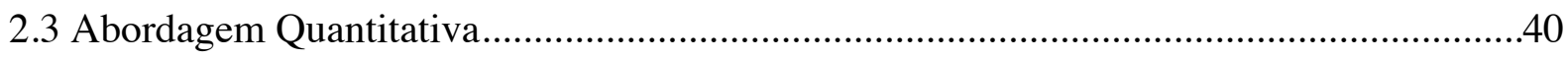

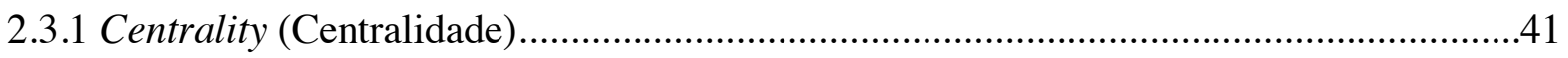

2.3.1.2 Degree Centrality (Grau de centralidade) ...............................................................43

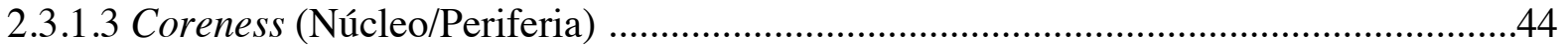

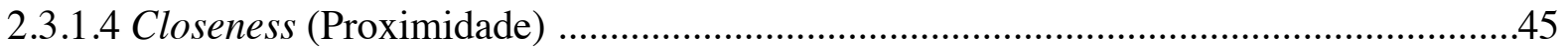

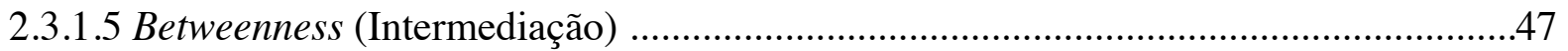

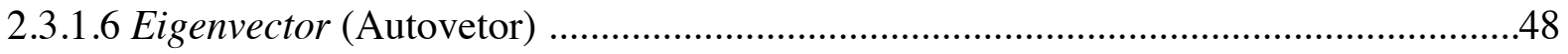

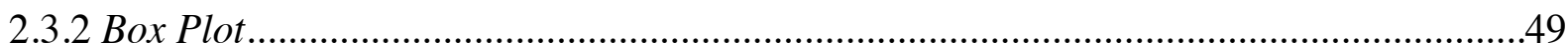

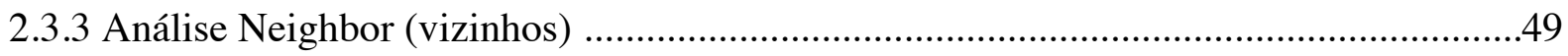

2.3.4 Density (Densidade) e Inclusiveness (Inclusão) ...........................................................50

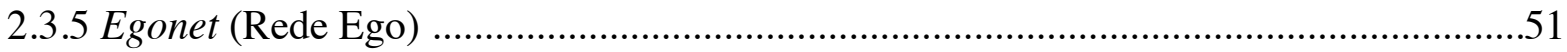

2.3.6 Structural Hole (Buraco Estrutural) ...........................................................................53

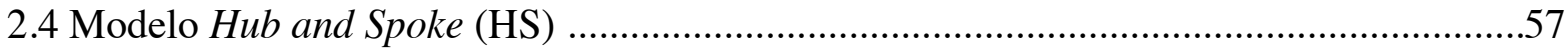

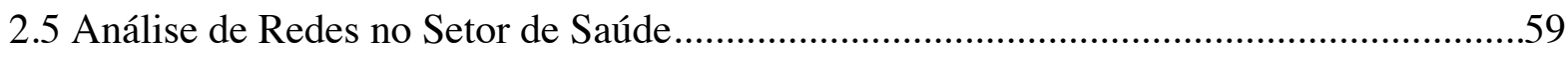

2.6 Sistema Único de Saúde (SUS) .....................................................................................64

3 MÉTODOS E PROCEDIMENTOS DE PESQUISA....................................................73

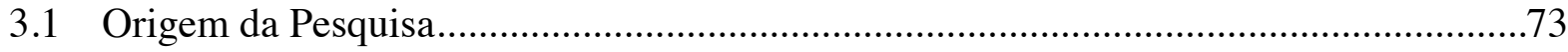

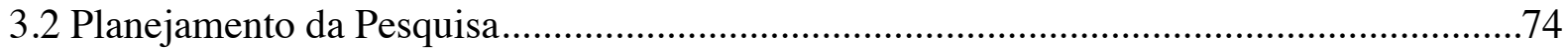

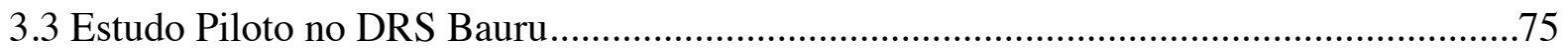

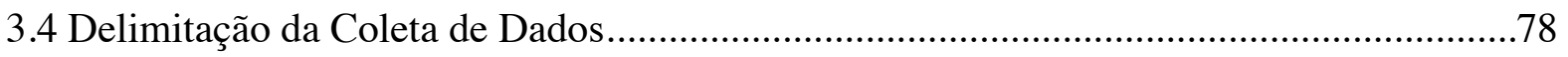




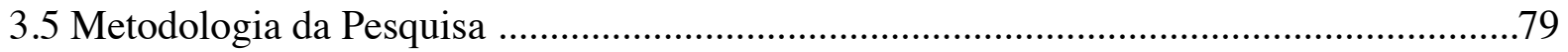

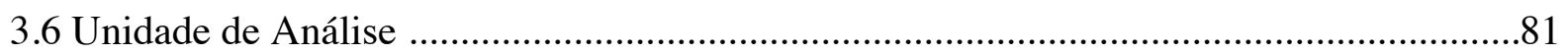

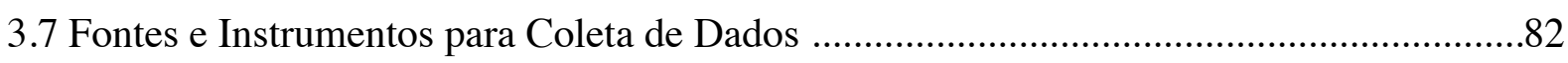

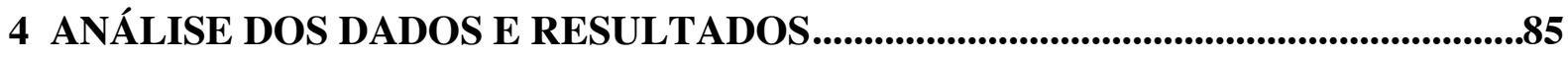

4.1 A análise dos dados quantitativos no software NetMiner3 …..........................................85

4.1.1 Nível de Análise - Organizacional (Unidades de Saúde) ...........................................85

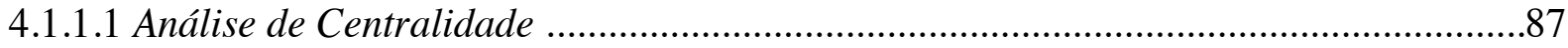

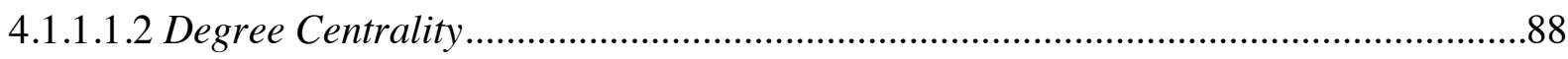

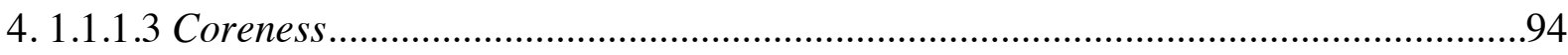

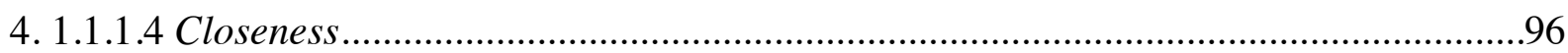

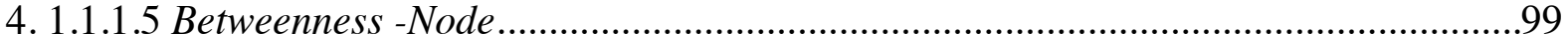

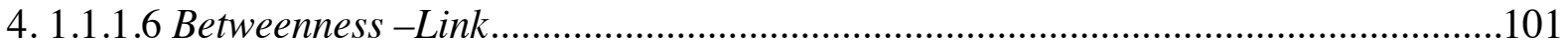

4. 1.1.1.7 Análise de Centralidade Gráfico Box Plot ...............................................................102

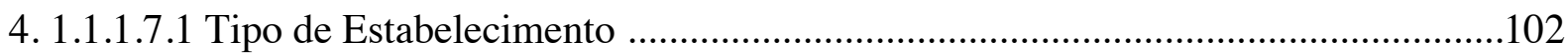

4. 1.1.1.7.2 Esferas de Gestão.......................................................................................104

4.1.1.2 Análise - Neighbor, Density e Inclusiveness .........................................................106

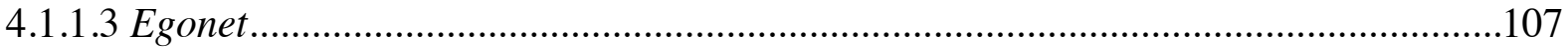

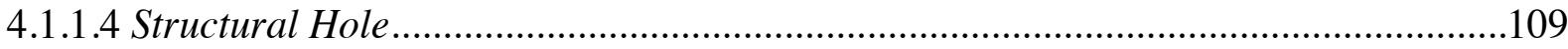

4.1.1.5 Análise geral da rede e síntese dos resultado........................................................112

4.1.2 Nível de Análise - Pessoas (Médicos) ............................................................................121

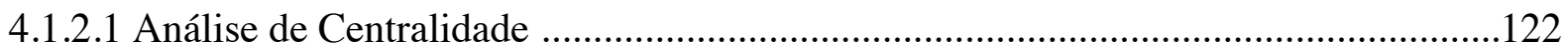

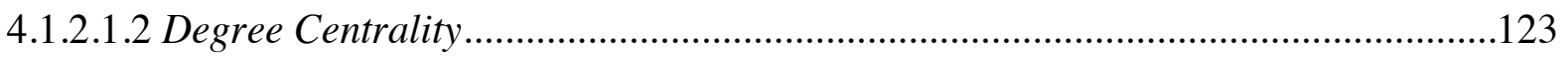

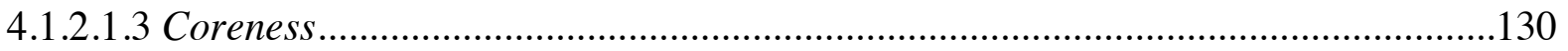

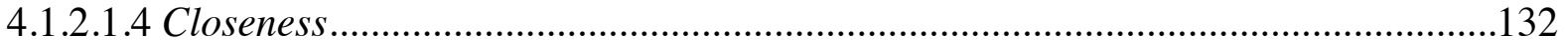

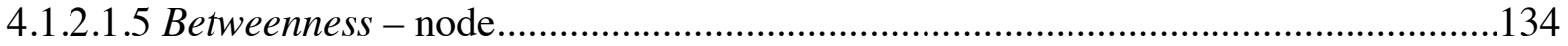

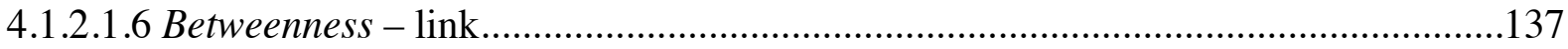

4.1.2.2 Análise - Neighbor, Density e Inclusiveness .........................................................137

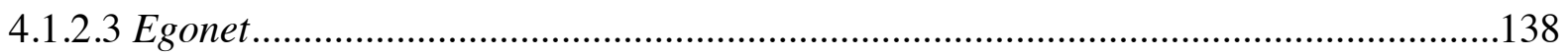

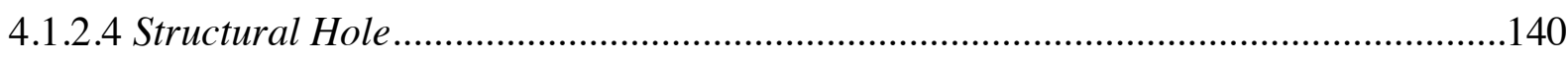

4.1.3 Nível de Análise - Ocupações dos Médicos................................................................145

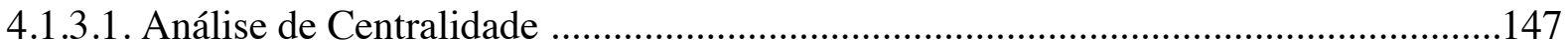

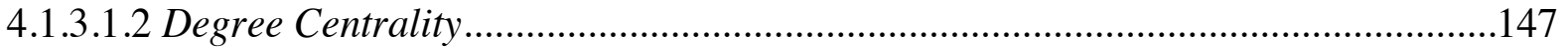

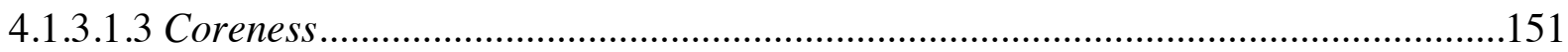

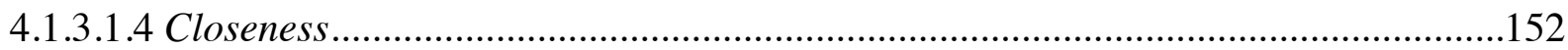




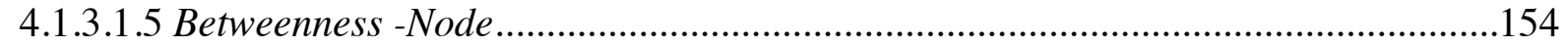

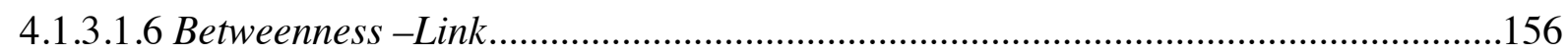

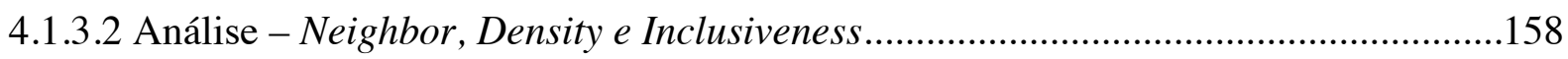

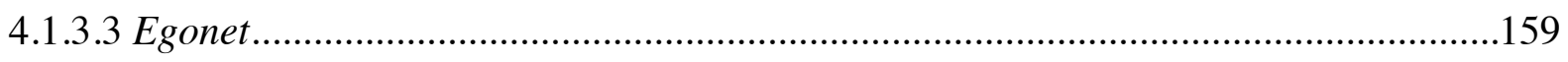

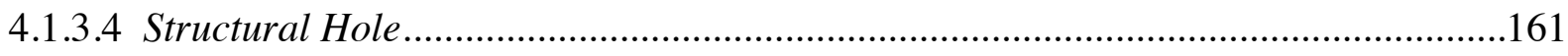

4.2 A análise do grau de Hubiness de unidades de saúde ...................................................166

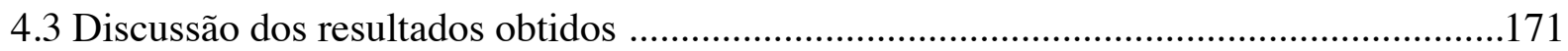

4.4 Proposta de um esquema conceitual de análise da rede de médicos do SUS .................174

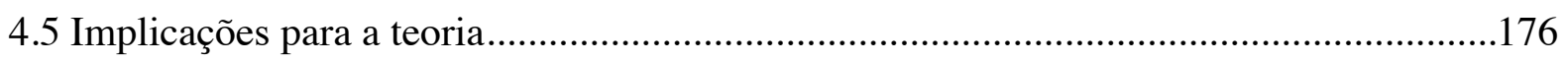

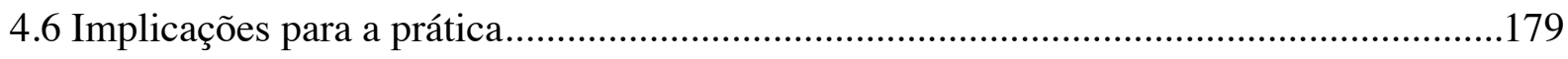

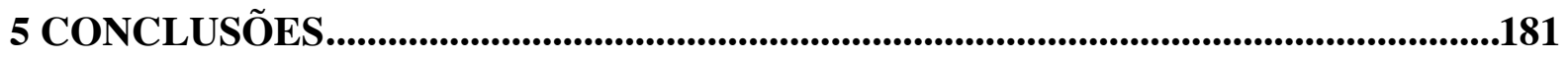

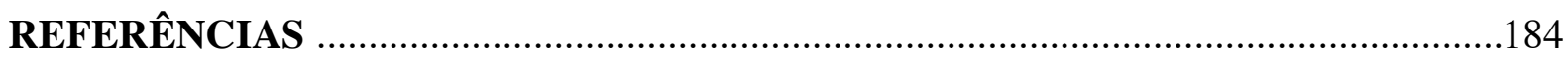

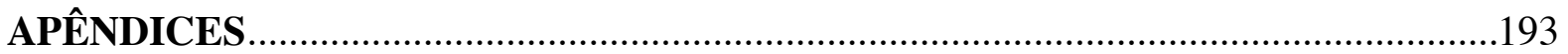




\section{APRESENTAÇÃO DO TRABALHO}

O objetivo deste capítulo introdutório é apresentar a proposta geral e o delineamento da questão de pesquisa, bem como os objetivos e a justificativa para a sua execução e, por fim, a estrutura do trabalho.

\subsection{Introdução}

O setor de saúde pública enfrenta desafios sociais e econômicos. Um aumento da população idosa, maiores expectativas de vida entre a população e a limitação dos recursos econômicos (LARSSON et al., 2012). Avanços no setor de saúde pública são necessários para a melhoria da produtividade e sustentabilidade social e econômica do sistema de saúde. Alexander et al. (2003) definem um sistema de saúde como um conjunto de arranjos organizacionais vinculados entre si e que são legalmente reconhecidos na área de saúde.

O setor da saúde pública do Brasil, suporta crescentes pressões de custo para manter o nível de serviço (BARBEIRA et al., 2012). Isso ocorre, porque o Brasil institucionalizou o direito e acesso à saúde, por meio da criação do Sistema Único de Saúde (SUS) (VIEGAS e PENNA, 2013). Assim, todos os cidadãos brasileiros passaram a ter direito a consultas, exames, internações e tratamentos nas unidades de saúde vinculadas ao SUS, sejam essas unidades públicas ou privadas, contratadas pelo gestor público de saúde (LONGARAY e ENSSLIN, 2014). Portanto, a ampliação do acesso ao sistema público de saúde trouxe a discussão sobre a eficácia e eficiência do setor público de saúde.

O modelo adotado pelo SUS, pressupõe que as ações e os serviços de saúde estão organizados em uma rede de saúde, regionalizada e hierarquizada, composta por níveis (layers), assim denominados: (1) Rede de Atenção Básica (AB) - é o primeiro nível de atenção à saúde, ou seja, a "porta de entrada" do sistema de saúde. A população tem acesso a especialidades básicas, que são: clínica médica (clínica geral), pediatria, obstetrícia e ginecologia; (2) Média Complexidade (MC) — são serviços como consultas hospitalares e ambulatoriais, exames e alguns procedimentos cirúrgicos e (3) Alta Complexidade (AC) são procedimentos que envolvem alta tecnologia e/ou custo elevado, tais como: cirurgias cardíacas e tratamentos oncológicos (BRASIL, 2006). 
Essas redes de saúde estão organizadas de acordo com as diretrizes da descentralização, atendimento integral e participação da comunidade (VIEGAS e PENNA, 2013). As unidades de saúde fazem parte de um intrincado sistema, composto por unidades de saúde interconectadas, que influenciam a dinâmica de funcionamento da rede (GOBBO, 2010). O termo "rede de saúde" é usado para descrever, também, relações entre pessoas, grupos ou organizações vinculadas ao setor de saúde (CUNNINGHAM et al., 2012).

A rede de saúde pode ser representada por um grafo não direcionado, onde os hospitais ou unidades de saúde são os nós, e as arestas representam os fluxos de pacientes, médicos, ou informações, ou seja, o conjunto compartilhado de fluxos pelos hospitais e organizações de saúde (JAY et al., 2008). A estrutura da rede de saúde (PENG e BOURNE, 2009) pode ser definida da seguinte forma: 1) conexão entre os atores - os laços de propriedade e relações contratuais, (2) o tamanho da rede - leitos hospitalares e número de empregados, (3) com lucro ou sem fins lucrativos (4) extensão de rede - a cobertura industrial e a cobertura geográfica e (5) governança.

Os médicos, assim como outros profissionais, trabalham melhor quando são autorizados a se vincular em agrupamentos de seu próprio interesse e preferência. A literatura indica que um dos principais recursos da rede de saúde são os médicos, e como esses se vinculam as unidades de saúde (Spokes) ou hospitais (Hubs), influenciam a forma como a informação é facilitada, e a condição que dita a robustez ou fragilidade da rede de saúde (BRAITHWAITE et al., 2009).

O modelo Hub and Spoke (HS), é um termo tradicionalmente conhecido na logística e muito utilizado por companhias aéreas. Dessa forma, a partir dos aeroportos (Hubs), as companhias aéreas levam os passageiros aos seus destinos finais (DERUDDER et al., 2007). Os Hubs podem ser definidos como nós altamente conectados, dentro de uma rede (BERLINGERIO et al., 2011). Nas companhias aéreas o número de rotas cai substancialmente quando uma companhia aérea adota o modelo HS: somente N-1 rotas precisam ser atendidos se um $h u b$ é estabelecido e os voos diretos são fornecidos entre o $h u b$ e todos os outros nós na rede (SHAW 1993 , p. 47). Segundo Govindarajan (2014), a configuração de redes de saúde conforme o modelo HS permite aos hospitais não somente reduzir custos, mas também, melhorar a qualidade.

Portanto, cabe o desafio de entender a configuração da rede de médicos com vínculos profissionais em unidades de saúde públicas e privadas, por meio do mapeamento dessa rede e dos fluxos de informações associados, e, potencialmente, propor soluções que auxiliem na 
gestão dos vínculos profissionais dos médicos que atendem o SUS. Dessa forma, em resumo, espera-se obter elementos para propor um esquema conceitual para análise da rede em estudo.

Considerando-se as questões teóricas e empíricas adotadas neste trabalho, tem-se a seguinte questão de pesquisa:

Como analisar, por meio da teoria de redes, a rede de médicos com vínculos profissionais em unidades de saúde públicas e privadas de um município do Estado de São Paulo?

A sub-questão formulada para responder essa questão específica é:

Q 1 - Qual a configuração da rede de médicos com vínculos profissionais em unidades de saúde públicas e privadas, delimitada a partir de unidades de saúde vinculadas ao SUS (Município de Bauru)?

\subsection{Objetivos}

O objetivo geral da pesquisa é desenvolver uma análise de uma rede de médicos com vínculos profissionais em unidades de saúde públicas e privadas. O estudo foi delimitado a partir de unidades de saúde vinculadas ao SUS do município sede de um Departamento Regional de Saúde (DRS) no Estado de São Paulo.

Como objetivos específicos, pretende-se: (1) mapear a rede de médicos e identificar os principais Hubs nas unidades de saúde no Município de Bauru; (2) explorar as ligações entre médicos e organizações de saúde públicas com base em dados de vínculos profissionais; (3) analisar conexões e conectividade, por meio dos vínculos profissionais médicos em organizações de saúde públicas das redes de saúde do SUS do Município de Bauru; (4) estabelecer questões de pesquisa descritivas para serem refinadas na forma de hipóteses a serem testadas em estudos futuros; (5) propor um esquema conceitual para análise da rede em estudo.

Dessa forma, análise da rede de médicos com vínculos profissionais em unidades de saúde públicas e privadas, pode auxiliar, tanto para entender a configuração atual da rede, 
quanto para identificar os principais Hubs de saúde. Geralmente, unidades de saúde que atuam como $H u b$ estão melhores posicionadas de modo a centralizar recursos financeiros e tecnológicos (equipamentos de alta tecnologia, médicos especializados).

Para tanto, a teoria de redes apresenta duas vertentes: uma quantitativa que faz uso de modelagem, ferramentas estatísticas, softwares (NetMiner, Ucinet, Social Network Analysis- SNA) e a outra vertente qualitativa, que vem da sociologia e, principalmente utiliza de métodos qualitativos. Desse modo, a Figura 1 ilustra e contextualiza a abordagem contextual para a análise da rede na presente pesquisa. Essa figura destaca tanto as variáveis quanto os constructos teóricos que foram estudados e analisados para melhor entendimento da rede em estudo. 


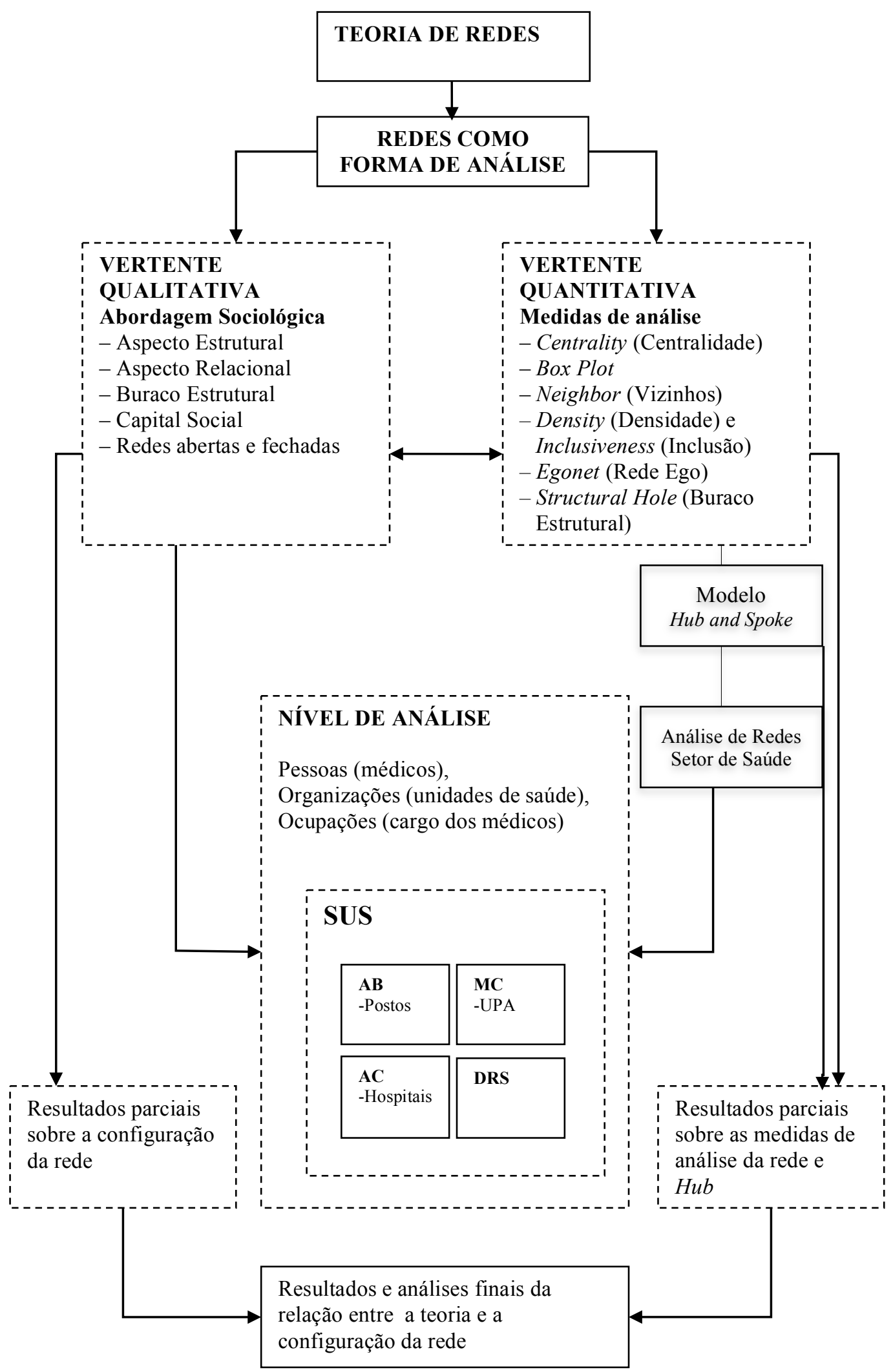

Figura 1 - Abordagem contextual para a análise da rede 


\subsection{Justificativa}

A teoria de redes sociais é uma base apropriada para pesquisar redes de saúde por duas razões. Primeiro, apesar da visão comum de médicos ou organizações de saúde isoladamente atendendo o fluxo de pacientes, é mais provável que essas ações envolvam uma estrutura maior, para possibilitar acesso a recursos e conhecimento. A segunda razão ocorre, porque a teoria de redes sociais é particularmente adequada para análise desse intrincado encadeamento de relações, por causa de sua habilidade de acessar, simultaneamente, conexões estruturais múltiplas e os relacionamentos representados por essas conexões (WASSERMAN e FAUST, 1994).

Provan e Kenis (2008) identificam uma discrepância considerável entre a atenção que as redes recebem e o conhecimento que se tem sobre o seu funcionamento geral. Ou seja, não é claro o processo pelo qual determinada condição de rede leva a vários resultados em nível de rede. Apesar de uma escola distinta ter emergido para discutir as configurações de redes mais favoráveis para a performance, nenhuma configuração ótima de atores dentro de uma rede foi identificada (GOBBO e OLSSON, 2010). Porém, pressupõe-se na literatura (MACIEL et al., 2010; MAGALHÃES et al., 2015) que a elevada carga horária de trabalho e a multiplicidade de vínculos profissionais dos médicos nas unidades que compõem as redes de saúde afetam a qualidade dos serviços de saúde.

A despeito de a literatura abordar o tema redes de saúde sobre diferentes aspectos, poucos estudos têm sido conduzidos sobre o vínculo profissional dos médicos nas redes de saúde (MACIEL et al., 2010; Bolze et al. 2010), sendo ainda menor, a quantidade desses estudos no setor público de saúde (OLIVEIRA et al., 2004; BITTAR e MAGALHÃES, 2010; BITTAR et al., 2011 e BARATA et al., 2010; MASCIA et al., 2013). A maioria dos trabalhos científicos no setor de saúde, que analisam a efetividade de redes, tende a ser mais teórico/conceitual, do que empírico (BRAITHWAITE et al., 2009).

Portanto, Chambers et al. (2012), argumentam que a principal limitação da revisão de literatura, reflete as limitações de evidências e a ausência de estudos envolvendo Análise de Redes Sociais - Social Network Analisys (SNA) como parte de uma intervenção no setor de saúde. Enquanto Cunningham et al. (2011) tratam a questão relacionada à forma como a pesquisa sobre redes sociais e profissionais de saúde com suporte da SNA, tem sido usada para examinar a eficácia e sustentabilidade das redes em relação à qualidade do atendimento e segurança. Desse modo, apesar da vantagem potencial e da necessidade de metodologias de 
pesquisa em gestão de suprimentos no setor de saúde, o uso da SNA também tem sido quase inexistente nesse campo (CARTER et al., 2007).

Pesquisadores que utilizam SNA, precisam definir os limites da rede em estudo, pois essas podem ir muito além dos limites da própria organização. Há uma ausência de evidências empíricas, a demonstrar que a utilização da SNA pode permitir um direcionamento da colaboração nos relacionamentos para facilitar uma melhor absorção e utilização de conhecimento. Futuros estudos envolvendo SNA na área da saúde devem ser projetados com intervenção e comparação (CHAMBERS et al., 2012).

A avaliação do grau de "Hubiness" (isto é, o grau de conexão dos nós na rede) também é importante, porque pouco se sabe sobre as principais unidades de saúde que intermediam conexões e fluxos na rede de saúde. O grau de "Hubiness" serve para identificar unidades de saúde com elevado grau de conectividade na rede de saúde. Nesse sentido, a fórmula do modelo $H u b$ and Spoke, proposta originalmente para a área de logística por Derudder et al. (2007), foi adaptada para avaliar o grau de Hubiness das unidades de saúde.

Redes sócio-profissionais, como é o caso das redes de médicos com vínculos profissionais em unidades de saúde públicas e privadas, são sub-estudadas e crescentemente vistas como determinantes cruciais no entendimento e melhoria da rede de saúde e serviços orientados a pacientes. Na revisão de literatura, o vínculo profissional dos médicos nas redes de saúde, emerge como um fator chave para o entendimento das questões relacionadas a performance da rede de saúde. Assim, há um forte consenso entre os estudiosos dessa área de pesquisa, que é importante que ocorra o desenvolvimento de modelos de avaliação adequados a realidade do setor e com o apoio de ferramentas de coleta de dados (BRAITHWAITE et al., 2009).

Adicionalmente, muito pouco se sabe sobre a formação de relacionamentos de trabalho entre ocupações na rede de médicos. Algumas ocupações, como cirurgiões gerais e anestesiologistas tendem a formar pares nos relacionamentos laborais, ou em determinados casos ocorrem a formação de pares entre iguais (ex. Pediatras com pediatras). Pearce e Gambrell (2016) demonstraram isso, no caso da recorrência de casamento, entre médicas de alta renda com seus pares. Portanto, evidencia-se a necessidade de identificar a formação de combinações de ligações laborais entre ocupações na rede de médicos. Isso irá possibilitar um melhor entendimento da formação de vínculos laborais entre as ocupações na área de medicina.

Apesar da relevância para o tema para a área de saúde pública, o mapeamento e análise de redes tende a ser pouco explorado nesse setor, o que contribui para uma lacuna 
neste campo de conhecimento, em termos acadêmicos (por meio da formulação de questões de pesquisa para serem refinadas na forma de hipóteses para teste empírico) e práticos (como a identificação da necessidade de políticas para a gestão dos vínculos profissionais médicos).

\subsection{Estrutura da Tese}

O texto apresentado é constituído por 5 capítulos.

O Capítulo 1, introdutório, discute o problema de pesquisa, seus objetivos, a justificativa em termos de relevância e a estrutura da tese.

O Capítulo 2 traz o referencial teórico deste trabalho. Busca-se identificar o estado da arte sobre teoria de redes, redes como forma de análise, modelo Hub and Spoke e, identificar os principais conceitos e trabalhos empíricos sobre o SUS e dos estudos de redes no contexto do setor de saúde, a fim de apresentar algumas de suas relações alternativas para sustentar as diretrizes do estudo empírico.

O Capítulo 3 compreende os aspectos metodológicos da pesquisa. Define e defende a escolha do método de pesquisa e detalha os procedimentos de coleta de dados da pesquisa e a forma de análise do estudo.

O Capítulo 4 envolve a análise dos dados e resultados da pesquisa empírica. Além disso, expõe a proposta de um esquema conceitual de análise da rede de médicos no SUS e são apresentadas as principais contribuições do estudo, suas implicações tanto teóricas quanto práticas.

O Capítulo 5 traz as conclusões do trabalho, delimitações e sugestões para pesquisas futuras. 


\section{FUNDAMENTAÇÃO TEÓRICA}

Este capítulo é dedicado à fundamentação teórica desta pesquisa em suas várias perspectivas. A partir de subseções, são identificados os principais conceitos e pesquisas empíricas já realizadas, referentes aos temas Redes como forma de análise; hub and spoke; análise de redes no setor de saúde e o SUS.

$\mathrm{O}$ arcabouço teórico explorado neste capítulo busca avançar nas pesquisas de redes e a sua forma de análise. Esse arcabouço forma um amplo conjunto de elementos, variáveis e conceitos para suportar a análise da rede de médicos com vínculos profissionais em unidades de saúde públicas e privadas no contexto do sistema de saúde. É a partir das teorias aqui apresentadas que pode-se compreender as principais discussões para entender a configuração da rede em estudo.

\subsection{Redes como forma de análise}

A teoria de redes é uma área da ciência da computação, da ciência de rede e parte da teoria dos grafos. Tem aplicação em outra áreas do conhecimento, incluindo Engenharia de Produção, Ciência da Computação, Economia, Biologia, Pesquisa Operacional e Sociologia. A teoria de redes envolve o estudo de gráficos como representação de uma relação simétrica, ou, geralmente de relações assimétricas entre os objetos discretos. Uma das aplicações da teoria de redes inclui as redes sociais, caracterizadas sob a forma de relacionamentos sociais entre os indivíduos. Esses atores muitas vezes são pessoas, mas geralmente podem ser grupos, organizações ou nações (WASERMAN e FAUST, 1994). Segundo Borgatti e Li (2009), a premissa fundamental na análise de redes é a noção de que os atores são interdependentes.

Segundo Galaskiewicz (2007) existe uma diferença entre aqueles que estudam redes como um conjunto de arcos e nós e focam nas propriedades formais de diferentes configurações, e, aqueles que estudam redes sociais. Estes últimos têm tratado o assunto sobre teoria formal, mas as questões como: por que as redes beneficiam de nós? ou por que redes mudam? por que alguns tipos de redes são mais eficazes do que outras?, são baseadas, na sua maior parte, em teorias de psicologia, derivada a partir de comportamento, ou seja, os pesquisadores tomaram micro teorias do comportamento, e testaram usando as organizações 
como as unidades de análise e a metodologia de redes. Além disso, existem aqueles que estudam os fluxos de conteúdo através de uma rede e aqueles que olham para os significados ligados a diferentes formas relacionais (BORGATTI e LI, 2009).

A análise de redes sociais é conhecida como Social Network Analysis (SNA). Ela pode ser usada para entender melhor os fluxos de comunicação e de intercâmbio de informações entre os atores (AUTRY e GRIFFIS, 2005), onde os atores podem ser definidos como indivíduos dentro de uma organização, organizações dentro de uma cadeia de suprimentos ou no caso de uma análise de citações, instituições acadêmicas dentro de uma disciplina acadêmica (CARTER, et al., 2007). A SNA pode permitir as organizações a gerenciar melhor conhecimento, informação e aprendizagem organizacional (HULT et al., 2000 e HULT et al., 2003).

Particularmente, a teoria de redes sociais é uma base apropriada para estudar tanto o grau de densidade de uma rede quanto para analisar o grau de centralidade dos atores na rede, por meio do fluxo de pessoas, por causa de sua habilidade para simultaneamente acessar as conexões estruturais múltiplas e os relacionamentos que essas conexões representam (WASSERMAN e FAUST, 1994; AUTRY e GRIFFIS, 2008). Estruturalmente, as redes podem ser densas ou difusas e, relacionalmente, as redes podem ter conexões fortes ou fracas (strong or weak ties) e são expressas por meio dos nós, elos ou conexões (linkages) entre as unidades de análise (SACOMANO NETO, 2004).

Para uma melhor compreensão das redes organizacionais, é necessário conhecer sua estrutura. Segundo Britto (2002), quatro elementos morfológicos genéricos constituem a estrutura das redes (Figura 2):

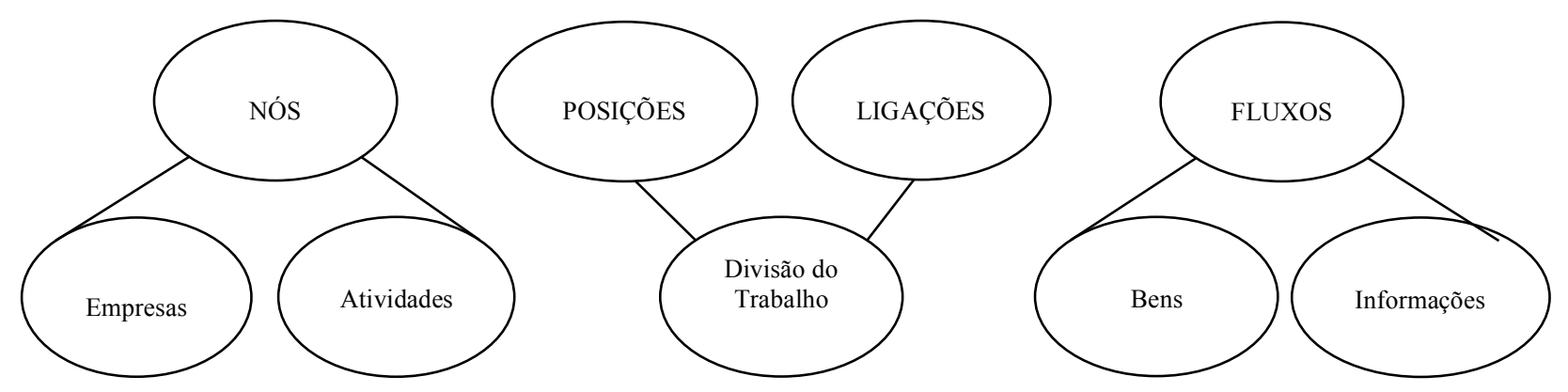

Figura 2 - Elementos morfológicos das redes Fonte: Adaptado de Britto (2002) 
- Nós: identificam as empresas que estão inseridas na rede e as atividades como pontos focais do arranjo;

- Posições: definem as localizações dos pontos (empresas ou atividades) no interior da estrutura. A posição está diretamente associada à divisão do trabalho;

- Ligações: determinam o grau de dispersão e os tipos de relacionamentos. Assim, pode ser determinada a densidade da rede;

- Fluxos: análise dos fluxos tangíveis (insumos e produtos) e intangíveis (informações), que conectam diferentes atores integrados à rede.

Entretanto, Britto (2002) ressalta que para o melhor entendimento da estrutura de uma rede é fundamental uma análise dos fluxos tangíveis (insumos e produtos) e intangíveis (informações). Além disso, nas redes é necessária uma descrição minuciosa dos relacionamentos organizacionais, produtivos e tecnológicos entre os atores da rede.

Nesse sentido, Diaz (2009) afirma que a SNA pode contribuir por meio de um mapa das inter-relações entre os atores/organizações que facilita a compreensão desses relacionamentos. Indicadores utilizados como centralidade, proximidade e intermediação - a capacidade para fazer pontes em diferentes partes da rede - nos permitem prever o que os atores farão, enquanto indicadores, tais como a coesão e a equivalência estrutural nos permitem prever o apoio ou a concorrência entre os atores. Mesmo o conceito de buracos estruturais (será tratado mais adiante) permite descobrir janelas de oportunidade, ou seja, espaços relacionais inexistentes ou vazios que podem se beneficiar os atores que encontrá-los, e as redes, no qual estão inseridos, levando a novas relações que contribuem com novos recursos para a rede. Adicionalmente, a análise de redes sociais fornece informações que facilita a ação focada na geração de mudança, já que a mudança é produzida em redes, aumentando ou reduzindo a centralidade, acelerando ou retardando o fluxo de comunicação e fortalece ou enfraquece a rede (DIAZ, 2009).

Ao ceder um mapa das interações, entre atores ou entidades que moldam a ação, SNA pode ser benéfica na proposição de melhorias. Na medida em que as ações acontecem em redes, o conhecimento de que a análise de rede fornece faz com que seja possível intervir em redes, a fim de produzir mudanças e alcançar objetivos futuros (DIAZ, 2009).

Quanto à análise das redes, existem aspectos estruturais e relacionais, que contribuem para o conceito embeddedness, termo criado por Granovetter (1973) que significa "grau de imersão", e trata como imersão social, que envolve o inter-relacionamento entre a estrutura social e a atividade econômica. Granovetter $(1973,1985)$ aplicou o conceito de 
embeddedness para apresentar o modo como as relações sociais condicionam o comportamento econômico dos atores e das organizações. A imersão social permite a compreensão das relações entre os atores, tanto no que se refere à rede social, quanto à sua inter-relação com as redes interorganizacionais (BALDI e VIEIRA, 2006).

As organizações estão posicionadas e imersas em uma estrutura de relações, que podem afetar a ação econômica da firma, resultados e comportamento de seus parceiros com quem está diretamente ou indiretamente ligada (UZZI, 1997, GILSING et al., 2007). Desse modo, durante períodos de troca de informações, atores não se comportam com racionalidade econômica perfeita porque estão imersos (embedded) dentro das redes sociais com outros atores, que são capazes de fornecer maior acesso aos recursos, informação (Granovetter $(1973,1985)$.

Granovetter (1985) considera dois tipos de embeddedness: o estrutural e o relacional. O estrutural enfatiza como a posição estrutural de um ator na rede afeta o seu comportamento, e o relacional está associado aos relacionamentos diretos e indiretos, ligando o ator a outros, ou seja, enfatiza a dependência do comportamento dos atores em relação à estrutura de mútuas expectativas. Por outro lado, Zukin e DiMaggio (1990) consideram somente o estrutural, mas discutem mais três aspectos de embeddedness: o cognitivo, o cultural e o político. O estrutural reflete a necessidade de se compreender como as estruturas de rede e as qualidades de suas relações afetam a atividade econômica. Enquanto que os três últimos refletem uma perspectiva social-construcionista.

Qualquer tipo de rede encerra uma estrutura e determinadas relações entre os atores. Essas relações constituem a estrutura social das organizações (PFEFFER E SALANCIK, 1982). Dentro desse contexto, a literatura ressalta que para a compreensão das redes sociais é importante conhecer a sua estrutura (SACOMANO NETO, 2004; WASSERMAN e FAUST,1994; BALESTRIN e VERSHOORE, 2008; BRITTO, 2002) e seus relacionamentos (UZZI,1997; GRANOVETTER, 1973; MASQUEFA, 2008).

Nesse sentido, as variáveis trabalhadas nesta pesquisa compreendem o aspecto de posicionamento estrutural e relacional em uma determinada rede. Estrutural porque envolve a densidade da rede e, relacional, pelo fato de que os atores por meio de seus relacionamentos podem influenciar as decisões tanto de uma organização quanto de outros atores que atuam na rede.

Diante desse contexto, a literatura apresenta duas vertentes: uma qualitativa, que vem da sociologia e, principalmente utiliza de métodos qualitativos (GRANOVETTER, 1973; ,1985; SACOMANO NETO, 2004; GILSING e NOTEBOOM, 2005; GILSING e 
DUYSTERS, 2008; GOBBO e OLSSON, 2010; GOBBO et al., 2014), a outra vertente quantitativa que utiliza modelagem, gráficos, ferramentas estatísticas e softwares (NetMiner, Ucinet, Nodexl) para análise de redes organizacional (Organizational Network Analysis ONA) e redes sociais (Social Network Analisys - SNA) (FREEMAN, 1978; BARABÁSI et al., 2002; CHAMBERS et al., 2012; SCHICH et al., 2014; ZHAO et al., 2013; ARROYABE et al., 2014). Essas duas vertentes são complementares e contribuem para a análise de redes organizacionais (Quadros 1 e 2).

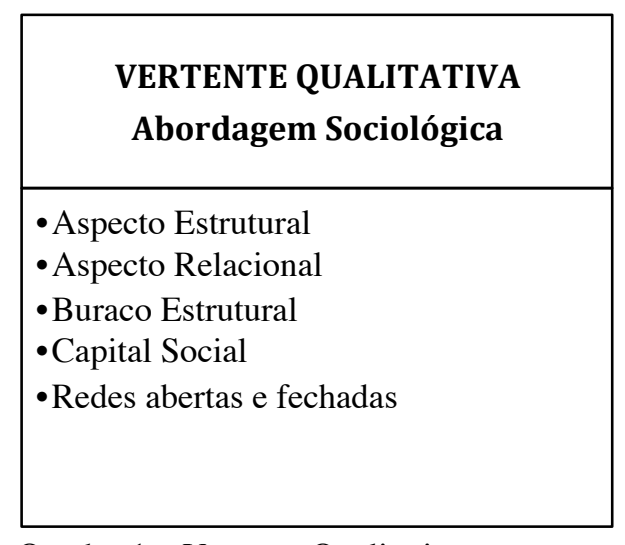

Quadro 1 - Vertente Qualitativa

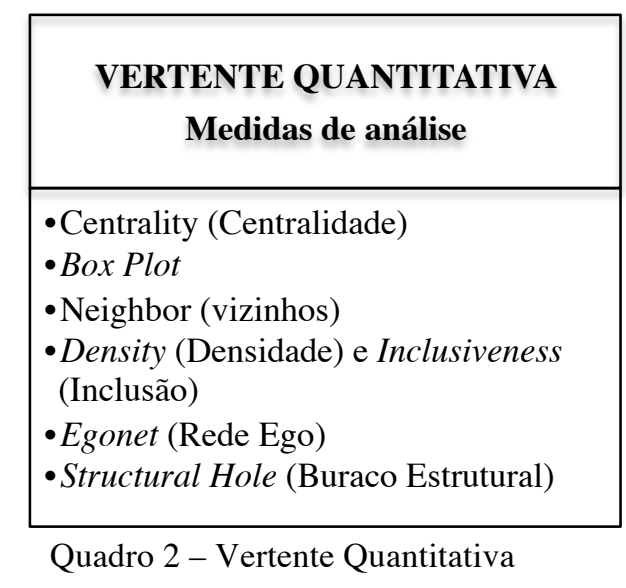

\subsection{Abordagem Sociológica}

Esta seção apresenta os principais conceitos teóricos que contribuem para a análise de redes sob o ponto de vista da sociologia.

\subsubsection{Aspecto Estrutural}

O aspecto estrutural descreve a arquitetura geral de uma rede. Para Rowley et al. (2000), o embeddedness estrutural - através da perspectiva das posições - vai além dos elos imediatos e enfatiza o valor informacional da posição estrutural que o parceiro ocupa na rede. É definido, especificamente, pela presença ou não de laços, e as fronteiras da rede como um todo pode ser conceituada com base no encerramento da rede (GOBBO et al., 2014). Além 
disso, o posicionamento estrutural de um ator varia entre a rede densa e a rede difusa (SACOMANO NETO, 2004).

Uma característica de estrutura da rede é a sua densidade. Quanto maior a interconexão, maior a densidade (GNYAWALI e MADHAVAN, 2001). Na rede densa, a intensidade de interconexão é maior, e os relacionamentos tendem ser de longo prazo. Nas redes difusas, o nível de interconexão é menor, possibilitando a entrada de novas informações, por meio dos relacionamentos de curto prazo (SACOMANO NETO, 2004). As redes densas facilitam fluxo de informação e outros recursos; funcionam como sistemas fechados de confiança e normas divididas onde as estruturas de comportamento padrão desenvolvem-se mais facilmente e facilitam a concessão de sanções (GNYAWALI e MADHAVAN, 2001). A Figura 3 ilustra estes tipos de redes, nota-se que o grau de interconexão das relações é demonstrado através das linhas mais espessas nas redes densas.

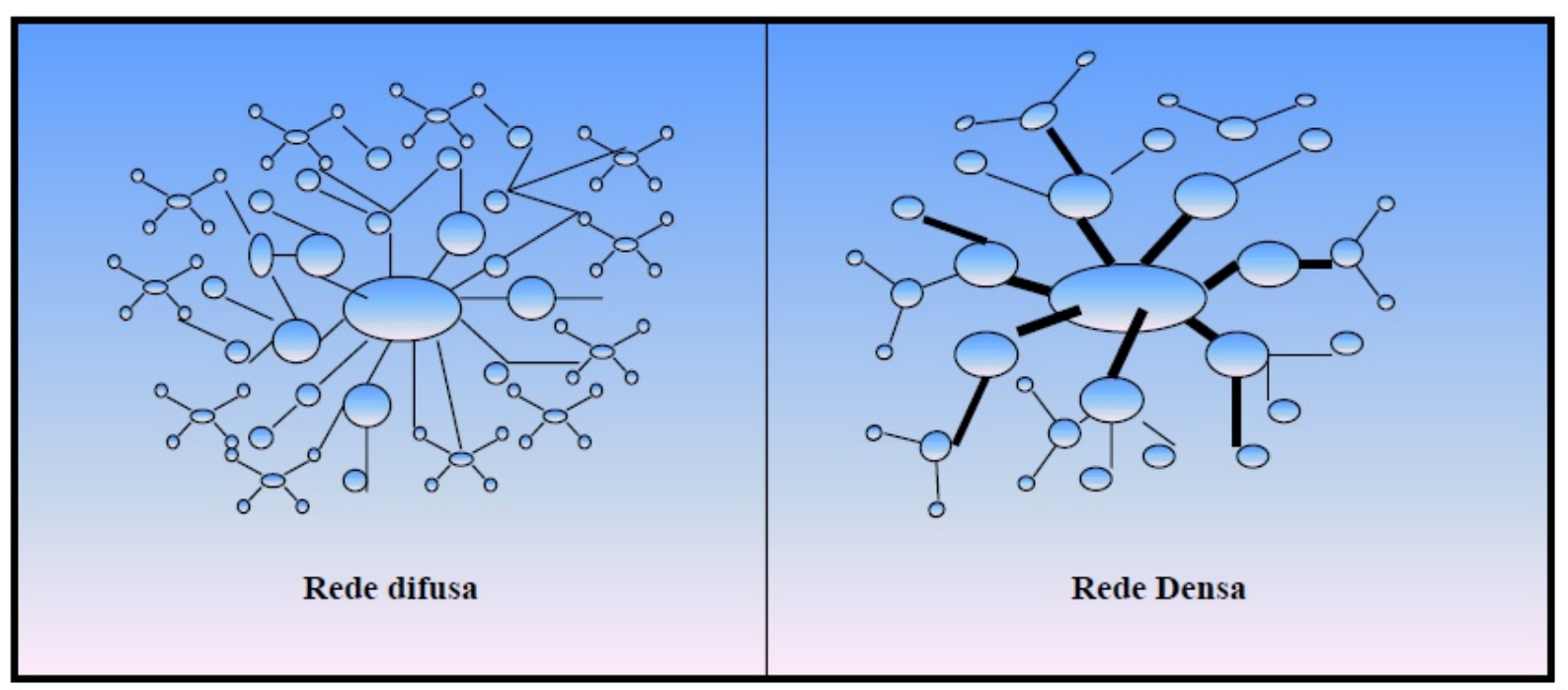

Figura 3 - Rede difusa e rede densa

Fonte: Sacomano Neto, 2004, p. 57

Rowley et al. (2000) argumentam que as redes densas com relações fortes envolvem significativos investimentos e são presentes nas joint ventures de manufatura e projetos de pesquisa e desenvolvimento, enquanto as redes difusas, com relações fracas, são mais adequadas à formação de arranjos de treinamento e marketing.

Para Wasserman e Faust (1994) a densidade estrutural de uma rede é a extensão pela qual possíveis conexões, dentro de uma rede, são ativadas e, frequentemente, operacionalizadas em razão de os laços ativos aos laços potencialmente ativos ministrarem uma medida geral de conectividade da rede. Centralidade na posição da rede permite medir o 
envolvimento de um ator; quanto mais uma organização está envolvida em sua rede, mais ela pode comparar informação por intermédio de múltiplas fontes de informações e acessar novos conhecimentos. Assim, esse ator tem acesso a recursos, poder e informações. Para Balestrin e Verschoore (2008), centralidade indica até que ponto uma empresa está conectada às demais.

Portanto, para uma melhor compreensão das redes organizacionais, é fundamental conhecer sua estrutura. Segundo Wasserman e Faust (1994) os elementos da estrutura de redes envolvem: (1) centralidade - permite medir o envolvimento de um ator na rede; (2) autonomia estrutural - ator que ocupa um buraco estrutural entre outros dois atores com quem está conectado; (3) equivalência estrutural - os atores ocupam posições parecidas; (4) densidade - os atores possuem fortes conexões uns com os outros; e (5) coesão - um ou alguns atores exercem poder sobre a rede (WASSERMAN E FAUST, 1994).

Assim, o Quadro 3 apresenta a estrutura da rede e os conceitos relacionados.

\begin{tabular}{|c|c|c|}
\hline $\begin{array}{l}\text { Estrutura da } \\
\text { rede }\end{array}$ & Conceitos & Autores \\
\hline Centralidade & $\begin{array}{l}\text { O nível de análise é o ator, que centraliza a relação com outros } \\
\text { atores da rede. Os efeitos resultam no acesso a recursos, poder, } \\
\text { informações do ator na rede. Permite acessar novos conhecimentos e } \\
\text { medir o envolvimento de um ator na rede. }\end{array}$ & $\begin{array}{l}\text { Wasserman e Faust, } \\
(1994) ; \text { Balestrin e } \\
\text { Verschoore (2008); } \\
\text { Sacomano Neto } \\
(2004)\end{array}$ \\
\hline $\begin{array}{l}\text { Autonomia } \\
\text { estrutural }\end{array}$ & $\begin{array}{l}\text { Um ator intermedia a relação entre outros dois atores. } \\
\text { O ator que ocupa um buraco estrutural entre outros dois atores com } \\
\text { quem está conectado. }\end{array}$ & $\begin{array}{l}\text { Wasserman e Faust, } \\
(1994) ;(\text { Sacomano } \\
\text { Neto, 2004). }\end{array}$ \\
\hline $\begin{array}{l}\text { Equivalência } \\
\text { estrutural }\end{array}$ & $\begin{array}{l}\text { Os atores ocupam posições semelhantes na estrutura da rede. Os } \\
\text { contatos equivalentes são aqueles que ligam cada ator na mesma } \\
\text { estrutura, também têm as mesmas fontes de informação resultando } \\
\text { em benefícios redundantes. }\end{array}$ & $\begin{array}{l}\text { s Wasserman e Faust, } \\
\text { (1994); Burt (1997) }\end{array}$ \\
\hline Densidade & $\begin{array}{l}\text { A densidade estrutural é a extensão pela quais possíveis conexões } \\
\text { dentro de uma rede são ativadas. Quanto maior a interconexão, } \\
\text { maior é a densidade } \\
\text { Rede Densa: Promove a confiança e a cooperação entre os seus } \\
\text { membros e pode gerar capital social. É a extensão da interconexão } \\
\text { entre os atores da rede, quanto maior a interconexão, maior a } \\
\text { densidade. É possível participar de uma rede densa e altamente } \\
\text { conectada com relações de longo prazo. } \\
\text { Rede Difusa: Obtenção de informações não redundantes. Pode } \\
\text { participar de uma rede difusa e obter novas informações. O nível de } \\
\text { interconexão é menor, possibilitando a entrada de novas } \\
\text { informações através dos relacionamentos de curto prazo. }\end{array}$ & $\begin{array}{l}\text { Wasserman e Faust, } \\
(1994) ;(\text { Sacomano } \\
\text { Neto, 2004). } \\
\text { Coleman (1988); } \\
\text { a Gnyawali e Madhavan } \\
\text { (2001); Sacomano } \\
\text { Neto (2004) } \\
\text { eBurt (1992); } \\
\text { eSacomano Neto } \\
\text { (2004) }\end{array}$ \\
\hline Coesão & $\begin{array}{l}\text { Um ou alguns atores exercem o domínio sobre a rede. } \\
\text { A coesão é intensidade do relacionamento (forte ou fraco) e os } \\
\text { efeitos estão relacionados ao ganho de informações, conhecimento } \\
\text { tácito, controle social e reciprocidade. }\end{array}$ & $\begin{array}{l}\text { Wasserman e Faust, } \\
(1994) \text {; } \\
\text { (Sacomano Neto, } \\
\text { 2004). }\end{array}$ \\
\hline
\end{tabular}

Quadro 3 - Estrutura da rede e os conceitos 


\subsubsection{Aspecto Relacional}

Os aspectos relacionais dizem respeito a reciprocidade entre os membros da rede. É uma forma de fechamento da rede que promove a similaridade cognitiva entre seus membros, por meio da seleção de parceiros e práticas de contratação. O foco recai sobre a força dos laços - a extensão pela qual os atores ou nós da rede são conectados uns aos outros e o conceito de laços fracos (weak ties) e de laços fortes (strong ties) criado por Granovetter (1973). Segundo o autor a força de um laço é uma combinação (provavelmente linear) da quantidade de tempo, intensidade emocional, intimidade (confiança mútua) e serviços recíprocos que caracterizam um laço. Laços fortes são aqueles que se caracterizam pela intimidade, pela proximidade e pela intencionalidade em criar e manter conexão entre duas pessoas. Por outro lado, os laços fracos, caracterizam-se por relações diversas, que não traduzem proximidade e intimidade.

Os laços fortes são associados a confiança e intercâmbio de informações entre os parceiros (UZZI, 1997). Por outro lado, os laços fracos levam a novas informações (GRANOVETTER, 1973), podem alcançar um amplo número de pessoas e percorrer maiores distâncias sociais do que os laços fortes, visto que são mais propensos a ligação através dos membros de diferentes grupos pequenos (MASQUEFA, 2008) e o seu acesso acontece por meio dos laços indiretos (GRANOVETTER, 1973).

Uma das formas de se entender os aspectos relacionais em uma rede é por meio da coesão das relações entre os atores. A coesão das relações pode ser percebida através da intensidade do relacionamento (forte ou fraco, estratégia de saída ou diálogo, relações de longo prazo, etc.) (SACOMANO NETO, 2004) e pela densidade, que é simplesmente o número de ligações entre um conjunto de nós, expresso como uma função do número de pares de nós (BORGATTI e LI, 2009).

Sob a perspectiva das relações interorganizacionais, Rowley et al. (2000) destacam que a estrutura pode ser compreendida pelo grau de densidade da rede, e as relações podem ser compreendidas pelo grau de coesão entre os pares de atores. Desse modo, uma pergunta pertinente é: Qual a melhor forma de se conectar a uma determinada rede? Os autores argumentam que a posição de um ator é dependente do contexto da indústria. Contudo, o ambiente e a relação com outras organizações é que vão determinar qual a melhor configuração da rede. 
Nesse sentido, a formação de relações da rede está intimamente relacionada com a criação de capital social. No entanto, as redes e capital social estão intimamente relacionados, mas não são conceitos idênticos (TODEVA e KNOKE, 2005). Este tema é tratado com mais detalhes a seguir.

\subsubsection{Capital Social e Buraco Estrutural}

O debate entre Burt (1992) e Coleman (1988) sobre buraco estrutural e capital social ilustra que os diferentes aspectos estruturais em uma rede podem ser benéficos para a performance da rede em análise.

Burt (1992) ressalta que as relações cooperativas geram um capital social capaz de instituir normas de confiança, previsibilidade das relações e contratos de longo prazo entre os atores produtivos. Não obstante disso, o capital social presente nas relações cooperativas promove confiança, cooperação, reciprocidade e maior controle social entre seus membros (COLEMAN, 1988).

Segundo Burt (1992) buracos estruturais são áreas dentro da rede onde há ausência de laços ou a densidade é baixa. O autor utiliza o conceito de "pontes", segundo o qual os atores pontes têm uma posição de intermediadores de informação. O conceito de "ponte" é uma linha, em uma rede, que provê o único caminho entre dois pontos (GRANOVETTER, 1973). Um laço forte pode ser uma ponte, portanto, apenas se nenhuma das partes tem qualquer outro vínculo forte, mas isso é improvável em uma rede social de qualquer tamanho (embora possível, em um pequeno grupo) e, particularmente em uma rede de saúde. Os laços fracos não sofrem nenhuma restrição desse tipo, embora, certamente, não sejam automaticamente pontes. O importante é que todas as pontes são laços fracos.

Segundo Burt (1997), dois benefícios decorrem das redes, os de informação e os de controle. São funções inversas de dois indicadores de redundância: a coesão e a equivalência estrutural. Os contatos coesivos retêm as mesmas informações, assim, fornecem benefícios redundantes. Na equivalência estrutural, por sua vez, os contatos equivalentes são aqueles que ligam cada ator às mesmas posições na estrutura da rede, também têm as mesmas fontes de informação resultando em benefícios redundantes.

Os contatos "não-redundantes" ou os contatos "não-conectados" decorrem dos "buracos estruturais" entre dois grupos em uma rede. Isso não significa que as pessoas de 
cada grupo desconheçam umas às outras. De acordo com Burt (1997), tais grupos estão focalizados em suas atividades e pouco atentos às atividades dos demais grupos. $\mathrm{O}$ "buraco estrutural" indica que circulam em diferentes fluxos de informação. No entanto, o ator que possui fortes relações com os dois grupos tem acesso a ambos os fluxos de informação, podendo intermediar os contatos. Esses atores intermediários também são conhecidos como brokers (SACOMANO NETTO, 2004).

Por outro lado, Coleman (1988) enfatiza que o capital social não se localiza em um ator específico, mas em um relacionamento entre atores, e é criado por meio de mudanças processadas nas relações entre as pessoas. Além disso, as funções do capital social representam uma espécie de fonte para os indivíduos reunidos em um grupo e, embora não esteja situado no patamar individual, pode ser empregado em finalidades coletivas ou individuais.

Para Coleman (1988) uma rede densa promove a confiança e a cooperação entre os seus membros e pode gerar capital social. O aumento da frequência de contato entre os atores conectados também permite facilidade na observação e replicação das atividades de rotina. É mais eficiente a reação para correção de comportamentos contra normas sociais. Segundo o autor, o capital social é inseparável da estrutura de relações situadas entre os atores. Só existe por meio desses contatos, que são as próprias fontes do capital social, uma característica que o diferencia das variadas formas de capital existentes. O seu valor aumenta, à medida que é mais usado. Ele se fortalece a partir de processos de interações repetidas.

Ambos os trabalhos, Coleman (1988) e Burt (1992; 1997) trazem uma importante contribuição para a análise de redes e são importantes a pesquisa. A seção seguinte trata as redes como um sistema aberto e fechado, cujo enfoque está relacionado a densidade de rede.

\subsubsection{Redes como um sistema aberto e fechado}

Diversos pesquisadores (COLEMAN 1990; BURT 1992; UZZI 1996; WALKER et al., 1997; KOGUT 2000; JACK, 2005 e ANDERSON et al., 2007) tratam redes como um sistema aberto - que aborda principalmente a transferência de recursos e informações e, geralmente, os laços entre os atores são fracos e escassos e redes como sistema fechado que foca no intercâmbio social, confiança e partilha normas e, os laços entre os atores são fortes e densos. 
Segundo Anderson et al. (2007), em um sistema aberto, as relações entre dois atores são o principal constructo e todos os relacionamentos entre os atores envolvidos são de caráter não-redundante. Dessa forma, um ator tendo dois ou mais relacionamentos não redundantes, com atores que não estão conectados entre si, ocupa uma forte posição de negociação conhecida como buraco estrutural (BURT, 1992). Atores situados em buracos estruturais têm uma posição mais forte dentro de uma rede, à medida que controlam o fluxo de conhecimento entre outros atores. Essa visão é também verdadeira para atores que são o nó entre duas redes, independentemente do grau de redundância dentro de cada rede separada, a medida que o ator em questão for o único conectando as duas redes. Redes desse tipo tendem a ter uma estrutura "hierárquica", de fato várias hierarquias. O ator posicionado entre essas redes, isto é, posicionado em um buraco estrutural, é o que controla o fluxo de conhecimento entre as redes ou atores (KOGUT, 2000).

O sistema fechado, por outro lado, promove a interação contínua entre os atores na rede e melhora a coordenação (COLEMAN, 1990). Os relacionamentos redundantes entre os atores da rede resultam em uma resolução para ações sobre problemas coletivos (KOGUT, 2000), e o sistema fechado também permite que o ator confira a qualidade, e reflita sobre, compare e avalie o conhecimento recebido (ANDERSON et al., 2007). Essa interação fechada e redundância de relacionamentos com outros atores resultam na dificuldade em manter o conhecimento dentro da firma. Ao invés, a interação enfatiza confiança e rotinas partilhadas (ANDERSON et al., 2007). Ao contrário do sistema aberto, um sistema fechado produz um compartilhamento de conhecimento entre os atores (ANDERSON et al., 2007).

De modo geral, as redes podem ser classificadas como densas ou difusas, e quanto maior for a interconexão, maior será a densidade (GNYAWALI e MADHAVAN, 2001). As redes como um sistema fechado, geralmente, são compostas por laços fortes e densos entre os atores, esse tipo de rede promove confiança e troca de conhecimento, mas as informações são redundantes. Por outro lado, as redes como um sistema aberto, o grau de interconexão é relativamente menor, envolvem, principalmente, a transferência de recursos e de informações não redundantes e são compostas por laços fracos e dispersos entre seus atores. Além disso, a rede fechada foca no intercâmbio social, na confiança e em normas partilhadas. Os laços que conectam seus atores são fortes e densos (GRANOVETTER, 1973; COLEMAN, 1988; BURT, 1992).

O Quadro 4 apresenta um resumo geral dos principais conceitos e autores, no que diz respeito, as formas de análise de redes. 


\begin{tabular}{|c|c|c|}
\hline Conceitos & Descrição & Autor (es) \\
\hline $\begin{array}{l}\text { Força dos } \\
\text { Laços }\end{array}$ & $\begin{array}{l}\text { Laço Forte: Confiança e intercâmbio de informações entre os parceiros. } \\
\text { Caracterizam-se pela intimidade, pela proximidade e pela intencionalidade em } \\
\text { criar e manter conexão entre duas pessoas. Relações sólidas, recíprocas e baseadas } \\
\text { em confiança entre os parceiros. } \\
\text { Laço Fraco: Caracterizam-se por relações diversas, que não traduzem proximidade } \\
\text { e intimidade. Os laços fracos levam a novas informações, e o seu acesso acontece } \\
\text { por meio dos laços indiretos. Podem alcançar um amplo número de pessoas e } \\
\text { percorrer maiores distâncias sociais do que os laços fortes. }\end{array}$ & $\begin{array}{l}\text { Uzzi (1997); } \\
\text { Granovetter } \\
(1973) \\
\text { Granovetter } \\
(1973) \\
\text { Masquefa } \\
(2008)\end{array}$ \\
\hline Coesão & $\begin{array}{l}\text { Coesão das relações é uma propriedade relacional dos pares de atores de uma rede } \\
\text { e pode ser compreendida pela intensidade do relacionamento (forte ou fraco; } \\
\text { estratégia de saída ou diálogo, relações de longo prazo).Na coesão, o nível de } \\
\text { análise são os pares de atores. A coesão é a intensidade do relacionamento (forte } \\
\text { ou fraco), e os efeitos estão relacionados ao ganho de informações, conhecimento } \\
\text { tácito, controle social e reciprocidade. }\end{array}$ & $\begin{array}{l}\text { Wasserman e } \\
\text { Faust, (1994) } \\
\text { Sacomano }\end{array}$ \\
\hline $\begin{array}{l}\text { Capital } \\
\text { social }\end{array}$ & $\begin{array}{l}\text { As relações cooperativas geram um capital social capaz de instituir normas de } \\
\text { confiança, previsibilidade das relações e contratos de longo prazo entre os atores } \\
\text { produtivos. O capital social presente nas relações cooperativas promove confiança, } \\
\text { cooperação, reciprocidade e maior controle social entre seus membros. }\end{array}$ & $\begin{array}{l}\text { Burt (1992); } \\
\text { Coleman } \\
(1988)\end{array}$ \\
\hline $\begin{array}{l}\text { Autonomia } \\
\text { estrutural }\end{array}$ & $\begin{array}{l}\text { Um ator intermedia a relação entre outros dois atores. } O \text { ator que ocupa um buraco } \\
\text { estrutural entre outros dois atores com quem está conectado. }\end{array}$ & $\begin{array}{l}\text { Sacomano } \\
\text { Neto (2004) }\end{array}$ \\
\hline $\begin{array}{l}\text { Buraco } \\
\text { Estrutural }\end{array}$ & $\begin{array}{l}\text { são áreas dentro da rede nas quais os laços estão em falta ou a densidade é baixa. } \\
\mathrm{O} \text { "buraco estrutural" indica que circulam diferentes fluxos de informação. }\end{array}$ & $\begin{array}{l}\text { Burt (1992); } \\
\text { Sacomano } \\
\text { Neto (2004) }\end{array}$ \\
\hline $\begin{array}{l}\text { Rede } \\
\text { Aberta } \\
\text { versus } \\
\text { Rede } \\
\text { Fechada }\end{array}$ & $\begin{array}{l}\text { Rede Aberta: As relações entre dois atores é o principal constructo, e todos os } \\
\text { relacionamentos entre os atores envolvidos são de caráter não redundante. O } \\
\text { conhecimento é compartilhado entre os atores. Aborda principalmente } \\
\text { transferência de recursos e informações. Este tipo de rede é necessário para } \\
\text { aplicação da inovação. } \\
\text { Rede Fechada: Permite que o ator confira a qualidade e reflita sobre, compare e } \\
\text { avalie o conhecimento recebido. A interação fechada e a redundância de } \\
\text { relacionamentos com outros atores resultam na dificuldade em manter o } \\
\text { conhecimento dentro da firma. A interação enfatiza confiança e rotinas partilhadas. } \\
\text { Interrompe o fluxo de conhecimento não-redundante. Foca o intercâmbio social, } \\
\text { confiança, e partilha normas. }\end{array}$ & $\begin{array}{l}\text { Anderson et al. } \\
\text { (2007); Jack } \\
(2005) \text {, Walker } \\
\text { et al. (1997) e } \\
\text { Ahuja (2000). } \\
\text { Anderson et al. } \\
\text { (2007); Jack } \\
(2005) \text {, Walker } \\
\text { et al. (1997) }\end{array}$ \\
\hline
\end{tabular}

Quadro 4 - Principais conceitos sobre as formas de análise de redes

\subsection{Abordagem Quantitativa}

Como já foram apresentados os conceitos de Redes Sociais e a Abordagem Sociológica, torna-se necessário descrever, a partir de agora, o conjunto de medidas 
disponíveis no domínio de SNA que auxiliaram o mapeamento da rede de médicos com vínculos profissionais em unidades de saúde públicas e privadas.

A seleção pelo conjunto de medidas de rede (Centrality (Centralidade); Neighbor (vizinhos); Density (Densidade) e Inclusiveness (Inclusão); Egonet (Rede Ego) e Structural Hole (Buraco Estrutural) e apresentadas a seguir, decorre de um processo de revisão de literatura acerca de estudos com redes organizacionais.

\subsubsection{Centrality (Centralidade)}

Um conceito-chave na análise de redes sociais é a centralidade do nó. Centralidade é a importância de um nó devido à sua posição estrutural na rede (BORGATTI, 2009).

Segundo Freeman (1978), um gráfico é composto por um conjunto de pontos, linhas ou arestas ligando os pares de pontos. Então, quando dois pontos estão diretamente conectados por uma aresta, eles são adjacentes. O número de outros pontos, para os quais um dado ponto é adjacente, é conhecido como grau daquele ponto. Na Figura 4, o grau do ponto P1 é 1 e, o grau do ponto P2 é 3.

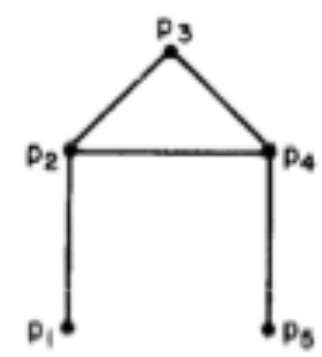

Figura 4 - Gráfico com 5 pontos e 5 arestas Fonte: Freeman (1978)

A posição de um ator na rede corresponde a um ponto no gráfico e a ligação de comunicação simétrica, corresponde a uma aresta ou linha que se conecta a um par de pontos (FREEMAN, 1978).

O termo centralidade é tratado como ponto de centralidade. O ponto no centro de uma estrela ou no Hub de uma roda, é a posição mais central possível (Figura 5). Essa figura ilustra que o ponto central é P3, adjacente de 4 outros pontos, cujo grau é 4 . No gráfico de cinco pontos, qualquer ponto pode ser adjacente somente para quatro pontos remanescentes, 
assim o grau máximo de qualquer ponto é quatro. Portanto, P3 é um exemplo de um ponto de grau máximo em um gráfico de cinco pontos (FREEMAN, 1978).

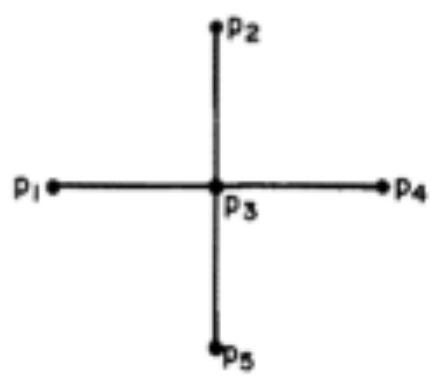

Figura 5 - Uma estrela ou roda com cinco pontos Fonte: Freeman (1978)

Borgatti (2005) aborda quatro aspectos de centralidade: Eigenvector (Autovetor central); Degree Centrality (Grau de centralidade); Closeness (proximidade) e Betweenness (intermediação). Na Figura 6, observa-se que o ator Linda apresenta um maior grau tanto de Degree quanto de Eigenvector. Já o ator Roger o índice de Closeness é maior que os demais atores da rede e o ator Conrad assume o papel de intermediador (Betweenness) na rede, pois ele conecta as duas redes.

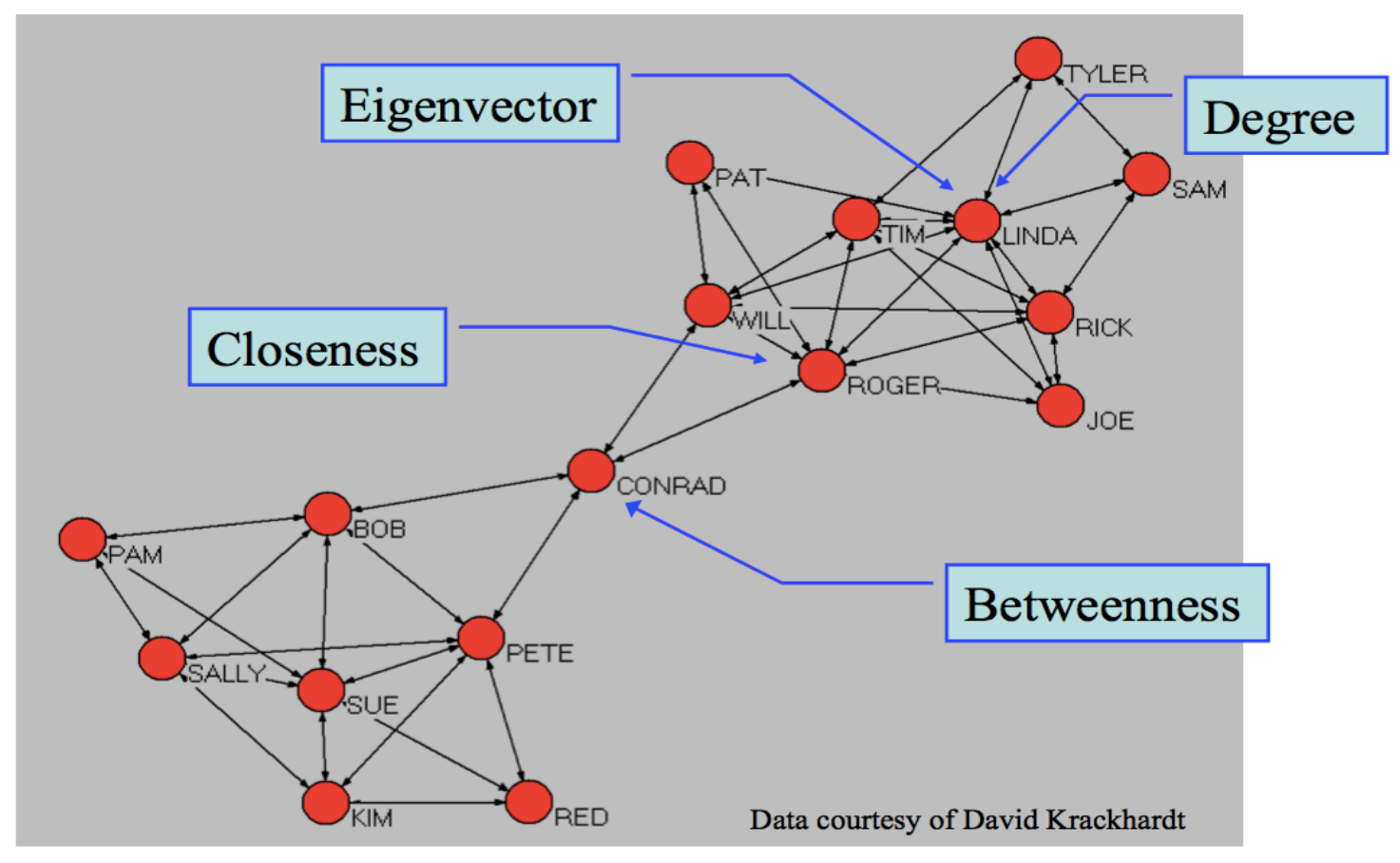

Figura 6-Quatro aspectos de centralidade Fonte: Borgatti (2005) 
Borgatti (2005) considera centralidade na rede, conforme os seguintes tópicos: (1) o número de laços que envolvem um determinado nó; (2) até que ponto a rede gira em torno de um único nó; (3) a medida em que a rede se assemelha a forma de estrela; (4) a diferença entre a pontuação da centralidade de cada nó e a pontuação do nó mais central.

Nesse contexto, diversos autores (FREEMAN, 1978; HANSEN; SHNEIDERMAN; SMITH, 2011; SCOTT, 2000; BORGATTI, 2005) descrevem um conjunto de medidas de centralidade, como: Degree Centrality (Grau de centralidade); Coreness (Núcleo); Closeness (Proximidade); Betweenness (intermediação) e Eigenvector (centralidade de autovetor).

\subsubsection{Degree Centrality (Grau de centralidade)}

O termo centralidade pode ser expresso como o grau de centralização da estrutura e traz duas perspectivas: a primeira, refere-se ao número de ligações que podem ser associadas a um ponto específico, ou pontos mais centralizados que concentram um grande número de ligações com outros nós. A segunda perspectiva enfatiza o número de pontos que servem de passagem entre as ligações de dois pontos quaisquer da estrutura. (BRITTO, 2002).

Nesse sentido, Carter et al. (2007), destaca que o termo "grau" é definido como o número de laços que um ator tem com outros atores na rede. O grau de atores pode ser calculado somando-se o número de ligações entre o ator e os outros atores em um sóciograma, ou adicionando valor dentro de uma linha ou coluna de uma matriz de adjacência (CARTER et al., 2007).

Para tanto, degree centrality, mede a centralidade da estrutura da rede baseada no grau de conexões. O grau de centralidade é calculado por uma porção de nós que são adjacentes para cada nó (CYRAM, 2008). Dado pela seguinte fórmula:

Grau de centralidade do nó $=\frac{\text { soma }[\text { peso de ligações incidentes }]}{\# \text { nós-1 }}$

Em uma rede ponderada de 1 modo, o índice do grau de centralização da rede pode ser maior que 1 (CYRAM, 2008). Para Freeman (1978) um único ator central é igual a 1 e os demais atores da rede é 0 . Assim, a referência varia de 0 (não central) a 1 (mais central). 
Não obstante disso, o grau de centralidade refere-se ao número de atores para os quais um ator está diretamente ligado. Então, dependendo da direção dos fluxos, o grau de centralidade, divide-se em: (1) Grau de entrada (in-degree centrality) é a soma das interações que os outros nós tem com o ator e, (2) Grau de saída (out-degree centrality) é a soma das interações que os atores tem com os outros (ALVAREZ e AGUILAR, 2005), conforme a ilustração do Quadro 5.

O índice do grau de centralização é a medida da variabilidade do índice de centralidade individual. Quanto maior o índice do grau de centralização, mais centralizado é o ator na rede (CYRAM, 2008).

\begin{tabular}{|l|l|c|}
\hline \multicolumn{1}{|c|}{ Medidas de Rede } & \multicolumn{1}{|c|}{ Descrição } \\
\hline $\begin{array}{l}\text { Indegree: são os vínculos "entrantes"(os que vem } \\
\text { desde os alter até ego); }\end{array}$ & $\begin{array}{l}\text { Outdegree: são os vínculos de "saída" (os que } \\
\text { Sentralidade - } \\
\text { centralidade) (Grau de }\end{array}$ & $\begin{array}{l}\text { Densidade total: quando os vínculos vão em ambos até os alter); } \\
\text { os sentidos, sendo indegree = outdegree }\end{array}$ \\
\hline
\end{tabular}

Quadro 5 - Medidas de Rede

Fonte: Adaptado de Zoppi (2012)

Nessa pesquisa, as ligações entre os nós da rede são consideradas como nãodirecionais, ou seja, as ligações entre nós não dependem de sua origem, portanto o indegree $=$ outdegree, conforme ilustra Quadro 5.

\subsubsection{Coreness (Núcleo/Periferia)}

A medida de Coreness é uma medida de centralidade (BORGATTI, 1999). Esse autor aborda o conceito como um modelo de estrutura de núcleo/periferia da rede de dados e, propõe a mensuração do grau de Coreness de cada ator. Os atores com a maior pontuação de 
Coreness são agrupados no núcleo da rede e, os demais na periferia da rede. Coreness identifica, progressivamente, os núcleos internos e analisa-se a rede por layers, revelando a estrutura das diferentes camadas (HE et al., 2011).

Na Figura 7 é apresentado um exemplo de núcleos de análise de uma rede. A partir desta figura, observa-se as propriedade de Coreness dos núcleos, sendo o nível central identificado como A.

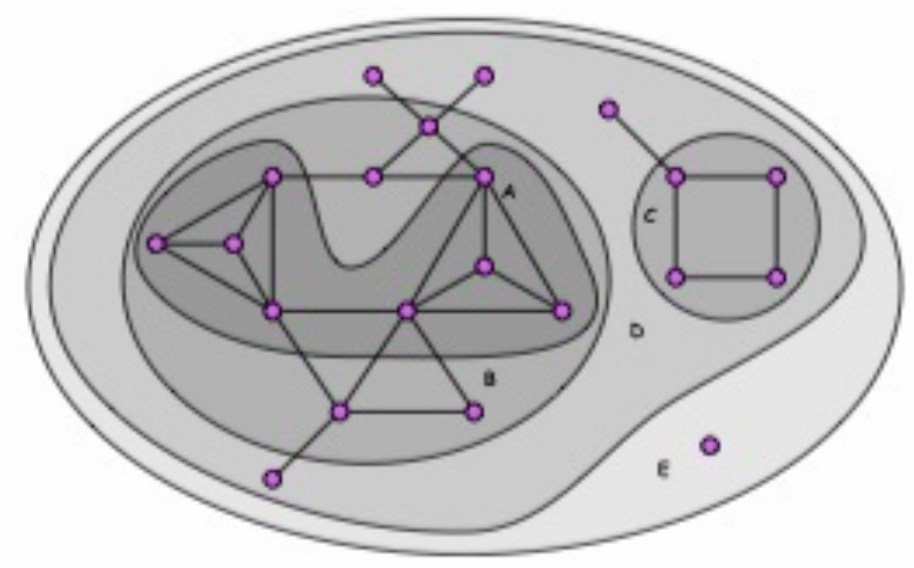

Figura 7 - Core de uma rede

Fonte: Adaptado de Batagelj e Zaversnik (2002)

Segundo Batagelj e Zaversnik (2002) a medida de Coreness permite a identificação de partes importantes de uma rede, na análise em redes significativamente grandes. Em resumo, a estrutura de redes grandes pode ser mostrada por meio da partilha da rede em partes menores.

\subsubsection{Closeness (Proximidade)}

Outra métrica disponível é a centralidade por proximidade (closeness). Fremann (1979) afirma que a independência de um ponto é determinada pela proximidade (closeness) em relação aos outros pontos do gráfico. Convém retornar para a Figura 4 (Gráfico de cinco pontos), onde o ponto P2 têm ligações diretas com três outros pontos, P1, P3 e P4. Assim, P2 está mais próximo do que P1 para todos os outros pontos, isto é , isso indica alta centralidade no sentido de ser independente dos outros pontos (FREMANN, 1979). 


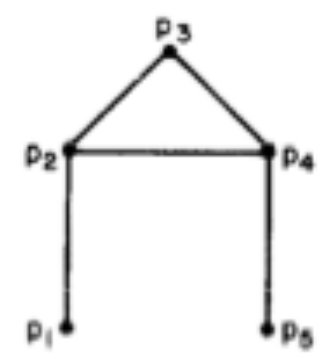

Figura 4 - Gráfico com 5 pontos e 5 arestas

Fonte: Freeman (1978)

Closeness é a soma das distâncias de todos os outros nós (BORGATTI, 2005). Quanto maior a pontuação de cada ator, e consequentemente, menor a distância em relação aos outros pontos, mais fácil é para o ator alcançar todos os outros atores na rede. Um ator tem alta centralidade de closeness (proximidade) quando ele é próximo a muitos outros atores em uma rede bem conectada. Dessa forma, a centralidade de closeness avalia a medida em que um ator focal ocupa uma posição central em uma rede, mas sendo relativamente autônomo, em termos de menor dependência dos intermediários (TASSELI, 2015; POWELL, KOPUT e DOERR, 1996).

A medida de closeness permite identificar os nós que estão localizados a uma curta distância da maioria dos outros nós (no sentido de caminho curto). Esses nós irão, em média, receber mais informações do que os nós que estão mais distantes da maioria dos outros nós da rede. Além disso, redes que são altamente centralizadas, no sentido de ter um nó próximo de todos os outros, são propensas a um bom desempenho em tarefas que requerem integração de informações (BORGATTI, 2009).

A medida de closeness calcula a centralidade de uma estrutura de rede com base em distâncias geodésicas entre os nós. Índice de Centralidade de closeness é uma medida da variabilidade do índice de centralidade de closeness individual. Esse índice mostra a pontuação da centralização de closeness e, seu valor varia de 0 a 1 . Se um nó tem, excepcionalmente, um grande valor de centralidade como, por exemplo, um gráfico de estrela, o índice de centralização de closeness é 1 (CYRAM, 2008).

Em resumo, em relação à proximidade, um ator é tão mais central quanto menor a distância geodésica que ele precisa percorrer para alcançar os outros nós da rede. Isso avalia, a independência do ator em relação ao controle por outros atores (MARTELETO, 2001). 


\subsubsection{Betweenness (Intermediação)}

Outra medida de centralidade em redes é "betweenness" (intermediação), definido, como os números de caminhos que passam por um ator entre os caminhos mais curtos que ligam dois outros atores (RONCHETTOR et al., 1989 apud CARTER et al., 2007; BORGATTI, 2005). Do ponto de vista da difusão do conhecimento, um ator com alto grau de centralidade de betweenness tem maior influência, na medida em que pode servir como uma ligação de fato entre áreas isoladas da rede (RONCHETTOR et al. , 1989 apud CARTER et al., 2007).

Baum et al. (2010) define betweenness como uma medida de centralidade que considera o número de vezes que um ator aparece entre os caminhos mais curtos para todos os pares de nós. É uma medida de controle informação: a alta centralidade de betweenness de um ator na rede, indica uma posição mais forte em termos de brokerage, ou seja, mais controle (e, assim, poder) sobre o fluxo de conhecimento por meio da rede. Borgatti (2005) considera betweenness como um potencial índice de brokers, ou seja, controlador de fluxo e intermediário em contatos com outras partes da rede.

A medida de Betweenness é dividida em: Betweenness - Node e Betweenness Link. O índice de Betweenness - Node é tratado como centralidade de uma estrutura de rede, baseada em par-dependência entre seus nós. Já a centralidade de Betweenness link é medida pela extensão do grau em que uma ligação, situa-se, entre todos os outros pares de nós em seus caminhos geodésicas. Então, quanto mais vezes uma ligação aparece nos caminhos, maior é a centralidade (CYRAM, 2008).

Betweenness Centrality é medida pela extensão com que um nó encontra-se entre todos os outros pares de nós em seus caminhos geodésicos. Portanto, quanto mais vezes um nó aparece nos caminhos mais curtos, maior é a sua centralidade (CYRAM, 2008).

O índice de Centralização de betweenness é uma medida da variabilidade dos escores de betweenness de centralidade individual. Esse índice mostra a pontuação da centralização e seu valor varia de 0 a 1 . Se cada nó tem um mesmo valor de centralidade, o índice de centralização é 0 . Se um nó tem, especialmente, um valor maior de centralidade, por exemplo, um gráfico de estrela, o índice de centralização é 1 (CYRAM, 2008). 
De modo geral, betweenness centrality é uma métrica que avalia o potencial daqueles que servem de intermediários (Quadro 6). Calcula-se, o quanto um ator atua como ponte, facilitando o fluxo de informação em uma determinada rede (MARTELETO, 2001).

\begin{tabular}{|l|l|c|}
\hline Medidas de Rede & \multicolumn{1}{|c|}{ Descrição } \\
\hline Centralidade - & Mensura o grau em que um nó aparece \\
Betweenness (Grau & intermediando todos os outros pares de nós nos \\
de Intermediação) & seus caminhos geodésicos (caminhos mais curtos)
\end{tabular}

Quadro 6 - Medidas de Rede

Fonte: Adaptado de Zoppi (2012)

\subsubsection{Eigenvector (Autovetor)}

A medida de centralidade de autovetor (eigenvector centrality) permite medir a importância de um vértice na estrutura da rede; seus valores variam entre 0 (menor relevância) e 1 (maior relevância) (HANSEN; SHNEIDERMAN; SMITH, 2011; BORGATTI, 2005). Esta métrica é, por exemplo, utilizada pelo Google para examinar a estrutura da rede (links da web) e, identificar a importância das páginas web para uma determinada pesquisa que se esteja realizando (SILVA, 2014).

Portanto, as quatro primeiras medidas de centralidade (Degree Centrality, Coreness, Closeness e Betweenness) aqui apresentadas, foram utilizadas nesta tese por serem comumente usadas em estudos de análise de centralidade da rede.

Uma vez que as medidas de centralidade foram apresentadas, resta descrever a análise gráfica de Box Plot e as demais métricas utilizadas para identificação da estrutura da rede: Neighbor (vizinhos); Density (Densidade) e Inclusiveness (Inclusão); Egonet (Rede Ego) e Structural Hole (Buraco Estrutural). 


\subsubsection{Box Plot}

O Box Plot é um recurso visual, oriundo da estatística descritiva. Esse gráfico é muito utilizado para descrever graficamente grupos de dados numéricos. Tem como base o resumo de cinco números: o valor mínimo; o primeiro quartil (Q1) corresponde ao quartil inferior (25\% dos menores valores dos dados); o segundo quartil (Q2 ou m) compreende à mediana dos dados (representada por uma linha horizontal dentro da caixa de um determinado gráfico); o terceiro quartil (Q3) corresponde ao quartil superior (75\% dos valores observados) e o valor máximo (CYRAM, 2008; KRZYWINSKI; ALTMAN, 2014).

Assim, o boxplot apresenta os outliers (desvios extremos da média) presentes na distribuição dos dados, o que auxilia a identificar o grau de dispersão e assimetria dos dados (SILVA, 2014).

\subsubsection{Análise Neighbor (vizinhos)}

Esta métrica analisa graus e tipos de nós na rede. Dois nós são "adjacentes", se há uma linha entre eles. Um nó é "incidente" para uma linha, se o nó é um dos pares de nós que definem a linha. "Grau” Nodal (de conexão) é o número de linhas que são incidente com ele. Ele mede o tamanho de sua vizinhança direta. Em uma rede dirigida, nodal "In-Degree" é o número de linhas para o qual o nó incidente é um alvo. E "Out-Degree" é o número de ligações para as quais o nó incidente é fonte. Ligações do nó para si mesmo são ignoradas no cálculo.

Além disso, os nós de um gráfico dirigido podem ser classificados em 5 tipos. O primeiro tipo, nó “isolado" significa que ele não tem quaisquer ligações. O segundo tipo, nó "transmissor" significa que o nó tem somente links de saída e não tem links de entrada. O terceiro tipo, nó "receptor" tem somente links de entrada, então apenas recebem algo. O quarto tipo, nó “carregador” requerem que ambos grau de entrada e grau de saída são iguais a 1. O último, tipo nó "ordinário" significa que os nós que não se enquadram nas categorias acima mencionadas (CYRAM, 2008). 


\subsubsection{Density (Densidade) e Inclusiveness (Inclusão)}

Um dos conceitos mais utilizados na teoria de redes, é o de densidade "density", o qual descreve o nível geral de ligações entre nós em uma rede. As Figuras 8 e 9, ilustram a densidade de uma rede. A Figura 8 apresenta uma rede com densidade de 22,56\%. Ao se comparar com a Figura 9, que apresenta uma densidade de 10,97\%, observa-se que a primeira rede é mais densa. A primeira é rede é considerada como uma rede densa porque os atores estão altamente conectados e, a segunda é uma rede é tida como de menor densidade, pois apresenta conexões mais esparsas e quantidades maiores de nós não conectados.

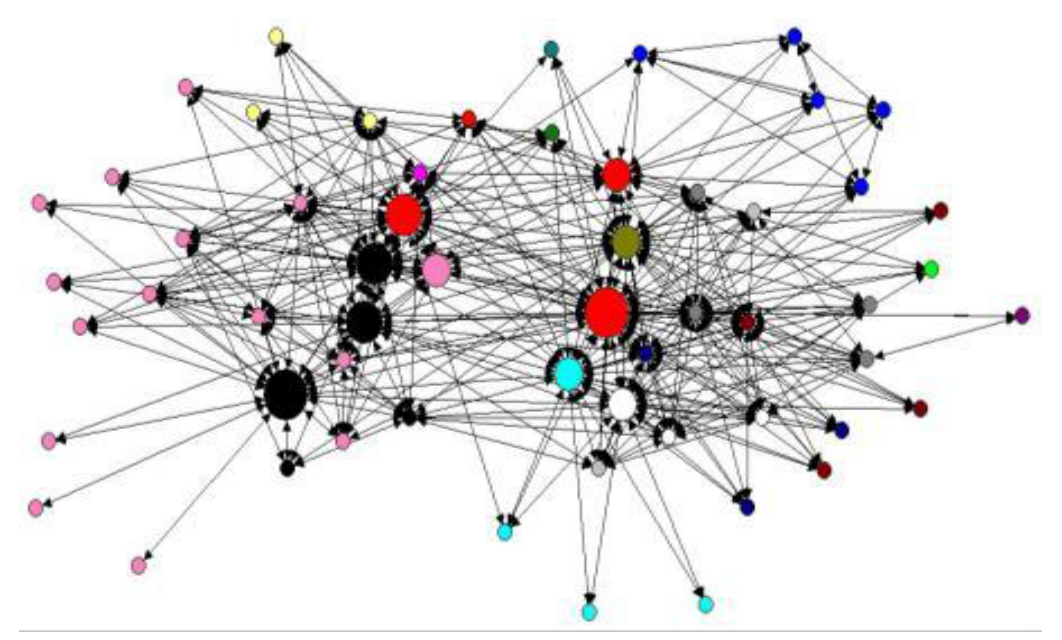

Figura 8 - Densidade de rede - Densidade $=22,56 \%$ Fonte: Zoppi, 2010

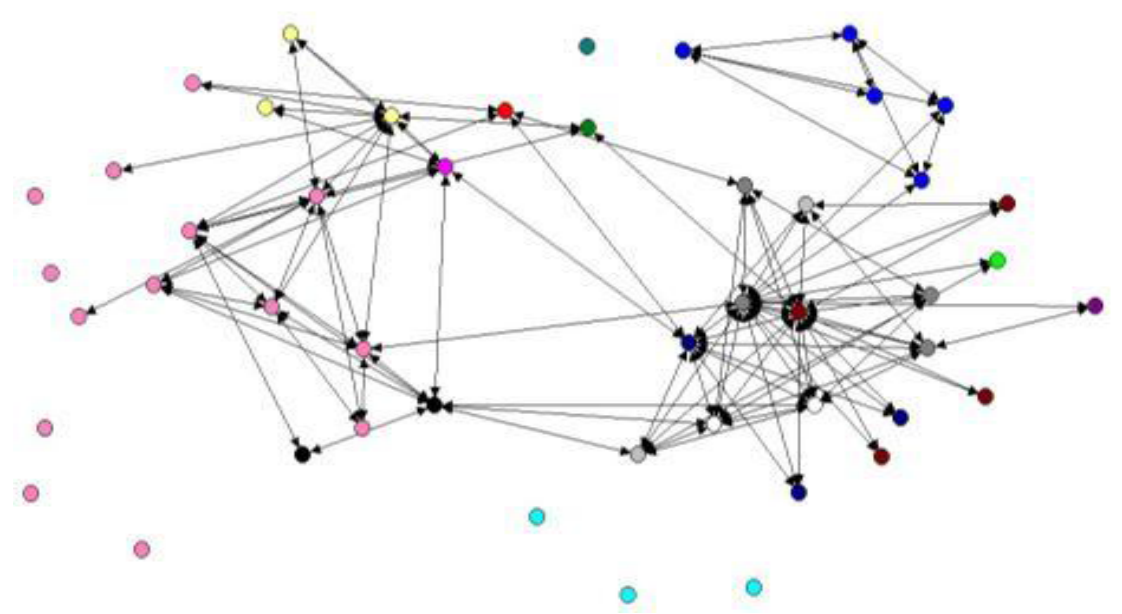

Figura 9 - Densidade de rede - Densidade $=10,97 \%$

Fonte: Zoppi, 2010 
A densidade (density) é medida pela razão entre o número de ligações presentes em relação ao máximo de ligações possíveis. Um gráfico "completamente conectado" é um no qual todos os pontos são adjacentes, cada nó é conectado diretamente com cada outro nó presente na rede (Tabela 1). Tal completude é rara, mesmo em redes muito pequenas, e o conceito de densidade é uma tentativa de sumarizar a distribuição geral de ligações, com o objetivo de medir o quão longe desse estado de completude de ligações, o gráfico está. Quanto mais nós estão conectados, uns aos outros, mais densa será essa rede. Densidade, então, depende de dois outros parâmetros da estrutura de rede, sendo esses, a inclusão "inclusiveness" do gráfico, e a soma de graus (degrees) de seus nós. Inclusão se refere ao número de nós, os quais estão incluídos dentro das várias partes conectados de um gráfico. Posto de outra forma, a inclusiveness de um gráfico é o número total de pontos menos o número de pontos isolados (SCOTT, 2000).

Tabela 1 - Comparação de densidade

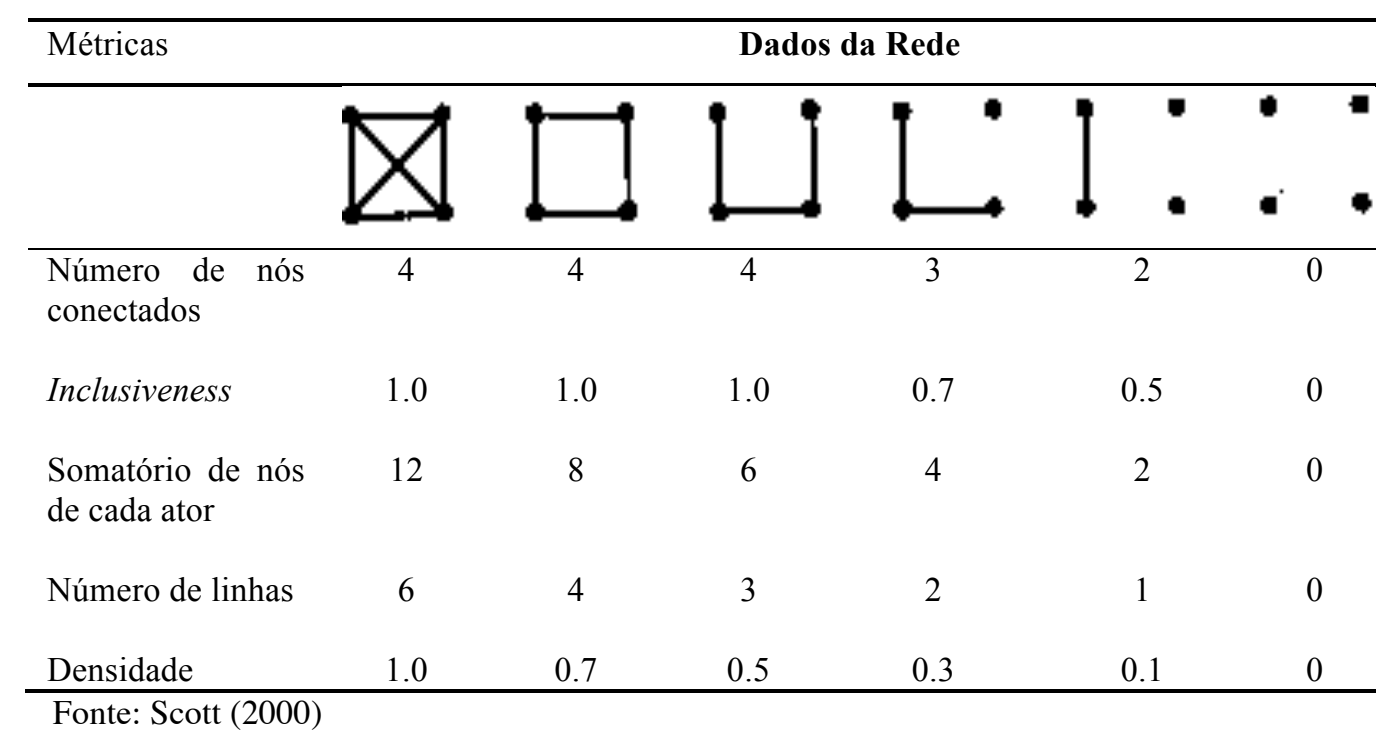

\subsubsection{Egonet (Rede Ego)}

A abordagem de Burt (1992) assume a perspectiva (ego) centrada, ou seja, a rede parte do indivíduo. Essa perspectiva é entendida como rotas de acesso para outras redes. Borgatti e Li (2009) destacam que a chamada rede ego, consiste em: (a) um ator focal, conhecida como ego; (b) o conjunto de atores com qualquer tipo de vínculo com o ego 
(conhecido como alter) e; (c) todos laços entre os alters e, entre os outros alters e o ego (Figura 10).

Quando a ligação alter ego é redundante, espera-se que o ego se torne mais bem informado rapidamente. Não-redundância também pode ser a base para um grande poder monopolizador do fluxo de recursos (incluindo informações) entre alters egos (REAGANS e ZUCKERMAN, 2008).

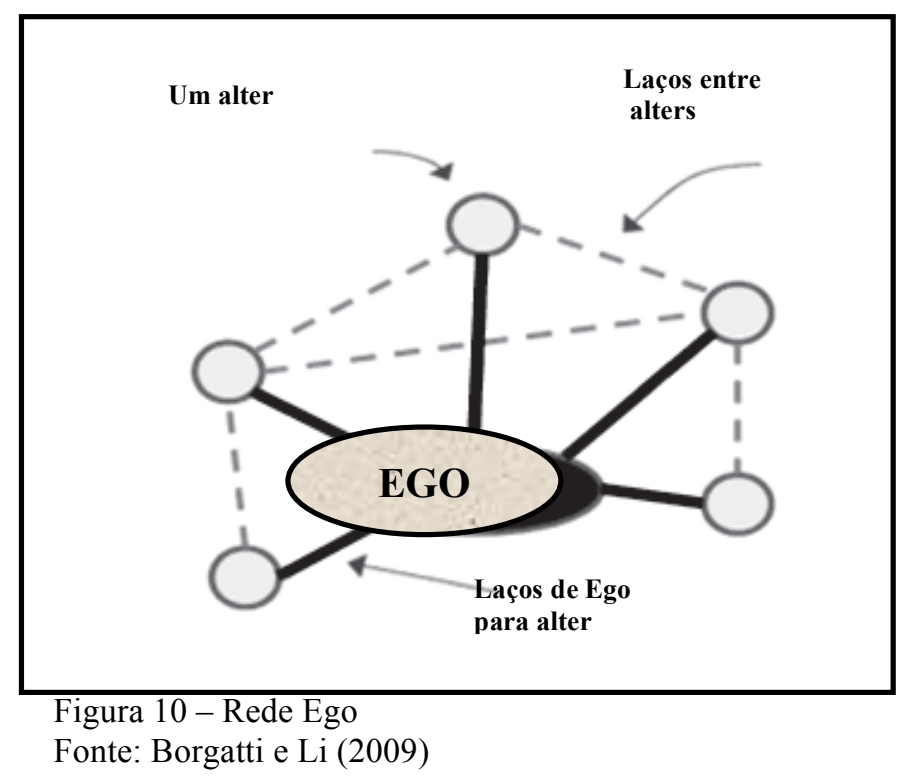

De acordo com Burt (2005), o principal benefício de buracos estruturais é a disponibilidade de informação (não redundante). Se os nós de alters estão ligados um ao outro, em seguida, a informação que possui um alter pode também ser possuído por outro alters ego, o que sugere que um laço para ambos seria redundante e, portanto, desnecessário. Assim, uma rede ego de tamanho similar, mas com menos laços entre alters é susceptível de proporcionar ao ego, informações não redundantes. A principal razão para restringir a atenção para a rede ego é, em princípio, a crença de que muitas conexões não são relevantes. Claro, também é muito mais conveniente coletar os dados da rede ego, do que os dados da rede completa, e principalmente se, a rede ego fornecer uma proximidade razoável para a posição em uma estrutura maior.

A medida de rede ego analisa a estrutura da conexão local de cada nó em uma rede. Uma rede ego consiste de um nó focal e um conjunto de nós adjacentes para ou a partir do nó focal. Medidas de rede ego, incluem: tamanho e densidade de cada rede ego. Assim, o tamanho da rede ego é, o número de nós adjacentes, ou a partir de um nó focal. A densidade 
da rede ego em estudo é calculada da seguinte forma: número de ligações atuais/número máximo possível de ligações.

\subsubsection{Structural Hole (Buraco Estrutural)}

As medidas de análise de buraco estrutural envolvem uma estrutura de conexão local de cada nó de uma rede. Com o pressuposto de que a relação não-redundante é relativamente eficiente, as medidas de buraco estrutural envolvem: Redundância, Eficiência, Tamanho Eficaz, Limitação e Hierarquia de cada nó (BURT, 1992; CYRAM, 2008).

- Redundância: é a quantidade de informações que o nó i pode receber, a partir de outros nós. Assim, a alta redundância de i, significa que i não irá gerenciar a sua rede de forma eficiente (BURT, 1992; CYRAM, 2008);

- Eficiência: essa medida maximiza o número de contatos não redundantes. A Figura 11 ilustra que quanto maior o número de contatos não redundantes, maior será a eficiência na rede. É o tamanho eficaz dividido pelo tamanho observado. Assim, a Figura 12, corrobora que o nó 3 é o mais eficiente, cujo resultado é 1 em comparação com os demais nós (BURT, 1992). Segundo Cyram (2008), Eficiência é redundância menos 1 resumido para todos os alters. 


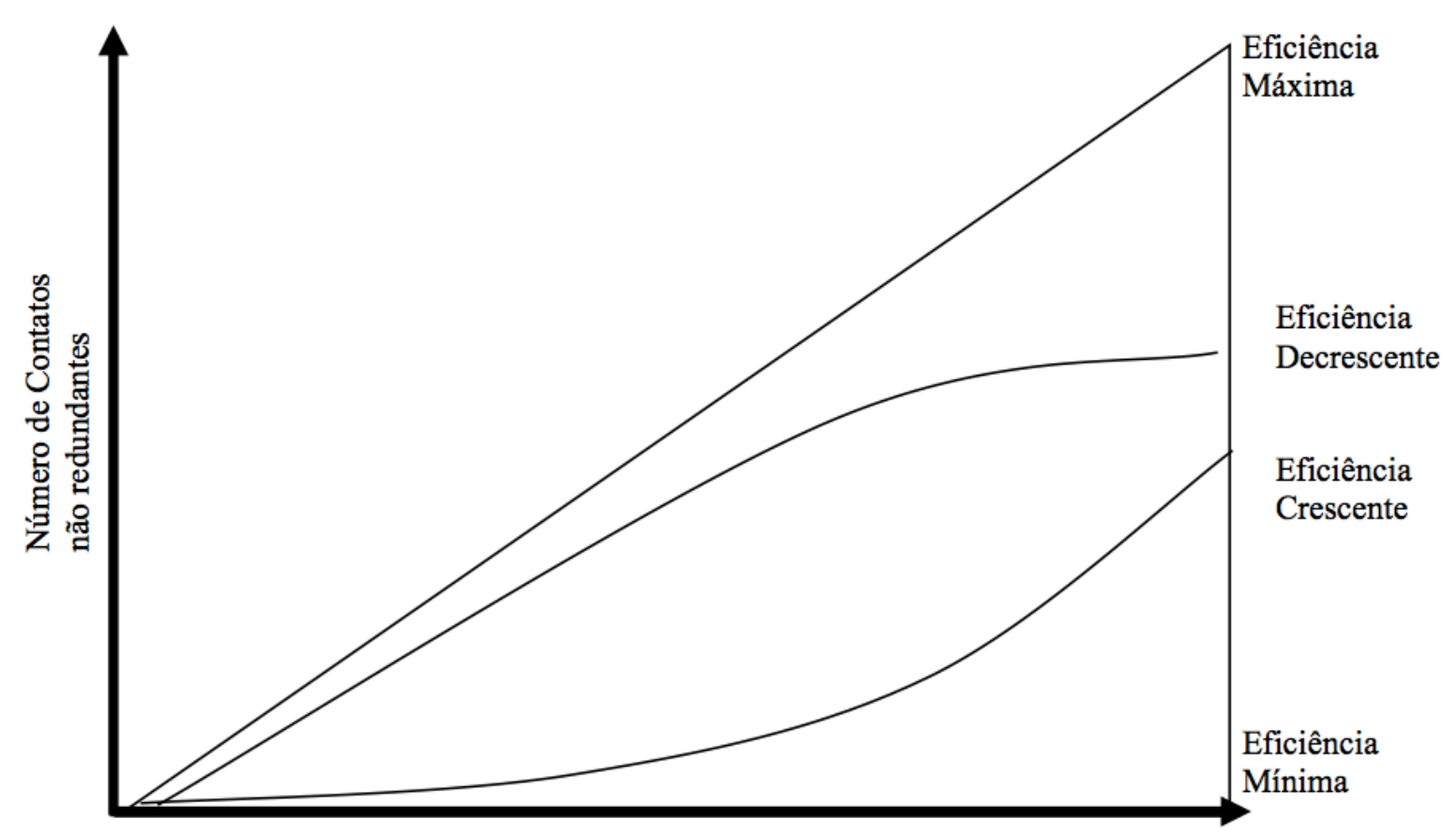

Número de Contatos

Figura 11 - Eficiência e Eficácia

Fonte: Burt (1992)

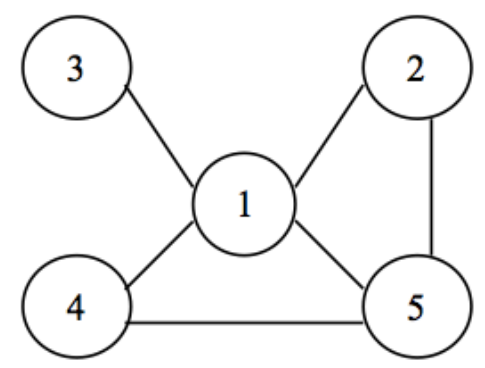

\begin{tabular}{|c|c|c|c|}
\hline Nó & Tamanho & $\begin{array}{c}\text { Tamanho } \\
\text { Eficaz }\end{array}$ & Eficiência \\
\hline 1 & 4 & 3 & 0.75 \\
\hline 2 & 2 & 1 & 0.5 \\
\hline 3 & 1 & 1 & 1.0 \\
\hline 4 & 2 & 1 & 0.5 \\
\hline 5 & 3 & 1.67 & 0.55 \\
\hline
\end{tabular}

Figura 12 - Eficiência dos nós Fonte: Burt (1992:71)

- Tamanho eficaz: é o número de nós que estão conectadas a ego, menos a redundância na rede, ou seja, permanece somente os elementos não redundantes da rede. Assim, Tamanho efetivo $=$ Tamanho - Redundância (BURT, 1992)

Segundo Cyram (2008) tamanho eficaz é a soma da eficiência em cada nó alter por meio dos relacionamentos (CYRAM, 2008). Desse modo, o calculo para o tamanho eficaz é feito pela seguinte fórmula. 


$$
\sum_{j}\left[1-\sum_{q} p_{i q} m_{j q}\right]
$$

Onde, o índice j de todas as pessoas que ego i tem contato, e q é cada terceira pessoa, com exceção de i ou j.

A quantidade $\left(p_{i q} m_{j q}\right)$ dentro dos colchetes é o nível de redundância entre ego e um alter especial, j.

- Limitação: é a medida da extensão em que o ego é investido em nós que estão ligadas em outros alters do ego (CYRAM, 2008). Segundo Burt (1992) conceitualmente, limitação, refere-se a forma que o ator tem espaço para negociar ou explorar potenciais buracos estruturais em sua rede. Assim, o cálculo de limitação é dado pela seguinte fórmula:

$$
C_{i j}=\left(p_{i j}+\sum_{q} p_{i q} p_{q j}\right)^{2}{\frac{\mathrm{p}_{\mathrm{ij}}}{\mathrm{iq}}}_{\mathrm{Cij}=\text { Investimento direto }(\mathrm{Pij})+\text { investimento indireto }}^{q}
$$

- Hierarquia: é a medida em que a limitação do ego é concentrada em um alter único. A posição é de 0 a 1 , se a hierarquia é 1 , a limitação do nó i é concentrada em apenas um alter, conforme a formula:

$$
H=\frac{\sum_{j}\left(\frac{C_{i j}}{C / N}\right) \ln \left(\frac{C_{i j}}{C / N}\right)}{N \ln (N)}
$$

O Quadro 7 apresenta um resumo geral dos principais conceitos e autores, no que diz respeito, as medidas e formas de análise de redes. 


\begin{tabular}{|c|c|c|}
\hline Medidas da rede & Conceitos & Autores \\
\hline Degree Centrality & \multicolumn{2}{|c|}{$\begin{array}{l}\text { É o grau de centralização da estrutura. Ponto de Centralidade é aBritto (2002);Freeman } \\
\text { posição mais central possível. Centralidade é a importância de um(1978); Borgatti } \\
\text { nó devido à sua posição estrutural na rede. }\end{array}$} \\
\hline Coreness & \multicolumn{2}{|c|}{$\begin{array}{l}\text { Provê a identificação de partes importantes de uma rede, na análise } \begin{array}{l}\text { Batagelj e Zaversnik, } \\
\text { em redes significativamente grandes. }\end{array} \\
(2002)\end{array}$} \\
\hline & $\begin{array}{l}\text { Analisa o número máximo do núcleo de cada nó; } \\
\text { Identifica os núcleos internos e analisa-se a rede por layers }\end{array}$ & $\begin{array}{l}\text { Cyram (2008) } \\
\text { He et al. (2011) }\end{array}$ \\
\hline Closeness & \multicolumn{2}{|c|}{$\begin{array}{l}\text { A independência de um ponto é determinado pelo Closeness paraFremann (1979) } \\
\text { todos os outros pontos do gráfico; } \\
\text { Alta centralidade de closeness (proximidade) quando o ator éTasseli (2015) } \\
\text { capaz de atingir muitos outros atores em uma rede bem conectada; } \\
\text { Redes que são altamente centralizadas são propensas a um bomborgatti (2009) } \\
\text { desempenho. }\end{array}$} \\
\hline Betweenness & \multirow{2}{*}{\multicolumn{2}{|c|}{$\begin{array}{l}\text { O número de caminhos que passam por um ator sobre os caminhos } \\
\text { mais curtos que ligam dois outros atores; } \\
\text { Um índice de centralidade de betweenness mais elevado para umal et al. } \\
\text { ator sugere uma posição mais forte; } \\
\begin{array}{l}\text { Potencial índice de brokers, controlador de fluxo e, contatos com Carter et } \\
\text { outras partes da rede }\end{array} \\
\begin{array}{ll}\text { Permite medir a importância de um vértice na estrutura da rede } \\
\text { Baum et al. (2010) } \\
\text { Borgatti (2005) }\end{array} \\
\begin{array}{l}\text { Hansen, Shneiderman } \\
\text { and Smith (2011) } \\
\text { Borgatti (2005). }\end{array}\end{array}$}} \\
\hline Eigenvector - & & \\
\hline Neighbor & Ele mede o tamanho de sua vizinhança direta & (Cyram, 2008) \\
\hline $\begin{array}{l}\text { Density } \\
\text { Inclusiveness }\end{array}$ & \multicolumn{2}{|c|}{$\begin{array}{l}\text { Quanto maior o número de nós conectados, maior é a densidade daScott (2000); } \\
\text { rede. } \\
\begin{array}{l}\text { Inclusão se refere ao número de nós, os quais estão incluídos } \\
\text { dentro das várias partes conectados em uma rede. }\end{array}\end{array}$} \\
\hline Egonet & $\begin{array}{l}\text { A rede parte do indivíduo. Essa perspectiva é entendida como rotas } \\
\text { de acesso para outras redes. A rede ego, consiste em (a) um ator } \\
\text { focal, conhecida como ego, ( b) o conjunto de atores com } \\
\text { qualquer tipo de vínculo com o ego (conhecido como alter) e ( c) } \\
\text { todos laços entre os alters e entre os alters e o ego. Enquanto o } \\
\text { alter ego são não-redundantes, o ego pode ser esperado para se } \\
\text { tornarem mais bem informado rapidamente. }\end{array}$ & $\begin{array}{l}\text { Burt (1992); Borgatti } \\
\text { (2009); Reagans e } \\
\text { Zuckerman (2008). }\end{array}$ \\
\hline Structural Hole & $\begin{array}{l}\text { As medidas de análise de buraco estrutural envolvem uma } \\
\text { estrutura de conexão local de cada nó de uma rede. O pressuposto } \\
\text { é que a relação não-redundante é relativamente eficiente. }\end{array}$ & $\begin{array}{l}\text { Burt (1992); Cyram, } \\
(2008)\end{array}$ \\
\hline
\end{tabular}

Quadro 7 - Medidas e formas de análise de redes

Foram aqui apresentados, até o momento, os conceitos, ferramentas e métricas provenientes do domínio de SNA que são a base de sustentação desta pesquisa de doutorado. Ademais, outros temas necessitam ainda ser trazidos para este contexto (como o modelo $\mathrm{Hub}$ and Spoke) por se entender que são elementos que podem enriquecer o processo de análise de redes e permitir a identificação dos principais Hubs de saúde, nesta pesquisa. 


\subsection{Modelo Hub and Spoke (HS)}

O modelo HS é um termo conhecido na área de logística e utilizado por companhias aéreas e, mais recentemente, passou a ser utilizado na área de saúde. Os Hubs são os nós fortemente conectados dentro de uma rede. Assim, o conceito de Hub depende das múltiplas dimensões da rede, cuja interação torna-se decisiva para a conexão de um nó (BERLINGERIO et al., 2011).

Segundo Derudder et al. (2007) a importância dos pontos de comutação específicos na rede global de companhias aéreas pode ser rastreada com a adoção do modelo HS como principal estratégia para a organização de estruturas de rotas. O modelo HS refere-se à imagem de uma roda de bicicleta com um componente central $(H u b)$ e muitos subcomponentes (os raios). Quando as companhias aéreas adotam esse modelo, elas estabelecem um ou mais pontos de comutação, onde os passageiros podem mudar de voos. A partir dos aeroportos Hubs, as companhias aéreas levam os passageiros aos seus destinos finais. Isto implica que um $H u b$ é essencialmente um "tipo de instalação" localizada numa rede, de tal maneira, a proporcionar um ponto de comutação de fluxos entre outros nós que interagem.

A estrutura HS com um único aeroporto central Hub é ilustrado na Figura 13. Nessa figura, pode se notar que, sete rotas são suficiente para conectar todos os nós na rede. $\mathrm{Na}$ prática, as estruturas de rotas de grandes companhias aéreas apresentam uma mistura de formas organizacionais com (1) ligações diretas entre grandes aeroportos, e (2) uma rede HS para garantir que cada nó está conectado à rede global. Nesse sentido, a Figura 13 apresenta um exemplo de uma rede HS “ideal”.

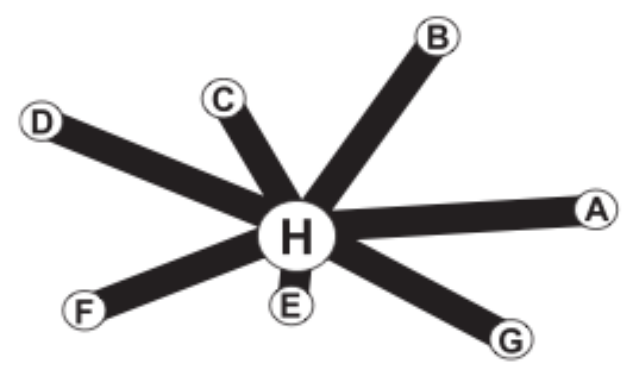

Figura 13 - Hub and Spoke Fonte: Derudder et al. (2007)

Outra forma de organizar a rede de companhias aéreas é por meio do modelo de ponto-a-ponto, que exige um total de $[\mathrm{N} \times(\mathrm{N}-1)] / 2$ rotas para conectar todos os nós na 
rede. Assim, na Figura 14, um total de 28 rotas precisam ser oferecidas. O número de rotas cai substancialmente quando uma companhia aérea adota o modelo HS. Nesse modelo, somente N-1 rotas precisam ser atendidas se um $H u b$ é estabelecido e os voos diretos são fornecidos entre o Hub e todos os outros nós na rede (SHAW 1993 , p. 47).

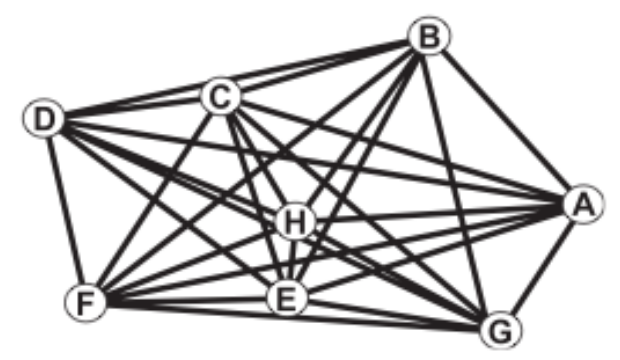

Figura 14 - Modelo ponto-a-ponto

Fonte: Derudder et al. (2007)

Dentro do contexto de saúde, a solução que alguns hospitais indianos encontraram para inovar foi a adoção do modelo HS, assim a configuração de redes de saúde conforme esse modelo, permite aos hospitais não somente reduzir custos, mas também, melhorar a qualidade. Nos hospitais centrais $(H u b s)$, os equipamentos são caros e há médicos mais especializados, enquanto que as unidades de saúde menores são conectadas por meio de tecnologias de informação e comunicação. Essas unidades de saúde menores prestam serviços mais simples, e quando um paciente precisa de uma cirurgia, ele é encaminhado para um centro hospitalar especializado (GOVINDARAJAN, 2014).

A fim de atender o maior número de pessoas, que precisam de cuidados de saúde, os hospitais indianos criaram centros de conexões em grandes áreas metropolitanas e abriram clínicas menores em áreas rurais que levam os pacientes para o hospital central, semelhante à maneira na qual passageiros nas rotas aéreas regionais são levados para os grandes $H u b s$ (GOVINDARAJAN e RAMAMURTI, 2013).

Cerca de 70\% dos indianos vivem em áreas rurais e de difícil acesso para as unidades de saúde, onde as infra-estruturas são mínimas, tornando a assistência médica disponível insuficiente. O modelo HS tem uma arquitetura que enfatiza a utilização ótima dos recursos de saúde escassos em áreas rurais (DEVARAKONDA, 2016)

Para a implementação do modelo HS na Geórgia, os hospitais rurais receberam um financiamento de US\$ 3 milhões (SKINKMAN, 2015). O sistema de saúde nas áreas rurais desse país está passando por dificuldades financeiras. Alguns hospitais rurais fecharam, então, houve a proposta da implementação do modelo HS, para tentar recuperar financeiramente o sistema de saúde. No projeto piloto quatro hospitais foram designados como $\mathrm{Hub}$ em todo o 
estado: Union General, Appling Health System, Crisp Regional e Emanuel Regional Medical Center. Desse modo, os pacientes que necessitam de cuidados especializados serão direcionados para esses Hubs (MERIT IPA, 2015)

Além das medidas de centralidade que foram adotadas nesta tese, outra medida foi proposta para a análise da rede. A fórmula de Hub and Spoke originalmente proposta para a área de logística por Derudder et al. (2007) foi adaptada para avaliar o grau de Hubiness das unidades de saúde.

Um Hub pode ser considerado "central", se seu papel como um importante ponto de comutação é complementado com outras características importantes do nó (por exemplo, nos fluxos de ponto-a-ponto). A noção de "intermediação", ao contrário, refere-se à situação em que a função de um nó como ponto de comutação passa a dominar a sua funcionalidade geral: o encaminhamento de tráfego tem precedência sobre todas as outras funções. (FLEMING e HAYUTH, 1994). Para Fleming e Hayuth (1994), os conceitos de centralidade e intermediação estão relacionados a $H u b$ de transportes. Assim, locais centrais podem ser definidos por conter o atributo de localização geral de centralidade; locais de rotas podem conter o atributo geral de intermediação. Ambos os conceitos se sobrepõem, no contexto de regiões, locais centrais, são também locais de intermediação entre pontos na região.

A seção, a seguir, apresenta um setor pouco explorado em análise de redes, o de saúde. Esse tema é tratado com mais detalhes a seguir.

\subsection{Análise de Redes no Setor de Saúde}

O setor de saúde está enfrentando grandes desafios - aumento da população idosa, maiores expectativas de vida entre os pacientes e recursos econômicos limitados. Novas soluções e inovações devem ser desenvolvidas para lidar com essa realidade em um futuro próximo. Dessa forma, fazer melhorias nos processos e tecnologias existentes, não são suficientes, visto que novas ideias e soluções serão necessárias (LARSSON et al., 2012).

Nesse sentido, diversos pesquisadores (Quadro 8) analisam as redes do setor de saúde sob a perspectiva social. As redes sociais, muitas vezes existem entre os indivíduos que são considerados chaves em uma rede interorganizacional. Essas relações são fundamentais para explicar por que as redes interorganizacionais são formadas, desintegradas, sucedidas ou 
falhas. A confiança é central na maioria das teorias de redes sociais eficazes, e também em redes de suprimentos (GALASKIEWICZ, 2011).

\begin{tabular}{|c|c|c|}
\hline Autor (es) & Objetivo do Estudo & $\begin{array}{l}\text { Unidade de } \\
\text { Análise }\end{array}$ \\
\hline Sternberg, 2000 & $\begin{array}{l}\text { Este artigo descreve o quadro teórico do European Regional Innovation } \\
\text { Survey (ERIS), resume os conceitos teóricos atuais para explicar a relação } \\
\text { entre redes de inovação e desenvolvimento regional. }\end{array}$ & Regiões \\
\hline $\begin{array}{l}\text { Hemstrom and } \\
\text { Selen, } 2006\end{array}$ & $\begin{array}{l}\text { Este artigo defende a utilização de um sistema de planejamento de recursos } \\
\text { casemix baseado em hospitais cirúrgicos que se concentra em maior nível de } \\
\text { planejamento em toda a rede de atores que suportam os processos cirúrgicos. }\end{array}$ & Hospitais \\
\hline Lenz et al., 2007. & $\begin{array}{l}\text { Tentam esclarecer como as diferentes normas contribuem para a integração } \\
\text { de sistemas (Redes de cuidados de saúde) ao distinguir diferentes aspectos e } \\
\text { dimensões da integração. O objetivo dessa abordagem é identificar e } \\
\text { caracterizar o "gap semântico", que não é coberto pelos padrões atuais, e que } \\
\text { é responsável pelo esforço elevado para integração de sistemas. O objetivo } \\
\text { deste esclarecimento é derivar recomendações para futuras arquiteturas de } \\
\text { sistemas e desenvolvimento de padrões. }\end{array}$ & $\begin{array}{l}\text { Sistemas de } \\
\text { informação de } \\
\text { saúde }\end{array}$ \\
\hline $\begin{array}{l}\text { N. Jay, F. Kohler, } \\
\text { and A. Napoli, } 2008\end{array}$ & $\begin{array}{l}\text { Os autores focam na capacidade de redes-iceberg para descobrir e representar } \\
\text { fluxos de pacientes dentro de uma rede de saúde. }\end{array}$ & $\begin{array}{l}\text { Hospital e } \\
\text { paciente }\end{array}$ \\
\hline $\begin{array}{l}\text { Peng and Bourne, } \\
2009\end{array}$ & $\begin{array}{l}\text { O estudo examinou a competição simultânea e a cooperação entre duas redes } \\
\text { na indústria taiwanesa de saúde, além dos níveis intra-organizacionais e inter- } \\
\text { organizacionais. }\end{array}$ & $\begin{array}{l}\text { Profissionais } \\
\text { de saúde, } \\
\text { administrador } \\
\text { es e hospitais }\end{array}$ \\
\hline Diaz, 2009 & $\begin{array}{l}\text { A pesquisa ilustra como a combinação de Análise de Redes e Futuros estudos } \\
\text { torna-se um poderoso instrumento de análise e prevendo futuros e mudança } \\
\text { social. }\end{array}$ & $\begin{array}{l}\text { Países, } \\
\text { pessoas, } \\
\text { empresas }\end{array}$ \\
\hline Stewart, 2009. & $\begin{array}{l}\text { Os autores constaram em seu estudo que sites de redes sociais tem provado } \\
\text { ser importantes para as pessoas que enfrentam doenças graves. Os membros } \\
\text { de um grupo ou rede particular podem compartilhar experiências e sugerir } \\
\text { opções de tratamento e, sobretudo, eles podem compartilhar apoio através de } \\
\text { mensagens públicas ou mensagens privadas. }\end{array}$ & Pacientes \\
\hline $\begin{array}{l}\text { Thrasher et al., } \\
2010 .\end{array}$ & $\begin{array}{l}\text { O estudo analisa duas pesquisas de saúde inter-relacionadas - o valor da } \\
\text { tecnologia da informação (TI) e a complementaridade de TI com processo e a } \\
\text { integração de decisão. }\end{array}$ & $\begin{array}{l}\text { Empresas, } \\
\text { diretores }\end{array}$ \\
\hline Domingos, 2010. & $\begin{array}{l}\text { Descreve a importância do uso de ferramentas on-line abordando a motivação } \\
\text { do usuário para o uso da ferramenta. Saúde } 2.0 \text { utiliza um software social } \\
\text { para promover a colaboração entre os pacientes, cuidadores, profissionais } \\
\text { médicos, e outras partes interessadas de saúde. }\end{array}$ & $\begin{array}{l}\text { Pacientes, } \\
\text { médicos e } \\
\text { profissionais } \\
\text { de saúde }\end{array}$ \\
\hline Meltzer et al., 2010 & $\begin{array}{l}\text { Delinearam como os princípios e métodos de análise de redes sociais pode } \\
\text { proporcionar conhecimentos práticos em questões melhoria de qualidade das } \\
\text { equipes de projetos. Demonstraram, usando como coleta de dados as redes } \\
\text { sociais médicas em um centro médico acadêmico. }\end{array}$ & $\begin{array}{l}\text { Médicos e um } \\
\text { centro médico }\end{array}$ \\
\hline $\begin{array}{l}\text { Cunningham et al., } \\
2011\end{array}$ & $\begin{array}{l}\text { Os autores examinaram a pesquisa empírica sobre a estrutura das redes de } \\
\text { profissionais de saúde, no que diz respeito à eficácia e sustentabilidade das } \\
\text { redes, especialmente em relação à qualidade do atendimento e segurança do } \\
\text { paciente. }\end{array}$ & $\begin{array}{l}\text { Profissionais } \\
\text { de saúde }\end{array}$ \\
\hline
\end{tabular}




\begin{tabular}{|c|c|c|}
\hline Grenier, 2011 & $\begin{array}{l}\text { A pesquisa foi a proposta de um modelo de estruturação de uma assistência } \\
\text { integrada através da diversidade promulgada. A estrutura do estudo envolveu } \\
\text { o foco (propósito da rede), e então, a expansão (integração dos vários atores). }\end{array}$ & $\begin{array}{l}\text { Profissionais } \\
\text { de saúde e } \\
\text { organização } \\
\text { de saúde }\end{array}$ \\
\hline $\begin{array}{l}\text { Dunn e Westbrook, } \\
2011 .\end{array}$ & $\begin{array}{l}\text { Os autores reuniram estudos de casos publicados para demonstrar como a } \\
\text { proposta técnica de validação padrão fornece uma base de comparação de } \\
\text { estudos dentro e entre redes. Os resultados confirmaram que a hierarquia, } \\
\text { centralização e de métricas de clustering são altamente sensíveis a mudanças } \\
\text { no tamanho ou densidade. }\end{array}$ & $\begin{array}{l}\text { Empregados } \\
\text { do hospital; } \\
\text { Membros } \\
\text { clínicos e não } \\
\text { clínicos }\end{array}$ \\
\hline $\begin{array}{l}\text { Chambers et al., } \\
2012\end{array}$ & $\begin{array}{l}\text { Avaliaram a utilização da técnica Social Network Analysis (SNA) como parte } \\
\text { de uma intervenção para apoiar a implementação de mudanças nas } \\
\text { organizações de saúde. Outro objetivo dos autores foi identificar e descrever } \\
\text { estudos que relatam os resultados de SNA realizado em um ambiente de } \\
\text { saúde. }\end{array}$ & $\begin{array}{l}\text { Revisão de } \\
\text { outros estudos }\end{array}$ \\
\hline Wang, 2012 & $\begin{array}{l}\text { Este estudo avalia a viabilidade política da reforma da saúde em Taiwan. } \\
\text { Aplicando análise de redes sociais, o trabalho investigou vários tipos de laços } \\
\text { entre as elites políticas e a distribuição de energia que evoluíram em eventos } \\
\text { políticos cruciais das reformas financeiras. }\end{array}$ & $\begin{array}{l}\text { Atores } \\
\text { Políticos }\end{array}$ \\
\hline $\begin{array}{l}\text { Griffiths, et al., } \\
2012\end{array}$ & $\begin{array}{l}\text { Analisam se as redes sociais compostas por pacientes e seus círculos sociais } \\
\text { podem competir com, ou complementar, redes profissionais para reunir } \\
\text { informações relacionadas a saúde. Os autores argumentam que a estrutura e a } \\
\text { dinâmica de tal rede tem implicações para o futuro da saúde. Os pacientes } \\
\text { estão usando redes sociais para contribuir e acessar informações sobre saúde. }\end{array}$ & $\begin{array}{l}\text { Pacientes, } \\
\text { Médicos }\end{array}$ \\
\hline Larsson et al., 2012 & $\begin{array}{l}\text { Os autores argumentam que inovação em helthcare exige colaboração. Então, } \\
\text { desenvolveram roteiros para criar um entendimento compartilhado dos } \\
\text { desafios que a saúde e a indústria de tecnologia médica na Suécia enfrentam } \\
\text { para criar a inovação e o crescimento. }\end{array}$ & $\begin{array}{l}\text { Profissionais } \\
\text { de saúde, } \\
\text { médicos, } \\
\text { enfermeiras }\end{array}$ \\
\hline $\begin{array}{l}\text { Almansoori et al., } \\
2012\end{array}$ & $\begin{array}{l}\text { Contribuem com a construção de um modelo de previsão para prever futuras } \\
\text { associações entre médicos. }\end{array}$ & Médicos \\
\hline $\begin{array}{l}\text { Barbeira et al., } \\
2012 .\end{array}$ & $\begin{array}{l}\text { O estudo foi propor e avaliar um instrumento para medir a partilha de } \\
\text { conhecimento em redes como facilitadores de Capacidades de Gestão do } \\
\text { Conhecimento. O estudo envolveu profissionais em análises clínicas e saúde } \\
\text { pública. }\end{array}$ & $\begin{array}{l}\text { Profissionais } \\
\text { de saúde }\end{array}$ \\
\hline Sánchez et al., 2013 & $\begin{array}{l}\text { O objetivo da pesquisa foi refletir sobre a possível utilidade da análise do } \\
\text { comportamento social ou rede de profissionais nas organizações de saúde. }\end{array}$ & $\begin{array}{l}\text { Médicos, } \\
\text { enfermeiras e } \\
\text { auxiliares }\end{array}$ \\
\hline Burt et al., 2014 & $\begin{array}{l}\text { Realizaram um estudo piloto destinado a informar a seleção de geradores de } \\
\text { nomes para o uso em estudos de redes sociais de médicos para melhoria da } \\
\text { qualidade de saúde. }\end{array}$ & Médicos \\
\hline Carswell et al., 2014 & $\begin{array}{l}\text { Os autores contribuem com a criação de uma evidencia e uma abordagem } \\
\text { teórica para avaliação de redes de clínicas/médicas. O modelo apresentado } \\
\text { oferece orientação sobre quais etapas seguir na construção de uma rede } \\
\text { clínica/médica, o que é necessário para apoiar o desenvolvimento e como } \\
\text { avaliar cada etapa. }\end{array}$ & Clínicas \\
\hline
\end{tabular}

Quadro 8 - Pesquisas sobre redes do setor de saúde

Desse modo, o termo "redes" é uma palavra usada extensivamente em pesquisas de saúde e na prestação de serviços de saúde. Redes é usado como sinônimo de parceria, colaboração, aliança e grupo, ou, mais especificamente, para descrever as relações entre 
pessoas, grupos ou organizações. O relacionamento com o paciente deve ser multiforme e confiável. Ambas as partes deve ter certo nível de comprometimento no relacionamento. Para trabalhar com cuidados médicos, do ponto de vista do paciente, existe a necessidade para uma intensiva cooperação entre diferentes unidades de saúde (LÄMSÄ e SAVOLAINEN, 2003).

Alexander et al. (2003) definem um sistema de saúde como um conjunto de arranjos vinculados que são legalmente reconhecidos. Por outro lado, uma rede de cuidados de saúde é definida como links que são arranjos voluntários e pouco estruturado que reúne organizações de saúde no local para um propósito comum. Diferentes tipos de conexão podem ter diferentes influências sobre a concorrência e a cooperação entre os atores.

De acordo com a lei francesa, o objetivo das redes de saúde são promover o acesso aos cuidados, a coordenação, a continuidade ou inter-disciplinaridade do atendimento ao paciente, particularmente, cuidados que são específicos para determinados grupos da população, doenças, ou atividades que são específicas a determinados grupos populacionais, doenças ou tipos de assistência ao paciente. Redes de saúde prestam cuidados que se adapta às necessidades do paciente, adaptado ao nível de educação em saúde, prevenção, diagnóstico e tratamento (GRENIER, 2011).

Com relação a estrutura da rede de saúde (PENG e BOURNE, 2009) definem da seguinte forma: 1) conexão entre os atores são os laços de propriedade e relações contratuais; (2) o tamanho da rede envolvem os leitos hospitalares e o número de empregados; (3) com lucro ou sem fins lucrativos; (4) extensão de rede considera a cobertura industrial e a cobertura geográfica e; (5) governança. Os autores constataram em seu estudo que as estruturas de rede influenciam a competição e cooperação entre as redes.

Já Hemstrom e Selen (2006) sugerem em sua pesquisa que o planejamento de alto nível dentro de um ambiente hospitalar deve abordar os seguintes aspectos:

- classificações de pacientes para garantir seus agrupamentos;

- fluxos de processo envolve o preparo do paciente, tratamento do paciente e as fases de tempo que permitem que grupos de pacientes sejam vinculados com os recursos adequados;

- pontos acordados de desacoplamento estruturais para gerir a variabilidade em recursos, capacidade, incerteza na demanda e diagnósticos por tratamento;

- gestão da demanda através da coordenação das previsões de demanda, internações hospitalares e capacidades de recursos;

- sistemas de informação que são capazes de reunir e permitir a coordenação dos recursos e dados do paciente; 
- controle agregado baseado em tempo compartilhado e recursos para minimizar as interrupções para os fluxos de pacientes.

O fluxo de pacientes dependem de várias restrições: geografia, localização de dispositivos de alta tecnologia e equipes médicas especializadas, as afinidades pessoais entre os médicos, regulamentos, tipo de doença, etc. (JAY et al. 2008).

Além da estrutura da rede de saúde, as redes interorganizacionais prestadoras de cuidados de saúde, estão permitindo uma maior exploração das informações de saúde para o planejamento dos cuidados de saúde. Dessa forma, a rede social está oferecendo um novo cenário para os pacientes reunirem informações de saúde. Os autores argumentam que a rede social, tem o potencial para mudar os padrões de desigualdades na saúde como; o acesso aos cuidados de saúde, alterar a estabilidade da prestação de cuidados de saúde, e, levar a uma reformulação do papel dos profisssionais de saúde. No entanto, mais pesquisas são necessárias para entender como a estrutura da rede combinada com sua dinâmica vai afetar o fluxo de informações e, potencialmente, a alocação de recursos de saúde (GRIFFITHS, et al., 2012).

De acordo com Domingos (2010), em 2004, começou o movimento Saúde 2.0. Esse movimento utiliza um software social para promover a colaboração entre os pacientes, cuidadores, profissionais médicos, e outras partes interessadas de saúde. Redes sociais de saúde fornece uma plataforma ativa para compartilhar ideias, discussões, e debates, opções de tratamento e tarefas que, juntos, prometem melhorar a assistência ao paciente. Essas redes podem ser médica ou orientada ao paciente. Redes sociais médicas fornecem uma infraestrutura técnica on-line para que os médicos compartilhem casos clínicos, imagens, vídeos e conhecimento médico. Redes sociais do paciente enfatiza o apoio direto ao paciente, promovendo a consciência da doença e os comportamentos positivos e proativo para se manter saudável, enquanto vive com uma doença. Ambos os tipos de redes podem melhorar a gestão de saúde.

Para Burt et al. (2014), o aumento do interesse na análise de redes sociais no setor de saúde reflete no reconhecimento de que os processos de saúde e os resultados são influenciados pela teia de conexões sociais dentro das quais os pacientes e os prestadores estão inseridos. Uma maneira simples de descrever a natureza de uma rede social, usando análise de redes, é comparar os valores das métricas de rede com os resultados de outras configurações possíveis (DUNN e WESTBROOK, 2011).

Sob o ponto de vista de alianças estratégicas, (THRASHER et al., 2010) argumentam que as alianças estratégicas em saúde pode proporcionar benefícios significativos, mas a 
formação da rede de aliança é um ponto de integração e de realização de benefícios de partida. Alianças estratégicas em redes de saúde são frequentemente adotadas como formas para melhorar o desempenho e criar vantagem competitiva. Os autores apresentaram uma visão mais holística da integração dentro da rede de alianças de cuidados de saúde.

Por outro lado, inovação em cuidados de saúde (LARSSON et al., 2012), requer a compreensão dos processos de saúde, identificando gargalos e, encontrar soluções mais eficientes em termos de custos. No entanto, o fator de sucesso frequentemente esquecido na inovação de cuidados de saúde, é uma compreensão da experiência do paciente. Portanto, cuidados de saúde são baseados em experiências e não apenas em processos.

Portanto, a atenção integrada é apresentada como uma resposta apropriada para a fragmentação do setor da saúde; o que leva ao uso ineficiente de recursos, a redundância ou a ausência de consultas de cuidados, interrupções no atendimento ao paciente e conhecimento disperso. O desafio está em como integrar uma variedade de atores e organizações, a fim de coordenar, cuidar do paciente para além das muitas barreiras que caracterizam esse setor (institucional, profissional, conhecimento, reguladora, competência para intervir etc.) (GRENIER, 2011). Dessa forma, novos conhecimentos criam melhores cuidados de saúde: artigos científicos estabelecem as bases para a implantação de novos conhecimentos na prática de saúde (LARSSON et al., 2012).

Nesse sentido, a próxima seção apresenta de modo introdutório, os princípios, o papel e o funcionamento do SUS no Brasil.

\subsection{Sistema Único de Saúde (SUS)}

O Brasil institucionalizou o direito à saúde a todos os cidadãos brasileiros com a divulgação da Constituição Federal de 1988. Essa Constituição criou o Sistema Único de Saúde (SUS) que foi regulamentado pelas Leis n. 8.080/90 (BRASIL, 1990) e n. 8.142/90 (BRASIL, 1990). Dessa forma, ofereceu aos brasileiros um sistema integrado e gratuito que cuida da prevenção, promoção, cura e reabilitação do povo brasileiro, fortaleceu a cidadania quando afirmou ser saúde direito de todos e dever do Estado (BRASIL, 2007).

Antes de 1988, o sistema público de saúde atendia somente àqueles que contribuíam com a Previdência Social, ou seja, os serviços hospitalares estavam restritos a 30 milhões de pessoas. As pessoas que não tinham recursos eram financiadas por filantropia. O sistema 
também era centralizado e de responsabilidade federal, sem a participação dos usuários (BRASIL, 2007).

A criação do SUS buscou melhorar o cenário de desigualdade na assistência à saúde da população, tornando obrigatório o atendimento público a qualquer cidadão, ofertando serviços na atenção primária, secundária e terciária (VIEGAS e PENNA, 2013). Assim, todos os cidadãos brasileiros passaram a ter direito a consultas, exames, internações e tratamentos nas unidades de saúde vinculadas ao SUS, sejam essas unidades públicas ou privadas, contratadas pelo gestor público de saúde (LONGARAY e ENSSLIN, 2014).

Atualmente, o sistema de saúde no Brasil é descentralizado, municipalizado e participativo com 77 mil conselheiros de saúde (PORTAL SAÚDE, 2014). Para que esse arranjo seja efetivo deve-se consolidar a capacidade de cada organização para executar novas funções e interagir com funções executadas pelas demais esferas de governo, mantendo um equilíbrio entre autonomia e interdependência (SPEDO et al., 2009).

Cerca de 140 milhões de pessoas têm no Sistema Único de Saúde (SUS) o seu único acesso aos serviços de saúde (PORTAL SAÚDE, 2014). As responsabilidades de financiamento do SUS são das três esferas de gestão - União, estados e municípios (BRASIL, 2007). A União é o principal financiador da saúde pública no país. Historicamente, metade dos gastos é feita pelo governo federal, a outra metade fica por conta dos estados e municípios. A União formula políticas nacionais, mas a implementação é feita por seus parceiros (estados, municípios, ONGs e iniciativa privada). Quanto à gestão, o município é o principal responsável pela saúde pública de sua população. A partir do Pacto pela Saúde, assinado em 2006, o gestor municipal passa a assumir imediata ou aos poucos a plenitude da gestão das ações e serviços de saúde oferecidos em seu território (BRASIL, 2006).

Em contraste, Bittar e Magalhães (2010) argumenta que nenhum hospital sobrevive somente com os repasses SUS. Receitas advindas de município, estado, união Receitas do tesouro federal, estadual ou municipal (acrescida de recursos do FUNDES, repasses das universidades e emendas parlamentares), representam juntas a maior fonte de recursos dos Hospitais de Ensino (HE), 47,27\%. A média encontrada refere-se à participação de cada item no valor total da receita dos $34 \mathrm{HE}$ que informaram os dados. A participação do SUS neste grupo de hospitais é de 37,4\%, enquanto a do município, do estado e da união é de $46 \%$ em 2009. As receitas provenientes dos planos de saúde representaram 12\% (BITTAR e MAGALHÃES, 2010).

De acordo com o último censo demográfico, o Brasil apresenta uma população de 202.768.562 pessoas, sendo que 44,03 milhões encontram-se no Estado de São Paulo (censo, 
2014, IBGE). Segundo Bittar et al. (2011), além de ser a mais populosa, São Paulo é a unidade da federação com maior desenvolvimento sócio-econômico, responsável por $34 \%$ do PIB, com ampla rede de serviços de saúde, públicos e privados. Dos 5.565 municípios brasileiros, 645 estão no Estado de São Paulo, que foi dividido em 64 regiões de saúde e 17 macro-regiões de saúde denominadas de Departamentos Regionais de Saúde - DRS (BITTAR et al., 2011; FERREIRA, 2009).

No Brasil, os serviços de atendimento hospitalar público contam com 5.900 hospitais credenciados (públicos, privados e filantrópicos) e 64 mil unidades de atenção primária. Os planos de saúde e atendimento privado atendem 38 milhões de pessoas, mas é o SUS que realiza 75\% dos procedimentos de alta complexidade no País (BRASIL, 2006).

Contudo, o SUS é apresentado como a política de maior inclusão social implementada no Brasil. Seus avanços são significativos, mas persistem problemas a serem enfrentados para consolidá-lo como um sistema público universal e lícito. O SUS é composto pelo conjunto das ações e de serviços de saúde sob gestão pública. Está organizado em redes regionalizadas e hierarquizadas e atua em todo o território nacional, com direção única em cada esfera de governo (BRASIL, 2007). Essas redes estão organizadas de acordo com as diretrizes da descentralização, atendimento integral e participação da comunidade (VIEGAS e PENNA, 2013).

Dentro desse contexto, a Rede de Atenção à Saúde pode ser entendida como uma teia que interconecta e integra estabelecimentos e serviços de saúde, estruturados de forma a considerar os diferentes níveis e densidades tecnológicas em um determinado território, visando ao atendimento integral aos usuários do SUS (SILVA JUNIOR, 2013). As redes são arranjos organizacionais que possibilitam a continuidade do cuidado de saúde e o êxito do princípio da integridade (SHIMIZU, 2013).

O conceito de rede no SUS aumentou sua relevância, em consequência da criação de novos vínculos e relações inter-governamentais na gestão da política de saúde. A ligação das redes SUS foi fundamental para a melhoria do seu desempenho, com estratégias de regionalização e planejamento integrado. O processo de regionalização permitiu a construção de exemplos de interdependência entre os três níveis de governo, garantindo o acesso universal e equitativo à saúde. A territorialização aumenta a interdependência construída com a regionalização e delimita a interação entre atores, organização e recursos, fixando linhas e vínculos de estruturação no nível local (JUNQUEIRA e DAPUZZO, 2010).

Para assegurar a assistência à saúde para todos os cidadãos brasileiros, Viegas e Penna (2013) argumentam a necessidade do estabelecimento de um sistema de referências, 
configurado na regionalização e na hierarquização. Os serviços devem ser organizados em níveis de complexidade, organizados numa área geográfica delimitada ou a definição da população a ser atendida. Dessa forma, segundo Falavigna et al. (2013) o SUS baseia-se nos princípios da universalidade, integralidade, equidade, participação da comunidade, descentralização política e administrativa, hierarquização e regionalização. O Quadro 9 ilustra os princípios que sustentam o seu propósito de promoção da saúde e prevenção de doenças.

\begin{tabular}{|l|}
\hline \multicolumn{1}{|c|}{ Princípios do Sistema Único de Saúde } \\
\hline Universalidade \\
\hline Integralidade \\
\hline Equidade \\
\hline Participação da Comunidade \\
\hline Descentralização Política e Administrativa \\
\hline Hierarquização e Regionalização \\
\hline
\end{tabular}

Quadro 9 - Princípio do SUS

Fonte: Falavigna et al. 2013

Para uma melhor compreensão do SUS, é fundamental conhecer os seus princípios básicos, sendo eles: (1) universalidade garante que todos os cidadãos brasileiros têm o direito à saúde; (2) integralidade a ênfase em cada ser humano único, com suas características biopsicossociais; (3) equidade é o direito de participar igualmente na rede de cuidados; (4) participação na comunidade estabelece que a população tem o direito e o dever de refletir sobre a situação de saúde local, e , em seguida, analisar os pedidos de mudanças nos diferentes níveis de atenção; (5) descentralização política e administrativa é fazer melhor o uso dos recursos desde o norte ao sul do Brasil (com direção única em cada esfera do governo), respeitando as especificidades culturais de cada região e (6) hierarquização e regionalização os cuidados de saúde no SUS está organizado hierarquicamente em três níveis de complexidade (primário, secundário e terciário), que organizam as necessidades de saúde de acordo com o nível de complexidade.

De acordo com Falavigna et al. (2013) o nível primário está relacionado com os cuidados de saúde primários e, dentro da dinâmica do SUS, é classificado como um conjunto de ações básicas, em geral, ginecológica, e visitas pediátrica médica, além de consultas com dentistas, atividades de prevenção, vacinação, acesso e contato com os serviços sociais e assistência psicológica. Assim, considera-se a "porta de entrada" para os outros dois níveis de 
cuidados, no qual será utilizado apenas quando necessário. Portanto, o primeiro acesso ao sistema de saúde deve ser preferencialmente a atenção básica (postos de saúde, centros de saúde, unidades de Saúde da Família etc.). A partir desse primeiro atendimento, o cidadão será encaminhado para os outros serviços de maior complexidade da saúde pública (hospitais e clínicas especializadas) (BRASIL, 2006).

$\mathrm{Na}$ medida que o nível de complexidade aumenta, portanto, os níveis secundários (média complexidade) e terciários (alta complexidade) são usados. No nível secundário, tratase da atenção médica especializada (consulta) (cardiologia, pneumologia, endocrinologia, dermatologia , urologia, cirurgia). Já o nível terciário é responsável por cuidados hospitalares, quando a tecnologia (equipamentos, procedimentos) torna-se necessária (isto é, em patologias descompensadas e trauma) (FALAVIGNA et al., (2013).

Diante deste contexto, os Hospitais de Ensino (HE) possuem um papel fundamental para o desenvolvimento do SUS em diversas áreas, como a de referência assistencial de alta complexidade, polos formadores de recursos humanos, desenvolvimento de pesquisas, técnicas e procedimentos para a Saúde Pública e incorporação de novas tecnologias que colaborem para a melhoria das condições de saúde da população brasileira (BARATA et al., 2010). Em todo Brasil são cerca de 183 HE e no Estado de São Paulo são 47 (DATASUS, 2013).

Segundo Barata et al. (2010) a contribuição dos Hospitais de Ensino (HEs) é um dos fatores essenciais para melhorar a saúde de todos os brasileiros. O desenvolvimento da assistência realizada pelos HEs, bem como de suas atividades didáticas e de pesquisa, algumas vezes estruturou-se de forma isolada dos demais serviços assistenciais, motivo pelo qual se faz necessário discutir e aperfeiçoar sua integração com a rede SUS.

Por outro lado, a realização de procedimentos de baixa complexidade nos HEs, apresenta vários inconvenientes, entre os quais: utiliza-se um serviço de alta capacidade instalada, com pessoal especializado e, portanto, com atendimentos em média mais custosos para procedimentos simples que seriam melhor realizados em unidades básicas de saúde (BARATA et al., 2010).

Bittar e Magalhães, identificou em seu estudo (HE no Estado de São Paulo: seis anos de acompanhamento) que existe uma baixa produtividade em alguns HE. O impacto disso, está na demora por atendimento de saúde dos usuários do SUS, motivo de preocupação dos gestores. Dessa forma, os autores destacam que as soluções estão: na melhoria da efetividade da Rede de Atenção Básica (AB); nos processos de regulação; no acompanhamento das redes de AC; na formação dos profissionais; na comunicação entre gestores, dirigentes de HE, 
profissionais de saúde, clientes e pacientes, assim como nos melhores critérios de agendamento de consultas.

Não obstante disso, as chamadas "filas de espera" no agendamento de consultas com especialistas devem ser tratadas com um critério rigoroso, pois são complexas e de solução custosa, sendo: falta de leitos de terapia intensiva, falta de especialistas, tetos financeiros que não permitem atendimento à demanda, problemas relativos à vigilância sanitária, dificuldades de acesso, entre outras para que sejam eliminadas (BITTAR e MAGALHÃES, 2010).

Esse tempo de espera pelos usuários que buscam por atendimento, Viegas e Penna (2013) destacam que são problemas ligados ao acesso e à referência a algumas especialidades e serviços. Dessa forma, esses problemas comprometem e afetam o princípio da integralidade, uma vez que, o usuário entra no Sistema, e, muitas vezes, o acesso é intrincado pelo longo tempo de espera por consulta com especialistas e exames diagnósticos, dificultando o sistema de referência e contra-referência. Portanto, a reorganização da atenção primária com vistas à universalidade do acesso a ações e serviços, à integralidade nas ações, implica também em que as demandas sejam respondidas na atenção secundária, quando se fizer necessário.

Com a crescente demanda por recursos de saúde no Brasil, torna-se necessário o estabelecimento de políticas voltadas ao controle dos gastos. O custo médio das internações é cem vezes maior que o custo médio dos atendimentos ambulatoriais (CESCONETTO et al., 2008). Dessa forma, a reorganização da atenção primária é importante para o principio da universalidade, para tanto, implica que as demandas sejam respondidas nos demais níveis de complexidade. A referência deve ser correspondida com a contra- referência para que o usuário não se perca pelo caminho e sim faça um trajeto na rede do SUS com respostas integrais e moderadas (VIEGAS e PENNA, 2013). Particularmente, as organizações do SUS não estão isoladas. Elas fazem parte de um complexo sistema de relações e atores que influenciam as decisões em relação à dinâmica com que devem ocorrer as operações da rede. Nesse sentido, alguns pesquisadores (Quadro 10) analisaram o SUS sob diversas perspectivas, desde o seu funcionamento (FALAVIGNA et al., 2013) até estudos voltados para o mapeamento das redes de deslocamento de pessoas (OLIVEIRA, et al., 2004) e análise sobre a multiplicidade de vínculos dos profissionais médicos do SUS no Estado do Ceará (MACIEL et al., 2010). No entanto, os dois últimos trabalhos são os que mais se aproximam desta tese, porém, Maciel et al. (2010) fez um estudo documental e identificou a quantidade de vínculos dos profissionais, mas não fez o uso de teoria e de softwares de análise de redes e Oliveira et al. (2004) fez o mapeamento das redes de deslocamento de pessoas e não de unidades de 
saúde e, esse autor, também não embasou o estudo em teoria de redes. Mesmo com a amplitude de pesquisas voltadas para o SUS, pode-se dizer que nenhuma delas (Quadro 10) fez uma análise da rede de médicos por meio dos vínculos profissionais em unidades de saúde públicas e privadas.

\begin{tabular}{|c|c|}
\hline Autor (es) & Objetivo do estudo \\
\hline Teixeira, 2002 & $\begin{array}{l}\text { o trabalho discute os limites e possibilidades de implementação de práticas de } \\
\text { promoção e vigilância da saúde, levando em conta a proposta de regionalização } \\
\text { contida na Norma Operacional da Assistência à Saúde (NOAS), adotada pelo } \\
\text { Ministério de Saúde em } 2001\end{array}$ \\
\hline Oliveira et al., 2004 & $\begin{array}{l}\text { o trabalho investiga dois tipos de redes estabelecidas pelos fluxos de pacientes para } \\
\text { os serviços de saúde: a de atenção hospitalar básica, definida pelos pro c e d i- } \\
\text { mentos com maior frequência de internação e as de atenção de alta complexidade } \\
\text { Agregaram-se os dados do Sistema de Informações Hospitalares do SUS sobre as } \\
\text { internações realizadas no ano de } 2000 \text { em todo o Brasil - segundo o município de } \\
\text { internação e o de residência dos pacientes. }\end{array}$ \\
\hline $\begin{array}{l}\text { Andrade e Barreto, } \\
2004\end{array}$ & $\begin{array}{l}\text { Os autores criaram o conceito PS Promoção saúde. O artigo vem em um momento } \\
\text { quando um alinhamento conceitual é necessário entre os atores institucionais no SUS } \\
\text { em relação à estratégia de Promoção da Saúde }\end{array}$ \\
\hline Campos, 2006. & $\begin{array}{l}\text { o artigo faz uma análise do conceito de equidade, bem como sobre as implicações } \\
\text { práticas de suas várias acepções e com casos do SUS }\end{array}$ \\
\hline $\begin{array}{l}\text { Cornwall e } \\
\text { Shankland, } 2008\end{array}$ & $\begin{array}{l}\text { o artigo foca nos mecanismos institucionais inovadores para a participação popular e } \\
\text { prestação de contas que fazem parte da arquitetura de governança do SUS }\end{array}$ \\
\hline $\begin{array}{l}\text { Cesconetto et al., } \\
2008 \text {. }\end{array}$ & $\begin{array}{l}\text { o objetivo do estudo foi identificar quais os hospitais da rede hospitalar de Santa } \\
\text { Catarina que são eficientes quanto ao aproveitamento de seus recursos e quanto é } \\
\text { possível aumentar a produção dos hospitais ineficientes }\end{array}$ \\
\hline Ferreira, 2009 & $\begin{array}{l}\text { o estudo avaliou, segundo a ótica regional, as condições do acesso aos serviços de } \\
\text { saúde da população residente no Estado de São Paulo - considerando-se os setores } \\
\text { público e privado - e a eficiência na utilização dos recursos para a produção } \\
\text { ambulatorial e hospitalar do SUS. }\end{array}$ \\
\hline Pinto et al., 2009 & $\begin{array}{l}\text { a pesquisa discute desafios para a (re)construção do SUS no município relacionados } \\
\text { com o contexto político-institucional e com mudanças de estrutura implementadas. }\end{array}$ \\
\hline Spedo et al., 2009 & $\begin{array}{l}\text { o trabalho analisou o processo de descentralização do SUS, em seu âmbito intra- } \\
\text { municipal, no Município de São Paulo. }\end{array}$ \\
\hline Pinto et al., 2010 & $\begin{array}{l}\text { o objetivo do artigo foi avaliar movimentos e ações realizados pelos atores } \\
\text { institucionais, a SMS-SP e a SES-SP, com referência na "imagem objetivo" da } \\
\text { integralidade, no sentido da construção de uma direção única do SUS no município } \\
\text { de São Paulo. }\end{array}$ \\
\hline $\begin{array}{l}\text { Bittar e Magalhães, } \\
2010\end{array}$ & $\begin{array}{l}\text { a pesquisa é resultado de seis anos de acompanhamento dos HE do Estado de SP. O } \\
\text { acompanhamento dos hospitais foi realizado por meio de relacionamento direto com } \\
\text { as unidades, com a utilização de dados do DATASUS e com a criação do Sistema de } \\
\text { Avaliação dos Hospitais de Ensino (SAHE), que compreende as informações para } \\
\text { uma análise integral da produção, produtividade, qualidade e aspectos financeiros de }\end{array}$ \\
\hline
\end{tabular}




\begin{tabular}{|c|c|}
\hline Maciel et al., 2010 & $\begin{array}{l}\text { suas atividades. } \\
\text { O objetivo do trabalho é analisar a multiplicidade de vínculos dos profissionais } \\
\text { médicos do Sistema Único de Saúde no Estado do Ceará. }\end{array}$ \\
\hline Barata et al., 2010 & $\begin{array}{l}\text { o trabalho apresenta-se algumas questões prioritárias que envolvem os HE na } \\
\text { atualidade: a sua integração com os outros serviços da rede SUS, a adequação das } \\
\text { práticas de ensino às necessidades do sistema, o desenvolvimento, avaliação e } \\
\text { incorporação de tecnologias e propostas de modificações organizacionais que } \\
\text { facilitem o desempenho de seu papel no sistema de saúde. }\end{array}$ \\
\hline Victora, et al., 2011 & $\begin{array}{l}\text { o estudo aborda algumas das principais conquistas e desafios restantes para a saúde } \\
\text { do povo brasileiro. }\end{array}$ \\
\hline Bittar et al., 2011 & $\begin{array}{l}\text { os autores fizeram um mapeamento das regionais do Estado de SP que envolveu } \\
\text { quantidade de hospitais público e privados, quantidade de leitos disponíveis e a taxa } \\
\text { de ocupação. A primeira parte é a apresentação e discussão de informações } \\
\text { pertinentes da rede hospitalar no Estado de São Paulo. A segunda parte é uma } \\
\text { apresentação de dados do SAHE (produção, indicadores de qualidade e de } \\
\text { produtividade). }\end{array}$ \\
\hline $\begin{array}{l}\text { Lemos e Chaves, } \\
2011\end{array}$ & $\begin{array}{l}\text { o objetivo do estudo foi caracterizar a dinâmica da produção física e financeira de } \\
\text { internações hospitalares, em } 25 \text { municípios da região de Ribeirão Preto, São Paulo, } \\
\text { Departamento Regional de Saúde XIII (DRS-XIII) }\end{array}$ \\
\hline Puccini et al, 2012 & $\begin{array}{l}\text { O trabalho analisa a concepção de profissionais de saúde quanto ao papel das } \\
\text { unidades básicas de saúde (UBS) na assistência a essa demanda. }\end{array}$ \\
\hline Mitre et al., 2012 & $\begin{array}{l}\text { a pesquisa faz uma análise crítica da produção bibliográfica, no Brasil, no período de } \\
1989 \text { a } 2009 \text {, sobre o acolhimento na operacionalização e qualificação do SUS na } \\
\text { APS. }\end{array}$ \\
\hline $\begin{array}{l}\text { Falavigna et al., } \\
2013\end{array}$ & $\begin{array}{l}\text { Os autores descrevem o sistema único de saúde e afirmam a necessidade de um } \\
\text { projeto computadorizado de sistema para dar apoio a melhoria da qualidade e } \\
\text { controle pelo SUS }\end{array}$ \\
\hline Granja et al., 2013 & $\begin{array}{l}\text { o objetivo deste estudo foi identificar os sentidos conferidos à equidade no discurso } \\
\text { dos gestores do SUS. }\end{array}$ \\
\hline Shimizu, 2013 & $\begin{array}{l}\text { o estudo teve como objetivo analisar as percepções de gestores sobre os desafios da } \\
\text { formação de Redes de Atenção à Saúde no Brasil. }\end{array}$ \\
\hline $\begin{array}{l}\text { Viegas e Penna, } \\
2013\end{array}$ & $\begin{array}{l}\text { o objetivo da pesquisa foi compreender a construção das práticas de integralidade em } \\
\text { saúde no trabalho cotidiano das equipes Saúde da Família e de gestores de } \\
\text { municípios do Vale do Jequitinhonha, Minas Gerais, Brasil. }\end{array}$ \\
\hline Morais e Costa, 2014 & $\begin{array}{l}\text { o artigo propõe um modelo para avaliação de sistemas de informação em saúde que } \\
\text { possa ser aplicado aos sistemas SUS. }\end{array}$ \\
\hline $\begin{array}{l}\text { Longaray e Ensslin, } \\
2014\end{array}$ & $\begin{array}{l}\text { o estudo utiliza a metodologia multicritério de apoio à decisão (MCDA) no } \\
\text { desenvolvimento de um modelo personalizado de avaliação de desempenho para } \\
\text { auxiliar os gestores de um hospital universitário da rede federal de educação } \\
\text { brasileira na identificação, operacionalização e mensuração de critérios que } \\
\text { contemplem as metas pactuadas com o MS/SUS para a obtenção ou renovação da } \\
\text { certificação junto a esse Ministério. }\end{array}$ \\
\hline
\end{tabular}

Quadro 10 - Pesquisas referentes ao SUS 
Diante do exposto, a presente tese contribui no principio que trata da universalidade, equidade e também da hierarquização e regionalização do SUS (Quadro 10), ou seja, nos níveis de complexidade, entendidos como atenção básica, média e alta complexidade. 


\section{MÉTODOS E PROCEDIMENTOS DE PESQUISA}

Este capítulo tem como objetivo apresentar a origem e planejamento da pesquisa; o estudo piloto; a definição do método de pesquisa; a unidade de análise; fontes e instrumentos para a coleta de dados.

\subsection{Origem da pesquisa}

Esta pesquisa foi motivada pela importância do SUS nos cuidados de saúde de todos os cidadãos brasileiros. Uma vez que, os seus princípios, visam garantir o acesso e o direito de participar igualmente na rede de cuidados de saúde gratuitamente, independente da renda do indivíduo, nível de escolaridade, ou emprego (BRASIL, 2007).

A pesquisa foi planejada em duas etapas, uma prática e a outra teórica. A primeira foi a observação direta no campo, por meio de uma visita em um Hospital de Ensino (HE) vinculado ao SUS, com dois pesquisadores integrantes do grupo de pesquisa LOGOSS-USP. A segunda etapa da pesquisa foi o estudo do referencial teórico capaz de suportar tal análise, assim como a experiência acadêmica da pesquisadora com o tema de "Teoria de Redes", objeto de estudo no mestrado.

Diante disso, verificou-se que o SUS está configurado em três diferentes níveis de atendimento (separados por níveis de complexidade - AB, MC e AC). Com base na estratégia de buscas na literatura adotada nesta pesquisa (inserida na Seção 3.2), poucos estudos (CUNNINGHAM et al., 2011; CHAMBERS et al., 2012) foram encontrados sobre a aplicação da teoria de redes no contexto de organizações de saúde e não foi encontrado nenhum estudo que tenha feito o mapeamento de uma rede de saúde por meio dos vínculos profissionais dos médicos. Portanto, analisar e mapear uma rede de médicos com vínculos profissionais em unidades de saúde públicas e privadas tornou-se uma contribuição importante na literatura sobre o tema. Isso é particularmente relevante para o setor de saúde porque um dos principais recursos de uma rede de saúde são os médicos. 


\subsection{Planejamento da Pesquisa}

Para atingir o objetivo proposto na presente tese, foi realizada uma revisão da literatura sobre redes como forma de análise, análise de redes no contexto de saúde, SUS e Hub and Spoke.

A revisão da literatura foi constituída em três etapas:

A primeira etapa foi a seleção dos artigos sobre teoria de redes, levantados durante a pesquisa de mestrado da autora (2008-2010), o período de busca não foi limitado, as bases de dados eletrônicas utilizadas foram: Web of Science, Scopus e o banco de dados de teses da UNESP e as palavras chaves utilizadas para fazer a busca foram: "social network"; "structural embeddedness" and "relational embeddedness";

A segunda etapa foi a condução de uma revisão da literatura sobre teoria de redes e, análise de redes no setor de saúde e SUS. Utilizou-se duas bases de dados: Web of Science, Science Direct e banco de dados de teses da USP. O filtro foi por ano de publicação dos artigos, delimitado de 2000 à 2014. As palavras-chaves utilizadas para fazer a busca foram: "healthcare and network", "hospital logistics", "social network and healthcare network", "social network and hospital network", "sus and hospital", "unified health system and Brazil". A finalidade foi fazer um levantamento detalhado com diferentes combinações de palavras chaves e identificar pesquisas relacionadas ao assunto. Contudo, a busca por artigos foi interrompida quando se notou a recorrência das referências encontradas.

A terceira etapa foi a seleção de artigos sobre hub and spoke; hub and spoke connection; hub and spoke healthcare e professional linkages; professional linkages healthcare. O filtro foi por ano de publicação dos artigos, delimitado de 2000 à 2016 e a base de dados utilizada foi a Web of Science.

Por questões práticas, a fim de entender melhor a configuração do SUS e os tipos de informações disponíveis para a análise da rede médicos com vínculos profissionais em unidades de saúde públicas e privadas - a partir de um DRS, achou-se conveniente realizar um estudo piloto no DRS de Bauru (Roteiro de Apêndice A) para verificar a viabilidade da pesquisa. 


\subsection{Estudo Piloto no DRS Bauru}

A administração regional de São Paulo foi reestruturada com a transformação das DIRs (Direção Regional de Saúde) em Departamentos Regionais de Saúde - DRS (MELLO, et al., 2011). Contudo, o Estado de São Paulo foi dividido em 17 DRS (Figura 15), que são responsáveis por coordenar as atividades da Secretaria de Estado da Saúde no âmbito regional e promover a articulação intersetorial, com os municípios e organismos da sociedade civil (BRASIL, 2006).

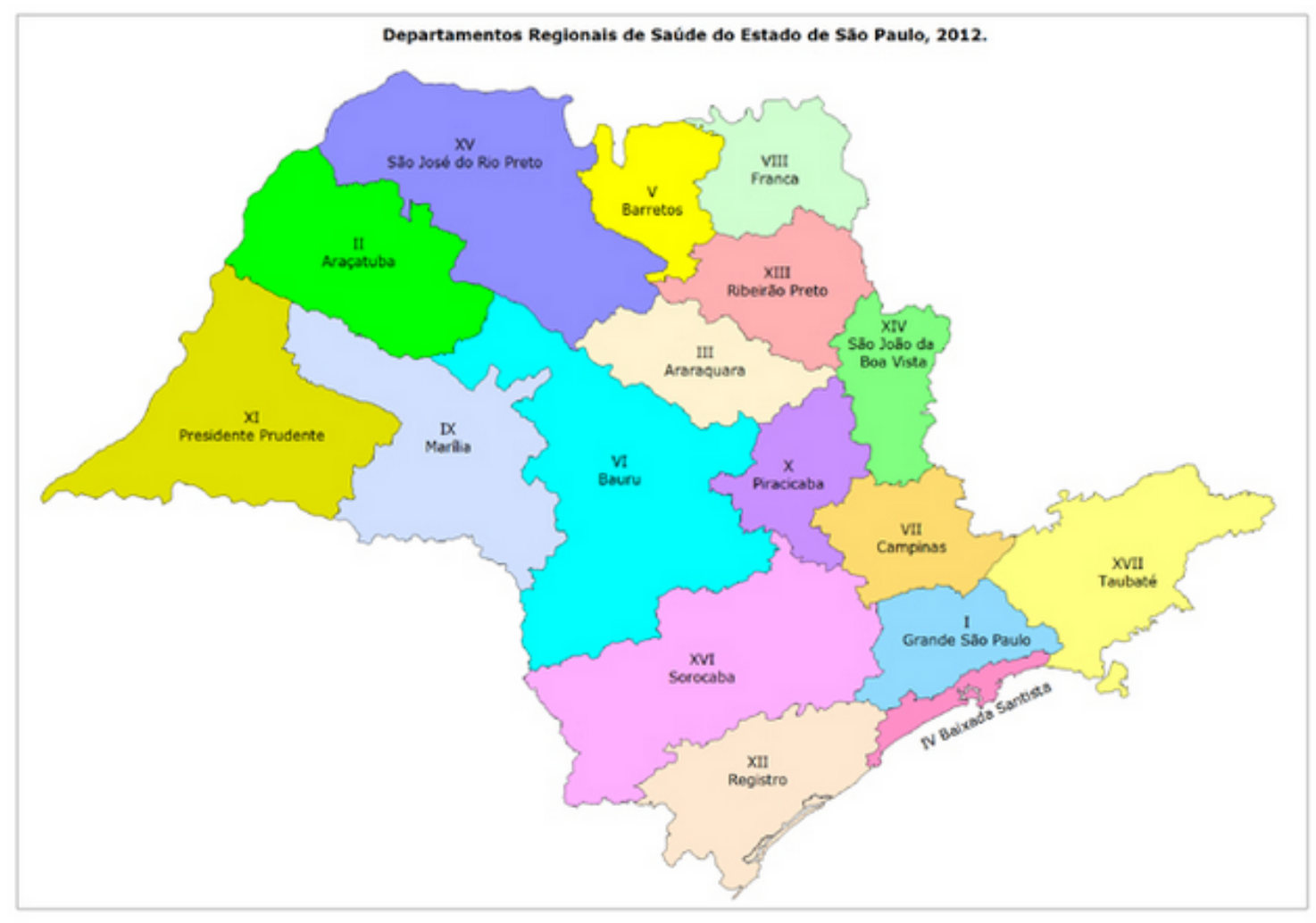

Figura 15 - Mapa com a divisão do Estado de São Paulo nos DRS Fonte: Secretaria da Saúde do Estado de São Paulo

Para Mello et al., (2011) os DRS são considerados como uma nova tentativa de arranjos institucionais apropriados à ação regional da Secretaria do Estado da Saúde de São Paulo (SES-SP): planejamento regional; coordenação e articulação dos sistemas municipais; além do apoio aos municípios na organização de sua rede básica.

De acordo com o Decreto DOE $n^{\circ} 51.433$, de 28 de dezembro de 2006, Artigo $11^{\circ}$ Os DRS têm uma série de atribuições, entre essas serão destacadas apenas as cinco consideradas mais relevantes para o estudo: 
- participar do planejamento do sistema de saúde dos municípios, incluindo os investimentos em saúde;

- tornar disponíveis as análises e os dados sobre qualidade de vida, capacidade instalada, produção de serviços e outras informações gerenciais que contribuam para a atuação intergovernamental, inter-setorial e para o exercício do controle social;

- avaliar as ações de saúde realizadas no município, incluindo a prestação de serviços;

- gerenciar as demandas do município, de acordo com as prioridades definidas a partir das análises do perfil epidemiológico;

- controlar a aplicação dos recursos estaduais e federais do SUS.

Nesta pesquisa, o estudo piloto foi realizado no DRS de Bauru. O DRS de Bauru, está divido em cinco regiões de saúde: (1) Região de Saúde de Bauru - 18 municípios; (2) Região de Saúde de Jaú - 12 municípios; (3) Região de Saúde do Vale do Jurumirim - 17 municípios; (4) Região de Saúde do Polo Cuesta - 13 municípios e (5) Região de Saúde de Lins -8 municípios.

A Figura 16 demonstra o mapeamento da rede do DRS de Bauru. Essa figura foi feita com o auxilio do software NetMiner3, conforme relatório fornecido pelo respondente. Desse modo, a pesquisa foi delimitada no município de Bauru, conforme demonstra o circulo maior (Figura 16). 


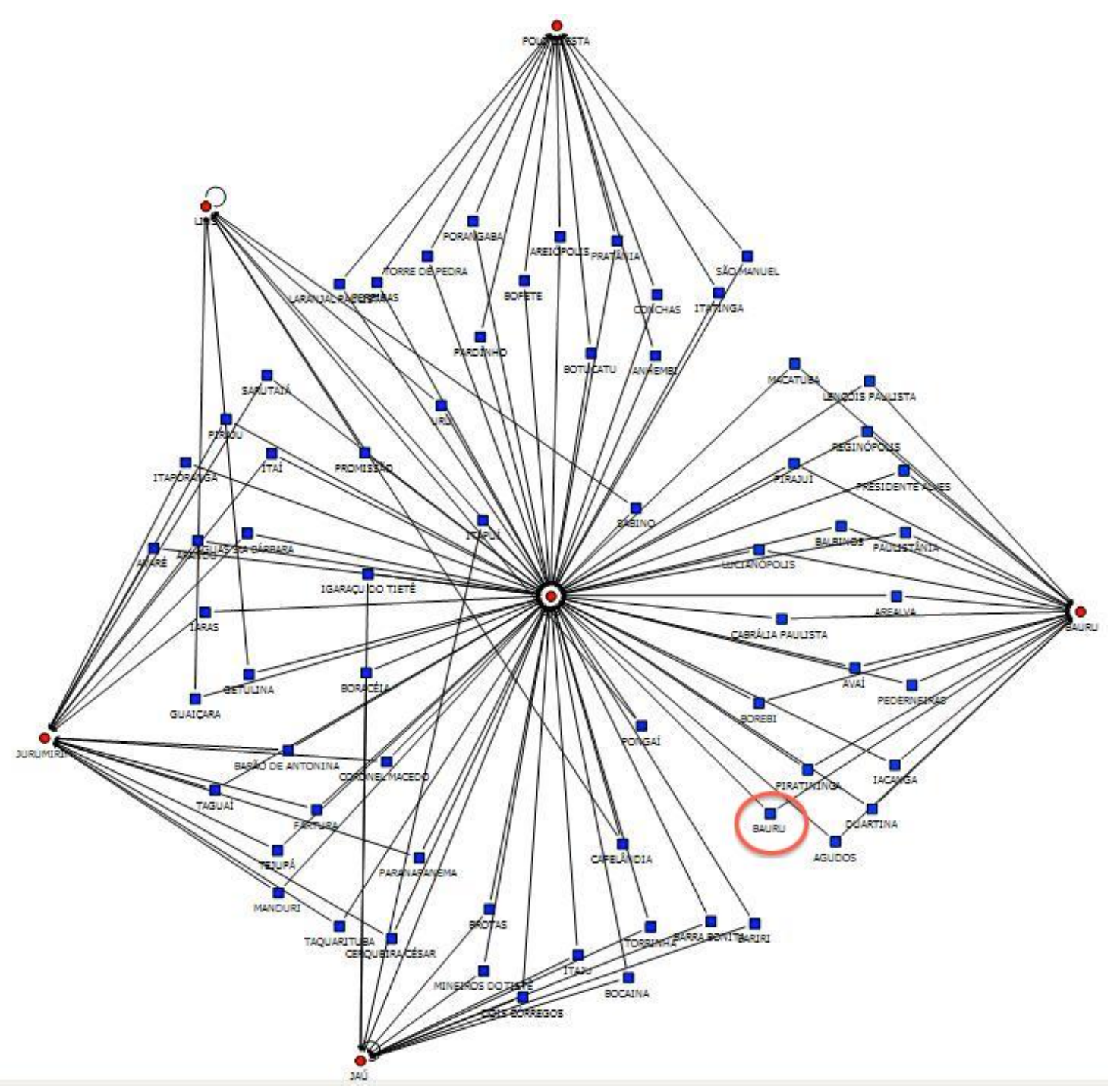

Figura 16 - Ilustração da rede do DRS de Bauru

A gestão do SUS é descentralizada onde cada município faz a sua gestão, conforme a sua estrutura de atendimento (BRASIL, 2006).

Embora a gestão dos municípios seja descentralizada, nem todos os municípios possuem todos os níveis de atendimento. Então, o acesso aos demais níveis de complexidade é feito pelo sistema de informação chamado Central de Regulação de Ofertas de Serviços de Saúde (CROSS). Cada município possui uma quantidade de cotas (distribuídas pelo Estado) e o encaminhamento de pacientes é feito por meio do sistema CROSS, após o diagnóstico realizado na Rede de Atenção Básica. Caso não haja vaga para o paciente em uma determinada unidade de saúde, o sistema indica onde há vaga, respeitando a disposição geográfica das mesmas. Desse modo, o encaminhamento é pré-determinado. 
Porém, existem casos de pacientes em que o município não consegue vaga no sistema para uma determinada especialidade, então, os mesmos são encaminhados para o DRS. O DRS, por sua vez, abre no sistema uma vaga no sistema CROSS, chamada de "vaga 0". Assim, esse paciente pode ser encaminhado para qualquer unidade de saúde fora do DRS de origem.

Esse tempo de espera no agendamento de consulta especializada são as chamadas "filas de espera", normalmente ocorrem em casos cirúrgicos (MC e AC). Na rede de atenção Básica quando existe uma demanda reprimida em alguma especialidade o Estado convoca os profissionais de saúde para fazer os mutirões de atendimento.

Outro sistema utilizado pelo DRS e pelas unidades de saúde é o DATASUS/ CNES (Cadastro Nacional dos Estabelecimentos de Saúde). Esse sistema inclui diversas informações e relatórios para uso do público em geral e também alguns dados são obtidos somente com a senha da unidade de saúde ou do gestor. Outro fato importante é que essa base de dados apresenta o quantitativo dos profissionais (indivíduos) e de vínculos cadastrados no CNES.

Portanto, o estudo piloto permitiu identificar os tipos de dados e informações disponíveis para a pesquisa (DATASUS/CNES), assim como os principais contatos e decretos do SUS publicado no diário oficial. Porém, várias questões do roteiro de entrevista (Apêndice A) ficaram em abertas por falta de conhecimento do respondente ou, em muitas vezes, por não estar autorizado a responder por outro setor do DRS.

\subsection{Delimitação da Coleta de Dados}

A pesquisa foi delimitada a partir de 61 unidades de saúde públicas que atendem exclusivamente ao SUS, ligadas ao DRS (Departamento Regional de Saúde) de Bauru e ao Município de Bauru.

O DRS de Bauru foi classificado como eficiente na utilização dos recursos para a produção ambulatorial e hospitalar do SUS e, engloba municípios localizados nas áreas metropolitanas ou em seu entorno, além disso, é considerado como importante polo de produção de serviços em saúde (FERREIRA, 2009). Nesta pesquisa foram analisadas somente as unidades de saúde do Município de Bauru (DRS Bauru), segundo dados do CNES, Bauru possui 628 unidades de saúde (públicas e privadas), sendo 7 hospitais gerais e três 
especializados. Bauru é considerado o município mais populoso do centro-oeste paulista, com 364.562 habitantes (IBGE, 2014).

\subsection{Metodologia da Pesquisa}

O caminho do pesquisador ao conhecimento pode ser abordado a partir da teoria (dedutivo) ou do empírico (indutivo) (KOVÁCS e SPENS, 2005).

Esta pesquisa pode ser classificada como abdutiva, baseada na inter-relação entre conceitos de pressupostos estabelecidos a partir da revisão da literatura existente e o estudo empírico. O raciocínio dedutivo consiste em construir lógicas, por meio do relacionamento entre antecedente e consequente, ente hipótese e tese, entre premissas e conclusão. $\mathrm{O}$ indutivo traduz o processo mental por intermédio do qual, partindo-se de dados particulares suficientemente constatados, se infere uma verdade geral ou universal. Portanto, o raciocínio indutivo e dedutivo se complementam (CERVO et al 2006).

A escolha do método de pesquisa foi baseada na busca de melhor responder a questão de pesquisa. Diante desse contexto, convém retornar as questões de pesquisa:

Q1 Como analisar, por meio da teoria de redes, a rede de médicos com vínculos profissionais em unidades de saúde públicas e privadas de um município do Estado de São Paulo?

Q2 - Qual a configuração da rede de médicos com vínculos profissionais em unidades de saúde públicas e privadas, delimitada a partir de unidades de saúde vinculadas ao SUS (Município de Bauru)?

Trata-se de um estudo de natureza tanto descritiva como exploratória, porque descreve a distribuição do resultado entre os subgrupos da população (FREITAS et al., 2000) e busca identificar padrões, ideias ou hipóteses (COELHO e SILVA, 2007). Em função dessa natureza, acha-se apropriado fazer um estudo quantitativo, pois, segundo Gunther (2006), esse estudo envolve o processamento de dados quantitativos, a fim de obter o mapeamento da rede e compreender a sua configuração. Nesse sentido, a rede de médicos com vínculos profissionais em unidades de saúde públicas e privadas foi mapeada e analisada (com o auxilio do software NetMiner 3). Esse mapeamento foi delimitado a partir do vinculo profissional de médicos em unidades de saúde públicas do Município de Bauru (integrante do 
DRS - Bauru) vinculadas ao SUS. O período do mapeamento ocorreu de outubro de 2015 à abril de 2016.

O software Netminer 3 apresenta alguns algoritmos para a visualização dos mapas da rede e, os utilizados nesta tese foram: Concentric (Layout do Algoritmo Concentric), Spring 2D (Layout do Algoritmo de Kamada e Kawai) e Spring 2D (Layout Eades). Informações adicionais, sobre os algoritmos neste software, podem ser consultadas em Cyram (2008). Esses algoritmos foram escolhidos para os desenhos da rede neste trabalho, motivo pelo qual, apresentam um método para desenhar gráficos ponderados e não-direcionados. Os mapas de rede gerados são não direcionados, pois os vínculos profissionais dos médicos não podem ser descritos como origem-destino, ou seja, eles não são direcionados.

Para a análise da rede em estudo, as principais medidas de rede que foram utilizadas nesta tese, incluem: Degree Centrality (Grau de Centralidade); Betweenness (Intermediação); Coreness (Núcleo); Closeness (Proximidade); Density (Densidade) e Inclusiveness (Inclusão); Neighbor (vizinhos); Structural Hole (Buraco Estrutural) e Egonet (Rede Ego), conforme ilustra o Quadro 11.

\begin{tabular}{|c|c|c|c|}
\hline $\begin{array}{l}\text { Medidas Globais } \\
\text { da Rede }\end{array}$ & Descrição & Referência & Autor \\
\hline Degree Centrality & $\begin{array}{l}\text { Mede a centralidade da estrutura da } \\
\text { rede baseada no grau de conexões. }\end{array}$ & $\begin{array}{l}0 \text { (não central) a } 1 \text { (mais } \\
\text { central). }\end{array}$ & Freeman (1978) \\
\hline Coreness & $\begin{array}{l}\text { Identifica os núcleos internos e analisa- } \\
\text { se a rede por layers }\end{array}$ & $\begin{array}{l}\text { Maior pontuação de } \\
\text { Coreness são agrupados } \\
\text { no núcleo da rede }\end{array}$ & HE et al. (2011) \\
\hline Closeness & $\begin{array}{l}\text { É a soma das distâncias de todos os } \\
\text { outros nós }\end{array}$ & $\begin{array}{l}0 \text { (não central) a } 1 \text { (mais } \\
\text { central). }\end{array}$ & Cyram (2008) \\
\hline Betweenness & $\begin{array}{l}\text { Mede a extensão com que um nó } \\
\text { encontra-se entre todos os outros pares } \\
\text { de nós em seus caminhos geodésicos. }\end{array}$ & $\begin{array}{l}0 \text { (não central) a } 1 \text { (mais } \\
\text { central). }\end{array}$ & Cyram (2008) \\
\hline Box Plot & $\begin{array}{l}\text { Descreve graficamente grupos } \mathrm{de} \\
\text { dados numéricos }\end{array}$ & $\begin{array}{l}\text { Q 1 inferior }(25 \%) ; \mathrm{Q} 2 \\
\text { mediana dos dados e Q3 } \\
\text { superior }(75 \%)\end{array}$ & $\begin{array}{l}\text { Cyram, (2008) } \\
\text { Krzywinski; } \\
\text { Altman (2014) }\end{array}$ \\
\hline Density & $\begin{array}{l}\text { É medida pela razão entre o número de } \\
\text { ligações presentes em relação ao } \\
\text { máximo de ligações possíveis. }\end{array}$ & $\begin{array}{l}\text { Gráfico "completamente } \\
\text { conectado" todos os nós } \\
\text { estão } \quad \text { conectados } \\
\text { (densidade }=100 \% \text { ) }\end{array}$ & Scott (2000) \\
\hline Inclusiveness & $\begin{array}{l}\text { Número de nós conectados/número de } \\
\text { nós }\end{array}$ & $\begin{array}{l}\text { Número total de pontos } \\
\text { menos o número de } \\
\text { pontos isolados }\end{array}$ & Scott $(2000)$ \\
\hline Neighbor & $\begin{array}{l}\text { Mede o tamanho de sua vizinhança } \\
\text { direta }\end{array}$ & $\begin{array}{l}\text { Refere-se a amostra dos } \\
\text { dados da rede }\end{array}$ & Cyram (2008) \\
\hline Structural Hole & $\begin{array}{l}\text { Mede a estrutura de conexão local de } \\
\text { cada nó de uma rede. }\end{array}$ & $\begin{array}{l}\text { Ver Capítulo } 2 \text { - Seção } \\
\text { 2.5.4 Structural Hole }\end{array}$ & $\begin{array}{l}\text { Burt (1992), } \\
\text { Cyram (2008) }\end{array}$ \\
\hline Egonet & Rotas de acesso para outras redes & $\begin{array}{l}\text { Ver Capítulo } 2 \text { - Seção } \\
\text { 2.5.4 Egonet }\end{array}$ & Burt (1992) \\
\hline
\end{tabular}


Adicionalmente, optou-se pelo uso de ferramentas de estatísticas básicas descritivas (média e correlação). Para identificar as principais unidades de saúde Hubs foi proposta uma adaptação da fórmula do modelo HS proposta originalmente para a área de logística por DERUDDER et al. (2007). Nesta tese, essa medida foi adaptada para avaliar o grau de Hubiness das unidades de saúde.

Contudo, a estratégia de análise foi a construção de explanação narrativa, é um tipo especial de adequação ao padrão (YIN, 2005), cujo objetivo foi analisar os dados do mapeamento da rede e construir uma explanação sobre a rede com base na literatura sobre o tema.

\subsection{Unidade de Análise}

Segundo Babie (2001) uma pesquisa pode envolver mais de uma unidade de análise. Esta tese envolve três unidades de análise: Unidades de Saúde, Médicos e Ocupações dos Médicos. O município de Bauru conta com 65 unidades de saúde públicas que atendem exclusivamente ao SUS. Foram excluídas dessa amostra, 4 unidades de saúde (USF Vila Dutra, USF Vila Santa Edwirges, Base Central de regulação USA II, UFS Nove de Julho Fortunato Rocha Lima), pois os médicos que atuam nessas unidades de saúde não possuem vínculos com outras unidades de saúde. Para tanto, foram delimitadas 61 unidades de saúde (ligadas ao SUS) do município de Bauru, que serviriam de ponto de partida para o mapeamento da rede, por meio dos vínculos profissionais dos médicos. Nessas unidades de saúde atuam 789 médicos, que por meio de outros vínculos profissionais, atendem a unidades de saúde públicas e privadas (i.e., totalizando 2.582 vínculos). Portanto, a partir da delimitação inicial de 61 unidades de saúde (ligadas ao SUS), obteve-se o mapeamento da rede de médicos com vínculos profissionais em 655 unidades de saúde públicas e privadas, no município de Bauru e em outros municípios. Considerou-se somente um vinculo profissional por unidade de saúde, para os casos em que médicos possuíam mais de 1 vínculo profissional com a mesma unidade de saúde (porém com ocupação diferente).

A Tabela 2 apresenta a amostra de dados do mapeamento da rede de médicos com vínculos profissionais em unidades de saúde públicas e privadas (DRS- Bauru). 
Tabela 2 - Amostra dos dados

\begin{tabular}{lc}
\hline \multicolumn{1}{c}{ Item } & Quantidade \\
\hline Unidades de saúde vinculadas ao SUS no Município de Bauru & 61 \\
Número total de vínculos profissionais médicos & 2.582 \\
Número total de médicos das unidades vinculadas ao SUS no & 789 \\
Município de Bauru & 65 \\
Número total das ocupações dos médicos na rede & 655 \\
Número total das unidades de saúde públicas e privadas mapeadas & \\
\hline por meio dos vínculos profissionais médicos & \\
\hline
\end{tabular}

Enfatiza-se que todas as unidades de saúde que atendem exclusivamente ao SUS no Município de Bauru foram mapeadas. Portanto, considerou-se o universo das unidades de saúde públicas que atendem ao SUS no município de Bauru.

De acordo com Carrington et al. (2005) apud Laumann et al. (1989) a fronteira da rede pode ser defina por meio de três estratégias: (1) Abordagem posicional baseada em características de objetos, ou critérios de associação formal; (2) Abordagem baseada em eventos apoiada na participação em algumas classes de atividades e (3) Abordagem social baseada em conexão social.

Nesta tese, a fronteira da rede foi delimitada por meio da primeira estratégia, ou seja, o emprego/vínculo por uma organização (como uma unidade de saúde) é um critério posicional.

\subsection{Fontes e Instrumentos para Coleta de Dados}

Para fazer o mapeamento da rede de médicos com vínculos profissionais em unidades de saúde públicas e privadas (DRS- Bauru), a principal base de dados utilizada foi o sistema DATASUS/CNES (Cadastro Nacional dos Estabelecimentos de Saúde http://cnes.datasus.gov.br), esses dados são públicos, atualizados mensalmente e, são de preenchimento obrigatório para as unidades de saúde. Desse modo, nenhum médico consegue solicitar qualquer exame ou procedimento cirúrgico no SUS se não tiver cadastro no sistema 
CNES (conforme informações do estudo piloto), apesar dos médicos vinculados ao Programa Mais Médicos não serem registrados nesse sistema.

O CNES reflete a série histórica do cadastro dos profissionais de saúde, por mês de competência, disponível, com defasagem de até 45 dias. Essa base apresenta o quantitativo de profissionais (indivíduos) e de vínculos cadastrados no CNES. As categorias profissionais são consideradas pela Classificação Brasileira de Ocupações (CBO), utilizando a CBO mais recente (2007). A CBO é uma tabela do Ministério do Trabalho que codifica títulos e descreve as características das ocupações do mercado de trabalho brasileiro. Essa tabela identifica os profissionais que atuam em estabelecimentos de saúde ambulatoriais e hospitalares. Quanto a origem dos dados, as informações disponíveis são geradas a partir dos dados enviados pelas Secretarias Municipais e Estaduais de Saúde por meio do Sistema de Cadastro Nacional de Estabelecimentos de Saúde (CNES/SUS) e consolidadas no Banco de Dados Nacional pelo DATASUS, conforme determina a Portaria SAS/SE/MS no 49 de 4 de julho de 2006 e SAS/MS 311 de 14 de maio de 2007.

Nesse sentido, ressalta-se que as bases do DATASUS/CNES são alimentadas diretamente pela administração de cada município brasileiro, então, tanto o volume de informações quanto a ampla variedade de situações administrativas, pode ocorrer erros em alguns dados e na atualização de cadastro, já que esses dados não foram conferidos com as unidades de saúde (BOLZE et al. 2010).

Para a coleta de dados, foram utilizados os dados do sistema DATASUS/CNES no período de abril de 2015 à junho/2015, para tanto, o acesso no sistema segue os seguintes passos: (1) Relatórios; (2) Tipos de Estabelecimentos; (4) Estado: SP e (5) Município: Bauru. O município de Bauru é composto por 628 unidades de saúde (conforme, Tabela 3). Essas unidades são públicas e privadas. Dessa forma, os consultórios isolados (unidades de saúde privadas) foram excluídos da amostra, e, foram verificadas, para as demais unidades, o vínculo ao SUS. Após esse levantamento de dados, constatou 65 unidades de saúde do município de Bauru vinculadas exclusivamente ao SUS e, a partir de cada uma delas listou-se todos os médicos e acessou a ficha de cada médico, assim foi construído um banco de dados no Excel, denominado BDD (Banco de Dados Detalhados), com os seguintes dados: Unidade de Saúde acessada, Nome do Médico, CBO do Médico, Unidades de Saúdes que os médicos possuem vínculos profissionais, Esfera de Gestão, Estado, Carga Horária, Vínculo no SUS e Residente. Além do BDD, foram elaboradas planilhas no Excel com dados qualitativos (Nível de Atendimento do SUS, Esferas de Gestão, Quantidade de Vínculos do médicos, Carga 
Horária semanal dos médicos, entre outras) e, posteriormente foram inseridos no software NetMiner3.

Tabela 3 - Relatório por unidade de saúde do Município de Bauru

\begin{tabular}{|c|c|c|}
\hline $\begin{array}{l}\text { MINISTÉRIO DA SAÚDE } \\
\text { SECRETÁRIA DE ATENCÃO À SAÚDE }\end{array}$ & & $\begin{array}{l}22 / 5 / 2015 \\
\text { DATASUS }\end{array}$ \\
\hline \multicolumn{3}{|c|}{ CNES - CADASTRO NACIONAL DE ESTABELECIMENTOS DE SAÚDE } \\
\hline & RELATÓRIO POR UNIDADE & \\
\hline \multicolumn{3}{|l|}{ ESTADO:SAO PAULO } \\
\hline \multicolumn{3}{|l|}{ MUNICIPIO:BAURU } \\
\hline TIPO DE UNIDADE: 3506002785501 & & \\
\hline
\end{tabular}

Total

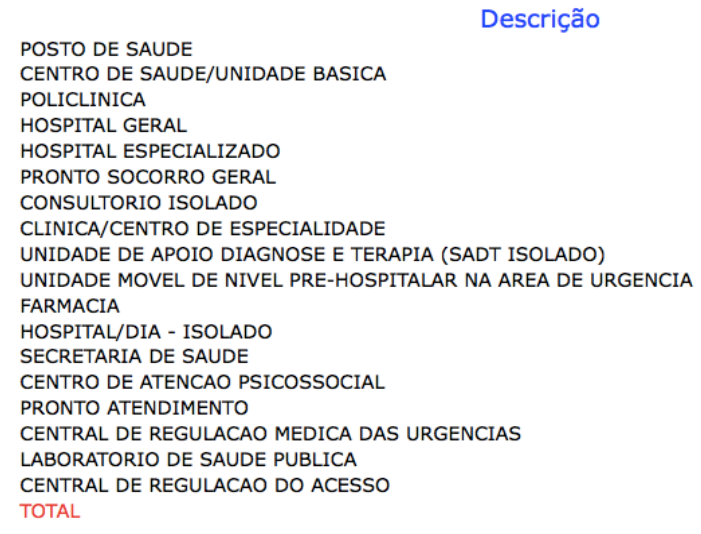

POSTO DE SAUDE
CENTRO DE SAUDE/UNIDADE BASICA
POLICLINICA
HOSPITAL GERAL
HOSPITAL ESPECIALIZADO
PRONTO SOCORRO GERAL
CONSULTORIO ISOLADO
CLINICA/CENTRO DE ESPECIALIDADE
UNIDADE DE APOIO DIAGNOSE E TERAPIA (SADT ISOLADO)
UNIDADE MOVEL DE NIVEL PRE-HOSPITALAR NA AREA DE URGENCIA
FARMACIA
HOSPITAL/DIA - ISOLADO
SECRETARIA DE SAUDE
CENTRO DE ATENCAO PSICOSSOCIAL
PRONTO ATENDIMENTO
CENTRAL DE REGULACAO MEDICA DAS URGENCIAS
LABORATORIO DE SAUDE PUBLICA
CENTRAL DE REGULACAO DO ACESSO
TOTAL




\section{ANÁLISE DOS DADOS E RESULTADOS}

Este capítulo tem como objetivos descrever e analisar o conjunto de dados obtidos a partir do mapeamento da rede de médicos com vínculos profissionais em unidades de saúde públicas e privadas. O capítulo está dividido em três fases distintas: (1) análise dos dados quantitativos no software NetMiner3; (2) análise do grau de hubiness de unidades de saúde e (3) síntese dos resultados obtidos.

\subsection{A análise dos dados quantitativos no software NetMiner3}

A primeira fase de análise dos dados evidencia os principais resultados do mapeamento da rede dos seguintes níveis de análise: Organizacional (Unidades de Saúde); Pessoas (Médicos) e Ocupações (Cargos dos Médicos). Esses resultados envolvem o processamento e análise das informações. Os dados do software NetMiner3 foram resumidos e sistematizados, através de mapas de rede. Geralmente, na análise de dados da rede, a visualização incide sobre a percepção do padrão global dos dados e alguns pontos iniciais a serem melhores investigados.

\subsection{1 - Nível de Análise - Organizacional (Unidades de Saúde)}

Esta seção apresenta as unidades de saúde como objeto de análise. As medidas de análise da rede foram realizadas pelo software NetMiner3. O mapeamento da rede de médicos com vínculos profissionais em unidades de saúde públicas e privadas (descrito no Capítulo 3, seção 3.4) resultou em 655 unidades de saúde, independente do Município e do atendimento ser público ou privado.

Para o processamento das informações, utilizou o arquivo do Banco de Dados (BDD) e criou uma nova planilha no Excel denominada US (Unidades de Saúde), com as unidades de saúde de origem e as unidades de saúde em que os médicos possuíam vínculos profissionais, independente no Município de origem. Então, essa planilha foi inserida no Software NodeXl 
para que os dados fossem tratados, ou seja, excluiu-se os dados duplicados e as unidades de saúde que possuíam vínculos com elas mesmas, assim, gerou uma matriz de 1 Modo, denominada Matriz US (Unidades de Saúde), com 655 unidades de saúde e suas interações e, posteriormente, a matriz de 1 modo foi inserida no Software NetMiner3, conforme demonstrado na Tabela 4 (parte da matriz), com 10 unidades de saúde.

Nessa matriz (Tabela 4), nota-se que o Hospital de Reabilitação Centrinho tem 1 relacionamento com as seguintes unidades de saúde: C P P DR Alberto B Bauru, Paulo C Fracischone e Hospital e Mat. Maria José, mas há 7 relacionamentos com o Hospital Unimed de Bauru, ou seja, 7 médicos que têm vínculo profissional na Unimed, também tem vínculo profissional com o Hospital Reab Centrinho. Na nomenclatura de grafos usada na análise de redes sociais, trata-se de uma rede não-direcional, isto é, as ligações entre nós independem de sua origem.

Tabela 4 - Parte da Matriz de 1 modo do mapeamento da rede de médicos com vínculos profissionais em unidades de saúde públicas e privadas

\begin{tabular}{|c|c|c|c|c|c|c|c|c|c|c|}
\hline & $\begin{array}{l}\text { C P P } \\
\text { DR } \\
\text { Alberto } \\
\text { B Bauru }\end{array}$ & $\begin{array}{l}\text { Imuno- } \\
\text { lógica }\end{array}$ & $\begin{array}{l}\text { Centro } \\
\text { Ref Mod } \\
\text { I SAE }\end{array}$ & $\begin{array}{l}\text { Hospital } \\
\text { Reab } \\
\text { Centrinho }\end{array}$ & $\begin{array}{l}\text { Paulo C } \\
\text { Fracischone }\end{array}$ & $\begin{array}{l}\text { CPP Prof } \\
\text { Noe Az } \\
\text { Bauru }\end{array}$ & $\begin{array}{l}\text { Santa } \\
\text { Casa } \\
\text { Jau }\end{array}$ & $\begin{array}{l}\text { SAMU } \\
\text { Jau }\end{array}$ & $\begin{array}{l}\text { Hosp } \\
\text { Mat } \\
\text { Maria } \\
\text { José }\end{array}$ & $\begin{array}{l}\text { Hospital } \\
\text { Unimed } \\
\text { Bauru }\end{array}$ \\
\hline $\begin{array}{l}\text { C P P DR } \\
\text { Alberto B } \\
\text { Bauru }\end{array}$ & 0 & 1 & 1 & 2 & 1 & 0 & 0 & 0 & 0 & 0 \\
\hline Imunológica & 0 & 0 & 0 & 0 & 0 & 0 & 0 & 0 & 0 & 0 \\
\hline $\begin{array}{l}\text { Centro Ref Mod } \\
\text { I SAE }\end{array}$ & 1 & 1 & 0 & 0 & 0 & 0 & 0 & 0 & 0 & 2 \\
\hline $\begin{array}{l}\text { Hospital Reab } \\
\text { Centrinho }\end{array}$ & 1 & 0 & 0 & 0 & 1 & 0 & 0 & 0 & 1 & 7 \\
\hline $\begin{array}{l}\text { Paulo C } \\
\text { Fracischone }\end{array}$ & 0 & 0 & 0 & 0 & 0 & 0 & 0 & 0 & 0 & 0 \\
\hline $\begin{array}{l}\text { CPP Prof Noe } \\
\text { Az Bauru }\end{array}$ & 0 & 0 & 0 & 0 & 0 & 0 & 1 & 1 & 1 & 1 \\
\hline $\begin{array}{l}\text { Santa Casa de } \\
\text { Jau }\end{array}$ & 0 & 0 & 0 & 0 & 0 & 0 & 0 & 0 & 0 & 0 \\
\hline SAMU Jau & 0 & 0 & 0 & 0 & 0 & 0 & 0 & 0 & 0 & 0 \\
\hline $\begin{array}{l}\text { Hosp Mat Maria } \\
\text { José }\end{array}$ & 0 & 0 & 0 & 0 & 0 & 0 & 0 & 0 & 0 & 0 \\
\hline $\begin{array}{l}\text { Hospital } \\
\text { Unimed Bauru }\end{array}$ & 0 & 0 & 0 & 0 & 0 & 0 & 0 & 0 & 0 & 0 \\
\hline
\end{tabular}

Além disso, foram geradas outras planilhas no Excel, a partir do arquivo BDD com informações qualitativas e inseridas no NetMiner3, tais como: Tipos de Estabelecimentos, Nível de Atendimento do SUS (AB, MC e AC), Atendimento SUS versus Privado e Esferas de Gestão. Esses dados qualitativos foram representados nos mapas da rede com diferenciação de formas e cores. 
As subseções da vertente quantitativa, apresentadas a seguir, são as medidas de análise de redes (Nível de análise - unidades de saúde) extraídas pelo software NetMiner3 (Quadro 12).

\begin{tabular}{|l|}
\hline \multicolumn{1}{|c|}{ VERTENTE QUANTITATIVA } \\
Medidas de análise \\
\hline • Centrality \\
Degree \\
Coreness \\
Closeness \\
Betweennes \\
-Box Plot \\
•Neighbor \\
•Density e Inclusiveness \\
- Egonet \\
-Structural Hole \\
Quadro 12- Medidas de análise \\
Nível de análise - unidades de saúde
\end{tabular}

\subsubsection{Análise de Centralidade}

Para extrair as medidas de centralidade da rede foi inserida a matriz de 1 modo da rede (655 unidades de saúde) no Software NetMiner3. Essas medidas são: (1) Degree Centrality (2) Coreness; (3) Closeness; (4) Betweenness-Node, (5) Betweenness -Link e (6) Gráfico Box Plot.

Após o processamento dos dados o Software NetMiner3 gerou-se 2 planilhas no Excel para cada medida de centralidade descrita. As planilhas são apresentadas em forma de tabela, sendo:

(1) Distribuição do índice do grau de centralidade - são os indicadores gerais de toda a rede (Tabela 5) onde se observa a Média de todas as relações; o Desvio Padrão, ou seja, a variação da média; Mínimo e Máximo, que indicam os graus máximo e mínimo de interações que os atores tem dentro da rede e, por fim, o Índice de centralização da rede é a soma de todas as relações e (2) Análise de Centralidade - é o resultado de centralidade para cada ator da rede. 
Embora as medidas geradas pelo Software NetMiner3 envolvam todos os atores (655) na rede, por questões práticas, apresenta-se, as 15 unidades de saúde com maior grau de centralidade.

\subsection{Degree Centrality}

Degree Centrality mede a centralidade da estrutura da rede baseada no grau de conexões (CYRAM, 2008). A Tabela 5 apresenta a distribuição do índice do grau de centralidade das unidades de saúde. As medidas de centralidade são as mesmas tanto para o In-Degree (grau de entrada) quanto para o Out-Degree (grau de saída), pois na representação em grafo a rede em estudo é não-direcional, ou seja, os vínculos vão em ambos os sentidos.

Os resultados da Tabela 5 mostram que a média do grau de centralidade é 0,004 e o Desvio Padrão, 0,015 em relação ao índice de centralização da rede, ou seja, as conexões que estão mais dispersas são relativamente alta em relação a média. Assim, o mínimo de conexões é 0 e o máximo é 0,239 . O grau de interação entre os atores e o índice de centralização da rede é $23,5 \%$. Portanto, nenhum ator na rede atingiu o índice 1, que segundo Freeman (1978) um único ator central é igual a 1 e os demais atores da rede é 0 , mas o maior índice encontrado foi 0,239 .

Tabela 5 - Distribuição do índice do grau de centralidade da rede

\begin{tabular}{lr}
\hline \multicolumn{1}{c}{ MEDIDA } & \multicolumn{2}{c}{ VALOR } \\
\cline { 2 - 2 } & \multicolumn{2}{c}{ Grau de Centralidade } \\
\hline Média & 0,004 \\
Desvio Padrão & 0,015 \\
Mínimo & 0 \\
Máximo & 0,239 \\
Índice de centralização da rede & $23,468 \%$ \\
\hline
\end{tabular}

A Tabela 6 apresenta os 15 atores com maior centralidade na rede. Embora os atores mais centrais da rede não alcançaram o índice 1, conforme a referência de Freeman (1979) 
para o ator mais central, esses atores apresentam um maior índice de centralidade em relação aos demais.

Nesta rede, o ator mais central, em termos de interações entre os atores da rede é o Hospital de Base de Bauru, isso corresponde $(0,238)$ de centralidade dos vínculos de ambos os sentidos, seguido do Hospital Estadual Bauru $(0,165)$ e do Pronto Socorro Central de Bauru $(0,116)$. Esses atores estão mais propensos a acessar novas informações, além de influenciar e ser influenciado diretamente por outros atores na rede (BORGATTI, 2009).

Para tanto, o nível de análise da rede são as unidades de saúde, que centralizam relações com outros atores na rede. Corroborando com Freeman (1979), nesta rede, o ponto de centralidade é o Hospital de Base, é a posição mais central possível. Essa unidade de saúde é caracterizada como Hospital geral, cujo atendimento é demanda espontânea e referenciada e conta com 145 médicos.

O segundo ator que ocupa a posição mais central é o Hospital Estadual de Bauru. Esse hospital é classificado pelo CNES como hospital geral e de ensino, o atendimento é demanda referenciada e possui 327 médicos.

E por fim, o Pronto Socorro Central, o terceiro mais central, é caracterizado como Pronto Socorro Geral e o atendimento é demanda espontânea e referenciada e atuam 78 médicos.

Essas três unidades de saúde com maior centralidade na rede atendem os níveis de média complexidade e alta complexidade. Elas centralizam as relações com os demais atores da rede e assumem o papel de Hubs (atores centrais) na rede em estudo, intermediando as informações com os demais atores da sua rede por meio dos vínculos profissionais dos médicos. Dessa forma, possibilita o acesso a novas informações, a entrada de novos conhecimentos e permite medir o grau de envolvimento dos atores na rede (WASSERMAN e FAUST, 1994), visando melhorias na unidade de saúde, consequentemente, os usuários do sistema de saúde.

Entretanto, essas unidades de saúde estão melhores posicionadas em relação às trocas e à comunicação, o que aumenta seu poder na rede (MARTELETO, 2001). 
Tabela 6 - Análise de centralidade (degree)

\begin{tabular}{llc}
\hline Item & \multicolumn{1}{c}{ Unidades de Saúde } & $\begin{array}{c}\text { Grau de } \\
\text { Centralidade }\end{array}$ \\
\hline 1 & Hospital de Base de Bauru & 0,238532 \\
2 & Hospital Estadual Bauru & 0,165138 \\
3 & Pronto Socorro Central de Bauru & 0,116208 \\
4 & AME Ambulatório Médico de Especialidades Bauru & 0,107034 \\
5 & Maternidade Santa Isabel & 0,102446 \\
6 & UPA Mary Dota & 0,056575 \\
7 & Núcleo de Saúde Centro de Bauru & 0,056575 \\
8 & UPA Geisel & 0,050459 \\
9 & Serviço de Orientação e Prevenção do Câncer & 0,042813 \\
10 & Núcleo de Saúde III Vila Cardia & 0,035168 \\
11 & Instituto Lauro de Souza Lima Bauru & 0,035168 \\
12 & Samu Regional & 0,033639 \\
13 & Núcleo de Saúde III N Habitacional Presidente Geisel & 0,033639 \\
14 & Núcleo de Saúde Beija Flor & 0,033639 \\
15 & Hospital Unimed de Bauru & 0,033639 \\
\hline
\end{tabular}

A rede de médicos com vínculos profissionais em unidades de saúde públicas e privadas permitiu extrair diferentes dados qualitativos, tais como: Nível de Atendimento do SUS, Esfera de Gestão das unidades de saúde, Classificação das unidades de saúde, Atendimento SUS e Privado.

Nesta tese, a representação da rede foi feita por meio de vários mapas para o melhor entendimento. A forma de visualização dos mapas e os algoritmos aplicados são: Concentric (Layout do Algoritmo Concentric), Spring 2D (Layout do Algoritmo de Kamada e Kawai) e Spring 2D (Layout Eades).

A Análise de Centralidade (Degree) é representada por meio dos mapas de rede (Figuras, 17 e 19), cuja a visualização é Concentric e, as Figuras (18 e 20) com a forma de visualização, Spring 2D.

Nos mapas da rede mencionados, apresentam-se, 655 (nós) unidades de saúde. Porém, os atores mais centrais estão localizados no núcleo da rede e, os demais atores estão na periferia da rede. Assim, os cinco atores com maior grau de centralidade na rede são: Hospital de Base de Bauru, Hospital Estadual Bauru, Pronto Socorro Central de Bauru, AMEAmbulatório Médico de Especialidade e Maternidade Santa Isabel. Das 655 unidades de saúde, 265 unidades de saúde apresentam algum grau de centralidade na rede. Contudo, o grau de centralidade dos atores na rede está entre 0,238 (o mais central) e 0,001 (o menos 
central) e, os demais atores estão na periferia da rede com 0 de centralidade.

Desse modo, nas Figuras 17 e 18 o destaque é o Nível de Atendimento do SUS, sendo: Atenção Básica (AB), cor Azul; Média Complexidade (MC), cor amarela e Alta Complexidade (AC), cor vermelha. Nesse sentido, observa-se que os atores com maior grau de centralidade, localizados no núcleo da rede são os que atendem os níveis de $\mathrm{AC}$ e $\mathrm{MC}$ e, os atores que atendem a $\mathrm{AB}$ estão localizados na periferia da rede. Já as formas representam os tipos de estabelecimentos das unidades de saúde, conforme classificação do CNES e, variam de tamanho conforme a centralidade do ator na rede, sendo ator mais central, maior a forma de representação (ver Legenda 1, Figura 17 e 18).

As Figuras 19 e 20 representam o grau de centralidade dos atores que atendem o SUS e dos atores que não atendem o SUS. A forma de círculo são os atores SUS e a forma de triângulo são os atores privados. Já as cores, na Figura 19 o Município de Bauru é representado pela cor cinza fosco e, os demais município diversas cores. Na Figura 20 o Município de Bauru é representado pela cor vermelho fosco. Assim, as unidades com maior grau de centralidade são as que prestam atendimento ao SUS e somente duas unidades privadas estão localizadas no núcleo da rede, sendo: o Hospital Unimed de Bauru e o Hospital e Maternidade Maria José, ambas unidades de saúde prestam atendimento de AC. 


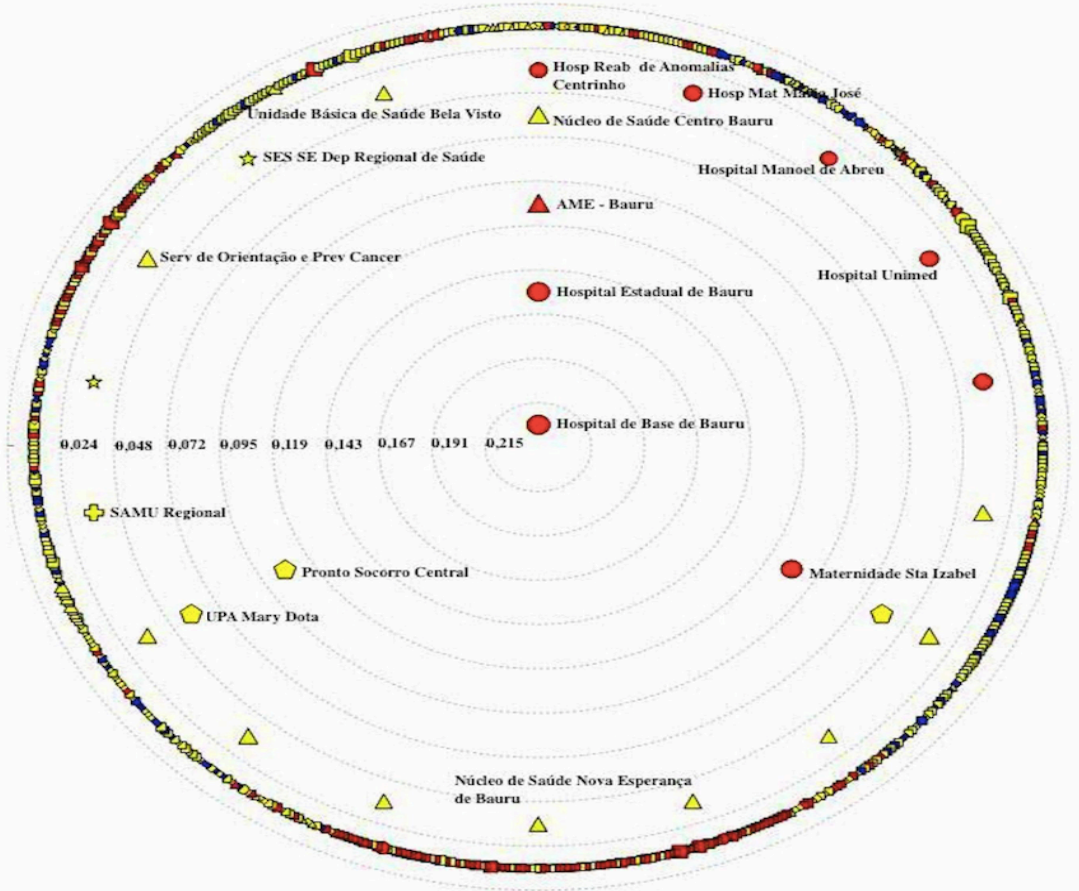

Figura 17 - Análise de centralidade (degree) - Nível de atendimento do SUS Visualização Concentric NetMiner 3

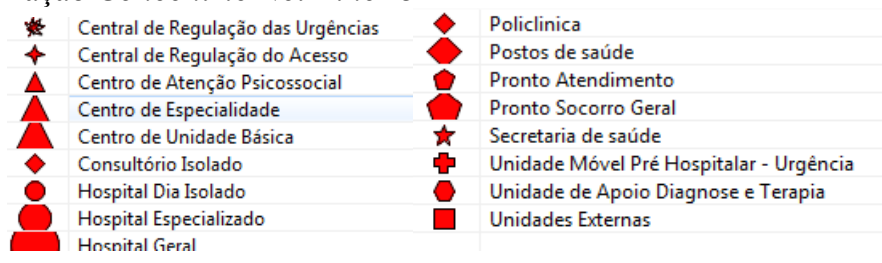

Legenda 1 -Tipos de Estabelecimentos representados na Figura 17 e 18

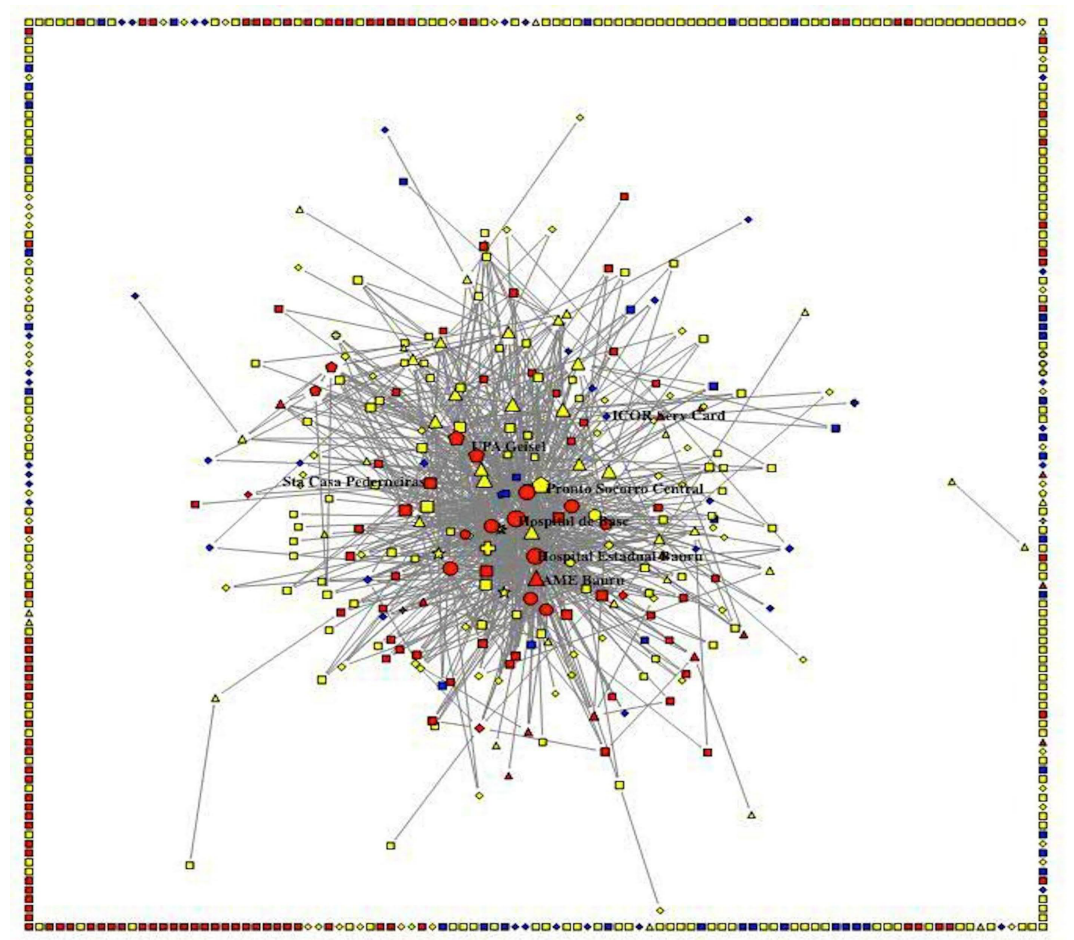

Figura 18 - Análise de centralidade (degree) - Nível de atendimento do SUS Visualização Spring $2 D$ NetMiner 3 


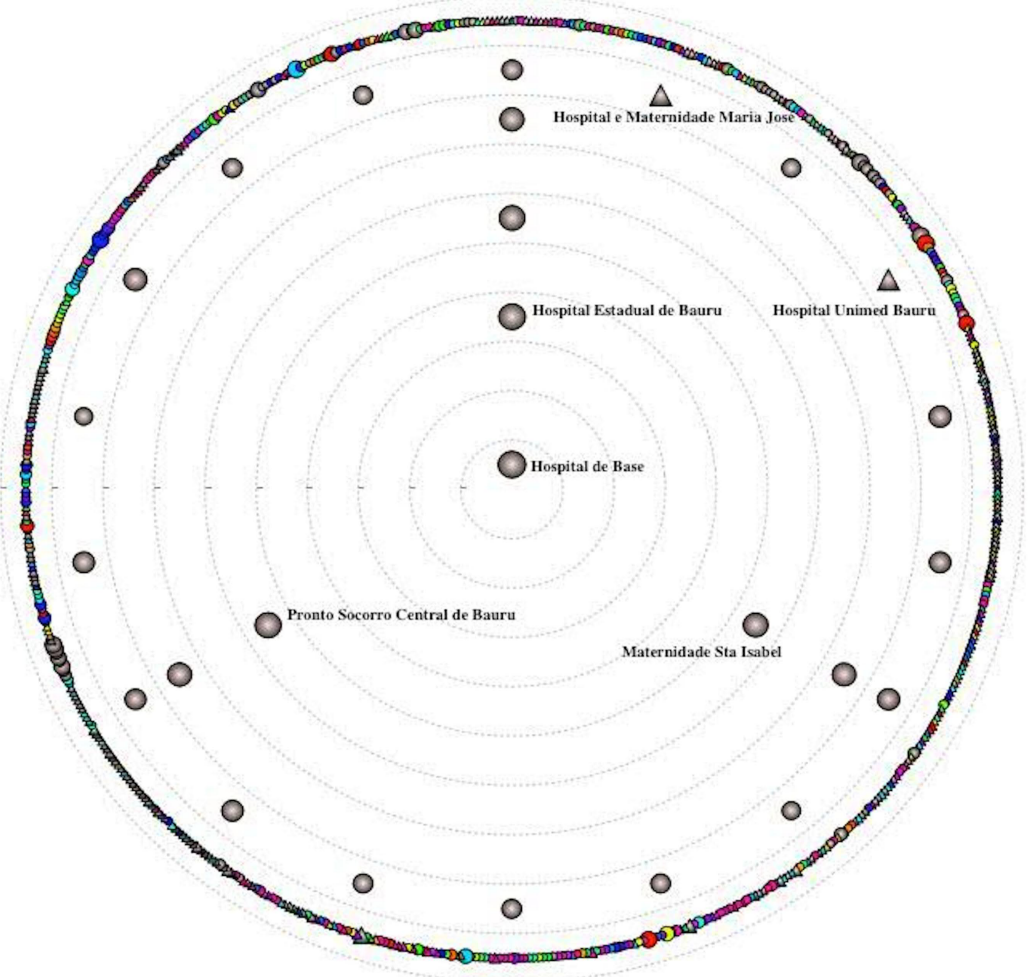

Figura 19 - Análise de centralidade (degree) - Atendimento SUS versus Privado Visualização Concentric NetMiner 3

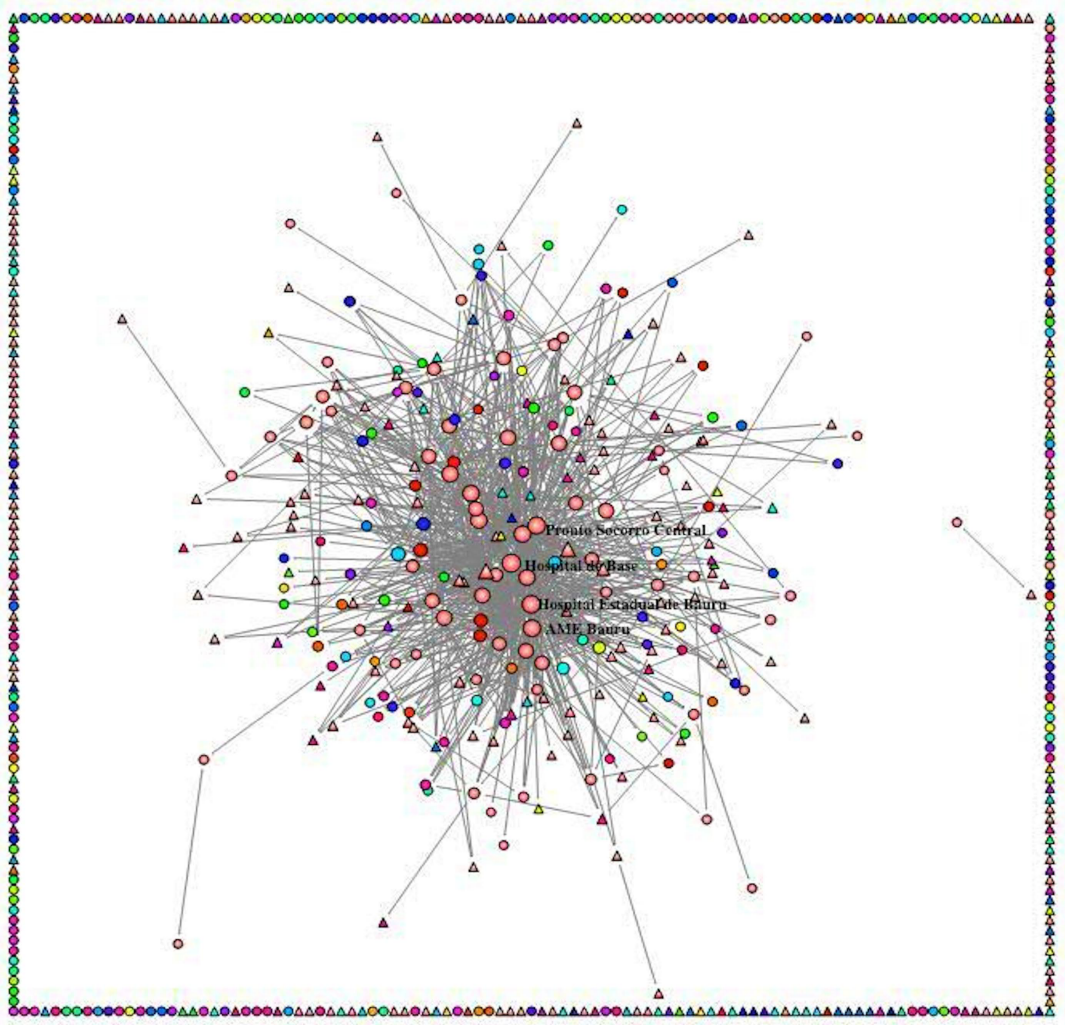

Figura - 20 - Análise de centralidade (degree) - Atendimento SUS versus Privado Visualização Spring 2D NetMiner 3 
De modo geral, nas Figuras 19 e 20, o Hospital de Base aparece no centro dos mapas, ou seja, com maior grau de centralidade.

Entretanto, os hospitais possuem maior interação por meio dos vínculos profissionais dos médicos e tendem a localizar-se em redes mais densas. A densidade da rede mostra a extensão da interconexão entre seus atores, assim quanto maior a interconexão, maior a densidade. A rede em estudo, parte é difusa, composta por 655 unidades de saúde. Contudo, o seu núcleo é denso, com alto grau de conectividade entre os principais atores, como ilustra as Figuras 17 e 18, cujo o núcleo é composto por 26 atores com grau de centralidade que varia de 0,215 a 0,024, observa-se que os demais atores encontram-se na periferia da rede. Esse tipo de rede pode promover confiança, cooperação e gerar capital social entre os membros da rede (COLEMAN, 1988).

\subsection{Coreness}

A medida Coreness avalia o número máximo do núcleo de cada nó. Assim, os atores com o maior índice Coreness são agrupados no núcleo da rede e, os demais na periferia da rede (HE et al., 2011).

No grau de centralização de cada membro da rede, identificou a existência de um grupo de 44 atores que apresentaram uma posição mais central de Coreness na rede. Para definir as unidades de saúde que revelaram o maior índice de centralização na rede, adotou o valor de Centralidade de Coreness de 9.

Assim, os 15 atores em ordem alfabética, com maior Coreness na rede são apresentados na Tabela 7. Entretanto, 44 unidades de saúde apresentaram um índice 9 de Coreness Centrality (núcleo principal), do total de 655 atores da rede. Essas 44 unidades de saúde consistem em 10 vértices, onde cada vértice tem pelo menos 9 vizinhos (unidades de saúde) no interior do núcleo da rede. Os resultados mostram que as unidades de saúde com maior índice de Coreness são: Hospitais, Núcleos de Saúde, UPAs e SAMU.

Conforme destaca o estudo de Batagelj e Zaversnik (2002) a estrutura de grandes redes podem ser demonstradas em partes menores, como é o caso desta rede com 655 atores. Além disso, vértices com o valor de core 0 , são vértices isolados, isto é, atores que não 
colaboram na rede, no entanto, nesta rede 391 atores apresentam o core 0 e os demais variam o core entre 1 e 9.

Tabela 7 - Análise de centralidade (coreness)

\begin{tabular}{llc}
\hline Item & \multicolumn{1}{c}{ Unidades de Saúde } & $\begin{array}{c}\text { Centralidade } \\
\text { Coreness }\end{array}$ \\
\hline 1 & AME Ambulatório Médico de Especialidades Bauru & 9 \\
2 & Central de Regulação Médica de Urgências & 9 \\
3 & Centro de Referência Modulo I Sae II Adt III Hd & 9 \\
4 & Centro de Saúde de Agudos & 9 \\
5 & Centro Integrado de Saúde & 9 \\
6 & Hospital Beneficência Portuguesa de Bauru & 9 \\
7 & Hospital das Clinicas de Botucatu & 9 \\
8 & Hospital de Agudos & 9 \\
9 & Hospital de Base de Bauru & 9 \\
10 & Hospital de Reabilitação de Anomalias Craniofaciais & 9 \\
11 & Bauru & 9 \\
12 & Hospital e Maternidade Maria José & 9 \\
13 & Hospital Estadual Bauru & 9 \\
14 & Hospital Nossa Senhora da Piedade & 9 \\
15 & Hospital São Lucas & 9 \\
\hline
\end{tabular}

A Figura 21 ilustra o grau de centralização de cada membro da rede, assim o destaque é o Nível de Atendimento do SUS, sendo: Atenção Básica (AB), cor Azul; Média Complexidade (MC), cor amarela e Alta Complexidade (AC), cor vermelha. Contudo, os 44 atores que representam o maior Coreness estão representados no centro da rede e esses atores são os que atendem os níveis de $\mathrm{AC}$ e $\mathrm{MC}$ e, os atores que atendem a $\mathrm{AB}$ alguns se encontram no núcleo da rede, porém com menor índice de Coreness, e, os demais estão localizados na periferia da rede (índice 0 ). 


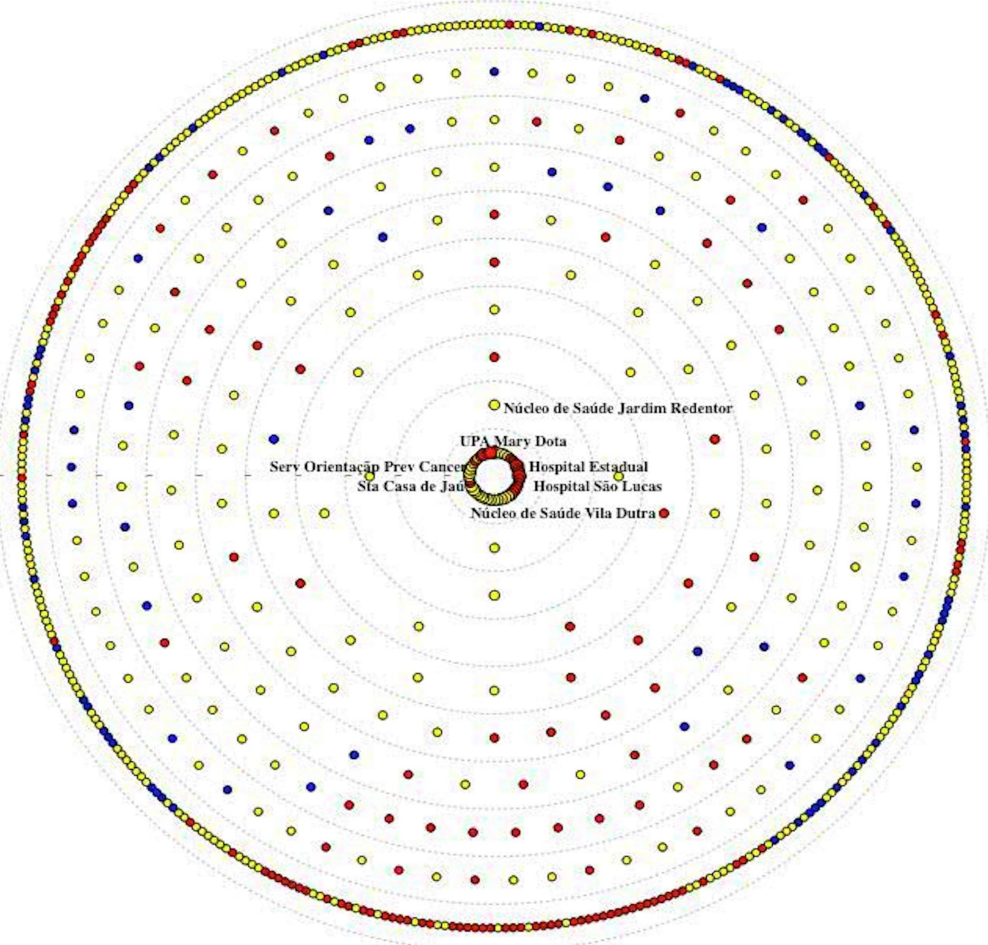

Figura 21 - Análise de centralidade (coreness) - Nível de atendimento do SUS Visualização Concentric NetMiner 3

\subsection{Closeness}

Os resultados da tabela 8 apontam a análise de centralidade da estrutura da rede com base nas distâncias geodésicas entre os nós. Assim, a média da distância de todos os nós é 0,065 e o Desvio Padrão, 0,081 (significativo) em relação a proximidade do ator na rede, ou seja, os atores que estão mais dispersos.

Portanto, o grau máximo de proximidade entre os atores da rede é 0,274. Esse índice representa o grau de independência dos atores de modo a possibilitar a comunicação com muitos outros atores em uma rede com o menor número de intermediários. Já o índice de centralização closeness da rede é $0,09 \%$ e indica a proximidade central dos atores em relação a rede toda. 
Tabela 8 - Análise de centralidade (closeness)

\begin{tabular}{lr}
\hline \multicolumn{1}{c}{ MEDIDA } & \multicolumn{2}{c}{ VALOR } \\
\cline { 2 - 3 } & \multicolumn{2}{c}{ Closeness } \\
\hline Média & 0,065 \\
Desvio Padrão & 0,081 \\
Mínimo & 0 \\
Máximo & 0,274 \\
Índice de centralização closeness da & $0,09 \%$ \\
rede & \\
\hline
\end{tabular}

$\mathrm{Na}$ rede em estudo, destaca-se as unidades de saúde mais centrais em relação a proximidade: o Hospital de Base de Bauru $(0,274)$, o Hospital Estadual Bauru $(0,245)$ e o Pronto Socorro Central de Bauru $(0,226)$.

Embora em posições diferenciadas, os atores que têm destaque em relação à centralidade de proximidade (ver tabela 9) os seis primeiros são basicamente os mesmos na medida de centralidade (Grau de Centralidade - ver Tabela 6).

Os resultados indicam que os três atores mencionados possuem alta centralidade no sentido de serem mais independentes dos outros, pois de acordo com Freeman (1979) a independência de um ponto é determinada pelo Closeness (proximidade) para todos os outros pontos do gráfico. Além disso, essas unidades de saúde estão localizadas a uma menor distância, comparado com a maioria das outras unidades de saúde (no sentido do caminho curto), desse modo, essas irão receber mais informações privilegiadas do que as unidades de saúde que estão localizadas distante da maioria (BORGATTI, 2009).

Tabela 9 - Análise de centralidade (closeness)

\begin{tabular}{llc}
\hline Item & \multicolumn{1}{c}{ Unidades de Saúde } & Closeness \\
\hline 1 & Hospital de Base de Bauru & 0,274107 \\
2 & Hospital Estadual Bauru & 0,245662 \\
3 & Pronto Socorro Central de Bauru & 0,226436 \\
4 & Maternidade Santa Isabel & 0,222565 \\
5 & AME Ambulatório Médico de Especialidades & 0,217909 \\
& Bauru & 0,204236 \\
7 & Upa Mary Dota & 0,202647 \\
8 & Upa Geisel & 0,201082 \\
9 & Hospital e Maternidade Maria José & 0,200309 \\
\hline
\end{tabular}




\begin{tabular}{llc}
\hline 10 & Serviço de Orientação e Prevenção do Câncer & 0,19916 \\
11 & Samu Regional & 0,198401 \\
12 & Promai & 0,198024 \\
13 & Centro de Saúde de Agudos & 0,194693 \\
14 & Unidade de Pronto Atendimento de Lençóis & 0,194329 \\
& Paulista & 0,194329 \\
\hline
\end{tabular}

A Figura 22 traz o grau de proximidade dos atores na rede, o mapa destaca o Nível de Atendimento do SUS, sendo: Atenção Básica (AB), cor Azul; Média Complexidade (MC), cor amarela e Alta Complexidade (AC), cor vermelha. Os três atores (Hospital de Base, Hospital Estadual e Pronto Socorro Central) que representam o maior Closeness estão representados no centro da rede e esses atores são os que atendem os níveis de AC e MC e, os atores que atendem a $\mathrm{AB}$ alguns se encontram no núcleo da rede, porém com menor índice de Closeness, e, os demais estão localizados nos arredores da rede.

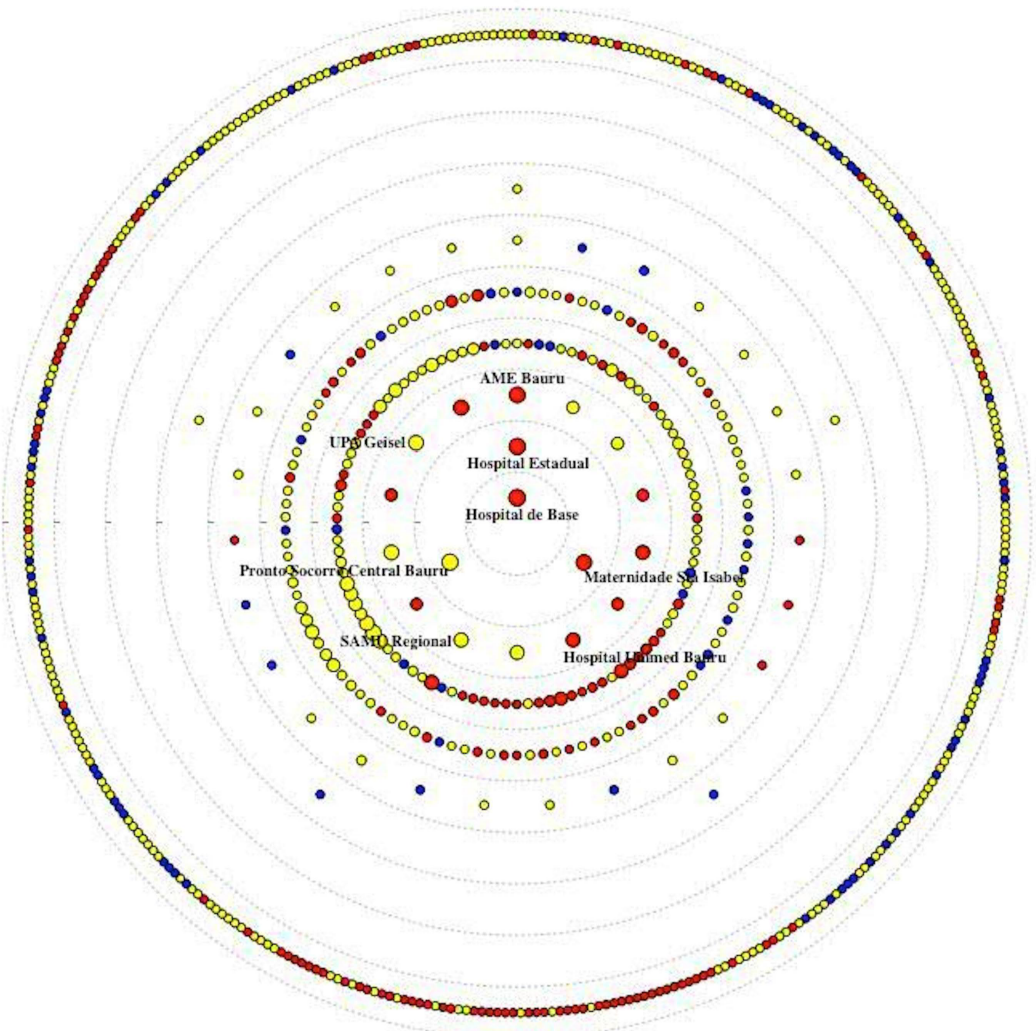

Figura 22 - Análise de Centralidade (Closeness) - Nível de atendimento do SUS Visualização Concentric NetMiner 3 


\subsection{Betweenness -Node}

A Tabela 10 expõe a análise da centralização de intermediação dos atores da rede. A média de todas as relações é 0 e o Desvio Padrão, 0,004 em relação ao grau de intermediação do ator na rede, ou seja, os atores que estão mais dispersos. Assim, o mínimo de centralidade betweenness é 0 e o máximo 0,079. Portanto, o grau de intermediação entre os atores e o índice de centralização betweenness da rede é $0,079 \%$. Esse índice representa a intermediação central dos atores em relação a rede toda.

A Tabela 10 - Análise de centralidade (betweenness - node)

\begin{tabular}{lr}
\hline \multicolumn{1}{c}{ MEDIDAS } & VALOR \\
\hline Média & 0 \\
Desvio Padrão & 0,004 \\
Mínimo & 0 \\
Máximo & 0,079 \\
Índice de centralização Betweenness da rede & $0,079 \%$ \\
\hline
\end{tabular}

Embora nenhum dos atores atingiram o índice 1 de centralidade (alta centralidade na rede), os destaques na análise de dados são: Hospital de Base Bauru $(0,079)$, Hospital Estadual Bauru $(0,032)$ e Pronto Socorro Central $(0,018)$, que aparecem como os três maiores intermediários na rede (Tabela 11).

Baum et al. (2010) consideram Betweenness como uma medida da centralidade e controle de informação, isto implica que essas unidades de saúde mencionadas possuem uma posição mais forte, com maior controle e poder sobre o fluxo de conhecimento na rede. Esses atores representam potencial índice de brokers, controladores de fluxos e, contatos com outras partes da rede (BORGATTI, 2009). Particularmente, esses atores atuam como ponte para a realização de diferentes frentes de colaboração, principalmente no que diz respeito à troca de informações sobre oportunidades de acesso a novas tecnologias e sobre a troca de conhecimento com os casos de pacientes. 
Tabela 11 - Análise de centralidade (betweenness - node)

\begin{tabular}{llc}
\hline Item & \multicolumn{1}{c}{ Unidades de Saúde } & $\begin{array}{c}\text { Betweenness } \\
\text { Node }\end{array}$ \\
\hline 1 & Hospital de Base Bauru & 0,079021 \\
2 & Hospital Estadual Bauru & 0,032435 \\
3 & Pronto Socorro Central de Bauru & 0,018083 \\
4 & Maternidade Santa Isabel & 0,013388 \\
5 & AME Ambulatório Médico de Especialidades Bauru & 0,011628 \\
6 & Upa Mary Dota & 0,008498 \\
7 & Upa Geisel & 0,005442 \\
8 & Núcleo de Saúde Centro de Bauru & 0,004948 \\
9 & Hospital e Maternidade Maria José & 0,004071 \\
10 & Núcleo Saúde III N Habitacional Presidente Geisel & 0,003823 \\
11 & Unidade Básica de Saúde Bela Vista & 0,003422 \\
12 & Hospital de Reabilitação de Anomalias Craniofaciais & 0,00318 \\
& Bauru & 0,002565 \\
13 & Instituto Lauro de Souza Lima Bauru & 0,002557 \\
14 & Promai & 0,002531 \\
\hline
\end{tabular}

A Figura 23 elucida o grau de intermediação entre os atores na rede, o mapa destaca o Nível de Atendimento do SUS, sendo: Atenção Básica (AB), cor Azul; Média Complexidade (MC), cor amarela e Alta Complexidade (AC), cor vermelha. Assim, como na medida Closeness, o três atores que representam maior grau de intermediação são: Hospital de Base, Hospital Estadual e Pronto Socorro Central. Eles estão representados no centro da rede, com destaque para o Hospital de Base, sendo o mais central e, esses atores são os que atendem aos níveis de $\mathrm{AC}$ e $\mathrm{MC}$ e, os atores que atendem a $\mathrm{AB}$ alguns se encontram no núcleo da rede, porém com menor índice de Betweenness e, os demais estão localizados na periferia da rede. 


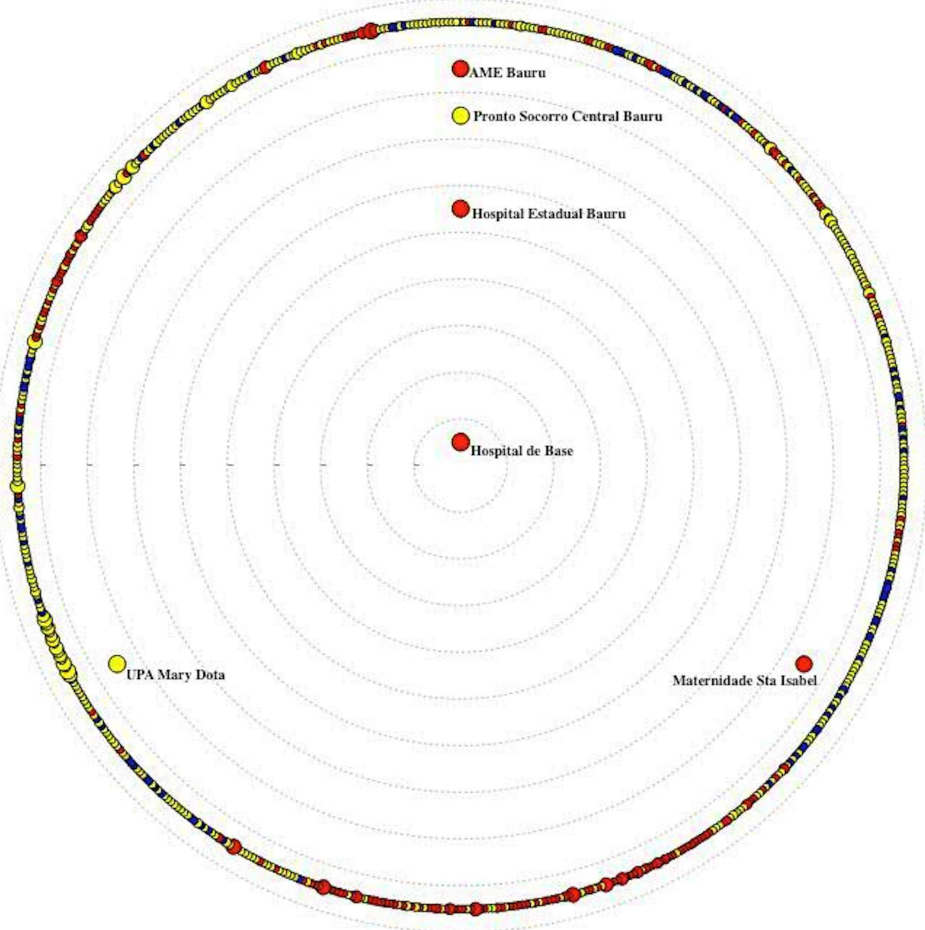

Figura 23 - Análise de centralidade (betweenness node) - Nível de atendimento do SUS Visualização Concentric NetMiner 3

\subsection{Betweenness -Link}

A Tabela 12 os dados referente à análise da centralização de intermediação das ligações dos atores da rede. A média de todas as ligações é 94,59 e o Desvio Padrão, 101.366 em relação ao grau de intermediação das ligações entre os atores na rede, ou seja, as ligações dos atores que estão mais dispersas. Assim, o mínimo é 1 e o máximo das ligações é 959,134.

Tabela 12 - Análise de centralidade (betweenness - link)

\begin{tabular}{|c|c|}
\hline MEDIDAS & VALOR \\
\hline Média & 94,587 \\
\hline Desvio Padrão & 101,366 \\
\hline Mínimo & 1 \\
\hline Máximo & 959,134 \\
\hline
\end{tabular}




\subsection{Análise de Centralidade Gráfico Box Plot}

Adicionalmente as medidas de centralidade, adotou-se a análise Box Plot, que são usadas para o melhor entendimento do nível de centralidade por tipo de estabelecimento e por esfera de gestão das unidades de saúde mapeadas, essa classificação é de acordo com o DATASUS/CNES.

Portanto, o relatório principal apresenta a distribuição da variável dependente, para cada valor da variável independente: Média, desvio padrão, valor mínimo, primeiro quartil, mediana, terceiro quartil e valor máximo são relatados.

\subsection{Tipo de Estabelecimento}

A Tabela 13 e a Figura 24 apresentam a análise de centralidade por tipo de estabelecimento, ou seja, por classificação das unidades de saúde. As unidades de saúde fora do município de Bauru foram classificadas como unidades externas.

Assim, os quatros tipos de estabelecimentos com maior grau de centralidade, seguido dos dados estatísticos são:

- Pronto Socorro Geral (Cor: rosa escuro; Centralidade: 0,116). Todos os índices estatísticos são 0,116 , exceto o desvio padrão que é 0 ;

- Hospitais Gerais (Cor: vermelho; Centralidade: 0,076), A concentração dos dados de distribuição é 0,076 (média); o nível de dispersão (Desvio Padrão) é 0,217, o mínimo é 0,014 e o máximo 0,165, os Quartis (Q1) 0,024 e (Q3) 0,099 e a mediana 0,034;

- Hospital Especializado (Cor: cinza; Centralidade: 0,056). A média 0,056, Desvio Padrão 0,057, o mínimo 0,031 e o máximo 0,102, os Quartis (Q1) 0,033 e (Q3) 0,069 e a mediana 0,035 ;

- Pronto Atendimento (Cor: pistache; Centralidade: 0,037). A média é 0,037, o Desvio Padrão é 0,034, o mínimo 0,02 e o máximo 0,057, os Quartis (Q1) 0,02 e (Q3) 0,054 e a mediana 0,035 .

O Pronto Socorro Geral (Figura 24) aparece como o mais central e somente com um círculo preto, ele não aparece a cor de representação, motivo pelo qual, ser uma única unidade de saúde. Essa unidade de saúde o atendimento é demanda espontânea e referenciada, atuam 
78 médicos, o nível de atendimento é MC e a esfera de gestão é Municipal.

Tabela 13 - Centralidade por tipo de estabelecimento - Dados Box Plot

\begin{tabular}{llllllll}
\hline Tipo de Estabelecimento & Média & $\begin{array}{l}\text { Desvio } \\
\text { Padrão }\end{array}$ & Mínimo & Q1 & Mediana & Q3 & Máximo \\
\hline Central de Regulação das & 0,023 & 0 & 0,023 & 0,023 & 0,023 & 0,023 & 0,023 \\
Urgências & & & & & & & \\
Central de Regulação do Acesso & 0,003 & 0,003 & 0 & 0 & 0,003 & 0,006 & 0,006 \\
Centro de Atenção Psicossocial & 0,006 & 0,007 & 0,002 & 0,003 & 0,005 & 0,008 & 0,011 \\
Centro de Especialidade & 0,009 & 0,109 & 0 & 0 & 0,002 & 0,006 & 0,011 \\
Centro de Unidade Básica & 0,021 & 0,063 & 0,002 & 0,009 & 0,021 & 0,029 & 0,057 \\
Consultório Isolado & 0,002 & 0,021 & 0 & 0 & 0 & 0,003 & 0,008 \\
Hospital Dia Isolado & 0,016 & 0,01 & 0,009 & 0,009 & 0,016 & 0,023 & 0,023 \\
Hospital Especializado & 0,056 & 0,057 & 0,031 & 0,033 & 0,035 & 0,069 & 0,102 \\
Hospital Geral & 0,076 & 0,217 & 0,014 & 0,024 & 0,034 & 0,099 & 0,165 \\
Policlínica & 0,005 & 0,011 & 0 & 0,002 & 0,005 & 0,006 & 0,012 \\
Postos de Saúde & 0,008 & 0,002 & 0,006 & 0,006 & 0,008 & 0,009 & 0,009 \\
Pronto Atendimento & 0,037 & 0,034 & 0,02 & 0,02 & 0,035 & 0,054 & 0,057 \\
Pronto Socorro Geral & 0,116 & 0 & 0,116 & 0,116 & 0,116 & 0,116 & 0,116 \\
Secretaria de Saúde & 0,027 & 0,003 & 0,024 & 0,024 & 0,027 & 0,029 & 0,029 \\
Unidade Móvel Pré Hospitalar - & 0,007 & 0,027 & 0 & 0 & 0,001 & 0,008 & 0,008 \\
Urgência & & & & & & & \\
Unidade de Apoio Diagnose e & 0,002 & 0,003 & 0 & 0 & 0 & 0,002 & 0,005 \\
Terapia & & & & & & 0 & \\
Unidades Externas & 0,001 & 0,066 & 0 & 0 & 0 & 0,002 & 0,003 \\
\hline
\end{tabular}




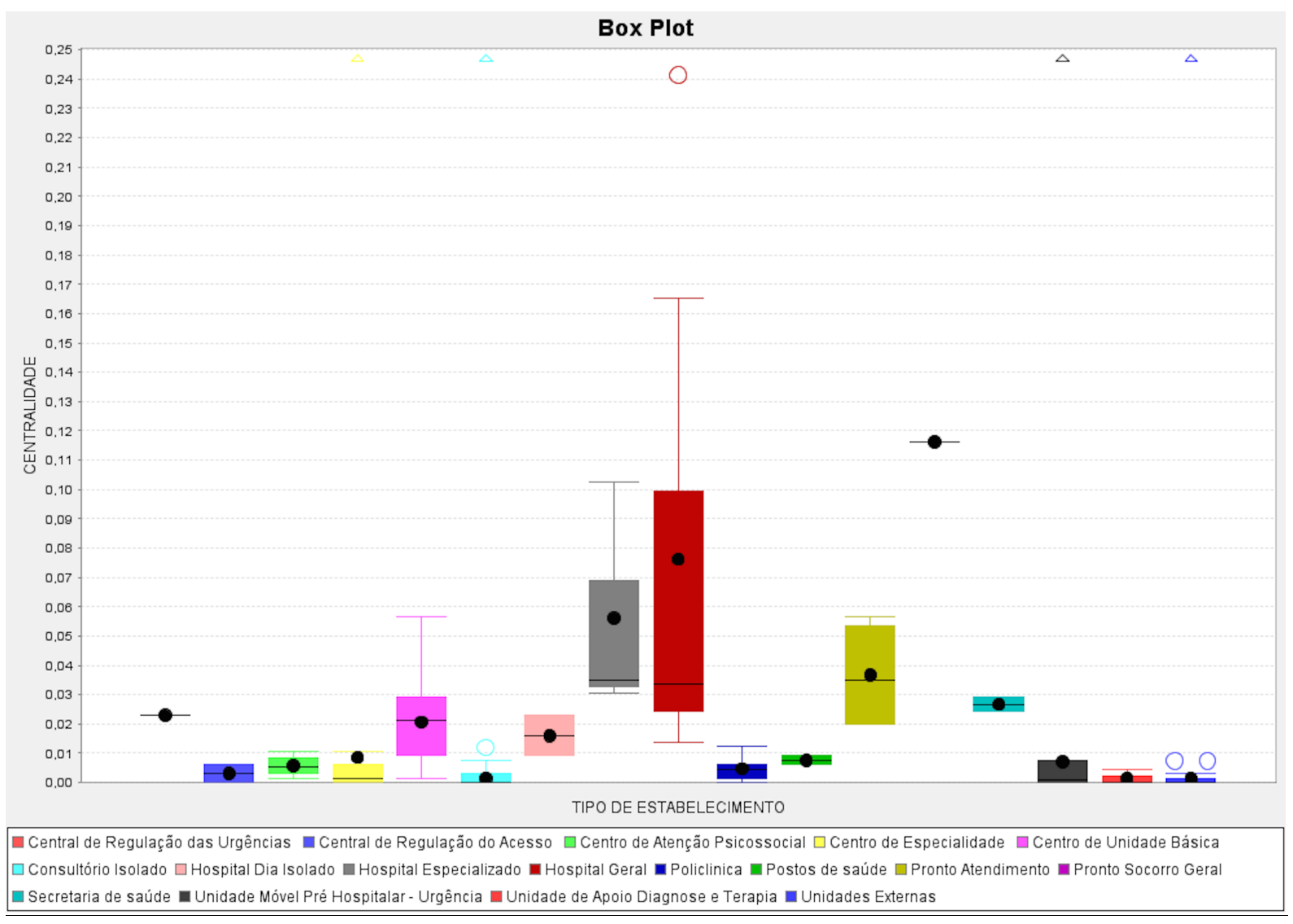

Figura 24 - Análise do grau de centralidade por tipo de estabelecimento Visualização Box Plot - NetMiner3

\subsection{Esferas de Gestão}

A Tabela 14 e a Figura 25 traz a análise de centralidade por Esferas de Gestão. Geralmente, as esferas de gestão são compostas pelos seguintes tipos de estabelecimentos: Esfera Federal: Hospital; Esfera Estadual: Hospital Geral, Hospital Especializado e AME; Esfera Municipal: Núcleo de Saúde, UPA, Pronto Socorro, etc. e Esfera Privada: Hospital, Centro de Especialidade e Consultórios Isolados.

Desse modo, a Esfera Estadual apresenta o nível de centralidade e uma média de 0,011, superior as demais esferas, isso significa que os hospitais e AME são atores mais centrais. Em seguida aparece a Esfera Municipal com o nível de centralidade de 0,006, a Esfera Privada com 0,002 de centralidade e a Esfera Federal 0, pois das unidades de saúde mapeadas no município de Bauru, não consta nenhuma sob a gestão Federal. 
Tabela 14 - Centralidade por esferas de gestão - Dados Box Plot

\begin{tabular}{lrrrrrrr}
\hline & Média & $\begin{array}{c}\text { Desvio } \\
\text { Padrão }\end{array}$ & Mínimo & Q1 & Mediana & Q3 & Máxima \\
\hline ESTADUAL & 0,011 & 0,296 & 0 & 0 & 0 & 0,006 & 0,012 \\
FEDERAL & 0 & 0 & 0 & 0 & 0 & 0 & 0 \\
MUNICIPAL & 0,006 & 0,168 & 0 & 0 & 0 & 0,006 & 0,011 \\
PRIVADA & 0,002 & 0,128 & 0 & 0 & 0 & 0,002 & 0,003 \\
\hline
\end{tabular}

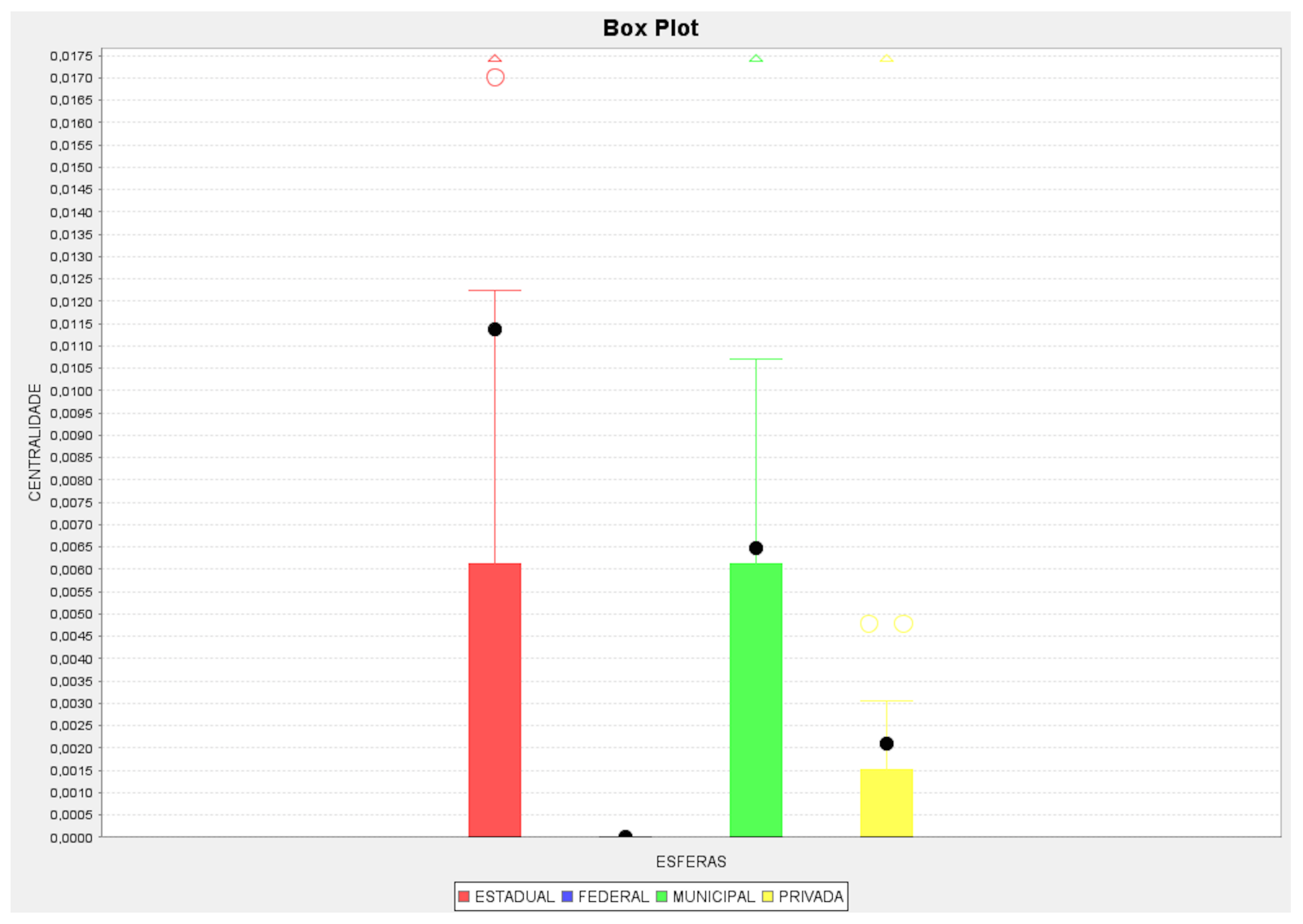

Figura 25 - Análise do grau de centralidade por esferas de gestão Visualização Box Plot - NetMiner3 


\subsubsection{Análise - Neighbor, Density e Inclusiveness}

A Tabela 15 apresenta a análise de centralidade (Neighbor-degree) o Grau nodal (de conexão), ou seja, o número de linhas e o tamanho da vizinhança. Os resultados dessa tabela mostram que a soma da relações 1802, a média é 2,751 e o Desvio Padrão, 9,839. O mínimo do grau de centralidade é 0 e o máximo é 156. O número de nós isolados é 391 (unidades de saúde), 68 nós pendentes e 40,305\% inclusiveness (o número de unidades de saúde conectadas expressas como uma proporção do número total de nós). A densidade da rede é 0,004 (baixa), ou seja, o número de linhas presentes para o máximo possível.

Tabela 15 - Análise de centralidade (neighbor-degree)

\begin{tabular}{lr}
\hline \multicolumn{1}{c}{ MEDIDAS } & \multicolumn{2}{c}{ VALOR } \\
\cline { 2 - 3 } & \multicolumn{2}{c}{ Neighbor Degree } \\
\hline Soma & 1802 \\
Média & 2,751 \\
Desvio Padrão & 9,839 \\
Mínimo & 0 \\
Máximo & 156 \\
\# de isolado & 391 \\
\# de pendente & 68 \\
inclusiveness $(\%)$ & $40,305 \%$ \\
Densidade da Rede & 0,004 \\
\hline
\end{tabular}

Os tipos de nós da rede (Tabela 16) foram quantificados como: 391 nós isolados (unidades de saúde que não possuem ligações), 0 nós transmissores e recebedores (fato pela rede ser não direcionada), 68 carregador (carrega os vínculos) e 196 nós ordinário (que não se enquadram nas demais categorias). Como essa rede é não direcionada, a análise Neighbor degree está relacionada com o quarto tipo de nó, "carregador" requerem que ambos grau de entrada e grau de saída são iguais a 1. 
Tabela 16 - Número do tipo de nó (Neighbor - degree)

\begin{tabular}{crrrr}
\hline Isolado & Transmissor & Recebedor & Carregador & Ordinário \\
\hline $\mathbf{3 9 1}$ & 0 & 0 & 68 & 196 \\
\hline
\end{tabular}

\subsubsection{Egonet}

A Tabela 17 expõe a distribuição das medidas da rede ego, sendo os seguintes valores: o tamanho da rede ego de cada nó tem em média 2,751 conexões e a densidade indefinida; no tamanho da rede ego o desvio padrão é 9,839 e a densidade indefinida (da rede toda). Já o valor mínimo tanto no tamanho quanto na densidade é 0 , e, o valor máximo no tamanho de conexões é 156 e na densidade é 1.

Tabela 17 - Análise da Rede ego (Egonet)

\begin{tabular}{lrr}
\hline \multirow{2}{*}{ Medidas } & \multicolumn{2}{c}{ Valor } \\
\cline { 2 - 3 } & \multicolumn{1}{c}{ Tamanho } & \multicolumn{1}{c}{ Densidade } \\
\hline Média & 2,751 & Indefinido \\
Desvio Padrão & 9,839 & Indefinido \\
Mínimo & 0 & 0 \\
Máximo & 156 & 1 \\
\hline
\end{tabular}

As 15 unidades de saúde com maior número de nós alter (nós que são adjacentes do nó focal) pode ser visto na Tabela 18. Segundo Borgatti (2009) essas redes são chamadas de rede ego e consistem em um ator focal (não está incluído no tamanho da rede ego), conhecido como ego.

As três unidades de saúde que representam o maior número de ligações do nó focal são: Hospital de Base, Hospital Estadual Bauru e Pronto Socorro Central.

Essas unidades de saúde acima mencionadas assumem o papel de ator focal na rede ego e os seus vínculos são conhecidos como alter, isso permite que minimizar as informações redundantes por meio dos alters e os egos (ator focal) se tornam mais bem informados e podem monopolizar o fluxo de recursos entre alters egos (REAGANS e ZUCKERMAN, 
2008). De modo geral, observa-se, que a rede de médicos com vínculos profissionais em unidades de saúde públicas e privadas é composta por redes ego.

Tabela 18- Análise da rede ego (Egonet) - tamanho

\begin{tabular}{llc}
\hline Item & \multicolumn{1}{c}{ Unidades de Saúde } & Tamanho \\
\hline 1 & Hospital de Base de Bauru & 156 \\
2 & Hospital Estadual Bauru & 108 \\
3 & Pronto Socorro Central de Bauru & 76 \\
4 & Ame Ambulatório Medico de Especialidades Bauru & 70 \\
5 & Maternidade Santa Isabel & 67 \\
6 & Núcleo de Saúde Centro de Bauru & 37 \\
7 & Upa Mary Dota & 37 \\
8 & Upa Geisel & 33 \\
9 & Serviço de Orientação e Prevenção do Câncer & 28 \\
10 & Núcleo de Saúde III Vila Cardia & 23 \\
11 & Instituto Lauro de Souza Lima Bauru & 23 \\
12 & Hospital e Maternidade Maria José & 22 \\
13 & Hospital Unimed de Bauru & 22 \\
14 & Núcleo de Saúde Beija Flor & 22 \\
15 & Núcleo Saúde III N Habitacional Presidente Geisel & 22 \\
\hline
\end{tabular}

A densidade da rede ego está entre 0 (não densa) e 1 (densa). Das 655 unidades de saúde, 101 unidades são densas com valor 1 . A Tabela 19 apresenta 15 unidades de saúde com maior densidade (em ordem alfabética). Como a análise de rede ego considera a estrutura da conexão local de cada nó em uma rede, então as unidades de saúde que são mais densas não são necessariamente com mais conexões na rede ego. Um exemplo é o Hospital de Base (Tabela 17) o tamanho é 156 e a densidade é 0,028 .

Tabela 19 - Análise da rede ego (Egonet) - densidade

\begin{tabular}{llc}
\hline \multicolumn{1}{c}{ Item } & \multicolumn{1}{c}{ Unidades de Saúde } & Densidade \\
\hline 1 & Ambulatório de Especialidades Dr Antonio Tedesco & 1 \\
2 & $\begin{array}{l}\text { Ambulatório Medico de Especialidade Ame de } \\
\text { Itapetininga }\end{array}$ & 1 \\
3 & Ame Ambulatório Med de Especialidades Dracena & 1 \\
4 & Ame Ambulatório Médico de Especialidades de Assis & 1 \\
5 & Ame Dr Joao Luiz Trevelim Promissão & 1 \\
6 & Anatomed Instituto de Anatomia Patológica de Bauru & 1 \\
7 & Anderson Monteiro & 1 \\
8 & Angiocor Hemodinâmica e Cirurgia Endovascular S S & 1 \\
\hline
\end{tabular}




\begin{tabular}{lll}
\hline 9 & Antonio Barbosa Nobre Junior & 1 \\
10 & Antonio Carlos Sant Ana & 1 \\
11 & Apae de Agudos & 1 \\
12 & Caedcentro de Assistência Especializada e de & 1 \\
& Diagnostico & 1 \\
13 & CDM Medicina Nuclear & 1 \\
14 & CDM Petct & 1 \\
\hline
\end{tabular}

\subsubsection{Structural Hole}

A distribuição de medidas de Buraco Estrutural da Tabela 20, refere-se a rede toda, sendo:

- Redundância: (a quantidade de informações que o nó i pode receber de outros nós) a média é 0,001 (relativamente baixa), o Desvio Padrão 0,019 e o mínimo 0 e o máximo 0,889 de redundância na rede. Assim, a redundância de informações entre as unidades de saúde na rede é baixa;

- Limitação: (a forma que você tem espaço para negociar ou explorar potenciais buracos estruturais em sua rede) a media é 0, o Desvio Padrão 0,015 e o mínimo 0 e o máximo 1 de limitação na rede. Embora alguns atores apresentem o índice 1, considerando a rede toda, o índice de limitação é baixo;

- Eficiência: (1 menos redundância somado para todos os alters) a média é 0,314 , o Desvio Padrão é 0,397 e o mínimo 0 e o máximo 1, embora a medida de eficiência da rede ainda esteja abaixo da média, mas em comparação com os demais indicadores de buraco estrutural, o resultado foi relativamente eficiente;

- Tamanho Eficaz: (é o número de pessoas que estão conectadas a ego, menos a redundância na rede) a média é 2,099, o Desvio Padrão é 7,982 e o mínimo 0 e o máximo 130,683, o tamanho eficaz é baixo;

- Hierarquia: (a medida em que a limitação do ego é concentrada em um alter único) a média é 0,156, o Desvio Padrão é 0,316 e o mínimo 0 e o máximo 1, assim a rede o nível de hierarquia é baixo na rede. 
Tabela 20 - Distribuição de medidas de buraco estrutural

\begin{tabular}{lrrrrr}
\hline \multirow{2}{*}{ Medidas } & \multicolumn{5}{c}{ Valor } \\
& \multicolumn{1}{c}{ Redundância } & Limitação & Eficiência & Tamanho Eficaz & Hierarquia \\
\cline { 2 - 6 } & 0,001 & 0 & 0,314 & 2,099 & 0,156 \\
Média & 0,019 & 0,015 & 0,397 & 7,982 & 0,316 \\
Desvio Padrão & 0 & 0 & 0 & 0 & 0 \\
Mínimo & 0,889 & 1 & 1 & 130,683 & 1 \\
Máximo & & & & & \\
\hline
\end{tabular}

A Tabela 21 traz os resultados da distribuição de medidas de Buraco Estrutural de Limitação Agregada e de Eficiência das 15 unidades de saúde (em ordem alfabética) com maior índice.

A análise é de cada nó da rede e contempla 655 unidades de saúde (nós), 69 unidades (na medida de Limitação Agregada) e 72 unidades (na medida de Eficiência) apresentaram índice 1 e os demais índices são menores.

Entretanto, na Limitação Agregada significa que as unidades de saúde com maior índice (exemplo: Agnaldo Miranda, Alberto Segalla Junior, Ambulatório de Saúde Mental de Bauru, entre outras) estão melhores posicionadas para acessar informações ou explorar potencias buracos estruturais em sua rede e, na Eficiência as unidades de saúde com maior índice (as mesmas citadas) implica que essas unidades maximizaram o número de contatos não redundantes (demonstram o tamanho efetivo da rede) e diminuíram o número de contatos redundantes na rede, dessa forma, permite o acesso a novas informações.

Os resultados indicam, presença de buraco estrutural, pois Burt (1992) afirma que os contatos não-redundantes sucedem dos "buracos estruturais" entre dois grupos em uma rede e indicam que circulam em diferentes fluxos de informação. Esses atores intermediários também são conhecidos como brokers (SACOMANO NETTO, 2004). Portanto, o principal benefício de buracos estruturais (as unidades de saúde que apresentaram índice 1) é a disponibilidade de informação não redundante (BURT, 2005). 
Tabela 21 - Buraco estrutural - Medidas de limitação agregada e eficiência

\begin{tabular}{|c|c|c|c|}
\hline Item & Unidades de Saúde & $\begin{array}{l}\text { Limitação } \\
\text { Agregada }\end{array}$ & Eficiência \\
\hline 1 & Agnaldo Miranda & 1 & 1 \\
\hline 2 & Alberto Segalla Junior & 1 & 1 \\
\hline 3 & $\begin{array}{l}\text { Ambulatório Municipal de Saúde Mental de } \\
\text { Bauru }\end{array}$ & 1 & 1 \\
\hline 4 & Ame Itapeva Edison Oliveira Martho & 1 & 1 \\
\hline 5 & Base Central e Regulação Usa III & 1 & 1 \\
\hline 6 & Caps Ad III Infanto Juvenil & 1 & 1 \\
\hline 7 & Centro de Detenção Provisória de Bauru & 1 & 1 \\
\hline 8 & $\begin{array}{l}\text { Centro de Especialidades Municipal Cesar } \\
\text { Torrezan R Bonito }\end{array}$ & 1 & 1 \\
\hline 9 & Centro de Excelência em Retina & 1 & 1 \\
\hline 10 & $\begin{array}{l}\text { Centro de Excelência Oftalmológica S C Ltda } \\
\text { Bauru }\end{array}$ & 1 & 1 \\
\hline 11 & $\begin{array}{l}\text { Centro de Referência Em Saúde do } \\
\text { Trabalhador }\end{array}$ & 1 & 1 \\
\hline 12 & Centro de Saúde Echapora & 1 & 1 \\
\hline 13 & Centro Médico São Gabriel & 1 & 1 \\
\hline 14 & $\begin{array}{l}\text { Centro Municipal Diagnose Boa Esperança do } \\
\text { Sul }\end{array}$ & 1 & 1 \\
\hline 15 & Cetro Clínica Esp Traum Reab e Ort Diadema & 1 & 1 \\
\hline
\end{tabular}

As medidas de Buraco Estrutural de Tamanho Eficaz e Hierarquia (Tabela 22) são apresentadas das 15 unidades de saúde com maior índice do total de 655 unidades de saúde.

Assim, as três unidades de saúde com maior índice de Tamanho Eficaz, são: Hospital de Base de Bauru $(130,682)$, Hospital Estadual Bauru $(90,667)$ e Pronto Socorro Central $(63,4605)$, desse modo, esses índices apresentam somente o número de unidades de saúde que estão conectadas a ego. Portanto, essas três unidades de saúde mencionadas são mais eficientes em termos de relacionamentos (CYRAM, 2008).

$\mathrm{Na}$ medida de hierarquia, 69 unidades de saúde apresentam o índice 1, as três unidades de saúde com maior índice (estão em ordem alfabética) são: Agnaldo Miranda, Alberto Segalla e Ambulatório Municipal de Saúde Mental de Bauru com índices 1, contudo, essas unidades demonstram ligação somente com um alter. $\mathrm{O}$ acesso aos buracos estruturais, exerce uma variedade de influências positivas sobre a criatividade individual, incluindo maior eficiência, melhor acesso aos recursos (incluindo informação ou conhecimento), e melhor identificação e respostas a ameaças e oportunidades emergentes (LIU, 2011). 
Tabela 22 - Buraco estrutural - Medidas de tamanho eficaz e hierarquia

\begin{tabular}{|c|c|c|c|c|}
\hline Item & Unidades de Saúde & $\begin{array}{l}\text { Tamanho } \\
\text { Eficaz }\end{array}$ & Unidades de Saúde & $\begin{array}{l}\text { Hierar- } \\
\text { quia }\end{array}$ \\
\hline 1 & Hospital de Base de Bauru & 130,682 & Agnaldo Miranda & 1 \\
\hline 2 & Hospital Estadual Bauru & 90,6674 & Alberto Segalla Junior & 1 \\
\hline 3 & $\begin{array}{l}\text { Pronto Socorro Central de } \\
\text { Bauru }\end{array}$ & 63,4605 & $\begin{array}{l}\text { Ambulatório Municipal de } \\
\text { Saúde Mental de Bauru }\end{array}$ & 1 \\
\hline 4 & Maternidade Santa Isabel & 55,5183 & $\begin{array}{l}\text { Ame Itapeva Edison Oliveira } \\
\text { Martho }\end{array}$ & 1 \\
\hline 5 & $\begin{array}{l}\text { Ame Ambulatório Médico de } \\
\text { Especialidades Bauru }\end{array}$ & 43,0511 & $\begin{array}{l}\text { Base Central E Regulação Usa } \\
\text { III }\end{array}$ & 1 \\
\hline 6 & Upa Mary Dota & 31,0506 & Caps Ad III Infanto Juvenil & 1 \\
\hline 7 & $\begin{array}{l}\text { Núcleo de Saúde Centro de } \\
\text { Bauru }\end{array}$ & 30,6876 & $\begin{array}{l}\text { Centro de Detenção Provisória } \\
\text { de Bauru }\end{array}$ & 1 \\
\hline 8 & Upa Geisel & 27,7817 & $\begin{array}{l}\text { Centro de Especialidades } \\
\text { Municipal Cesar Torrezan R } \\
\text { Bonito }\end{array}$ & 1 \\
\hline 9 & $\begin{array}{l}\text { Núcleo Saúde III N } \\
\text { Habitacional Presidente Geisel }\end{array}$ & 19,6588 & Centro de Excelência em Retina & 1 \\
\hline 10 & $\begin{array}{l}\text { Núcleo de Saúde III Vila } \\
\text { Cardia }\end{array}$ & 19,2034 & $\begin{array}{l}\text { Centro de Excelência } \\
\text { Oftalmológica S C Ltda Bauru }\end{array}$ & 1 \\
\hline 11 & $\begin{array}{l}\text { Serviço de Orientação e } \\
\text { Prevenção do Câncer }\end{array}$ & 18,9928 & $\begin{array}{l}\text { Centro de Referência em Saúde } \\
\text { do Trabalhador }\end{array}$ & 1 \\
\hline 12 & Núcleo de Saúde Beija Flor & 18,3361 & Centro de Saúde Echapora & 1 \\
\hline 13 & SAMU Regional & 17,3407 & Centro Médico São Gabriel & 1 \\
\hline 14 & $\begin{array}{l}\text { Instituto Lauro de Souza Lima } \\
\text { Bauru }\end{array}$ & 16,6287 & $\begin{array}{l}\text { Centro Municipal Diagnose Boa } \\
\text { Esperança do Sul }\end{array}$ & 1 \\
\hline 15 & $\begin{array}{l}\text { SES Se Departamento } \\
\text { Regional de Saúde 06 Bauru }\end{array}$ & 16,0134 & $\begin{array}{l}\text { Cetro Clínica Esp Traum Reab e } \\
\text { Ort Diadema }\end{array}$ & 1 \\
\hline
\end{tabular}

\subsubsection{Análise geral da rede e síntese dos resultados}

A visualização geral da rede de médicos com vínculos profissionais em unidades de saúde públicas e privadas (a partir do Município de Bauru) é representada pelos mapas das Figuras 26, 27 e 28, esse mapeamento envolveu 655 unidades de saúde. Esses mapas foram plotados de acordo com Visualização Spring 2D e o Layout Eades do NetMiner3.

A Figura 26 ilustra o Mapa geral da rede por Esferas de Gestão, as diferentes cores representam as esferas de gestão das unidades de saúde, sendo: (1) Cor vermelha: Esfera estadual, (2) Cor rosa: Esfera Federal, (3) Cor azul claro: Esfera Municipal e (4) Cor azul escuro: Esfera Privada. Já as formas representam os tipos de estabelecimentos das unidades de saúde, conforme classificação do CNES e, variam de tamanho conforme a centralidade do ator na rede, sendo o ator mais central, maior é a forma de representação. 
As 655 unidades de saúde do mapa (Gráfico 1 e Figura 26) correspondem aos seguintes tipos de gestão:

Na esfera de gestão Estadual, correspondem 69 unidades de saúde (10,5\% da rede), entre elas cerca de 34 são Hospitais e 21 unidades de saúde são AMEs, as demais, são institutos e centros de especialidade. Esses atores estão localizados com maior grau de centralidade na rede, como exemplo: Hospital de Base, AME de Bauru, Hospital Estadual de Bauru e Hospital Manoel de Abreu.

Na Esfera Federal, somente 3 unidades de saúde (0,46\% da rede) correspondem a esse tipo de gestão, sendo: FAI UFSCAR São Carlos, Hospital das Clínicas e Hospital Universitário da Universidade Federal de São Carlos.

Já na Esfera Municipal, correspondem 171 unidades de saúde (26\% do total da rede), nessa esfera de gestão estão: as UPAs, Pronto Socorro, Samu e alguns hospitais municipais e, esses atores estão localizados com maior grau de centralidade na rede (Pronto Socorro Central de Bauru, UPA Geisel, SAMU) além disso, as unidades básicas de saúde e núcleo de saúde também fazem parte dessa esfera de gestão e, algumas são atores mais centrais (Núcleo de saúde Mary Dota) e as demais são atores periféricos.

E por fim, as unidades de saúde sob a gestão da Esfera Privada correspondem 412 unidades (63\% da rede), cerca de 61 unidades no município de Bauru são hospitais e também algumas estão com alto grau de centralidade, como exemplo: Hospital Unimed Bauru e Hospital e Maternidade Maria José.

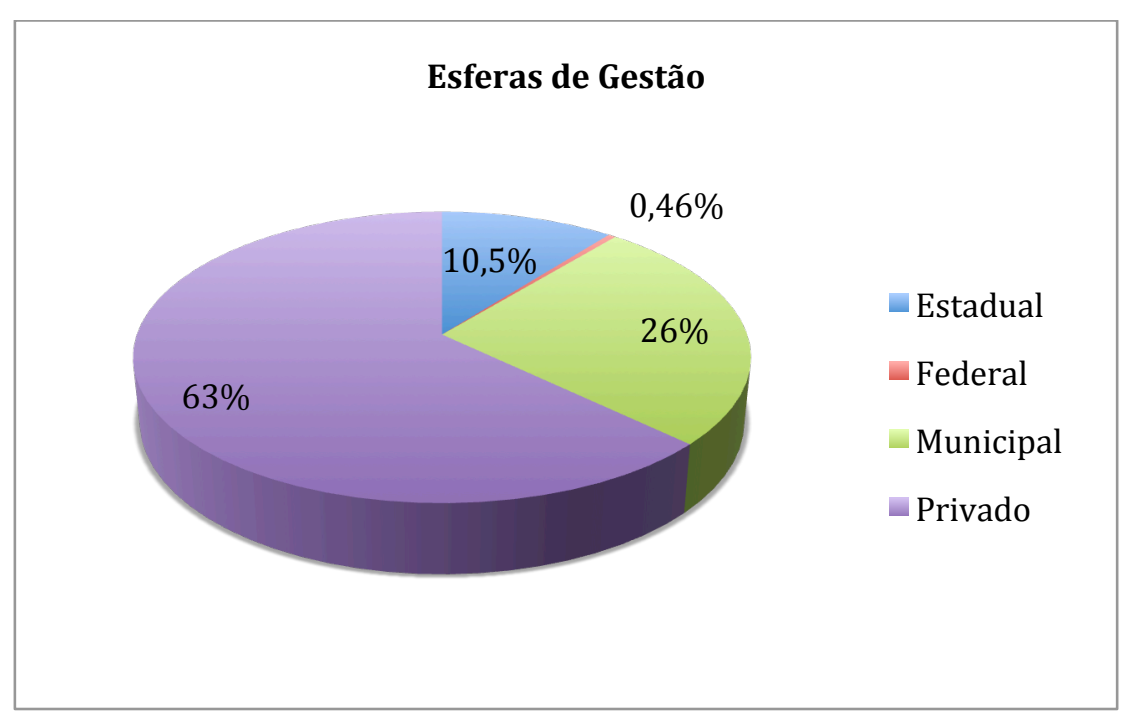

Gráfico 1 - Unidades de saúde distribuídas por Esferas de Gestão 
Não obstante disso, foram utilizadas as ferramentas do Excel de estatísticas básicas descritivas (média e desvio padrão) da carga horária semanal de trabalho dos médicos, por esferas de gestão. Como os dados representam toda a população, utilizou a medida de desvio padrão STDEVP do Excel.

Assim, a média da carga horária semanal e o desvio padrão são:

- Esfera Estadual: a média é 12,91 horas/semanais e o desvio padrão é 12,33;

- Esfera Federal: a média é 26 horas/semanais e o desvio padrão é 13,34;

- Esfera Municipal: a média é 12,40 horas/semanais e o desvio padrão é 9,13;

- Esfera Privada: a média é 9,33 horas/semanais e o desvio padrão é 9,49.

Os resultados demonstram que a carga horária semanal média, por esferas de gestão, é baixa em comparação com a carga média dos médicos da rede (42 horas semanais) e o desvio padrão é alto em comparação com a carga horário semanal média. A medida em que a esfera de gestão é mais alta na hierarquia pública, maior é a carga horária, sendo a esfera privada a de menor carga horária média. Geralmente, nas esferas federais e estaduais concentram se hospitais. 


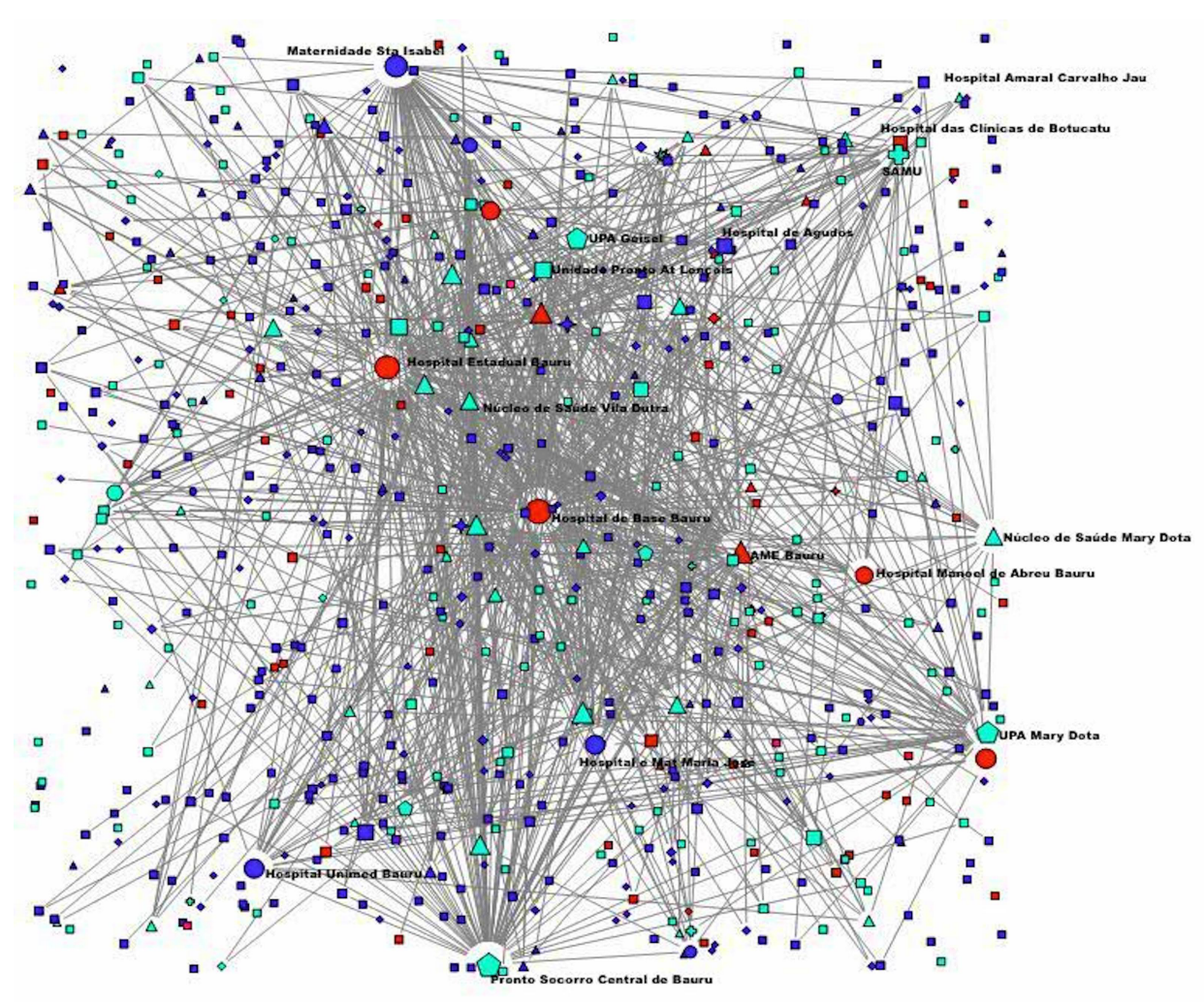

Figura 26 - Mapa geral da rede por esferas de gestão Visualização Spring 2D NetMiner 3

\begin{tabular}{|ll|l|} 
& Central de Regulação das Urgências \\
Central de Regulação do Acesso \\
Centro de Atenção Psicossocial
\end{tabular}

Legenda 1 - Esferas de Gestão e Tipos de Estabelecimentos representados na Figura 26

A Figura 27 demonstra o Mapa geral da rede por Atendimento SUS versus Privado e também os municípios. A forma de círculo são os atores SUS e a forma de triângulo são os atores privados. Já as cores, o Município de Bauru é representado pela cor vermelho fosco e os demais municípios diversas cores. Assim, as unidades com maior grau de centralidade estão representadas com formas maiores, tais como: o Hospital Unimed, Hospital e Maternidade Maria José (ambas unidades de saúde privadas, representadas em forma de triângulo) o Hospital de Base de Bauru e o Hospital Estadual de Bauru (ambas atendem o SUS, apresentados em forma de círculo).

O Município de Bauru aparece em destaque com atores com maior grau de centralidade na rede (cor vermelho fosco), isso explica, o fato da rede ter sido mapeada a partir do município de Bauru. 


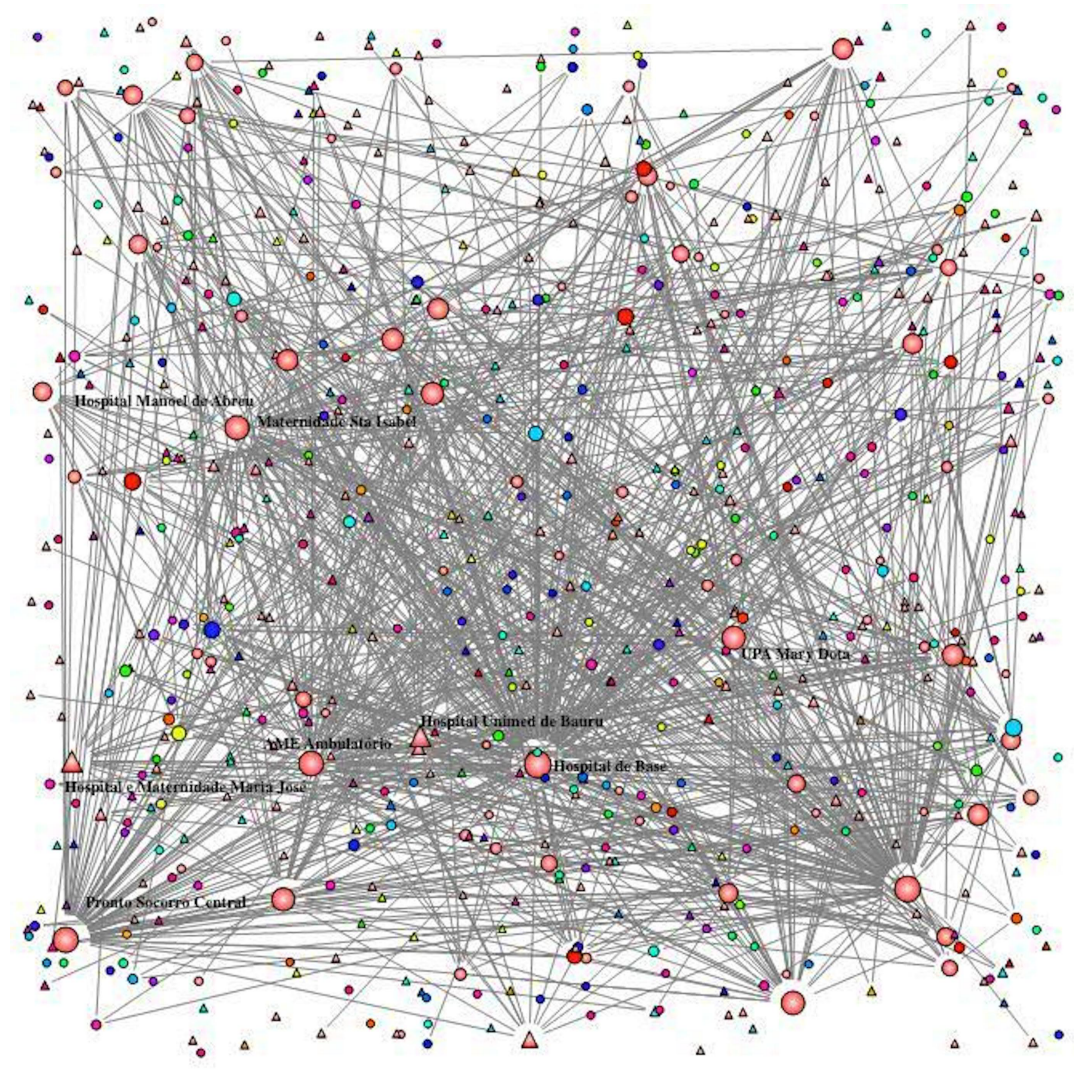

Figura 27 - Mapa geral da rede - Atendimento SUS versus Atendimento Privado Visualização Spring 2D NetMiner 3

Embora as unidades de saúde que apresentam a esfera de gestão privada, algumas dessas prestam algum tipo de atendimento no SUS. Então, das 655 unidades de saúde mapeadas, 318 unidades não prestam atendimento ao SUS (48,5\% da rede), ou seja, o atendimento é exclusivamente privado, 225 unidades de saúde prestam atendimento somente ao SUS $(35,35 \%)$ e, 112 unidades de saúde prestam algum tipo de atendimento no SUS e também no setor privado $(17,15 \%)$, conforme demonstra o Gráfico 2. 


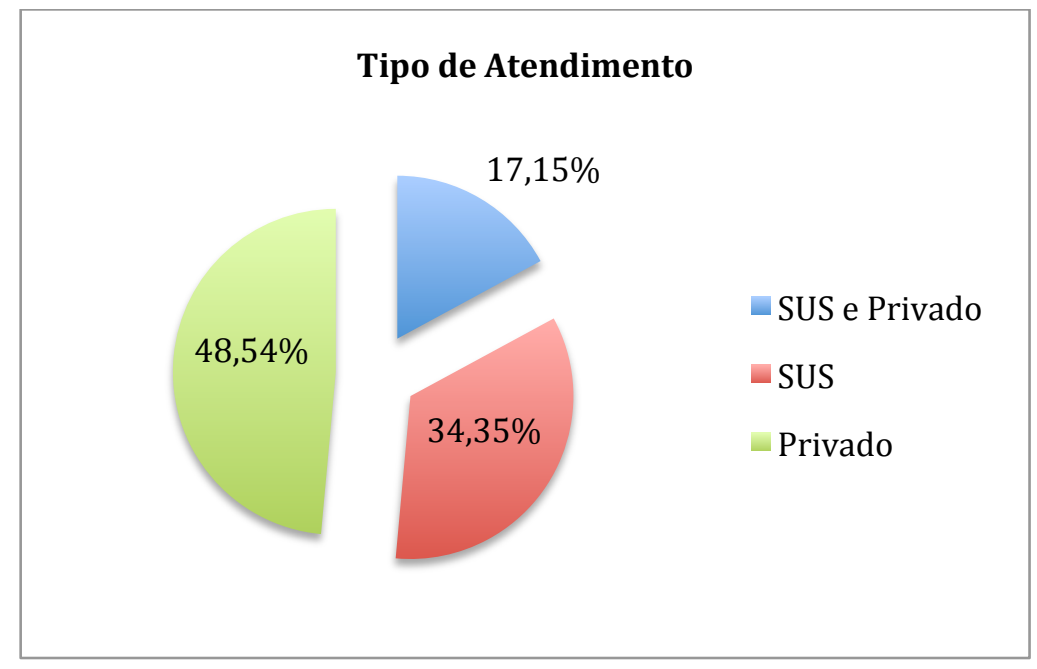

Gráfico 2 - Tipo de Atendimento

Uma visualização geral da rede é ilustrada por Nível de Atendimento do SUS, assim: (1) Atenção Básica (AB), (2) cor Azul; Média Complexidade (MC), cor amarela e (3) Alta Complexidade (AC), cor vermelha (ver Figura 28). O tamanho das formas refere-se as unidades de saúde centrais, quanto maior a forma, maior é o grau de centralidade do ator na rede.

$\mathrm{Na}$ rede em estudo, os atores com alto grau de centralidade atendem o nível de AC no município de Bauru, sendo: Hospital de Base de Bauru e Hospital Estadual de Bauru. Outro aspecto relevante, as unidades de saúde fora do município de Bauru que apresentam algum grau de centralidade, geralmente, as conexões desses atores são tipicamente com unidades Hubs da rede em estudo (ver Figuras 29, 30 e 31), isso pode ser um padrão encontrado na rede.

Para ilustrar o padrão referido acima, três unidades de saúde fora do município de Bauru que se destacam:

- Hospital das Clínicas de São Paulo (grau de centralidade - 0,006) tem ligações com os seguintes atores Hubs: Hospital Estadual, AME Bauru, etc. e, esses atores atendem o nível de AC (Figura 29);

- Hospital das Clínicas de Botucatu (grau de centralidade 0,016) as conexões são com atores Hubs: Maternidade Santa Isabel, Samu Regional, etc. e, esses atores atendem os níveis de AC e MC (Figura 30);

- Santa Casa de Pederneiras (grau de centralidade 0,021) a maioria das ligações são com os atores Hubs: Hospital de Base de Bauru, Pronto Socorro Central, etc. e, esses atores que atendem os níveis de AC e MC (Figura 31). 


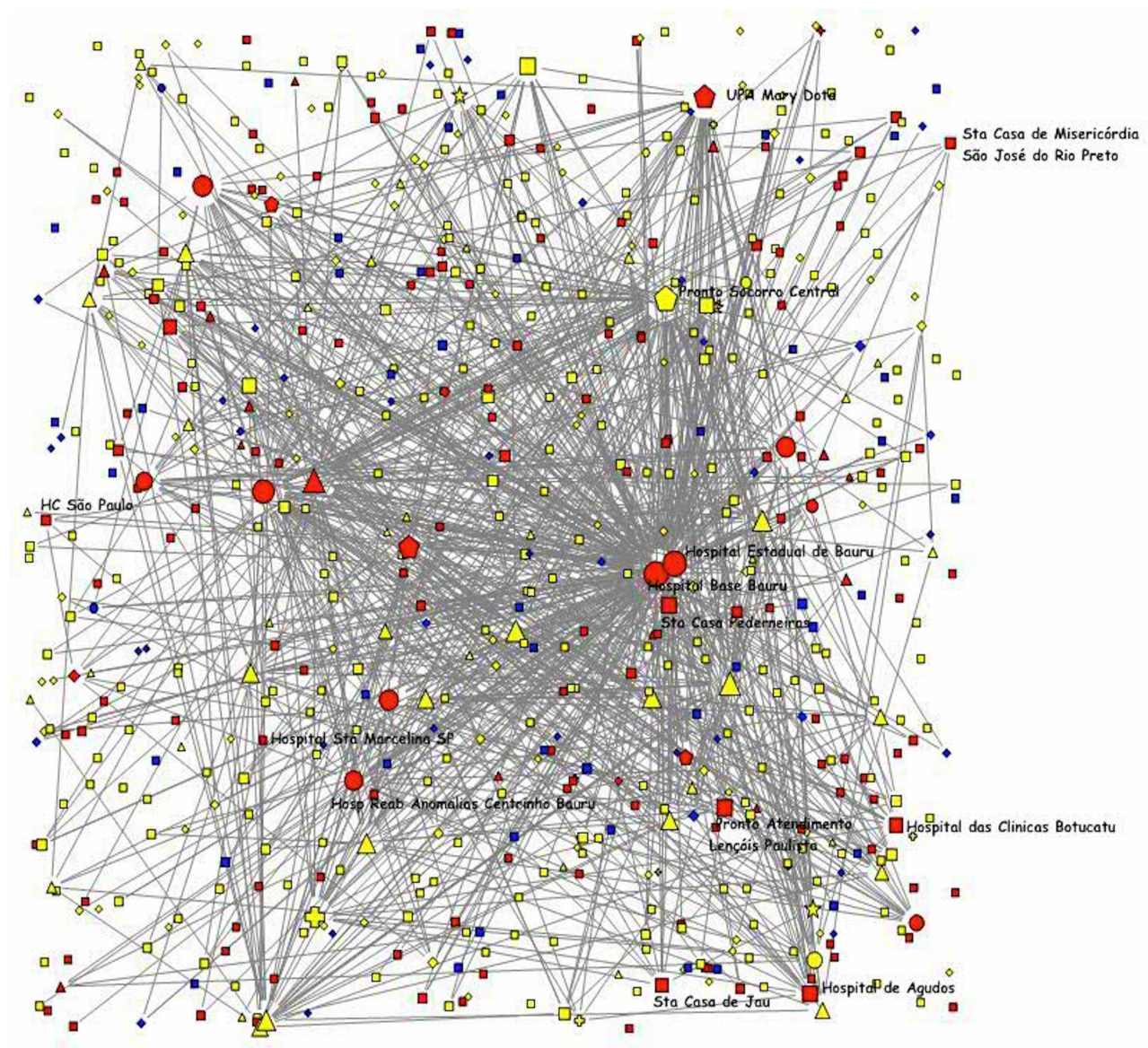

Figura 28 - Mapa geral da rede - Nível de Atendimento do SUS Visualização Spring 2D NetMiner 3

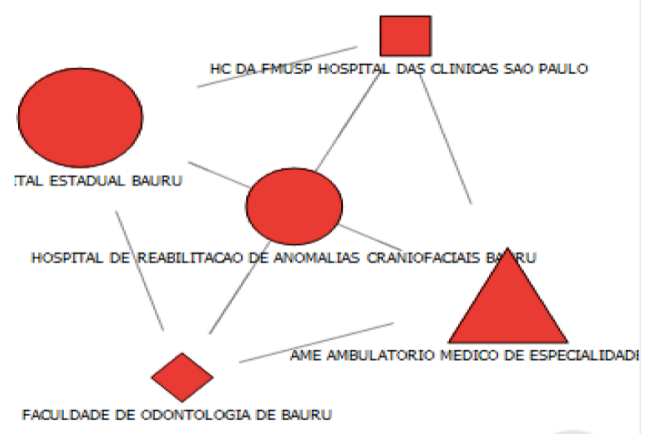

Figura 29 - Visualização dos vizinhos do Hospital das Clínicas de SP

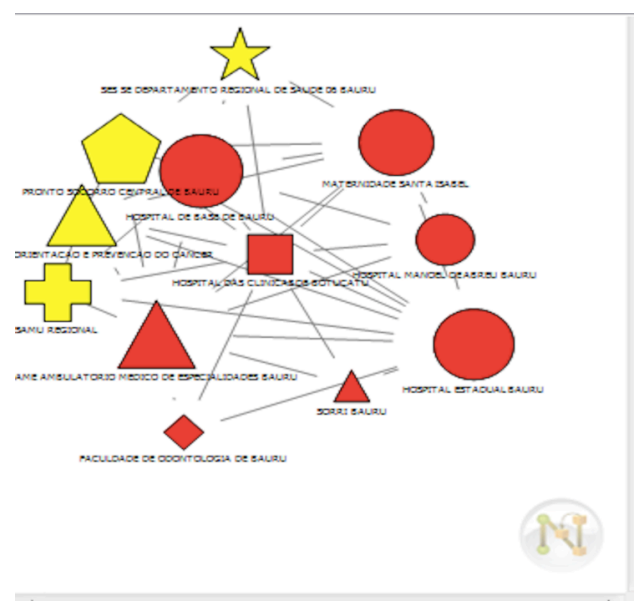

Figura 30 - Visualização dos vizinhos do Hospital das Clínicas de Botucatu 


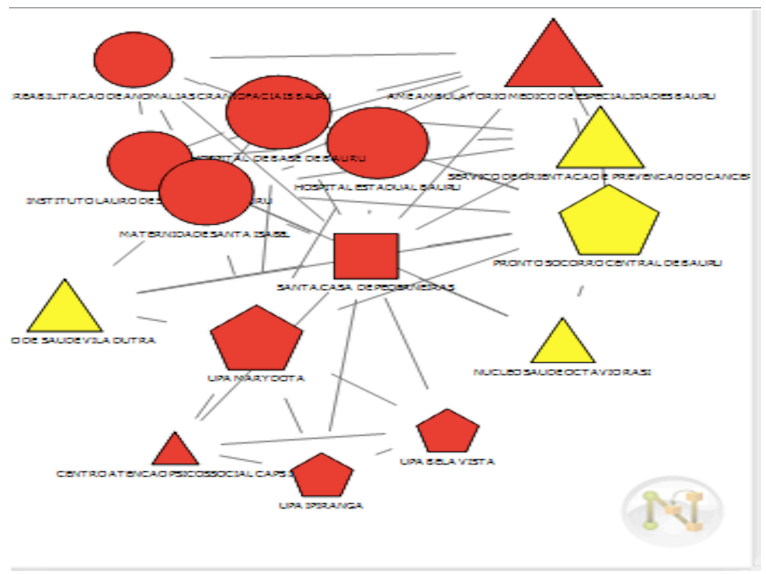

Figura 31 - Visualização dos vizinhos da Santa Casa de Pederneiras

Na rede em estudo, das 655 unidades de saúde, 170 unidades (25\% da rede) atendem o nível de AC e, dessas 170 unidades, 33 estão localizadas no município de Bauru. No nível de atendimento de MC a rede conta com 393 unidades de saúde (60\% da rede) e, dessas 393 unidades, 152 são situadas no município de Bauru. Já o atendimento para o nível de AB a rede é composta por 92 unidades de saúde (14\% da rede) e 47 estão no município de Bauru (GRÁFICO 3).

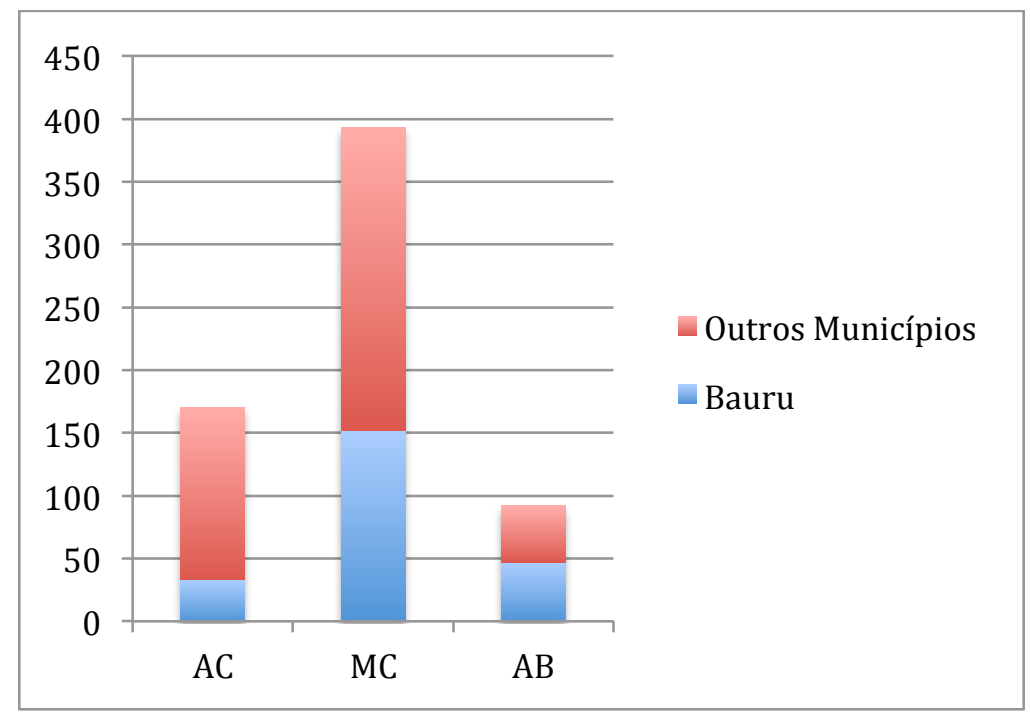

Gráfico 3 - Unidades de Saúde por Nível de Atendimento no SUS

Tendo concluída esta fase de análise (unidades de saúde), chega-se a finalização com o Quadro 13 que traz um resumo das discussões sobre as medidas da rede e os principais achados no nível de análise das unidades de saúde. 


\begin{tabular}{|c|c|c|}
\hline \multicolumn{3}{|c|}{ NÍVEL DE ANÁLISE: UNIDADES DE SAÚDE } \\
\hline Medidas da rede & Principais achados/Autores & Autores \\
\hline Degree & $\begin{array}{l}\text { O índice de centralização na rede é } 23,46 \% \text {. Cinco atores destacam- } \\
\text { se na rede e, o grau de centralidade desses atores variam entre } 10 \% \text { e } \\
24 \% \text {. Das } 655 \text { unidades de saúde, } 265 \text { unidades de saúde possuem } \\
\text { algum grau de centralidade na rede, sendo } 0,238 \text { (o mais central) e } \\
0,001 \text { (o menos central). Portanto, a maioria dos atores encontram-se } \\
\text { na periferia da rede. } \\
\text { Essas unidades de saúde centralizam as relações com os demais } \\
\text { atores da rede e assumem o papel de } H u b s \text { (atores centrais) na rede } \\
\text { em estudo, intermediando as informações com os demais atores da } \\
\text { sua rede por meio dos vínculos profissionais dos médicos } \\
\text { Entretanto, essas unidades de saúde estão melhores posicionadas em } \\
\text { relação às trocas e à comunicação, o que aumenta seu poder na rede. }\end{array}$ & $\begin{array}{l}\text { (Wasserman e } \\
\text { Faust, 1994). } \\
\text { (Marteleto, } \\
\text { 2001). }\end{array}$ \\
\hline Coreness & $\begin{array}{l}44 \text { atores representam o maior Coreness, ou seja, 9. Esses atores } \\
\text { estão localizados no centro da rede e esses atores são os que atendem } \\
\text { os níveis de AC e MC e, os demais estão localizados na periferia da } \\
\text { rede. Os atores com maior Coreness são: Hospitais, Núcleos de } \\
\text { Saúde, UPAs e SAMU. A medida Coreness permite que estrutura de } \\
\text { redes grandes podem ser demonstradas em partes menores, como é o } \\
\text { caso desta rede com } 655 \text { atores. }\end{array}$ & $\begin{array}{l}\text { Batagelj } \\
\text { Zaversnik, } \\
2002\end{array}$ \\
\hline Closeness & $\begin{array}{l}\text { O índice de Closeness é } 0,09 \text {. Os três atores (Hospital de Base, } \\
\text { Hospital Estadual e Pronto Socorro Central) que representam o maior } \\
\text { Closeness atendem os níveis de AC e MC e, os atores que atendem a } \\
\text { AB alguns se encontram no núcleo da rede, porém com menor índice } \\
\text { de Closeness, e, os demais estão localizados nos arredores da rede. } \\
\text { Essas unidades de saúde estão localizadas a uma distância curta, } \\
\text { comparado a maioria das outras unidades de saúde, desse modo, } \\
\text { essas irão receber informações privilegiadas do que as unidades de } \\
\text { saúde que estão localizadas longe da maioria }\end{array}$ & Borgatti, 2009 \\
\hline Betweenness & $\begin{array}{l}\text { O índice de Betweenness é } 0,079 \% \text {. Os três maiores intermediários } \\
\text { na rede atendem os níveis de AC e MC, são: Hospital de Base Bauru } \\
(0,079) \text {, Hospital Estadual Bauru }(0,032) \text { e Pronto Socorro Central } \\
(0,018) \text {, esses são potenciais índices de brokers }\end{array}$ & Borgatti, 2009 \\
\hline Density & $\begin{array}{l}\text { A rede é difusa, composta por } 655 \text { unidades de saúde, isso permite a } \\
\text { obtenção de informações não redundantes, porém o núcleo é denso } \\
\text { (composto por } 26 \text { atores com grau de centralidade que varia de } 0,215 \\
\text { a } 0,024) \text {, com alto grau de conectividade entre os principais atores. } \\
\text { Assim, tanto a interconexão quanto a densidade entre os atores do } \\
\text { núcleo da rede é maior. O índice de densidade da rede é de } 0,004 \text {. } \\
\text { Tal índice de densidade tem como significado que apenas } 0,4 \% \text { das } \\
\text { relações possíveis dentro da rede se efetivam, assim é uma rede com } \\
\text { baixa densidade. }\end{array}$ & $\begin{array}{l}\text { (Burt, 1992) } \\
\text { (Gnyawali e } \\
\text { Madhavan, } \\
2001\end{array}$ \\
\hline Inclusiveness & $\begin{array}{l}\text { O índice de inclusão da rede é de } 40,30 \% \text {, o número de nós } \\
\text { conectados (unidades de saúde) expressas como uma proporção do } \\
\text { número total de nós. Esse índice está abaixo da média, mas } \\
\text { considerando o tamanho da rede (grande) o número de nós } \\
\text { conectados é significativo. }\end{array}$ & Zoppi, 2012 \\
\hline $\begin{array}{l}\text { Box Plot - Tipo } \\
\text { de } \\
\text { Estabelecimento }\end{array}$ & $\begin{array}{l}\text { Na análise por tipo de estabelecimento, o Pronto Socorro Geral é o } \\
\text { mais central }(0,116) \text {, o atendimento é demanda espontânea e } \\
\text { referenciada, atuam } 78 \text { médicos, o nível de atendimento é MC e a } \\
\text { esfera de gestão é Municipal. }\end{array}$ & \\
\hline $\begin{array}{ll}\text { Box Plot } \quad- \\
\text { Esferas de Gestão }\end{array}$ & $\begin{array}{l}\text { A Esfera Estadual apresenta o nível de centralidade e uma média de } \\
0,011 \text {, superior as demais esferas, isso significa que os hospitais e } \\
\text { AME são atores mais centrais. O nível de atendimento é MC e AC. }\end{array}$ & \\
\hline Egonet & $\begin{array}{l}\text { A rede em estudo é composta por redes ego. As três unidades de } \\
\text { saúde que representam o maior número de ligações do nó focal são: } \\
\text { Hospital de Base, Hospital Estadual Bauru e Pronto Socorro Central. } \\
\text { Essas unidades de saúde assumem o papel de ator focal na rede ego e }\end{array}$ & $\begin{array}{l}\text { Reagans } \mathrm{e} \\
\text { Zuckerman, }\end{array}$ \\
\hline
\end{tabular}




\begin{tabular}{|c|c|c|}
\hline & $\begin{array}{l}\text { se tornam mais bem informados e podem monopolizar o fluxo de } \\
\text { recursos entre alters egos }\end{array}$ & 2008 \\
\hline $\begin{array}{l}\text { Buraco } \\
\text { Estrutural }\end{array}$ & $\begin{array}{l}\text { A análise contempla } 655 \text { unidades de saúde (nós), } 69 \text { unidades (na } \\
\text { medida de Limitação Agregada) e } 72 \text { unidades (na medida de } \\
\text { Eficiência) apresentaram o maior índice, ou seja, } 1 \text { e os demais } \\
\text { índices são menores. Essas unidades de saúde estão melhores } \\
\text { posicionadas para acessar informações ou explorar potencias buracos } \\
\text { estruturais em sua rede. } \\
\text { Na medida Tamanho Eficaz os destaques são: Hospital de Base de } \\
\text { Bauru (130,682), Hospital Estadual Bauru (90,667) e Pronto Socorro } \\
\text { Central (63,4605), desse modo, esses índices apresentam somente o } \\
\text { número de unidades de saúde que estão conectadas a ego. } \\
\text { Na hierarquia, } 69 \text { unidades de saúde apresentam o índice } 1 \text {, contudo, } \\
\text { essas unidades demonstram ligação somente com um alter. }\end{array}$ & (BURT, 1992) \\
\hline
\end{tabular}

A próxima seção é apresentada a análise dos dados da rede e, o nível de análise são as pessoas (médicos).

\subsubsection{Nível de Análise - Pessoas (Médicos)}

Esta seção apresenta os médicos como objeto de análise. As medidas de análise da rede foram realizadas pelo software NetMiner3. Para o mapeamento da rede utilizou-se o arquivo BDD e criou uma nova planilha no Excel denominada VMED (Vínculos Médicos), com o nome dos médicos e as unidades de saúde que os médicos possuíam os vínculos profissionais, independente do Município de origem. Posteriormente, o nome dos médicos foram substituídos por códigos, sendo de A1 a A789. Então, essa planilha foi inserida no Software NetMiner 3 para que os dados fossem tratados e transformados em uma matriz de 1 modo, ou seja, os relacionamentos dos médicos com outros médicos por meio das unidades de saúde vinculadas. Excluiu-se os dados duplicados, assim, gerou uma matriz de 1 Modo com 789 médicos e suas interações (Tabela 23, parte da matriz.) Contudo, os dados foram gerados como rede não-direcional, isto é, as ligações entre nós independem de sua origem.

Nessa matriz, nota-se que o médico A6 possui 1 relacionamento com o médico A5, ou seja, os vínculos profissionais de ambos os médicos se coincidem em alguma unidade de saúde. 
Tabela 23 - Parte da Matriz de 1 modo do mapeamento da rede de médicos com vínculos profissionais em unidades de saúde públicas e privadas - Unidade de análise Médicos

\begin{tabular}{|c|c|c|c|c|c|c|c|c|c|c|c|}
\hline & $\mathbf{A 1}$ & $\mathbf{A 2}$ & $\overline{\mathrm{A3}}$ & A4 & $\overline{\mathrm{A5}}$ & $\overline{\mathrm{A6}}$ & A7 & $\overline{\mathrm{A8}}$ & A9 & $\overline{\mathrm{A10}}$ & \\
\hline$\overline{\mathrm{A1}}$ & & 0 & 1 & 0 & 0 & 0 & 0 & 0 & 0 & 0 & $\overline{0}$ \\
\hline A2 & & 1 & 0 & 0 & 0 & 0 & 0 & 0 & 0 & 0 & 0 \\
\hline $\mathbf{A 3}$ & & 0 & 0 & 0 & 1 & 0 & 0 & 0 & 0 & 0 & 0 \\
\hline A4 & & 0 & 0 & 1 & 0 & 0 & 0 & 0 & 0 & 0 & 0 \\
\hline A5 & & 0 & 0 & 0 & 0 & 0 & 1 & 0 & 0 & 0 & 0 \\
\hline A6 & & 0 & 0 & 0 & 0 & 1 & 0 & 0 & 0 & 0 & 0 \\
\hline A7 & & 0 & 0 & 0 & 0 & 0 & 0 & 0 & 0 & 0 & 0 \\
\hline A8 & & 0 & 0 & 0 & 0 & 0 & 0 & 0 & 0 & 1 & 1 \\
\hline A9 & & 0 & 0 & 0 & 0 & 0 & 0 & 0 & 1 & 0 & 1 \\
\hline A10 & & 0 & 0 & 0 & 0 & 0 & 0 & 0 & 1 & 1 & 0 \\
\hline
\end{tabular}

As subseções da vertente quantitativa, apresentadas a seguir, são os resultados medidas de análise de redes (Nível de análise - médicos) extraídas pelo software NetMiner3 (Quadro 14).

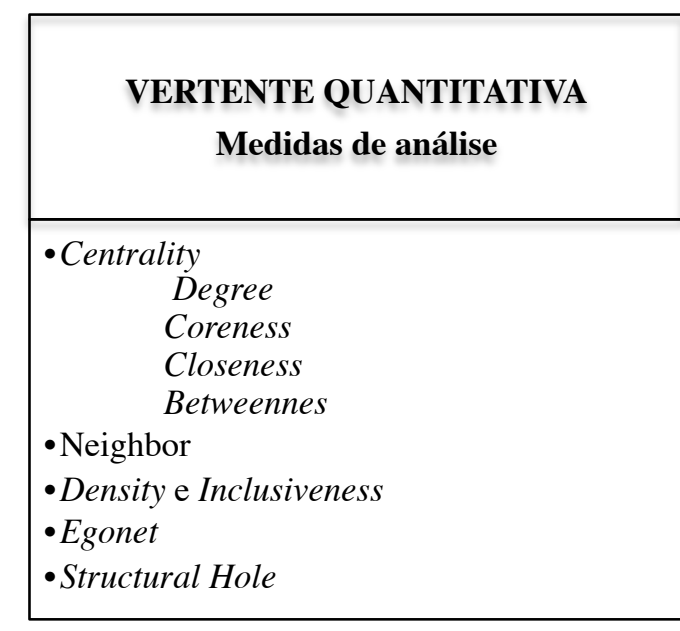

Quadro 14 - Medidas de análise

Nível de análise - médicos

\subsubsection{Análise de Centralidade}

As medidas de centralidade da rede foram extraídas por meio do software Netminer3, para tanto, foi inserida nesse software a matriz de 1 modo da rede de médicos com vínculos profissionais em unidades de saúde públicas e privadas (789 médicos e suas interações). Essas 
medidas são: Degree Centrality; Coreness; Closeness; Betweenness -Node; Betweenness Link.

Os dados foram processados no Software NetMiner3 e, gerou 2 planilhas no Excel para cada medida de centralidade mencionada. As planilhas são apresentadas em forma de tabela, sendo: (1) Distribuição do índice do grau de centralidade - são os indicadores gerais de toda a rede, eles mensuram a Média de todas as relações; o Desvio Padrão, ou seja, a variação da média; Mínimo e Máximo, que indicam os graus máximo e mínimo de interações que os atores tem dentro da rede e, por último, o Índice de centralização da rede é a soma de todas as relações e (2) Análise de Centralidade - é o resultado de centralidade para cada ator da rede.

Nesse sentido, as medidas produzidas pelo Software NetMiner3 envolvem todos os médicos envolvidos (789) na rede, por questões práticas, apresenta-se, os 15 atores (médicos) com maior grau de centralidade. As ligações entre eles são por meio de seus vínculos profissionais em unidades de saúde públicas e privadas.

\subsection{Degree Centrality}

A Tabela 24 traz a distribuição do índice do grau de centralidade dos médicos na rede. Os resultados dessa tabela apontam que no grau de centralidade a média de todas as relações é 0,119 e o Desvio Padrão, 0,149 em relação ao índice de centralização da rede, ou seja, as ligações que estão mais dispersas. Assim, o mínimo de conexões é 0 e o máximo é 0,669 . Todavia, o grau de interação entre os atores e o índice de centralização da rede é $55,029 \%$. Isso representa, cerca de 55,029\% dos médicos da rede são mais centralizados em relação a amostra da rede toda. 
Tabela 24 - Distribuição do índice do grau de centralidade

\begin{tabular}{lr}
\hline \multicolumn{1}{c}{ MEDIDA } & \multicolumn{2}{c}{ VALOR } \\
\cline { 2 - 2 } & \multicolumn{1}{c}{ Grau de Centralidade } \\
\hline Média & 0,119 \\
Desvio Padrão & 0,149 \\
Mínimo & 0 \\
Máximo & 0,669 \\
Índice de centralização da rede & $55,029 \%$ \\
\hline
\end{tabular}

Os 15 atores (médicos) com maior centralidade na rede estão dispostos na Tabela 25. Nessa tabela, destaca-se os quatro médicos mais centrais, em termos de interações com os atores da rede. Os dois primeiros médicos são: o A223 e o A204, ambos apresentam 0,668 de grau de centralidade. Em seguida, o A251 (0,644 de centralidade) e o A172 (0,643 de centralidade). Esses médicos mais centrais apresentam as seguintes ocupações: O A223, possui três ocupações, médico clínico, anestesiologista e ortopedista e, o médico A204 tem como ocupação médico anestesiologista. E por fim, os dois últimos médicos, o A251 tem 4 ocupações declaradas, médico clínico, anestesiologista, médico cirurgião geral e médico urologista e, o médico A172 possui cinco ocupações, médico clínico, gastroentereologia, médico cirurgião geral, urologista e radiologista.

Nota-se que os quatro médicos mencionados possuem vínculos profissionais públicos e privados, sendo a maior carga horária em hospitais e a ocupação anestesiologista e médico clínico está presente em três médicos acima mencionados.

O posicionamento de centralidade permite esses atores a acessar novos conhecimentos (BORGATTI, 2005), recursos e informações na rede (WASSERMAN e FAUST, 1994). Particularmente, no contexto de saúde, os médicos que estão localizados no núcleo da rede são mais suscetíveis de beneficiar da disseminação de conhecimento e receber mais informações do que os atores periféricos. 
Tabela 25 - Análise de centralidade (degree)

\begin{tabular}{ccc}
\hline Item & Médicos & Grau de Centralidade \\
\hline 1 & A223 & 0,668782 \\
2 & A204 & 0,668782 \\
3 & A251 & 0,64467 \\
4 & A172 & 0,643401 \\
5 & A197 & 0,639594 \\
6 & A215 & 0,629442 \\
7 & A143 & 0,623096 \\
8 & A220 & 0,615482 \\
9 & A208 & 0,615482 \\
10 & A198 & 0,615482 \\
11 & A173 & 0,615482 \\
12 & A148 & 0,615482 \\
13 & A145 & 0,615482 \\
14 & A222 & 0,612944 \\
15 & A194 & 0,612944 \\
\hline
\end{tabular}

A Figura 32 ilustra o grau de centralidade dos atores (médicos) na rede, assim os atores que estão no núcleo da rede apresentam o maior grau de centralidade, conforme a explicação da Tabela 25. A representação das cores do círculo nessa figura, refere-se a quantidade de ocupação que o médico possui na rede (ver legenda da Figura 32), assim o máximo de ocupação por profissional médico na rede em estudo são 7. A cor do círculo vermelho demonstra o ator que possui 7 ocupações e a cor do círculo azul escuro indica que o ator possui 1 ocupação. Após a análise da quantidade de ocupações por profissionais médicos da rede em estudo, verificou-se, que a média de ocupação dos profissionais médicos na rede é de 2.

Observa-se que 6 médicos da rede que possuem o maior número de ocupações e, 2 desses destacam-se por alto grau de centralidade. Desses 6 médicos, 3 deles apresentaram 7 diferentes ocupações, o médico A199 apresenta alto grau de centralidade $(0,604)$ na rede e, os outros dois médicos o A317 e o A325 apresentam baixo grau de centralidade na rede. Os outros 3 médicos que apresentaram 6 diferentes ocupações são, o médico A203, também ocupa uma posição central na rede (centralidade de 0,579 ) e os outros dois médicos o A673 e o A151 apresentam baixa centralidade na rede. Já o número de médicos que possuem 5 ocupações são 15, os de 4 ocupações são 38, e por fim, os médicos que possuem 3 ocupações são 103. Os demais estão dentro da média ou abaixo, conforme demonstra Gráfico 4. 


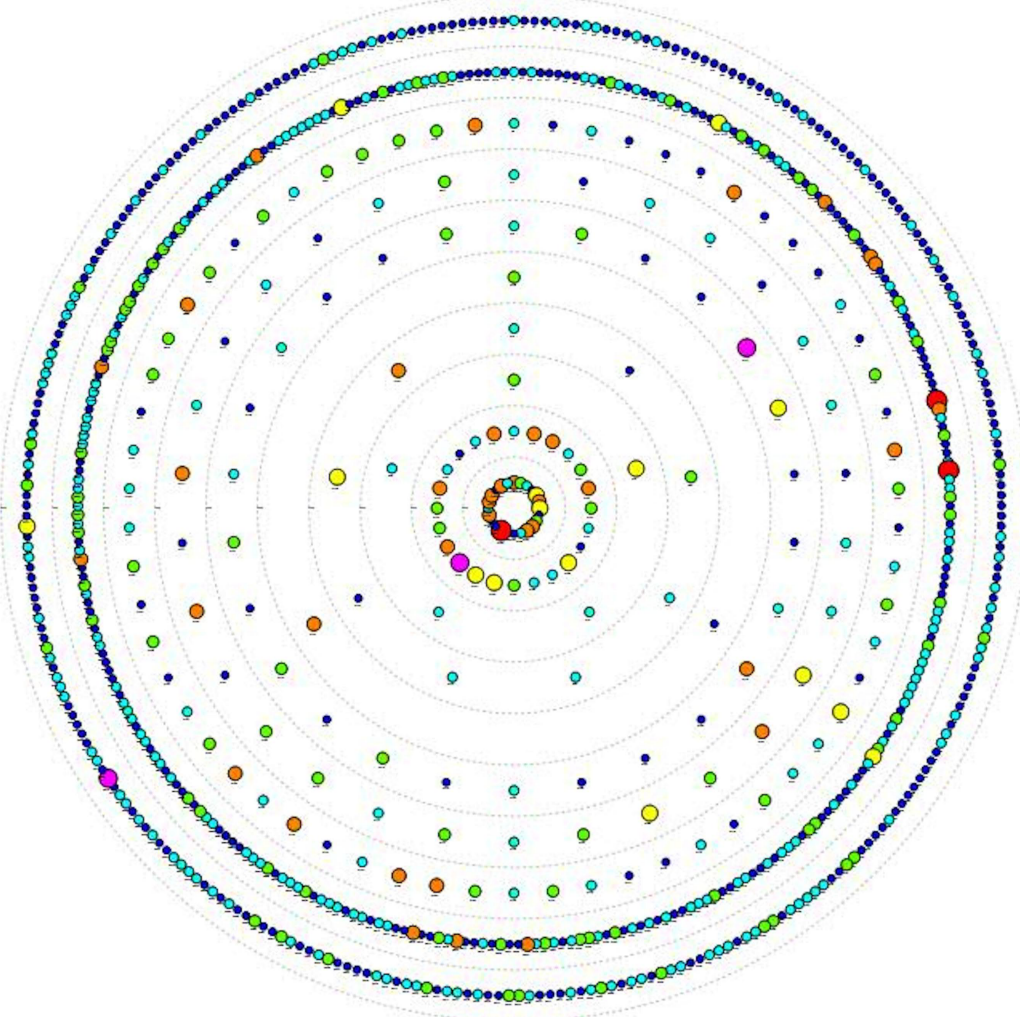

\begin{tabular}{l|l}
\hline & 1.0 \\
\hline & 2.0 \\
\hline & 3.0 \\
\hline & 4.0 \\
$\bigcirc$ & 5.0 \\
$\bigcirc$ & 6.0 \\
\hline & 7.0 \\
\hline
\end{tabular}

Figura 32 - Análise de centralidade (degree) Quantidade de ocupação dos médicos Visualização Concentric NetMiner 3

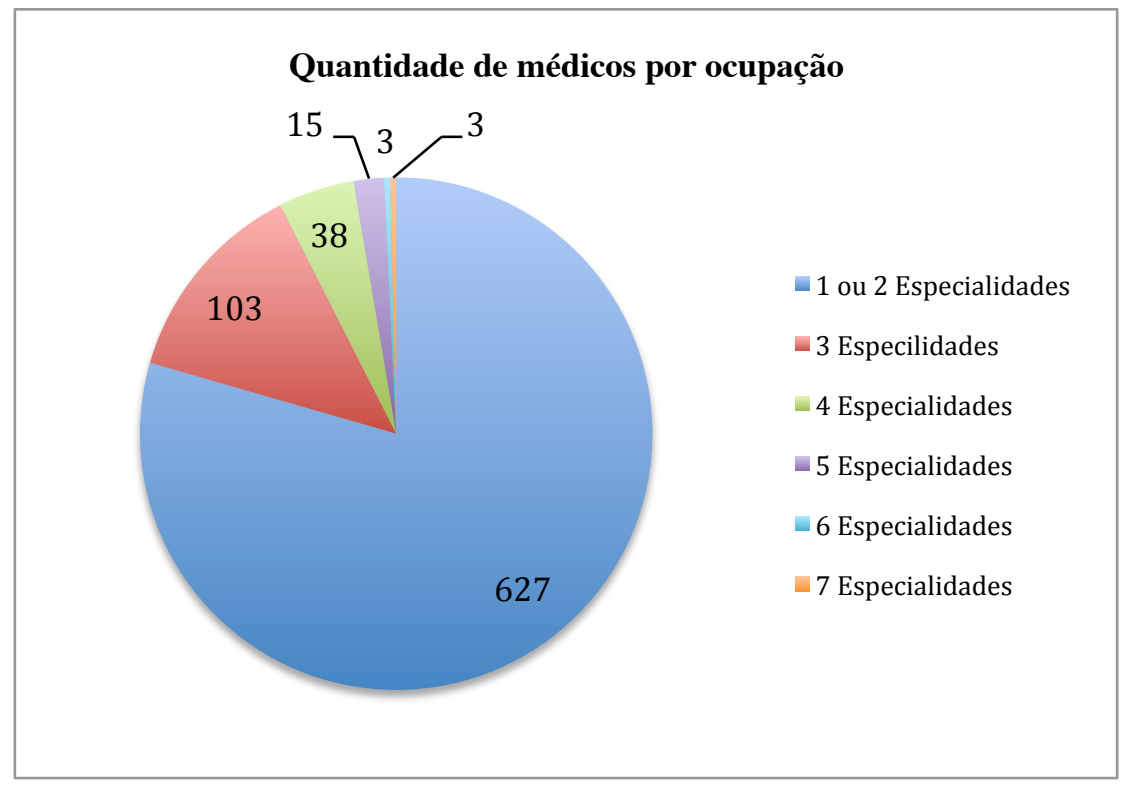

Gráfico 4 - Quantidade de médicos por ocupação 
A Figura 33 também ilustra o grau de centralidade dos médicos da rede, mas a forma de representação no mapa é por meio da quantidade de vínculos profissionais dos médicos. As cores dos círculos começam no azul claro (menor quantidade de vínculo) e variam até a cor vermelha (maior quantidade de vínculos). A quantidade de vínculos profissionais dos médicos na rede em estudo está entre 1 e 27 vínculos, conforme demonstra o Gráfico 5.

Entretanto, ao verificar-se que 11 médicos apresentam um grande números de vínculos profissionais, cabe ressaltar que pelo menos uma das ocupações desses médicos é em Radiologia e Diagnóstico por Imagem e, esses vínculos profissionais variam de 11 a 27. Os demais são abaixo de 10 vínculos profissionais e a média de vínculos profissionais na rede é 3. Entre os profissionais médicos com ocupação em radiologia o A172 (grau de centralidade 0,643) é o único que ocupa uma posição mais central na rede, os demais com essa ocupação estão localizados na periferia da rede. Isso significa que esses médicos localizados na periferia da rede estão mais propensos a explorar conhecimento, provavelmente, por meio de contatos não redundantes, atores periféricos podem ser capazes de criar novos conhecimentos que podem levar ao desenvolvimento de inovações (GILSING et al, 2007). A quantidade de vínculos profissionais dos 15 médicos com maior grau de centralidade mencionados na Tabela 25, varia entre 3 e 11 vínculos profissionais, tais como, o ator A223 possui 6 vínculos e o A204 possui 4 vínculos, ambos estão ocupando o maior grau de centralidade na rede. Portanto, uma grande quantidade de vínculos profissionais não significa ocupar uma posição mais central na rede. 


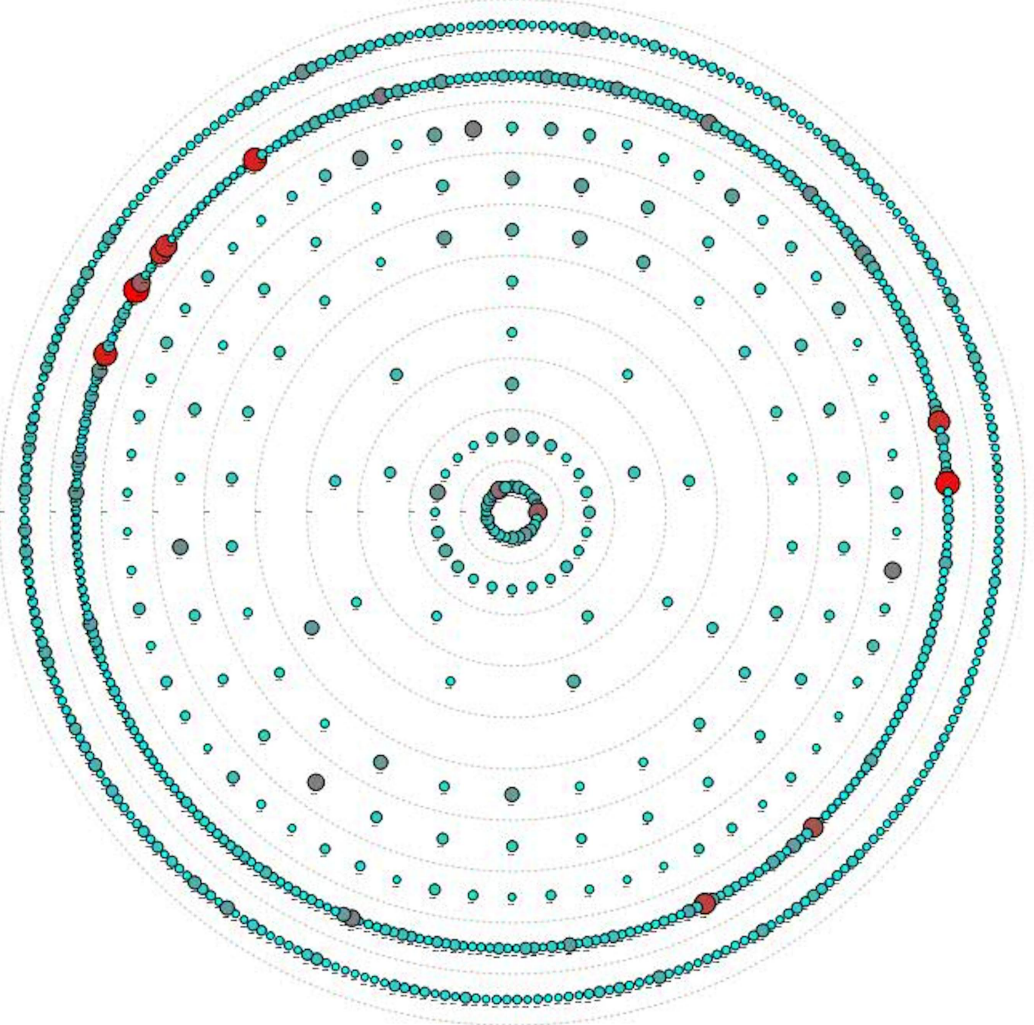

Figura 33 - Análise de centralidade (degree) Quantidade de vínculos dos médicos Visualização Concentric NetMiner 3

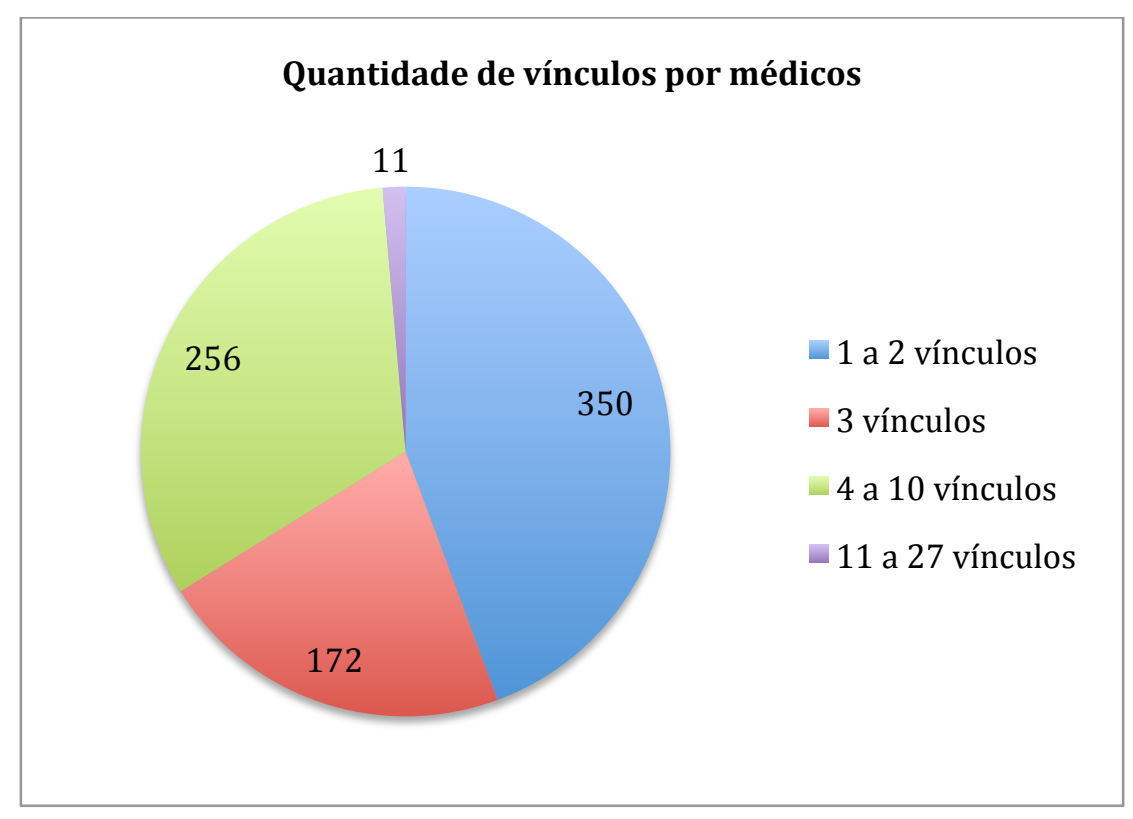

Gráfico 5-Quantidade de vínculos profissionais por médicos 
A Figura 34 demonstra o grau de centralidade dos atores na rede e ilustra a rede por meio da quantidade de carga horária semanal de trabalho dos médicos. As cores e o tamanho dos círculos se iniciam com azul claro (menor carga horária semanal) e variam até a cor vermelha (maior carga horária semanal).

A média de carga horária semanal de trabalho dos médicos da rede em estudo é 42 horas, mas a carga horária semanal de trabalho dos médicos da rede está entre 2 horas e 130 horas, assim verificou-se que os médicos que têm carga horária elevada (100 e 130) são aqueles que atuam como residentes e possuem pelo menos 1 ocupação.

Entre todas as ocupações da rede de médicos, destacam-se três ocupações com a média maior de carga horária semanal de trabalho: Médico Residente (51 horas semanais), Médico Radioterapeuta (40 horas semanais) e Médico da Estratégia de Saúde da Família (39 horas), ressalta-se que a média foi da carga horária total de cada ocupação da rede.

Contudo, os quatro atores com maior grau de centralidade (representados pelos círculos vermelhos no mapa) não apresentam carga horária entre 100 e 130 horas semanais, mas estão acima da média de horas semanais, sendo os seguintes atores: A204 (78 horas e 0,668 de centralidade), A223 (56 horas e 0,668 de centralidade), A251 (79 horas e 0,644 de centralidade) e o A172 (61 horas e 0,643 de centralidade).

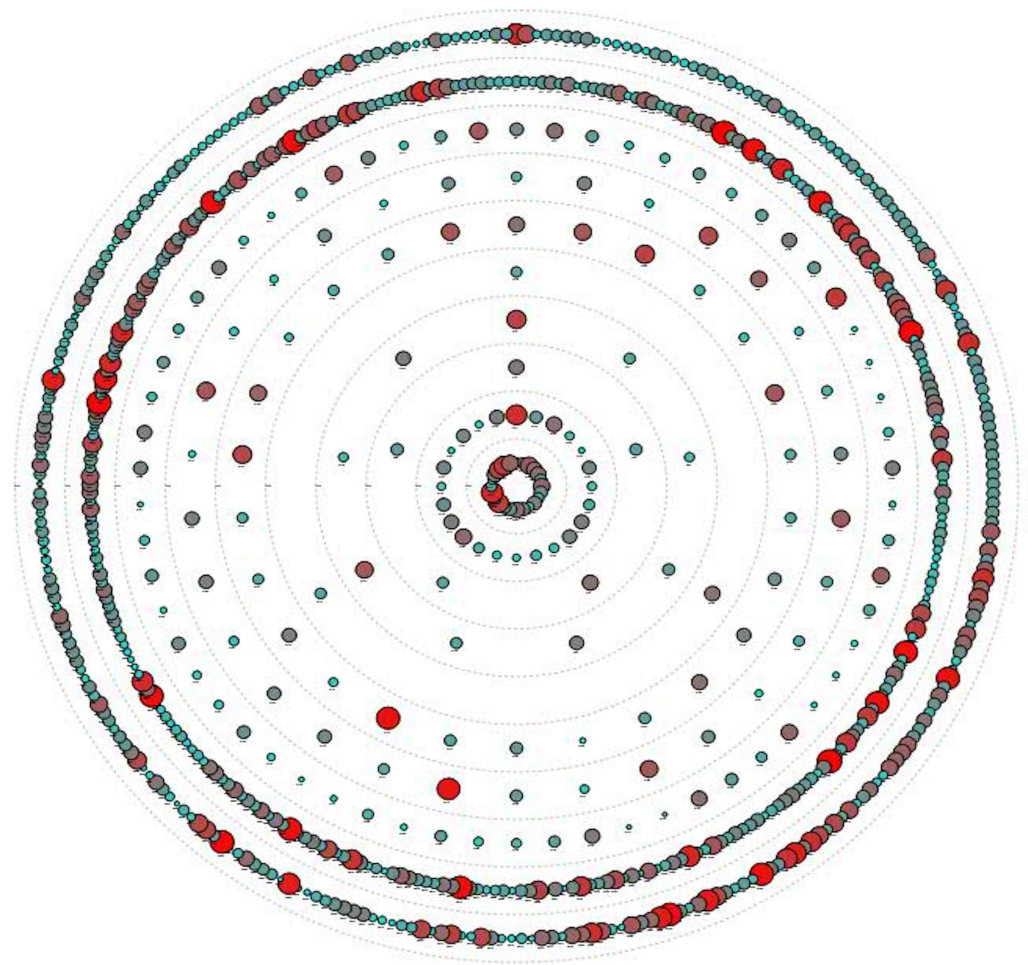

Figura 34 - Análise de centralidade (degree)

Quantidade de carga horária semanal de trabalho dos médicos Visualização Concentric NetMiner 3 


\subsection{Coreness}

Para o grau de centralização de cada membro da rede, verificou-se a existência de um grupo de 148 atores que apresentaram uma posição mais central na rede do total de 789 atores, ou seja, o grau de centralidade de Coreness apresentou-se 122. Isso significa que esses atores com maior Coreness estão agrupados no núcleo da rede (HE et al., 2011) e colaborando principalmente dentro desse núcleo principal (BATAGELJ e ZAVERSNIK, 2002). Assim, a Tabela 26 traz os 15 atores primeiros atores (na ordem que o software gerou) com maior Coreness na rede. Nota-se que os três primeiros dessa tabela possuem uma carga horária maior em hospitais e centros de especialidades. O médico A760 atua a maior parte de sua carga horária de trabalho em hospitais e a ocupação é Neurologista, o médico A718 também trabalha a maior parte do tempo em hospitais e no AME e a ocupação é Ortopedia e o médico A717 tem como ocupações declaradas, urologista, cirurgião geral e anestesiologista com vínculos profissionais em hospitais e no AME, sendo dois hospitais público e um privado.

Tabela 26 - Análise de centralidade (coreness)

\begin{tabular}{ccc}
\hline Item & Médicos & Centralidade Coreness \\
\hline 1 & A760 & 122 \\
2 & A718 & 122 \\
3 & A717 & 122 \\
4 & A693 & 122 \\
5 & A691 & 122 \\
6 & A579 & 122 \\
7 & A571 & 122 \\
8 & A492 & 122 \\
9 & A448 & 122 \\
10 & A438 & 122 \\
11 & A433 & 122 \\
12 & A427 & 122 \\
13 & A269 & 122 \\
14 & A268 & 122 \\
15 & A267 & 122 \\
\hline
\end{tabular}

A Figura 35 demonstra os atores com maior grau de Coreness e ilustra a rede por meio da quantidade carga horária semanal dos médicos. As cores e o tamanho dos círculos se iniciam com azul claro (menor carga horária semanal) e variam até a cor vermelha (maior 
carga horária semanal). Nessa figura, nota-se que os atores com maior grau de Coreness estão identificados, progressivamente, nos núcleos internos e podem ser visualizados em uma estrutura de diferentes camadas (HE et al., 2011).

Outro fato relevante é que os 15 atores com maior carga horária semanal de trabalho, tem cargas semanais que variam entre 66 e 98 horas, e esses estão localizados no núcleo da rede e apresentam o círculo mais escuro e também o formato maior (tais como os atores: A218, A171 e A215).

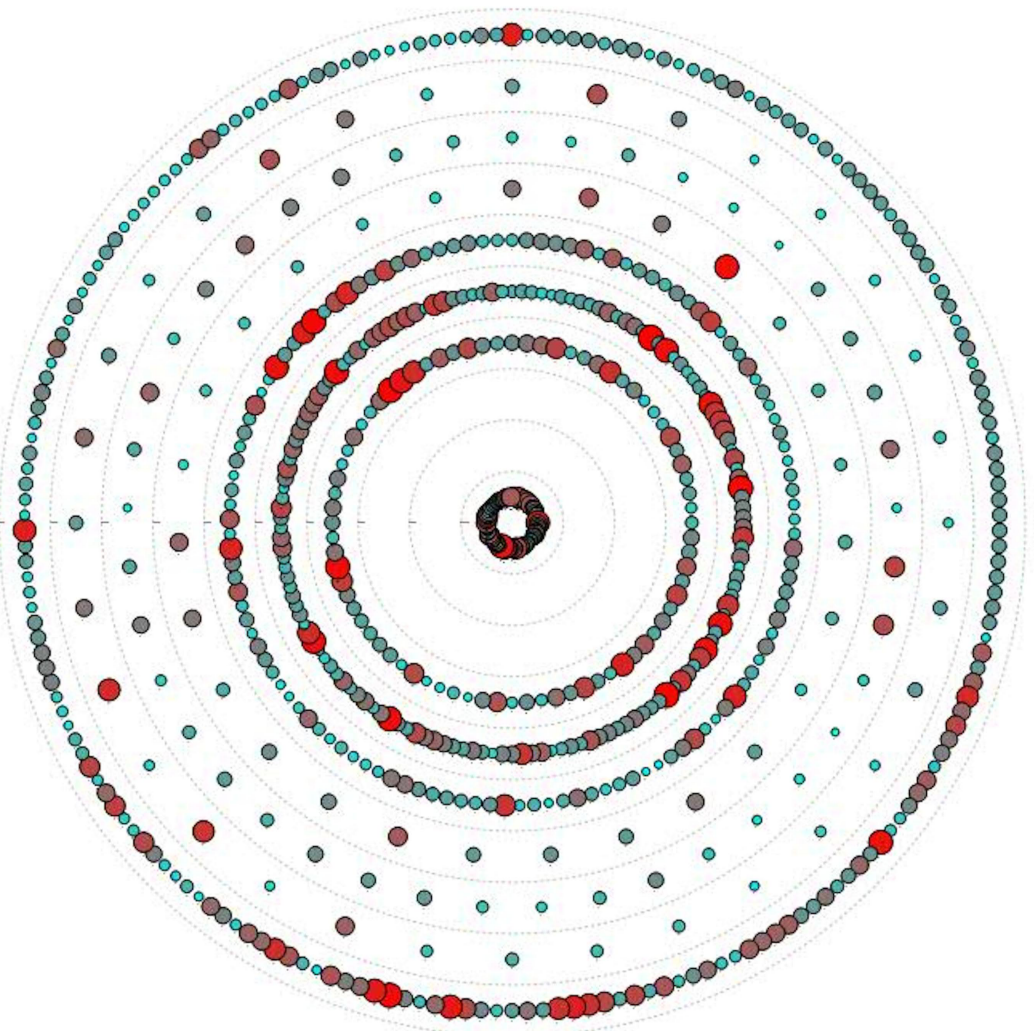

Figura 35 - Análise de centralidade (coreness)

Quantidade de carga horária dos médicos Visualização Concentric NetMiner 3 


\subsection{Closeness}

$\mathrm{Na}$ análise de centralidade da estrutura da rede com base em distâncias geodésicas entre os nós, os resultados da Tabela 27 mostram os seguintes indicadores: a média de todas as relações de proximidade é 0,477 e o Desvio Padrão, 0,101 em relação a proximidade do ator na rede, ou seja, os atores que estão mais dispersos. Portanto, o grau de proximidade entre os atores e o índice de centralização closeness da rede é 0,49\%. Esse índice representa a proximidade central dos atores em relação a rede.

Tabela 27 - Análise de centralidade (closeness)

\begin{tabular}{lr}
\hline \multicolumn{1}{c}{ MEDIDAS } & \multicolumn{2}{c}{ VALOR } \\
\cline { 2 - 3 } & \multicolumn{2}{c}{ Closeness } \\
\hline Média & 0,477 \\
Desvio Padrão & 0,101 \\
Mínimo & 0 \\
Máximo & 0,73 \\
Índice de centralização closeness da rede & $0,49 \%$ \\
\hline
\end{tabular}

Os resultados dos 15 médicos mais centrais em relação a proximidade, encontram-se descritos na Tabela 28. Embora em posições diferenciadas, os atores que têm destaque em relação à centralidade de proximidade, os doze primeiros, são basicamente os mesmos que os dados mostraram serem centrais na medida de centralidade (ver Tabela 25).

Nesta análise, observa-se que os três médicos com maior índice de closeness também apresentam o maior grau de centralidade (degree centrality) (ver Tabela 25). Esses médicos (A204, A223 e A172) com maior índice de closeness apresentam maior carga horária de trabalho em hospitais e seus vínculos profissionais são em unidades de saúde públicas e privadas. Corroborando, com a literatura esses atores (três mencionados) possuem um índice maior de centralidade closeness em relação aos demais atores da rede, isso permite contatar facilmente muitos outros atores (TASSELI, 2015; POWELL, KOPUT e DOERR, 1996). 


\begin{tabular}{ccc}
\hline Item & Médicos & Closeness \\
\hline 1 & A204 & 0,730043 \\
2 & A223 & 0,723756 \\
3 & A172 & 0,716217 \\
4 & A197 & 0,714188 \\
5 & A251 & 0,7115 \\
6 & A215 & 0,710832 \\
7 & A143 & 0,704213 \\
8 & A220 & 0,7016 \\
9 & A208 & 0,7016 \\
10 & A198 & 0,7016 \\
11 & A173 & 0,7016 \\
12 & A148 & 0,7016 \\
13 & A245 & 0,697074 \\
14 & A175 & 0,697074 \\
15 & A169 & 0,697074 \\
\hline
\end{tabular}

O mapa da Figura 36 explana os atores com maior grau de closeness, e esses estão localizados no centro do mapa. Além do grau de centralidade de closeness, a rede é ilustrada por meio da quantidade da carga horária semanal de trabalho dos médicos. Dessa forma, no mapa as cores e o tamanho dos círculos se iniciam com azul claro (menor carga horária semanal) e variam até a cor vermelha (maior carga horária semanal).

Os três médicos com maior grau de closeness não são os que apresentam maior carga horária semanal de trabalho, porém eles estão acima da média (42 horas semanais). O primeiro, o médico A204, apresenta um grau de closeness de 0,730 e uma carga horária de trabalho de 78 horas/semanais. Na sequência, o médico A223, o grau de closeness é 0,723 e carga horária de trabalho de 56 horas/semanais. E por fim, o médico A172 o índice de closeness é 0,716 e carga horária de trabalho de 61 horas/semanais. Esses médicos estão localizados no núcleo da rede (com círculo mais escuro e também o formato maior) e propensos a um bom desempenho em trabalhos que requerem integração de informações (BORGATTI, 2009). 


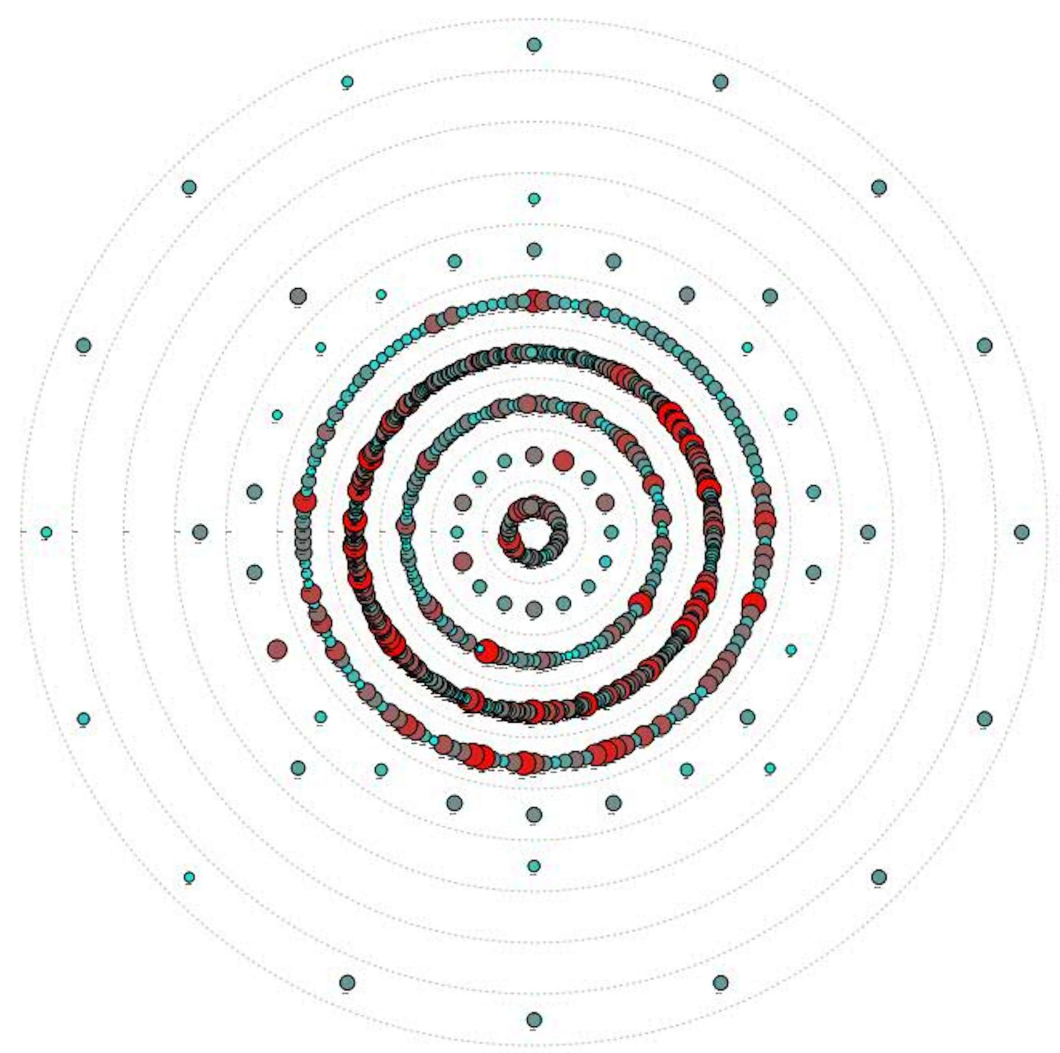

Figura 36 - Análise de centralidade (closeness)

Quantidade de carga horária semanal de trabalho dos médicos Visualização Concentric NetMiner 3

\subsection{Betweenness - node}

A Análise de Betweenneess - node é a centralização de intermediação dos atores da rede, conforme apresenta a tabela 29. Assim a média de todas as relações é 0,001 e o Desvio Padrão, 0,005 em relação ao grau de intermediação do ator na rede, ou seja, os atores que estão mais dispersos. Assim, o mínimo de centralidade betweenness é 0 e o máximo 0,092. De modo geral, o grau de intermediação entre os atores e o índice de centralização betweenness da rede é $0,091 \%$. Esse índice representa a intermediação central dos atores em relação a rede. 
Tabela 29 - Análise de centralidade (betweenness - node)

\begin{tabular}{lr}
\hline \multicolumn{1}{c}{ MEDIDAS } & \multicolumn{2}{c}{ VALOR } \\
\hline Média & 0,001 \\
Desvio Padrão & 0,005 \\
Mínimo & 0 \\
Máximo & 0,092 \\
Índice de centralização Betweenness da rede & $0,091 \%$ \\
\hline
\end{tabular}

A Tabela 30 ilustra que os 15 atores com maior índice de Betweenneess. No entanto, os médicos A223, A204 e A31 aparecem como os três maiores intermediários na rede e atuam a maior parte da carga horária de trabalho em hospitais e, seus vínculos profissionais são públicos e privados. Tanto o ator A223 quanto a A204 aparecem na mesma posição da análise de centralidade (degree centrality ver Tabela 25). Os três atores mencionados são beneficiados como um potenciais pontos para o controle da comunicação (FREMANN, 1979).

Tabela 30 - Análise de Centralidade (Node Betweenness)

\begin{tabular}{ccc}
\hline Item & Médicos & Betweenness Centrality \\
\hline 1 & $\mathrm{~A} 223$ & 0,091766 \\
2 & $\mathrm{~A} 204$ & 0,081119 \\
3 & $\mathrm{~A} 31$ & 0,022641 \\
4 & $\mathrm{~A} 215$ & 0,022301 \\
5 & $\mathrm{~A} 47$ & 0,018177 \\
6 & $\mathrm{~A} 197$ & 0,01777 \\
7 & $\mathrm{~A} 98$ & 0,017546 \\
8 & $\mathrm{~A} 132$ & 0,016523 \\
9 & $\mathrm{~A} 172$ & 0,014981 \\
10 & $\mathrm{~A} 251$ & 0,014392 \\
11 & $\mathrm{~A} 218$ & 0,013098 \\
12 & $\mathrm{~A} 252$ & 0,013028 \\
13 & $\mathrm{~A} 71$ & 0,01178 \\
14 & $\mathrm{~A} 187$ & 0,010489 \\
15 & $\mathrm{~A} 87$ & 0,010485 \\
\hline
\end{tabular}


A Figura 37 ilustra o grau de intermediação dos atores na rede de médicos (Node Betweenness) com destaque para a quantidade carga horária semanal dos médicos. As cores e o tamanho dos círculos se iniciam com azul claro (menor carga horária semanal) e variam até a cor vermelha (maior carga horária semanal).

É possível notar que no mapa se destacam dois médicos que ocupam uma posição mais central, embora esses atores estejam mais favoráveis para intermediar as informações que circulam na rede, eles não são os que apresentam maior carga horária semanal de trabalho, porém eles também estão acima da média (42 horas) dos demais membros da rede: o ator A223 (com grau de Betweeness 0,091 e carga horária 56 horas/semanais) representado no mapa pela cor de círculo marrom e o A204 (com grau de Betweeness 0,081 e carga horária 78 horas/semanais) é representado pela cor de círculo vermelho.

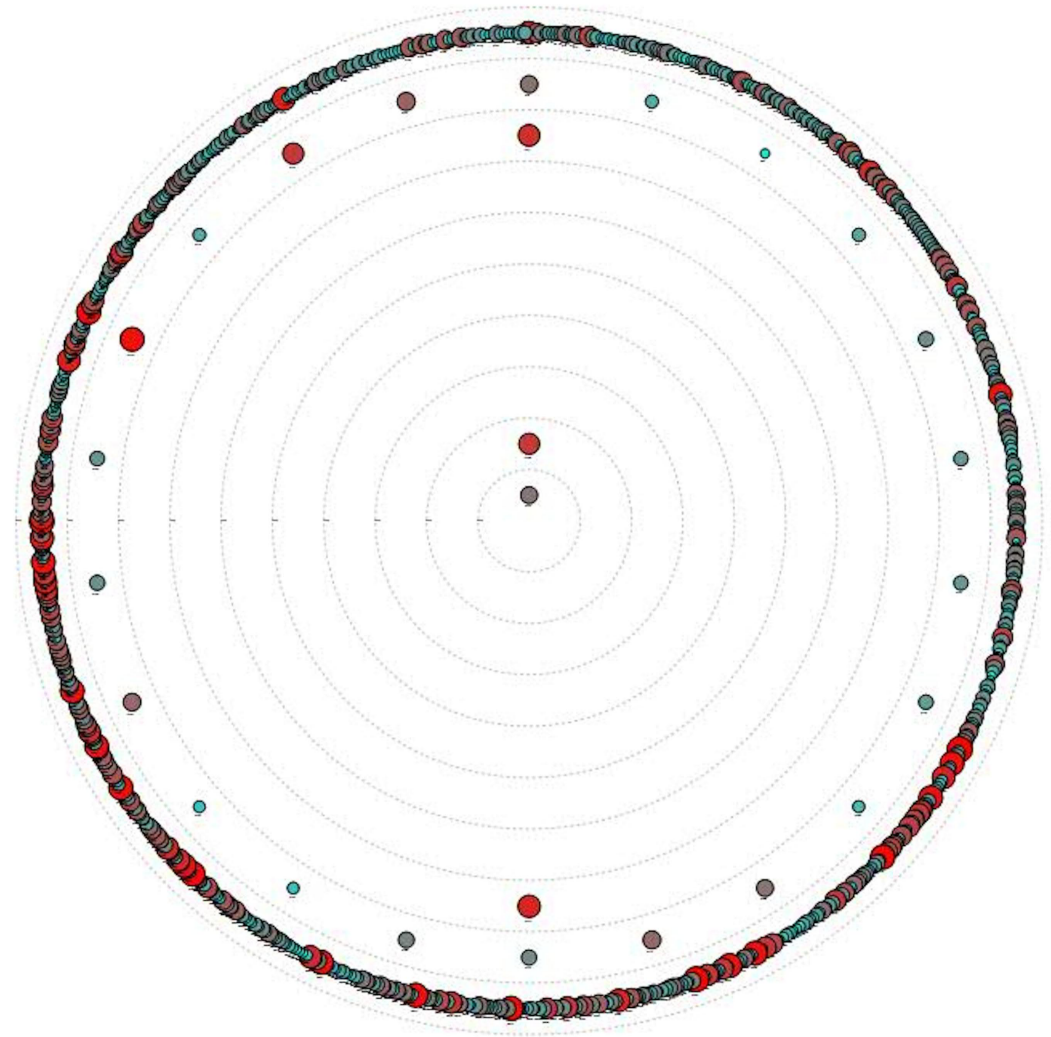

Figura 37 - Análise de centralidade (Node Betweeness) Quantidade de carga horária semanal de trabalho dos médicos Visualização Concentric NetMiner 3 


\subsection{Betweenness - link}

A tabela 31 evidencia que na análise da centralização de intermediação das ligações dos atores da rede, a média de todas as ligações é 16,60 e o Desvio Padrão, é 45,94 em relação ao grau de intermediação das ligações entre os atores na rede, ou seja, as ligações dos atores que estão mais dispersas. Assim, o mínimo é 1 e o máximo das ligações é 1.540.

A Tabela 31 - Análise de centralidade (betweenness - link)

\begin{tabular}{|c|c|}
\hline MEDIDAS & VALOR \\
\hline Média & 16,605 \\
\hline Desvio Padrão & 45,949 \\
\hline Mínimo & 1 \\
\hline Máximo & 1.540 \\
\hline
\end{tabular}

\subsubsection{Análise - Neighbor, Density e Inclusiveness}

$\mathrm{Na}$ análise de centralidade (Neighbor - degree) é possível identificar os graus e tipos de nós da rede. A Tabela 32 demonstra os resultados do Grau nodal (de conexão), ou seja, o número de linhas e o tamanho da vizinhança. Essa tabela apresenta a soma da relações, cujo índice é 74.102, a média é 93,919 e o Desvio Padrão, 117,296 em relação ao índice de centralização da rede, ou seja, os vínculos que estão mais dispersos. O mínimo do grau de centralidade é 0 e o máximo é 527. O número de nós isolados é 9 (médicos), 14 nós pendentes e 98,859\% inclusiveness, ou seja, o número de nós conectados (médicos) expressas como um tamanho do número total de nós. A densidade é 0,119 , ou seja, o número de linhas presentes para o máximo possível. Isso significa que a rede é densa, pois o índice de inclusiveness é alto, visto que somente 9 médicos estão desconectados da rede (SCOTT, 2000). 
Tabela 32 - Análise de centralidade (neighbor - degree)

\begin{tabular}{lr}
\hline \multicolumn{1}{c}{ MEDIDAS } & \multicolumn{2}{c}{ VALOR } \\
\cline { 2 - 2 } & \multicolumn{2}{c}{ Neighbor-degree } \\
\hline Soma & 74102 \\
Média & 93,919 \\
Desvio Padrão & 117,296 \\
Mínimo & 0 \\
Máximo & 527 \\
\# de isolado & 9 \\
\# de pendente & 14 \\
inclusiveness (\%) & $98,859 \%$ \\
Densidade da Rede & 0,119 \\
\hline
\end{tabular}

Os resultados da Tabela 33 indicam 9 nós isolados (médicos), 0 nós transmissores e recebedores, 14 carregador (carrega os vínculos) e 766 nós ordinários. A rede em estudo é não direcionada, então, a análise Neighbor - degree está pertinente com o quarto tipo de nó, “carregador" e requerem que ambos grau de entrada e grau de saída são iguais a 1.

Tabela 33 - Número do tipo de nó (neighbor - degree)

\begin{tabular}{crrrrr}
\hline Isolado & Transmissor & Recebedor & Carregador & Ordinário \\
\hline 9 & 0 & 0 & 14 & 766 \\
\hline
\end{tabular}

\subsubsection{Egonet}

A distribuição das medidas da rede ego, é apresentada na Tabela 34, sendo os seguintes valores: o tamanho da rede ego de cada nó tem em média tem 93,919 conexões e a densidade indefinida; no tamanho da rede ego o desvio padrão é 117,296 e a densidade indefinida. Já o valor mínimo tanto no tamanho quanto na densidade é 0 , enquanto que o valor máximo no tamanho de conexões é 527 e o mínimo é 1. 
Tabela 34 - Análise da rede ego (Egonet)

\begin{tabular}{|c|c|c|}
\hline \multirow[t]{2}{*}{ Medidas } & \multicolumn{2}{|c|}{ Valor } \\
\hline & Tamanho & Densidade \\
\hline Média & 93,919 & indefinido \\
\hline Desvio Padrão & 117,296 & indefinido \\
\hline Mínimo & 0 & 0 \\
\hline Máximo & 527 & 1 \\
\hline
\end{tabular}

A seguir é apresentada a Tabela 35 onde consta os 15 médicos com maior número de nós alter (nós que são adjacentes do nó focal). Entretanto, é importante ressaltar que o nó focal não está incluído no tamanho da rede ego. Os três médicos que representam o maior número de ligações do nó focal são: A223 (tamanho da rede ego é 527) e (densidade 0,23002), A204 (tamanho da rede ego é 527) e (densidade - 0,230215) e A251 (tamanho da rede ego é 508) e (densidade 0,248653). Esses médicos revelam o papel de ator focal na rede ego e, tornam-se informados rapidamente (REAGANS e ZUCKERMAN, 2008), além do mais, eles possuem o maior número de conexões/parcerias onde aumenta a possibilidade de inovar (BAUM et al., 2010).

Tabela 35 - Análise da rede ego (Egonet) - tamanho

\begin{tabular}{ccc}
\hline Item & Médico & Tamanho \\
\hline 1 & A223 & 527 \\
2 & A204 & 527 \\
3 & A251 & 508 \\
4 & A172 & 507 \\
5 & A197 & 504 \\
6 & A215 & 496 \\
7 & A143 & 491 \\
8 & A220 & 485 \\
9 & A208 & 485 \\
10 & A198 & 485 \\
11 & A173 & 485 \\
12 & A148 & 485 \\
13 & A145 & 485 \\
14 & A222 & 483 \\
15 & A194 & 483 \\
\hline
\end{tabular}


A Tabela 36 demonstra os 15 médicos com maior densidade na rede ego, a escala varia de 0 (não densa) e 1 (densa). A soma de todos os atores são 789, desse total, 257 são densos com valor 1. Assim os três atores com maior densidade (conforme ordem do software NetMiner) são: A268, A267 e A267. Como a análise de rede ego considera a estrutura da conexão local de cada nó em uma rede, então os médicos com maior densidade não são necessariamente com mais conexões na rede ego (ver Tabela 35).

Tabela 36 - Análise da rede ego (Egonet) - densidade

\begin{tabular}{ccc}
\hline Item & Médico & Densidade \\
\hline 1 & A268 & 1 \\
2 & A267 & 1 \\
3 & A264 & 1 \\
4 & A261 & 1 \\
5 & A258 & 1 \\
6 & A542 & 1 \\
7 & A541 & 1 \\
8 & A539 & 1 \\
9 & A534 & 1 \\
10 & A533 & 1 \\
11 & A530 & 1 \\
12 & A528 & 1 \\
13 & A524 & 1 \\
14 & A521 & 1 \\
15 & A519 & 1 \\
\hline
\end{tabular}

\subsubsection{Structural Hole}

A Tabela 37 traz os resultados da distribuição de medidas de Buraco Estrutural, essas medidas referem-se a rede, sendo:

- Redundância: (a quantidade de informações que o nó i pode receber de outros nós) a média é 0,046 (relativamente baixa), o Desvio Padrão 0,142 e o mínimo 0 e o máximo 0,992 de redundância na rede. Assim, a redundância de informações entre os médicos na rede é baixa; 
- Limitação: (a forma que você tem espaço para negociar ou explorar potenciais buracos estruturais em sua rede) a media é 0, o Desvio Padrão 0,006 e o mínimo 0 e o máximo 1 de limitação na rede, ou seja, nessa rede é baixa a limitação;

- Eficiência: (1 menos redundância somado para todos os alters) a média é 0,532, o Desvio Padrão é 0,156 e o mínimo 0 e o máximo 1, embora a medida de eficiência da rede esteja na média, mas em comparação com os demais indicadores de buraco estrutural, a rede é relativamente eficiente;

- Tamanho Eficaz: (é o número de pessoas que estão conectadas a ego, menos a redundância na rede) a média é 57,72, o Desvio Padrão é 88,929 e o mínimo 0 e o máximo 417,449 - o tamanho eficaz é baixo;

- Hierarquia: (a medida em que a limitação do ego é concentrada em um alter único) a média é 0,061, o Desvio Padrão é 0,144 e o mínimo 0 e o máximo 1, assim a rede o nível de hierarquia é baixo na rede.

Tabela 37 - Distribuição de medidas de buraco estrutural

\begin{tabular}{lrrrrr}
\hline \multirow{2}{*}{ Medidas } & \multicolumn{5}{c}{ Valor } \\
\cline { 2 - 6 } & Redundância & Limitação & Eficiência & Tamanho Eficaz & Hierarquia \\
\hline Média & 0,046 & 0 & 0,532 & 57,72 & 0,061 \\
Desvio Padrão & 0,142 & 0,006 & 0,156 & 88,929 & 0,144 \\
Mínimo & 0 & 0 & 0 & 0 & -0 \\
Máximo & 0,992 & 1 & 1 & 417,449 & 1 \\
\hline
\end{tabular}

Os resultados da distribuição de medidas de Buraco Estrutural são apresentados na Tabela 38. Essa tabela demonstra 15 médicos com maior índice (conforme ordem do software NetMiner) e, a análise é de cada nó da rede. A análise contempla 789 médicos (nós) para todas as medidas referente a Buraco Estrutural.

Na medida de Limitação Agregada 3 médicos apresentaram o índice 1,125 e 14 médicos apresentaram o índice 1, já os demais índices são menores. Todavia, na Limitação Agregada significa que os médicos com maior índice (A125, A126, A127, A5 entre outros) estão melhores posicionados para acessar informações ou explorar potencias buracos estruturais em sua rede (BURT, 1992). Os médicos A125, A126 e A127 são médicos de Estratégia e Saúde da Família, atuam em unidade básica de saúde com apenas 1 vínculo profissional e a carga horária semanal de trabalho é 40 horas e, o médico A5 tem como ocupação declarada de médico clínico, atua em um centro de unidade básica de saúde com 
apenas 1 vínculo profissional e a carga horária semanal de trabalho é 40 horas. Esses médicos apresentam baixa centralidade na rede e, estão localizados na periferia da rede.

Em termos de medida de Eficiência, dos 789 médicos, os 15 médicos com maior índice apresentaram o resultado 1 , isto implica que esses médicos maximizaram o número de contatos não redundantes (demonstram o tamanho efetivo da rede) e diminuíram o número de contatos redundantes na rede. Isso evidencia que esses atores são mais eficientes, dessa forma, esse posicionamento na rede permite o acesso a novas informações. Nota-se que tanto na medida de Limitação Agregada quanto na de Eficiência 13 médicos possuem o mesmo indicador 1, exceto os médicos A125, A126 e A127 que apresentam 1,125. Os médicos A118, A119 e A120 são médicos de Estratégia e Saúde da Família ou com mais 1 ocupação (psiquiatria) e atuam em centro de unidade básica de saúde, carga horaria varia entre 40 horas e 45 horas semanais e possuem de 1 a 2 vínculos profissionais. Esses médicos apresentam baixa centralidade na rede e, estão localizados na periferia da rede.

No Tamanho Eficaz, os 15 médicos mencionados na tabela que apresentam o maior índice variam de 417,448 a 365,108, sendo os três primeiros: A204 (417,448), A223 $(411,781)$ e o A172 $(393,090)$, desse modo, esses índices apresentam somente o número de médicos que estão conectados a ego. Esses médicos são atores mais centrais, com maior número de ocupações (1 a 5) e a maior carga horária de trabalho está concentrada em hospitais (52 horas/semanais a 67 horas/semanais).

E por fim, na medida Hierarquia, dos 789 médicos, os 14 médicos com maior índice apresentam índice 1, porém, esses médicos demonstram ligação somente com um alter. Os cinco primeiros médicos, quatro deles são os mesmos médicos que apresentam maior índice na medida de eficiência, então esses atores estão localizados na periferia da rede e apresentam baixo grau de centralidade.

Tabela 38 - Medidas de buraco estrutural

\begin{tabular}{lllllllll}
\hline Item & Médicos & Limitação & Médicos & Eficiência & Médicos & $\begin{array}{l}\text { Tamanho } \\
\text { Eficaz }\end{array}$ & Médicos & $\begin{array}{l}\text { Hierar } \\
\text {-quia }\end{array}$ \\
\hline $\mathbf{1}$ & A125 & 1,125 & A5 & 1 & A204 & 417,448 & A5 & 1 \\
$\mathbf{2}$ & A126 & 1,125 & A118 & 1 & A223 & 411,781 & A119 & 1 \\
$\mathbf{3}$ & A127 & 1,125 & A119 & 1 & A172 & 393,090 & A120 & 1 \\
$\mathbf{4}$ & A5 & 1 & A120 & 1 & A251 & 389,384 & A122 & 1 \\
$\mathbf{5}$ & A119 & 1 & A122 & 1 & A197 & 386,594 & A123 & 1 \\
$\mathbf{6}$ & A120 & 1 & A123 & 1 & A215 & 382,547 & A124 & 1 \\
$\mathbf{7}$ & A122 & 1 & A124 & 1 & A31 & 380,529 & A129 & 1 \\
$\mathbf{8}$ & A123 & 1 & A129 & 1 & A143 & 372,162 & A725 & 1 \\
\hline
\end{tabular}




\begin{tabular}{lllllllll}
\hline $\mathbf{9}$ & A124 & 1 & A725 & 1 & A148 & 367,851 & A726 & 1 \\
$\mathbf{1 0}$ & A129 & 1 & A726 & 1 & A173 & 367,851 & A727 & 1 \\
$\mathbf{1 1}$ & A725 & 1 & A727 & 1 & A198 & 367,851 & A728 & 1 \\
$\mathbf{1 2}$ & A726 & 1 & A728 & 1 & A208 & 367,851 & A729 & 1 \\
$\mathbf{1 3}$ & A727 & 1 & A729 & 1 & A220 & 367,851 & A736 & 1 \\
$\mathbf{1 4}$ & A728 & 1 & A736 & 1 & A145 & 365,108 & A738 & 1 \\
$\mathbf{1 5}$ & A729 & 1 & A738 & 1 & A146 & 364,852 & A2 & 0,6209 \\
\hline
\end{tabular}

Esta seção buscou mapear a rede de médicos com vínculos profissionais em unidades de saúde públicas e privadas, além das medidas globais da rede que foram produzidas com o auxilio do Software NetMiner3, adicionalmente, foram utilizadas as ferramentas de estatísticas básicas descritivas, tais como: média e correlação.

Para tanto, a amostra envolveu todos os médicos do município de Bauru que possuem algum vinculo profissional com o SUS, totalizando 789 médicos. O total dos vínculos desses médicos são 2.582 e, a média da quantidade dos vínculos por médico é 3 . Com relação a carga horária de trabalho semanal dos médicos, a média é 42 horas e, as horas semanais de trabalho por vínculo, a média é 17 horas semanais.

Foram analisadas as relações entre as seguintes variáveis:

(1) Carga horária total dos médicos e vínculo profissional dos médicos, cujo o resultado foi 0,27 , ou seja, uma correlação linear positiva, porém é baixa, caso estivesse próxima de 1 existiria uma correlação linear forte (TOLEDO e OVALLE, 1988);

(2) Grau de centralidade dos médicos e a carga horária total dos médicos, o resultado foi próximo de nulo $(0,046)$, ou seja, as correlações entre as variáveis apresentam correlações de pequena a quase imperceptível significância. Embora não exista correlação entre essas variáveis, observa-se que os quatro médicos com maior grau de centralidade (ver Tabela 25) estão com uma carga horária semanal acima da média (42 horas), sendo o primeiro A223, 56 horas, o segundo A204 com 78 horas semanais, o terceiro A251, 79 horas e o quarto A172 com 61 horas semanais. Entretanto, os resultados comprovam que a maioria dos atores centrais não possuem maior carga horária;

(3) Grau de centralidade dos médicos e a quantidade de vínculos profissionais, o resultado foi de uma correlação linear positiva 0,22 , porém baixa. Observa-se que dos quatro médicos com maior grau de centralidade, conforme mencionado na Tabela 25, apresentam um número de vínculos profissionais acima da média (3 vínculos), sendo: os dois primeiros, o A223 e A204, possuem, respectivamente, 6 e 4 vínculos profissionais, já o terceiro médico A251 possui 10 
vínculos e o quarto médico possui 11 vínculos profissionais. Dessa forma, pode-se afirmar que os atores centrais possuem mais vínculos profissionais, comparado com os atores que encontram-se na periferia da rede. Como evidência, os atores: A557, A740 e A119 possuem 1 vínculo profissional, sendo os dois primeiros 0 de centralidade e o último A119 possui o grau de centralidade 0,001 .

Concluída esta fase de análise (médicos), o Quadro 15, resume as principais discussões sobre as medidas da rede e os principais achados no nível de análise dos médicos.

\begin{tabular}{|c|c|c|}
\hline \multicolumn{2}{|r|}{ NÍVEL DE ANÁLISE: MÉDICOS } & \multirow[b]{2}{*}{ Autores } \\
\hline Medidas da rede & Principais achados & \\
\hline Degree & $\begin{array}{l}\text { O índice de centralização da rede é } 55,029 \% \text { e, o núcleo da rede é } \\
\text { composto por muitos atores. Esse índice é composto por } 242 \text { atores e, } \\
\text { varia entre } 10 \% \text { e } 67 \% \text { de centralização. Dos } 789 \text { médicos, } 781 \text { médicos } \\
\text { possuem algum grau de centralidade na rede. O posicionamento de } \\
\text { centralidade permite esses atores a acessar novos conhecimentos, } \\
\text { recursos e informações na rede } \\
\text { Nota-se que os quatro médicos mais centrais possuem vínculos } \\
\text { profissionais públicos e privados, sendo a maior carga horária em } \\
\text { hospitais e a ocupação anestesiologista e médico clínico está presente em } \\
\text { três médicos que ocupam a posição mais central na rede. }\end{array}$ & $\begin{array}{l}\text { Borgatti, } \\
2005 \\
\text { Wasserma } \\
\text { n e Faust, } \\
1994\end{array}$ \\
\hline Coreness & $\begin{array}{l}\text { O índice de Coreness é 122. Assim, um grupo de } 148 \text { atores } \\
\text { apresentaram uma posição mais central na rede do total de } 789 \text { atores. } \\
\text { Isso significa que esses atores com maior Coreness estão colaborando } \\
\text { principalmente dentro do núcleo principal. }\end{array}$ & $\begin{array}{l}\text { Batagelj e } \\
\text { Zaversnik, } \\
2002\end{array}$ \\
\hline Closeness & $\begin{array}{l}\text { O índice de Closeness é } 0,49 \% \text {. Os três médicos com maior grau de } \\
\text { closeness não são os que apresentam maior carga horária semanal de } \\
\text { trabalho, porém eles estão acima da média ( } 42 \text { horas) são eles: o A204 } \\
\text { (centralidade } 0,730 \text { e carga horária } 78 \text { ), o A223 (centralidade } 0,723 \text { e } \\
\text { carga horária } 56 \text { e o A172 (0,716 e carga horária } 61) \text {. Esses estão } \\
\text { localizados no núcleo da rede e possuem um índice maior de } \\
\text { centralidade closeness em relação aos demais atores da rede, isso } \\
\text { permite contatar facilmente muitos outros atores }\end{array}$ & $\begin{array}{l}\text { Tasseli, } \\
2015 ; \\
\text { Powell, } \\
\text { Koput e } \\
\text { Doerr, } \\
1996\end{array}$ \\
\hline Betweenness & $\begin{array}{l}\text { O índice de Betweenness é } 0,091 \% \text {. Os três atores com maior } \\
\text { Betweenness atuam a maior parte de sua carga horária em hospitais e, } \\
\text { seus vínculos profissionais são públicos e privados. Esses atores são } \\
\text { benéficos como um potencial índice de um ponto para o controle da } \\
\text { comunicação. } \\
\text { Esses médicos possuem uma posição mais forte em termos de } \\
\text { brokerage, ou seja, mais controle (e, assim, poder) sobre o fluxo de } \\
\text { conhecimento através da rede. }\end{array}$ & $\begin{array}{l}\text { Fremann, } \\
\text { 1979). } \\
\text { Baum et } \\
\text { al., } 2010\end{array}$ \\
\hline Density & $\begin{array}{l}\text { Embora a rede seja grande, composta por muitos atores (789), ela é } \\
\text { densa e com alto grau de conectividade entre os principais atores. O } \\
\text { índice de densidade é de } 0,119 \text {. Tal índice de densidade tem como } \\
\text { significado que } 11 \% \text { das relações possíveis dentro da rede se efetivam. } \\
\text { Promove a confiança e a cooperação entre os médicos e pode gerar } \\
\text { capital social. }\end{array}$ & $\begin{array}{l}\text { Coleman, } \\
1988\end{array}$ \\
\hline Inclusiveness & $\begin{array}{l}\text { O índice de inclusão da rede é de } 98,859 \% \text {, o número de nós conectados } \\
\text { (médicos) expressas como uma proporção do número total de nós. Tal } \\
\text { índice, chega quase } 100 \% \text {, então considera-se um grande número de nós } \\
\text { conectados. }\end{array}$ & $\begin{array}{l}\text { Zoppi, } \\
2012\end{array}$ \\
\hline
\end{tabular}




\begin{tabular}{|l|l|l|}
\hline Egonet & $\begin{array}{l}\text { Os três médicos que representam o maior número de ligações do nó } \\
\text { focal são: A223, A204 e A251. Esses médicos revelam o papel de ator } \\
\text { focal na rede ego, então os médicos com maior número de } \\
\text { conexões/parcerias tem grande possibilidade de inovar. }\end{array}$ & $\begin{array}{l}\text { BAU } \\
\text { al., }\end{array}$ \\
\hline Structural Hole & $\begin{array}{l}\text { A análise contempla } 789 \text { médicos (nós), } 3 \text { médicos apresentaram o } \\
\text { índice 1,125 e } 14 \text { médicos apresentaram o índice 1 (na medida de }\end{array}$ & 1992). \\
& $\begin{array}{l}\text { Limitação Agregada) e } 15 \text { médicos com maior índice apresentaram o } \\
\text { resultado 1 (na medida de Eficiência) e os demais índices são menores. } \\
\text { Esses médicos estão melhores posicionados para acessar informações ou } \\
\text { explorar potencias buracos estruturais em sua rede. Além disso, eles } \\
\text { apresentam baixa centralidade na rede e, estão localizados na periferia da } \\
\text { rede } \\
\text { No Tamanho Eficaz, os três médicos que apresentam maior índice são: } \\
\text { A204, A223 e o A172, desse modo, esse índice apresenta somente o } \\
\text { número de médicos que estão conectados a ego. Esses médicos são } \\
\text { atores mais centrais, com maior número de ocupações (1 a 5) e a maior } \\
\text { carga horária de trabalho está concentrada em hospitais, sendo de 52 } \\
\text { horas a 67 horas semanais. } \\
\text { Na medida de hierarquia, 14 médicos apresentaram o maior índice, ou } \\
\text { seja, 1. Esses médicos apresentam baixa centralidade na rede e, estão } \\
\text { localizados na periferia da rede }\end{array}$ \\
\hline
\end{tabular}

Quadro 15 - Resumo das discussões sobre as medidas da rede no nível de análise - médicos

\subsubsection{Nível de Análise - Ocupações dos Médicos}

Esta seção se dedica a apresentar a rede de ocupações dos médicos. Para a análise da rede as medidas foram extraídas pelo software NetMiner3. Para o mapeamento da rede utilizou-se o arquivo BDD e criou uma nova planilha no Excel denominada OMED (Ocupações dos Médicos), com os nomes dos médicos e as ocupações que os médicos possuíam nos vínculos profissionais, independente de ser alguma ocupação médica ou cargo administrativo, conforme classificação da CBO (Cadastro Brasileiro de Ocupações). Posteriormente, os nomes dos médicos foram substituídos por códigos, sendo de A1 a A789.

Então, essa planilha foi inserida no software NetMiner3 para que os dados fossem tratados, excluídos os dados duplicados e transformados em uma matriz de 1 modo. Assim, gerou uma matriz de 1 Modo com 65 ocupações e suas interações. A Tabela 39 mostra uma parte da matriz, ou seja, 10 ocupações e suas relações. Nessa matriz, observa-se que diferentes ocupações possuem relações, tais como: o Médico Anestesiologista possui 42 ligações com o Médico Clínico, o Médico Cirurgião geral possui 66 ligações com o Médico Clínico e o Médico Pediatra possui 17 ligações com o Médico de Medicina Intensiva. Outro dado observado são as mesmas ocupações, nota-se que o número de interações é maior quando comparado com as diferentes ocupações. Os Médicos Clínicos possuem 357 vínculos com os 
Médicos Clínicos e os Médicos Cardiologistas possuem 54 ligações com os Médicos Cardiologistas. Do mesmo modo, aos demais níveis de análise nesta pesquisa, essa rede também é uma rede não-direcional, isto é, as ligações entre nós não dependem de sua origem.

Tabela 39 - Matriz (parte) da rede de ocupações dos médicos

\begin{tabular}{|c|c|c|c|c|c|c|c|c|c|c|}
\hline & $\begin{array}{l}\text { Anestesio } \\
\text {-logista }\end{array}$ & Clínico & $\begin{array}{l}\text { Citopato- } \\
\text { logista }\end{array}$ & $\begin{array}{c}\text { Cirurgião } \\
\text { Geral }\end{array}$ & $\begin{array}{l}\text { Anatomopa } \\
\text {-tologista }\end{array}$ & $\begin{array}{c}\text { Psiquia } \\
\text {-tra }\end{array}$ & Pediatra & $\begin{array}{l}\text { Medicina } \\
\text { Intensiva }\end{array}$ & $\begin{array}{c}\text { Cirurgião } \\
\text { Cardio- } \\
\text { vascular }\end{array}$ & $\begin{array}{l}\text { Cardio- } \\
\text { logista }\end{array}$ \\
\hline $\begin{array}{l}\text { Anestesio- } \\
\text { logista }\end{array}$ & 93.0 & 42.0 & 0 & 24.0 & 0 & 0 & 2.0 & 8.0 & 6.0 & 7.0 \\
\hline Clínico & 42.0 & 357.0 & 0 & 66.0 & 0 & 3.0 & 24.0 & 30.0 & 14.0 & 29.0 \\
\hline $\begin{array}{l}\text { Citopato- } \\
\text { logista }\end{array}$ & 0 & 0 & 6.0 & 2.0 & 6.0 & 0 & 0 & 0 & 0 & 0 \\
\hline $\begin{array}{l}\text { Cirurgião } \\
\text { Geral }\end{array}$ & 24.0 & 66.0 & 2.0 & 106.0 & 2.0 & 0 & 1.0 & 4.0 & 7.0 & 5.0 \\
\hline $\begin{array}{l}\text { Anatomo- } \\
\text { patologista }\end{array}$ & 0 & 0 & 6.0 & 2.0 & 10.0 & 0 & 0 & 0 & 0 & 0 \\
\hline Psiquiatra & 0 & 3.0 & 0 & 0 & 0 & 16.0 & 1.0 & 0 & 0 & 0 \\
\hline Pediatra & 2.0 & 24.0 & 0 & 1.0 & 0 & 1.0 & 103.0 & 17.0 & 0 & 1.0 \\
\hline $\begin{array}{l}\text { Medicina } \\
\text { Intensiva }\end{array}$ & 8.0 & 30.0 & 0 & 4.0 & 0 & 0 & 17.0 & 48.0 & 8.0 & 14.0 \\
\hline $\begin{array}{l}\text { Cirurgião } \\
\text { Cardio- } \\
\text { vascular }\end{array}$ & 6.0 & 14.0 & 0 & 7.0 & 0 & 0 & 0 & 8.0 & 18.0 & 10.0 \\
\hline $\begin{array}{l}\text { Cardiolo- } \\
\text { gista }\end{array}$ & 7.0 & 29.0 & 0 & 5.0 & 0 & 0 & 1.0 & 14.0 & 10.0 & 54.0 \\
\hline
\end{tabular}

As subseções a seguir se dedica a apresentar, os resultados das medidas de análise do mapeamento da rede de ocupações do médicos, por meio do software NetMiner3 (Quadro 16).

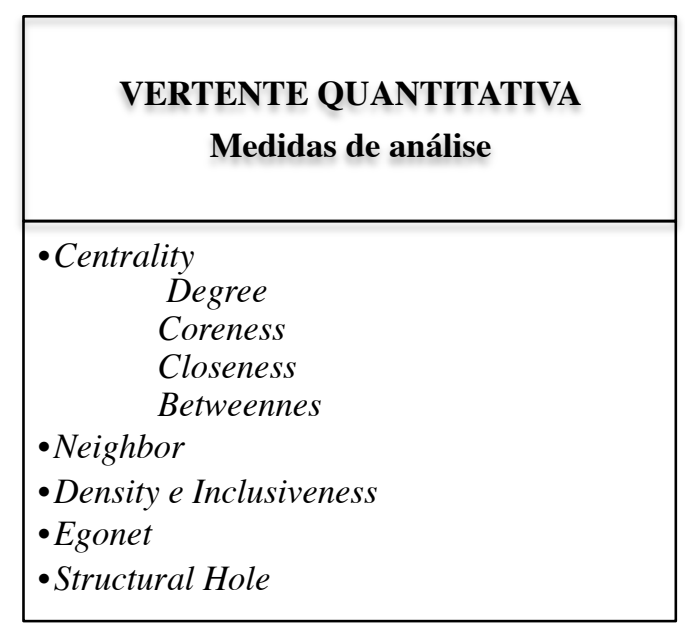

Quadro 16 - Medidas de análise

Nível de Análise - ocupações dos médicos 


\subsubsection{Análise de Centralidade}

As medidas de Centralidade da rede de ocupações dos médicos realizadas por meio do software Netminer3, incluem: Degree Centrality; Coreness; Closeness; Betweenness Node; Betweenness-Link.

O mapeamento da rede por meio do software NetMiner3, gerou-se 2 planilhas no Excel para cada medida de centralidade mencionada. As planilhas são apresentadas em forma de tabela, sendo: (1) Distribuição do índice do grau de centralidade - são os indicadores gerais da rede, eles mensuram a Média de todas as relações; o Desvio Padrão, ou seja, a variação da média; Mínimo e Máximo, que indicam os graus máximo e mínimo de interações que os atores tem dentro da rede e, por último, o Índice de centralização da rede é a soma de todas as relações e (2) Análise de Centralidade - é o resultado de centralidade para cada ator da rede.

O mapeamento da rede de ocupações dos médicos envolveu 65 ocupações, por questões práticas, apresenta-se, as 15 ocupações com maior grau de centralidade.

\subsection{Degree Centrality}

Os indicadores gerais das ocupações dos médicos da rede são apresentados na Tabela 40. Os resultados dessa tabela traz a média de todas as relações, 0,118 e o Desvio Padrão, 0,134 em relação ao índice de centralização da rede, ou seja, as conexões que estão mais dispersas. Assim, o mínimo de conexões é 0 e o máximo é 0,844 . Logo, o grau de o índice de centralização da rede de ocupações é 73,68\%, isso indica alto grau de centralidade dos atores na rede. Isso resulta no acesso a recursos, poder, informações do ator na rede (tanto os médicos quanto as unidades de saúde) por meio das ocupações dos médicos (BALESTRIN e VERSCHOORE, 2008) 
Tabela 40 - Distribuição do índice do grau de centralidade

\begin{tabular}{lr}
\hline \multicolumn{2}{c}{ MEDIDA } \\
\cline { 2 - 2 } & \multicolumn{2}{c}{ GALOR } \\
\hline Média & 0,118 \\
Desvio Padrão & 0,134 \\
Mínimo & 0 \\
Máximo & 0,844 \\
Índice de centralização da rede & $73,68 \%$ \\
\hline
\end{tabular}

Os resultados da Tabela 41 mostram, os 15 atores com maior centralidade na rede. Centralidade é a importância de um nó (de uma ocupação) devido à sua posição estrutural na rede (BORGATTI, 2009). Dessa forma, o ator que ocupa a posição mais central desta rede, em termos interações dentro da rede é a Ocupação de Médico Clínico, isso corresponde um grau de centralidade de 0,84375, seguido do Médico Cirurgião Geral com grau de centralidade de 0,53125 e do Médico Anestesiologista com grau de centralidade de 0,4375. Essas ocupações mais centrais na rede permite o acesso de novos conhecimentos e medir o envolvimento de um ator na rede (WASSERMAN e FAUST, 1994).

Tabela 41 - Análise de centralidade (degree)

\begin{tabular}{clc}
\hline Item & \multicolumn{1}{c}{ Ocupações } & $\begin{array}{c}\text { Degree } \\
\text { Centrality }\end{array}$ \\
\hline $\mathbf{1}$ & Médico Clínico & 0,84375 \\
$\mathbf{2}$ & Médico Cirurgião Geral & 0,53125 \\
$\mathbf{3}$ & Médico Anestesiologista & 0,4375 \\
$\mathbf{4}$ & Médico Pediatra & 0,359375 \\
$\mathbf{5}$ & Médico em Medicina Intensiva & 0,3125 \\
$\mathbf{6}$ & Médico em Radiologia e Diagnostico por Imagem & 0,234375 \\
$\mathbf{7}$ & Diretor de Serviços de Saúde & 0,21875 \\
$\mathbf{8}$ & Médico Oncologista Clínico & 0,21875 \\
$\mathbf{9}$ & Médico Cardiologista & 0,21875 \\
$\mathbf{1 0}$ & Médico Cirurgião Cardiovascular & 0,171875 \\
$\mathbf{1 1}$ & Médico em Cirurgia Vascular & 0,15625 \\
$\mathbf{1 2}$ & Medico Gastroenterologista & 0,15625 \\
$\mathbf{1 3}$ & Médico Residente & 0,15625 \\
$\mathbf{1 4}$ & Médico Hematologista & 0,15625 \\
$\mathbf{1 5}$ & Médico Ginecologista e Obstetra & 0,15625 \\
& & \\
\hline
\end{tabular}


Para ilustrar o grau de centralidade da rede de ocupações dos médicos, apresenta-se, o mapa da Figura 38. Essa figura mostra a ocupação de Médico Clínico no centro do mapa, ou seja, com maior grau de centralidade. Todavia, as ocupações que possuem maior interação, por meio dos vínculos profissionais dos médicos, tendem, a localizar-se em redes mais densas.

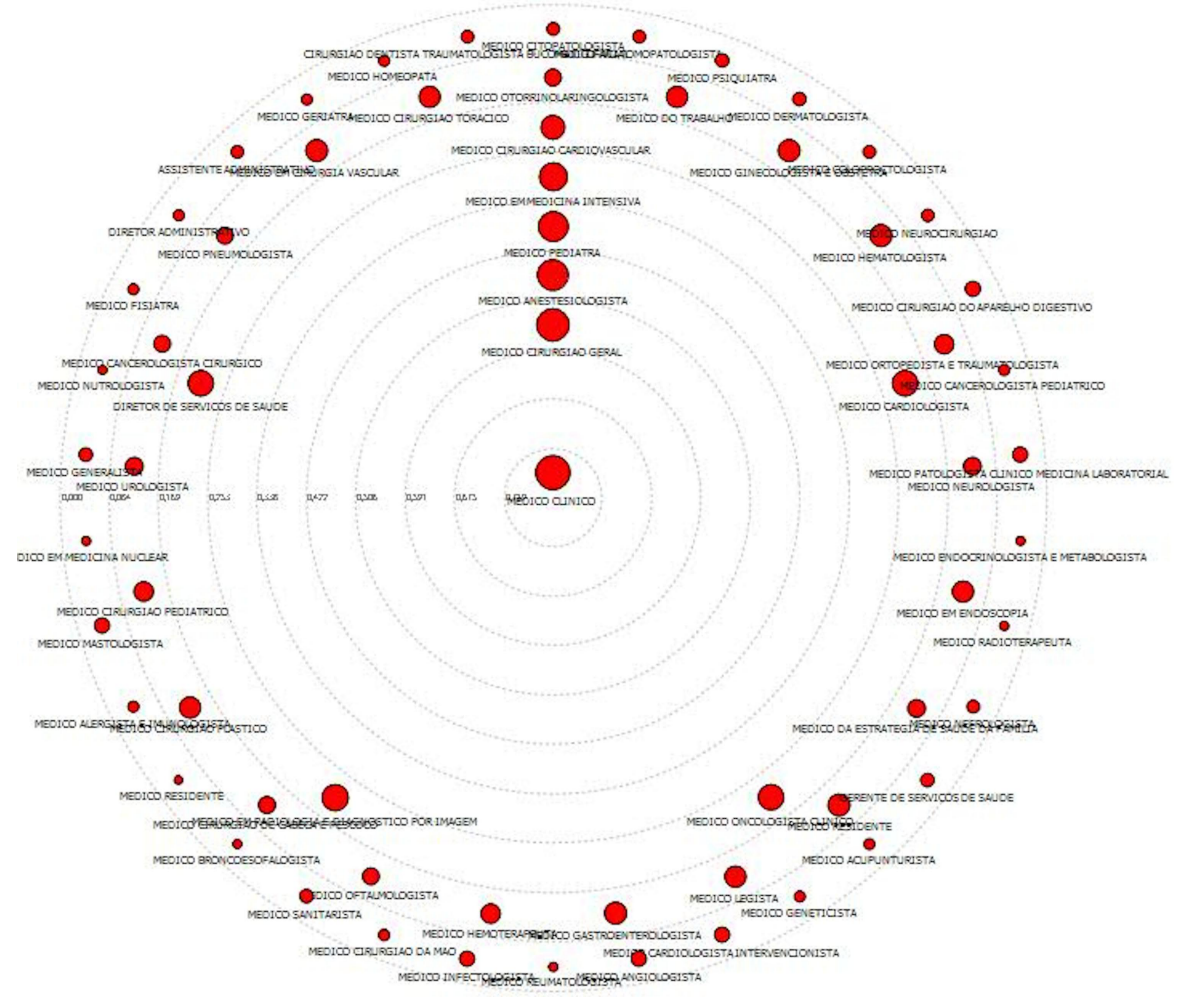

Figura 38 Análise de centralidade (degree)

Visualização Concentric NetMiner 3

Os mapas das Figuras 39 (mapa do núcleo da rede) e 40 (mapa completo da rede) ilustram que quanto maior for o tamanho do círculo vermelho, maior será o grau de centralidade do ator na rede, então, observa-se que as ocupações dos médicos com o maior grau de centralidade são: Médico Clínico, Cirurgião Geral, Médico Anestesiologista, entre outros. Por outro lado, os menos centrais são: Médico Broncoesofalogista, Médico Radioterapeuta, Médico em Medicina Nuclear, entre outros e, esses estão na periferia da rede com baixo grau de centralidade. 


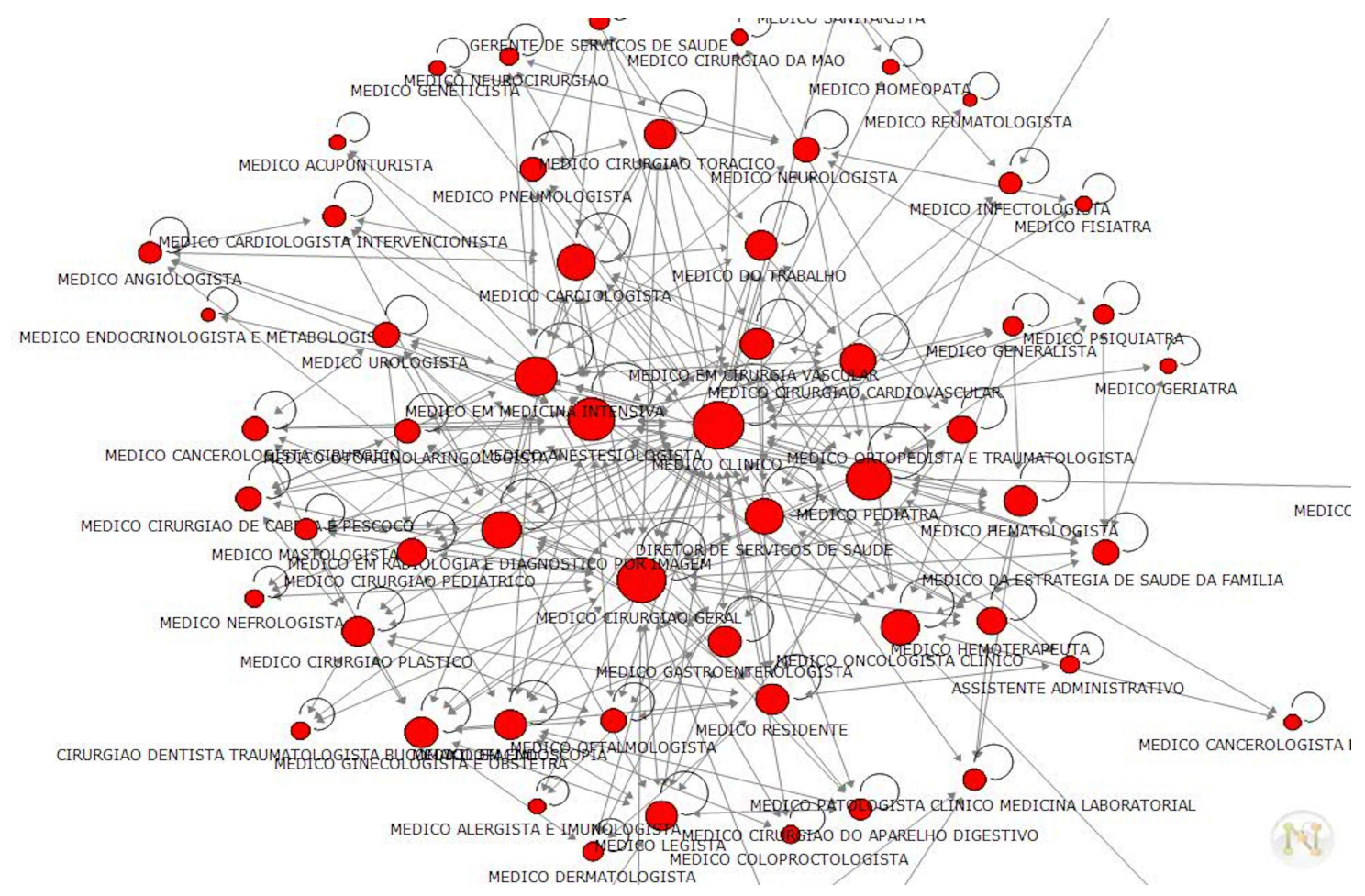

Figura 39 - Análise de centralidade (mapa do núcleo)

Visualização Spring 2D NetMiner 3

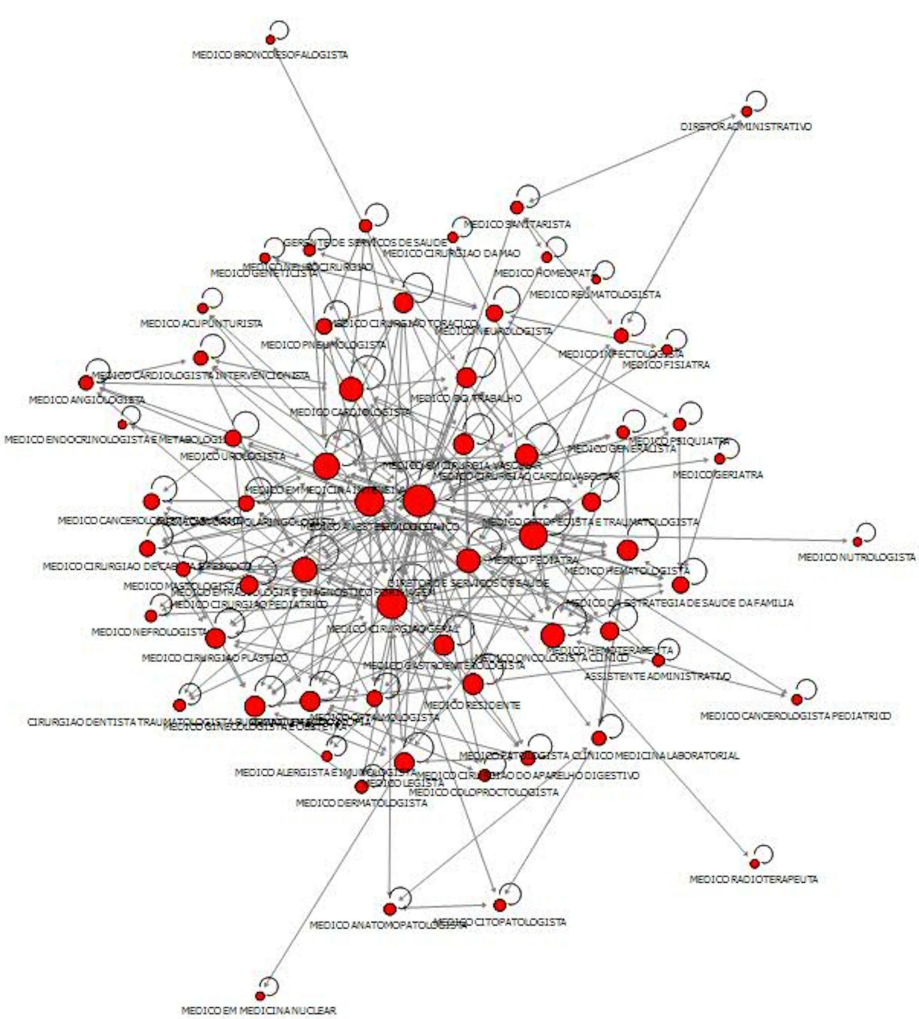

Figura 40 - Análise de centralidade (mapa completo) Visualização Spring 2D NetMiner 3 


\subsection{Coreness}

A medida de Coreness indica o grau de centralização de cada membro da rede, assim, verificou-se a existência de um grupo de 14 atores que apresentaram uma posição mais central na rede, ou seja, o valor 8 . Esse valor varia de 1 a 8 , sendo o 8 com maior índice de centralidade e o 1 com menor centralidade na rede. Observa-se que entre os 65 atores que apresentam o maior Coreness são: Médico Cirurgião Torácico, Médico Cardiologista, Médico Clínico, entre outros (Tabela 42). Assim, esses atores estão agrupados no núcleo da rede e, os demais na periferia da rede (HE et al., 2011).

Tabela 42 - Análise de centralidade (coreness)

\begin{tabular}{clc}
\hline Item & \multicolumn{1}{c}{ Ocupações } & $\begin{array}{c}\text { Coreness } \\
\text { Centrality }\end{array}$ \\
\hline $\mathbf{1}$ & Médico Cirurgião Torácico & 8 \\
$\mathbf{2}$ & Médico em Cirurgia Vascular & 8 \\
$\mathbf{3}$ & Diretor de Serviços de Saúde & 8 \\
$\mathbf{4}$ & Médico em Radiologia e Diagnostico por Imagem & 8 \\
$\mathbf{5}$ & Médico Hemoterapeuta & 8 \\
$\mathbf{6}$ & Médico Oncologista Clínico & 8 \\
$\mathbf{7}$ & Médico Hematologista & 8 \\
$\mathbf{8}$ & Médico Cardiologista & 8 \\
$\mathbf{9}$ & Médico Cirurgião Cardiovascular & 8 \\
$\mathbf{1 0}$ & Médico em Medicina Intensiva & 8 \\
$\mathbf{1 1}$ & Médico Pediatra & 8 \\
$\mathbf{1 2}$ & Médico Cirurgião Geral & 8 \\
$\mathbf{1 3}$ & Médico Clínico & 8 \\
$\mathbf{1 4}$ & Médico Anestesiologista & 8 \\
$\mathbf{1 5}$ & Médico Cancerologista Cirúrgico & 7 \\
\hline
\end{tabular}

A medida de Coreness da rede de ocupações dos médicos é ilustrada no mapa da Figura 41 e, esse foi plotado de acordo com o Layout Algoritmo de Concentric. Nota-se que o Médico Clínico está agrupado no núcleo da rede por apresentar maior pontuação de Coreness (HE et al., 2011). Já as ocupações de Médico Residente, Médico Endocrinologista, Médico Fisiatra, entre outros, estão localizados na periferia da rede. Portanto, os atores com maior Coreness estão colaborando especialmente dentro do núcleo central (BATAGELJ e ZAVERSNIK, 2002). 


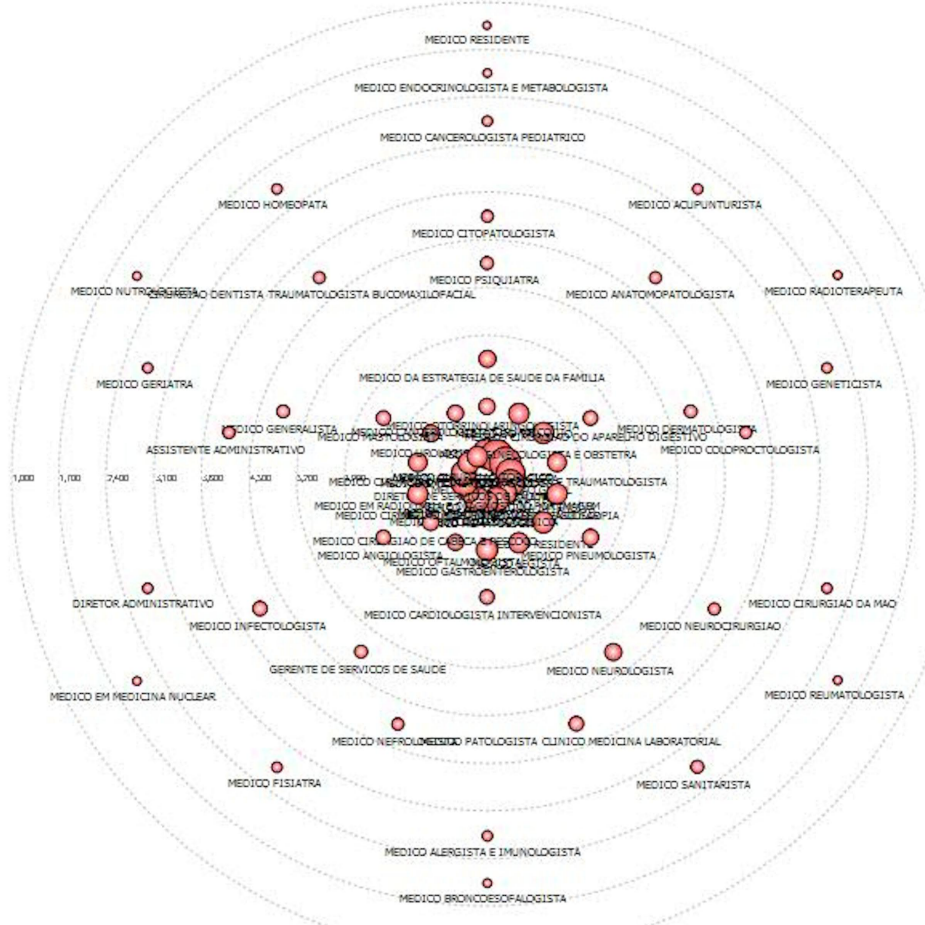

Figura 41 - Análise de centralidade (coreness)

Visualização Concentric NetMiner 3

\subsection{Closeness}

A medida de Closeness indica a análise de centralidade da estrutura da rede com base em distâncias geodésicas entre os nós, assim a média de todas as relações de proximidade é 0,483, o Desvio Padrão, 0,096 em relação a proximidade do ator na rede, ou seja, os atores que estão mais dispersos e o Mínimo 0 e o Máximo 0,861, conforme Tabela 43. Portanto, o grau de proximidade entre os atores e o índice de centralização Closeness da rede é 0,748. Esse índice representa a proximidade central dos atores em relação a rede toda. Considerando que a posição mais central é 1 (CYRAM, 2008), observa-se que o resultado de Closeness está acima da média, então é considerado alto o índice de proximidade dos atores na rede. 
Tabela 43 - Distribuição do índice do grau de centralidade (closeness)

\begin{tabular}{lr}
\hline \multicolumn{1}{c}{ MEDIDA } & \multicolumn{2}{c}{ VALOR } \\
\cline { 2 - 3 } & \multicolumn{2}{c}{ Closeness } \\
\hline Média & 0,483 \\
Desvio Padrão & 0,096 \\
Mínimo & 0 \\
Máximo & 0,861 \\
Índice de centralização da rede & $0,748 \%$ \\
\hline
\end{tabular}

$\mathrm{Na}$ rede de ocupações dos médicos que atendem o SUS, destacam-se como ocupações mais centrais em relação a proximidade: o Médico Clínico $(0,861)$, o Médico Cirurgião Geral $(0,666)$ e o Médico Anestesiologista $(0,620)$, conforme demonstra Tabela 44. Assim, esses atores estão posicionados no núcleo da rede e estão conectados a relacionamentos mais densos e, essa posição permite que eles sejam menos dependente dos atores intermediários (TASSELI, 2015; POWELL, KOPUT e DOERR, 1996). Não obstante disso, os quatro primeiros atores nas medidas de closeness são os mesmos que os dados mostraram serem centrais na medida de grau de centralidade, Tabela 41.

Tabela 44 - Análise de centralidade (closeness)

\begin{tabular}{clc}
\hline Item & \multicolumn{1}{c}{ Ocupações } & Closeness \\
\hline 1 & Médico Clínico & 0,861328 \\
2 & Médico Cirurgião Geral & 0,666835 \\
3 & Médico Anestesiologista & 0,620156 \\
4 & Médico Pediatra & 0,590625 \\
5 & Médico Medicina Intensiva & 0,574219 \\
6 & Médico Radiologia e Diagnostico por Imagem & 0,543997 \\
7 & Médico Oncologista Clinico & 0,539266 \\
8 & Médico Cardiologista & 0,539266 \\
9 & Diretor de Servicos de Saude & 0,530048 \\
10 & Médico Cirurgião Cardiovascular & 0,525556 \\
11 & Médico em Cirurgia Vascular & 0,52114 \\
12 & Médico Gastroenterologista & 0,52114 \\
13 & Médico Hematologista & 0,52114 \\
14 & Médico Hemoterapeuta & 0,512526 \\
15 & Médico Residente & 0,512526 \\
\hline
\end{tabular}


O Mapa da Figura 42 ilustra a análise de centralidade de Closeness, esse mapa foi plotado na forma de Visualização Concentric. O Médico Clínico é o ator mais central e o Médico Residente e o Médico Radioterapeuta são os menos centrais, ou seja, estão localizados na periferia da rede. Esses atores que encontram-se na periferia da rede são mais independentes em relação ao controle por outros atores (MARTELETO, 2001).

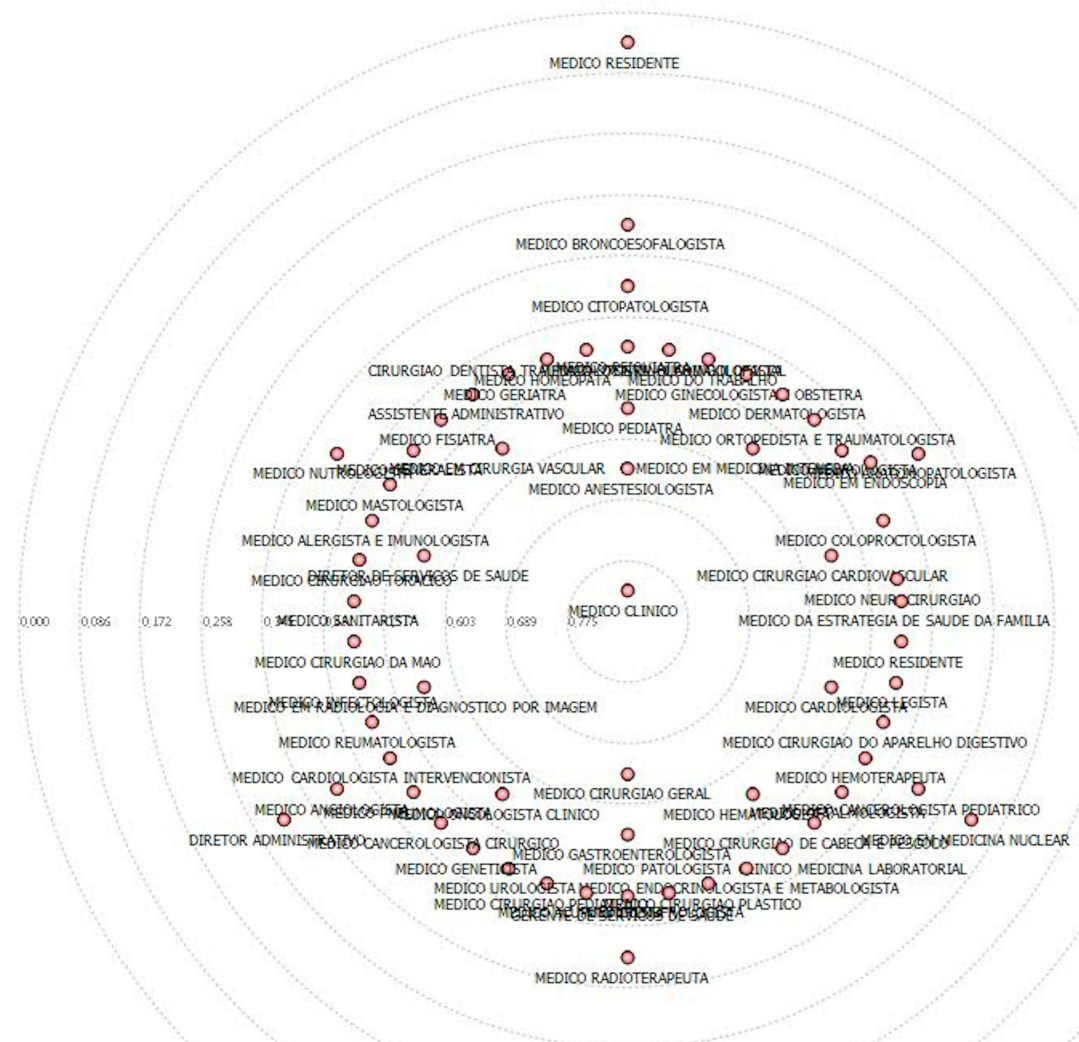

Figura 42 - Análise de centralidade (closeness)

Visualização Concentric NetMiner 3

\subsection{Betweenness -Node}

A Tabela 45 evidencia que na análise da centralização de intermediação da ocupação dos médicos da rede, a média de todas as relações é 0,016 e o Desvio Padrão, 0,066 em relação ao grau de intermediação do ator na rede. Entretanto, o mínimo de centralidade betweenness é 0 e o máximo 0,516. Portanto, o grau de intermediação entre os atores e o 
índice de centralização betweenness da rede é 0,508\%. Esse índice representa a intermediação central dos atores em relação a rede toda.

Tabela 45 - Análise de centralidade (betweenness - node)

\begin{tabular}{lr}
\hline \multicolumn{1}{c}{ MEDIDAS } & \multicolumn{2}{c}{ VALOR } \\
\hline Média & 0,016 \\
Desvio Padrão & 0,066 \\
Mínimo & 0 \\
Máximo & 0,516 \\
Índice de centralização Betweenness da rede & $0,508 \%$ \\
\hline
\end{tabular}

A Tabela 46 apresenta os resultados do Betweenness node de cada ator na rede, além disso, esses resultados permitem descobrir qual ocupação serve como mediador entre os outros atores conectados (IÑIGUEZ et al., 2014). Dessa forma, os destaques são: Médico Clínico (0,516), Médico Cirurgião Geral $(0,130)$ e Médico Pediatra $(0,084)$, que aparecem como os três maiores intermediários na rede, ou seja, determina qual ocupação dos médicos que tem o caminho mais curto entre qualquer par de nós. Particularmente, esse resultado indica pelo fato de qualquer unidade de saúde possuir pelo menos um médico clínico.

Tabela 46 - Análise de centralidade (betweenness - node)

\begin{tabular}{|c|c|c|}
\hline Item & Ocupações & $\begin{array}{c}\text { Node Betweenness } \\
\text { Centrality } \\
\end{array}$ \\
\hline 1 & Médico Clínico & 0,516058 \\
\hline 2 & Médico Cirurgião Geral & 0,130138 \\
\hline 3 & Médico Pediatra & 0,084238 \\
\hline 4 & Médico Anestesiologista & 0,058658 \\
\hline 5 & Médico Oncologista Clínico & 0,045593 \\
\hline 6 & Médico Legista & 0,032085 \\
\hline 7 & Médico Cirurgião Torácico & 0,031349 \\
\hline 8 & Médico em Medicina Intensiva & 0,027964 \\
\hline 9 & Médico Infectologista & 0,019484 \\
\hline 10 & $\begin{array}{l}\text { Médico em Radiologia e Diagnóstico por } \\
\text { Imagem }\end{array}$ & 0,014336 \\
\hline 11 & Médico Sanitarista & 0,01206 \\
\hline 12 & Médico Cardiologista & 0,010994 \\
\hline 13 & Diretor de Serviços de Saúde & 0,010914 \\
\hline 14 & $\begin{array}{l}\text { Médico Patologista Clínico } \\
\text { Laboratorial }\end{array}$ & 0,008723 \\
\hline 15 & Médico Residente & 0,005802 \\
\hline
\end{tabular}


A medida Betweenness node da rede de ocupações dos médicos é delineada pelo mapa da Figura 43 de acordo com o Layout Algoritmo de Concentric. Assim, a centralização de intermediação da ocupação dos médicos da rede o ator que aparece com maior índice de centralidade, ou seja, está localizado no centro do mapa é o Médico Clínico e em seguida o Médico Cirurgião geral, mas com o índice menor.

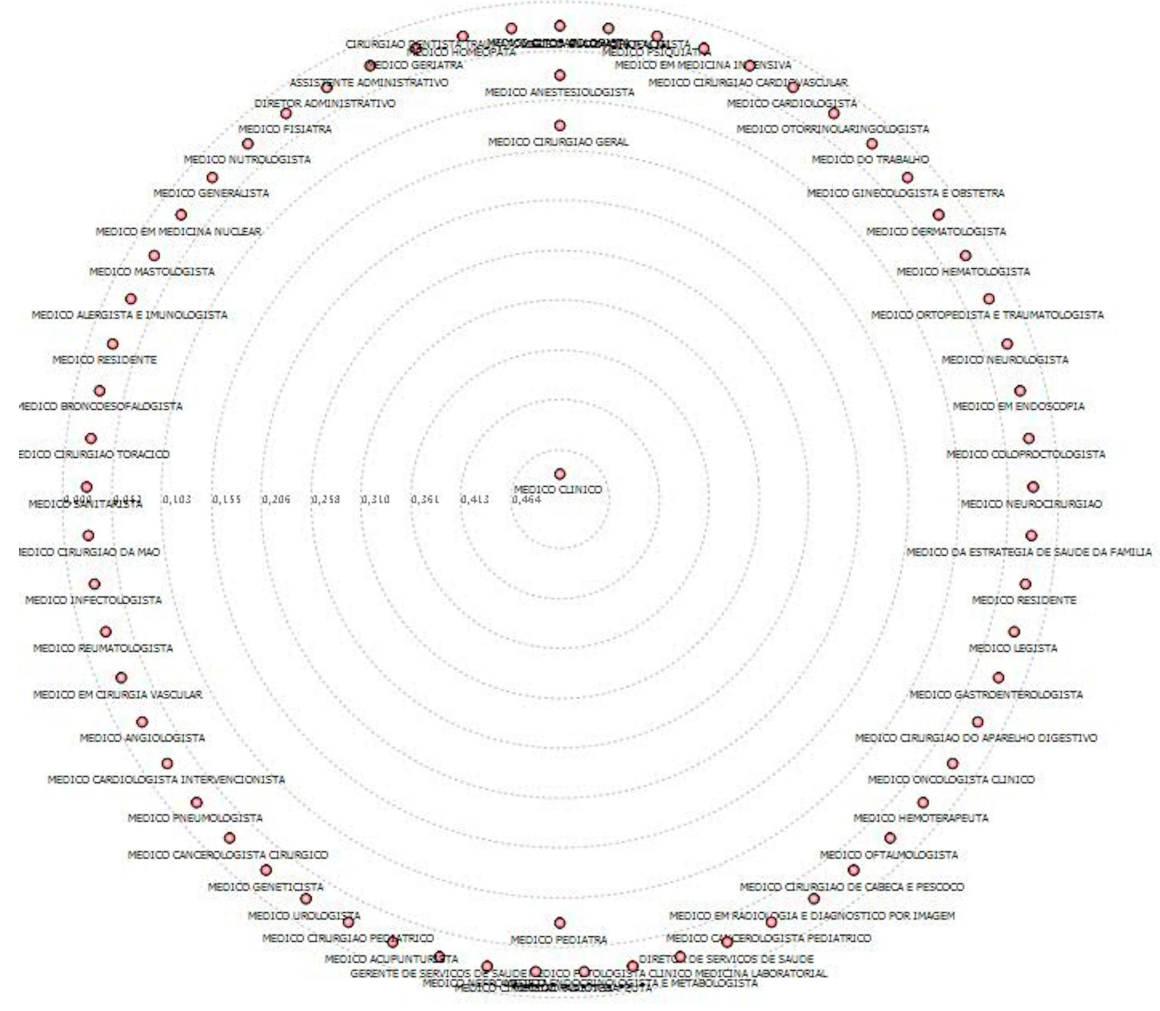

Figura 43 - Análise de Centralidade ( betweenness - node) Visualização Concentric NetMiner 3

\subsection{Betweenness -Link}

A tabela 47 ilustra a análise da centralização de intermediação das ligações dos atores da rede, a média de todas as ligações é 16,821 e o Desvio Padrão, 16,899 em relação ao grau de intermediação das ligações entre os atores na rede, ou seja, as ligações dos atores que estão mais dispersas. Assim, o mínimo é 1 e o máximo das ligações é 80,979. 
Tabela 47 - Análise de centralidade (betweenness - link)

\begin{tabular}{|c|c|}
\hline MEDIDAS & VALOR \\
\hline Média & 16,821 \\
\hline Desvio Padrão & 16,899 \\
\hline Mínimo & 1 \\
\hline Máximo & 80,979 \\
\hline
\end{tabular}

O Mapa da Figura 44 apresenta a rede toda, destaca-se os atores com maior grau de centralidade e ligações, representados pelas círculos maiores, tais como: Médico Clínico, Médico Pediatra, Médico Cirurgião Geral, entre outros. Já os círculos menores são os atores com menor centralidade e ligações, sendo: Diretor Administrativo, Médico Psiquiatra, Médico Dermatologista, Médico Citopalogista, entre outros. Entretanto, observa-se que as quatro ocupações com maior índice de centralidade, são: Médico Clínico, Médico Cirurgião Geral, Médico Pediatra e Médico Anestesiologista, pois possuem maior interação por meio dos vínculos profissionais dos médicos, portanto maior afinidade entre as ocupações tendem a localizar-se em redes mais densas.

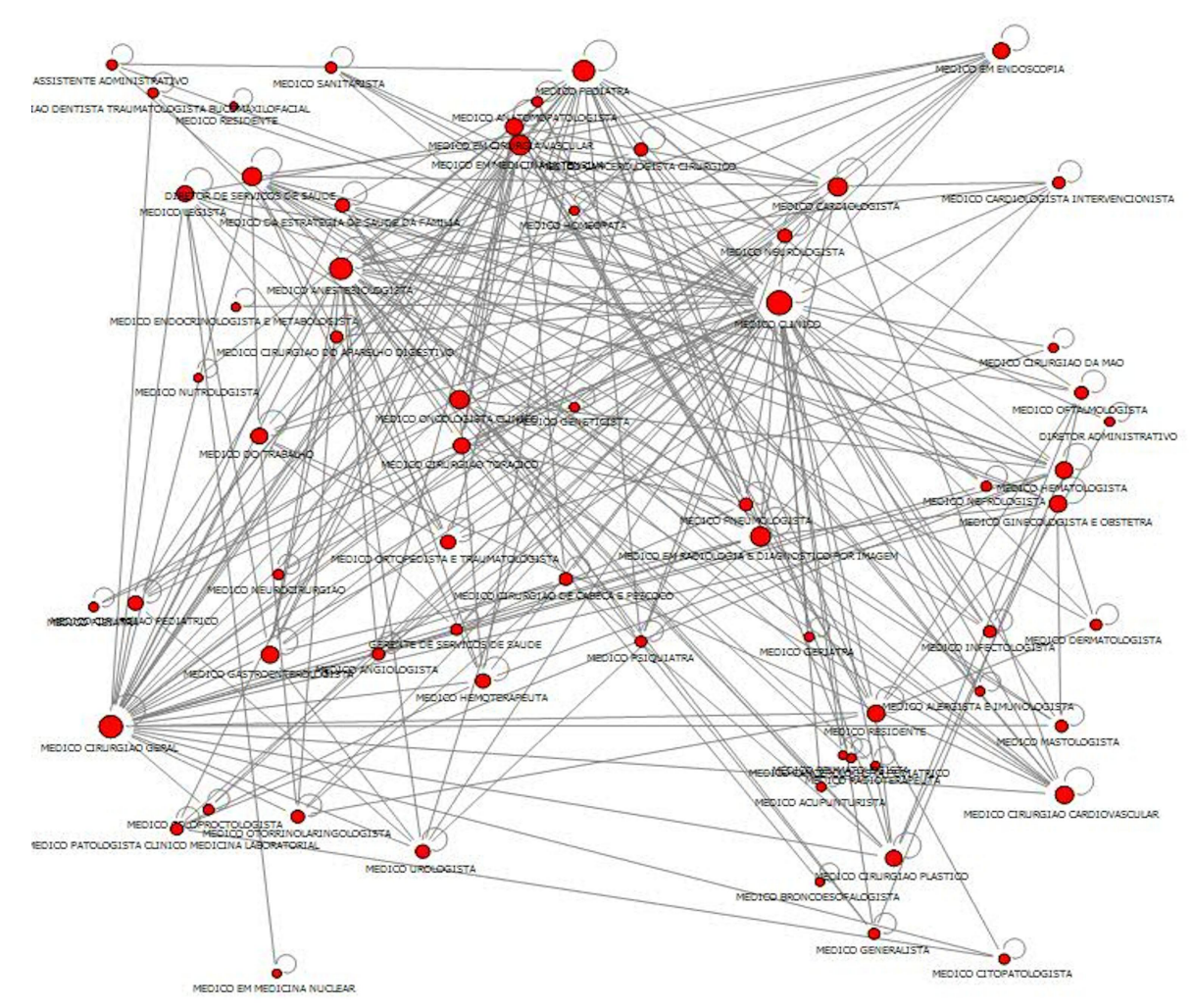

Figura 44 - Mapa geral da rede de ocupações dos Médicos Visualização Spring 2D NetMiner 3 


\subsubsection{Análise - Neighbor, Density e Inclusiveness}

Os resultados da Tabela 48 apresentam a análise de centralidade (Neighbor degree), o Grau nodal (de conexão), ou seja, o número de linhas e o tamanho da vizinhança. Assim, a soma das relações é 492, a média é 7,569 e o Desvio Padrão é 8,552 em relação ao índice de centralização da rede. O mínimo do grau de centralidade é 0 e o máximo é 54 . O número de nós isolados é 9 (ocupações dos médicos), 14 nós pendentes e 98,859\% inclusiveness, ou seja, o número de nós conectados (ocupações dos médicos) expressas como uma proporção do número total de nós. Por fim, a densidade é 0,118 , ou seja, o número de linhas presentes para o máximo possível.

Tabela 48 - Análise de centralidade (neighbor - degree)

\begin{tabular}{lr}
\hline \multicolumn{2}{c}{ MEDIDAS } \\
\cline { 2 - 2 } & \multicolumn{2}{c}{ VALOR } \\
\hline Soma & 492 \\
Média & 7,569 \\
Desvio Padrão & 8,552 \\
Mínimo & 0 \\
Máximo & 54 \\
\# de isolado & 9 \\
\# de pendente & 14 \\
inclusiveness (\%) & $98,859 \%$ \\
\hline Densidade da Rede & 0,118 \\
\hline
\end{tabular}

A Tabela 49 apresenta 1 nós isolados (ocupações dos médicos), 0 nós transmissores e recebedores, 6 carregador (carrega os vínculos) e 58 nós ordinários. Essa rede é não direcionada, então, a análise Neighbor - degree está relacionada com o quarto tipo de nó, “carregador" requerem que ambos grau de entrada e grau de saída são iguais a 1.

Tabela 49 - Número do tipo de nó (neighbor-degree)

\begin{tabular}{crrrrr}
\hline Isolado & Transmissor & Recebedor & Carregador & \multicolumn{2}{c}{ Ordinário } \\
\hline 1 & 0 & 0 & 6 & 58 \\
\hline
\end{tabular}




\subsubsection{Egonet}

Os resultados da Tabela 50 demonstram a distribuição das medidas da rede ego, sendo os seguintes valores: (1) o Tamanho da Rede Ego de cada nó tem em média tem 8,569 conexões, o desvio padrão é 8,552, o mínimo é 1 e o máximo no tamanho das conexões é 55 e (2) a Densidade é indefinida tanto na média quanto no desvio padrão, o valor mínimo é 0,154 e o máximo é 1.

Tabela 50 - Análise da rede ego (Egonet)

\begin{tabular}{lrr}
\hline \multirow{2}{*}{ Medidas } & \multicolumn{2}{c}{ Valor } \\
\cline { 2 - 4 } & Tamanho & \multicolumn{2}{c}{ Densidade } \\
\hline Média & 8,569 & Indefinido \\
Desvio Padrão & 8,552 & Indefinido \\
Mínimo & 1 & 0,154 \\
Máximo & 55 & 1 \\
\hline
\end{tabular}

A Tabela 51 apresenta os resultados da Análise de Rede Ego das 15 ocupações dos médicos com maior número de nós alter (nós que estão adjacentes do nó focal). Assim, o nó focal não está incluído no tamanho da rede ego. Entretanto, as três ocupações dos médicos que representam o maior número de ligações do nó focal são: Médico Clínico (tamanho - 55) e (densidade - 0,153), Médico Cirurgião Geral (tamanho - 35) e (densidade - 0,281) e Médico Anestesiologista (tamanho - 29) e (densidade 0,337). Isso indica que os médicos que possuem uma dessas três ocupações (atores ego), provavelmente se tornarão mais bem informados comparado com as demais ocupações da rede (REAGANS e ZUCKERMAN, 2008).

Tabela 51 - Análise de Rede Ego (Egonet) - tamanho

\begin{tabular}{clc}
\hline Item & \multicolumn{1}{c}{ Ocupações } & Tamanho \\
\hline 1 & Médico Clínico & 55 \\
2 & Médico Cirurgião Geral & 35 \\
3 & Médico Anestesiologista & 29 \\
4 & Médico Pediatra & 24 \\
5 & Médico em Medicina Intensiva & 21 \\
6 & Médico em Radiologia e Diagnostico por & 16 \\
7 & Imagem & 15 \\
8 & Médico Cardiologista & 15 \\
\hline
\end{tabular}




\begin{tabular}{clc}
\hline 9 & Diretor de Serviços de Saúde & 15 \\
10 & Médico Cirurgião Cardiovascular & 12 \\
11 & Médico Ginecologista e Obstetra & 11 \\
12 & Médico Hematologista & 11 \\
13 & Médico Residente & 11 \\
14 & Médico Gastroenterologista & 11 \\
15 & Médico em Cirurgia Vascular & 11 \\
\hline
\end{tabular}

A Tabela 52 apresenta a densidade da rede ego de 15 ocupações dos médicos, a escala varia de 0 (não densa) e 1 (densa). Mas das 65 ocupações dos médicos 22 são densas com valor 1. Essa Tabela apresenta 15 ocupações (ordem decrescente do software NetMiner). Assim uma das três redes ego com maior densidade são: Médico Coloproctalogista, Médico Neurocirurgião e Médico Cirurgião do Aparelho Digestivo. A análise de rede ego considera a estrutura da conexão local de cada nó em uma rede, então as ocupações dos médicos que são mais densas não são necessariamente com mais conexões na rede ego, conforme demostra (Tabela 52) em que o Médico Clínico possui 55 conexões e a densidade é 0,153.

Tabela 52 - Análise da rede ego (Egonet) - densidade

\begin{tabular}{clc}
\hline Item & \multicolumn{1}{c}{ Ocupações } & Densidade \\
\hline 1 & Médico Coloproctologista & 1 \\
2 & Médico Neurocirurgião & 1 \\
3 & Médico Cirurgião do Aparelho Digestivo & 1 \\
4 & Médico Cancerologista Pediátrico & 1 \\
5 & Médico Endocrinologista e Metabologista & 1 \\
6 & Médico Radioterapeuta & 1 \\
7 & Médico Nefrologista & 1 \\
8 & Médico Acupunturista & 1 \\
9 & Médico Geneticista & 1 \\
10 & Médico Reumatologista & 1 \\
11 & Médico Cirurgião da Mão & 1 \\
12 & Médico Broncoesofalogista & 1 \\
13 & Médico Alergista e Imunologista & 1 \\
14 & Médico em Medicina Nuclear & 1 \\
15 & Médico Generalista & 1 \\
\hline
\end{tabular}




\subsubsection{Structural Hole}

A distribuição de medidas de Buraco Estrutural, são apresentadas na Tabela 53, e essa refere-se a rede toda, sendo:

- Redundância: (a quantidade de informações que o nó i pode receber de outros nós) a média é 0,039 (baixa), o Desvio Padrão 0,121 e o mínimo 0 e o máximo 0,813 de redundância na rede. Então, a redundância de informações entre as ocupações dos médicos na rede é baixa;

- Limitação: (a forma que você tem espaço para negociar ou explorar potenciais buracos estruturais em sua rede) a media é 0,009, o Desvio Padrão 0,059 e o mínimo 0 e o máximo 1 de limitação na rede, ou seja, nessa rede é baixa a limitação;

- Eficiência: (1 menos redundância somado para todos os alters) a média é 0,566, o Desvio Padrão é 0,111 e o mínimo 0,353 e o máximo 1, a medida de eficiência da rede está um pouco acima da média, assim comparando com os demais indicadores de buraco estrutural, a rede é relativamente eficiente;

- Tamanho Eficaz: (é o número de atores que estão conectados a ego, menos a redundância na rede) a média é 5,334, o Desvio Padrão é 7,042 e o mínimo 1 e o máximo 49,667 - o tamanho eficaz é baixo;

- Hierarquia: (a medida em que a limitação do ego é concentrada em um alter único) a média é 0,359, o Desvio Padrão é 0,242 e o mínimo 0 e o máximo 0,856, assim a rede o nível de hierarquia é baixo na rede.

Tabela 53 - Distribuição de medidas de buraco estrutural

\begin{tabular}{lrrrrr}
\hline \multirow{2}{*}{ Medidas } & \multicolumn{5}{c}{ Valor } \\
\cline { 2 - 6 } & \multicolumn{1}{c}{ Redundância } & Limitação & Eficiência & Tamanho Eficaz & Hierarquia \\
\hline Média & 0,039 & 0,009 & 0,566 & 5,334 & 0,359 \\
Desvio Padrão & 0,121 & 0,059 & 0,111 & 7,042 & 0,242 \\
Mínimo & 0 & 0 & 0,353 & 1 & 0 \\
Máximo & 0,813 & 1 & 1 & 49,667 & 0,856 \\
\hline
\end{tabular}


A Tabela 54 ilustra os resultados da distribuição de medidas de Buraco Estrutural de Limitação Agregada e de Eficiência de 15 ocupações dos médicos com maior índice e, a análise é de cada nó da rede.

Na Limitação Agregada os três atores com maior índice são: Médico em Medicina Nuclear (10,554), Médico Psiquiatra (7,838) e Médico da Estratégia de Saúde da Família $(7,063)$ estão melhores posicionados para acessar informações ou explorar potencias buracos estruturais em sua rede (BURT, 1992). Esses atores apresentam baixa centralidade na rede e estão localizados na periferia.

Já na medida de Eficiência as ocupações com maior índice são: Médico Residente (1), Médico Clínico $(0,903)$ e Médico Pediatra $(0,704)$, isso implica que essas ocupações dos médicos são caracterizados como os nós mais eficientes da rede, pois maximizaram o número de contatos não redundantes (demonstram o tamanho efetivo da rede) e reduziram o número de contatos redundantes na rede, dessa forma, permite o acesso a novas informações (BURT, 1992).

Tabela 54 - Distribuição de medidas de buraco estrutural (limitação e eficiência)

\begin{tabular}{|c|c|c|c|c|c|}
\hline Item & Ocupação & Limitação & Item & Ocupações & Eficiência \\
\hline 1 & Médico em Medicina Nuclear & 10,554 & 1 & Médico Residente & 1 \\
\hline 2 & Médico Psiquiatra & 7,838 & 2 & Médico Clínico & 0,903034 \\
\hline 3 & $\begin{array}{l}\text { Médico da Estratégia de Saúde } \\
\text { da Família }\end{array}$ & 7,063 & 3 & Médico Pediatra & 0,704462 \\
\hline 4 & Médico Radioterapeuta & 5,093 & 4 & Médico Cirurgião Geral & 0,703132 \\
\hline 5 & $\begin{array}{l}\text { Médico Endocrinologista e } \\
\text { Metabologista }\end{array}$ & 4,501 & 5 & Médico Sanitarista & 0,684545 \\
\hline 6 & Médico Reumatologista & 3,797 & 6 & $\begin{array}{l}\text { Médico Ginecologista e } \\
\text { Obstetra }\end{array}$ & 0,6762 \\
\hline 7 & Médico Oftalmologista & 3,256 & 7 & Médico Infectologista & 0,668434 \\
\hline 8 & Médico Homeopata & 3,174 & 8 & Médico Oncologista Clínico & 0,659139 \\
\hline 9 & Médico Anatomopatologista & 3,144 & 9 & $\begin{array}{l}\text { Médico em Radiologia e } \\
\text { Diagnostico por Imagem }\end{array}$ & 0,656689 \\
\hline 10 & Médico Infectologista & 3,111 & 10 & Médico Legista & 0,656442 \\
\hline 11 & Médico Fisiatra & 3,026578 & 11 & Médico Mastologista & 0,651749 \\
\hline 12 & Médico Neurologista & 2,913645 & 12 & $\begin{array}{l}\text { Médico Patologista Clinico } \\
\text { Medicina Laboratorial }\end{array}$ & 0,650606 \\
\hline 13 & Médico Sanitarista & 2,752559 & 13 & Médico Anestesiologista & 0,650351 \\
\hline 14 & $\begin{array}{l}\text { Médico Ginecologista } \\
\text { Obstetra }\end{array}$ & 2,719123 & 14 & Médico Cirurgião Pediátrico & 0,645556 \\
\hline 15 & Médico Dermatologista & 2,36315 & 15 & Médico Neurologista & 0,645103 \\
\hline
\end{tabular}

A Tabela 55 mostra as medidas de Buraco Estrutural de Tamanho Eficaz e Hierarquia das 15 ocupações dos médicos com maior índice. 
Nesse sentido, as três ocupações dos médicos com maior índice de Tamanho Eficaz, são: Médico Clínico $(49,666)$, Médico Cirurgião Geral $(24,609)$ e Médico Anestesiologista $(18,860)$. Entretanto, esses índices mostram somente o número de ocupações dos médicos que estão conectadas a ego.

Já na medida de hierarquia, as três ocupações com maior índice são: Médico Clínico $(0,856)$, Médico da Estratégia de Saúde da Família $(0,837)$ e Médico Psiquiatra $(0,802)$, contudo, essas ocupações comprovam ligação somente com um alter. É uma rede hierárquica.

Tabela 55 - Distribuição de medidas de buraco estrutural (tamanho e hierarquia)

\begin{tabular}{|c|c|c|c|c|c|}
\hline Item & Ocupações & $\begin{array}{c}\text { Tamanho } \\
\text { Eficaz }\end{array}$ & Item & Ocupação & Hierarquia \\
\hline 1 & Médico Clínico & 49,666 & 1 & Médico Clínico & 0,856197 \\
\hline 2 & Médico Cirurgião Geral & 24,609 & 2 & $\begin{array}{l}\text { Médico da Estrategia de Saúde } \\
\text { da Familia }\end{array}$ & 0,83708 \\
\hline 3 & Médico Anestesiologista & 18,860 & 3 & Médico Psiquiatra & 0,802608 \\
\hline 4 & Médico Pediatra & 16,907 & 4 & Médico Pediatra & 0,785027 \\
\hline 5 & $\begin{array}{l}\text { Médico em } \\
\text { Intensiva }\end{array}$ & 12,818 & 5 & $\begin{array}{l}\text { Médico Ginecologista } \\
\text { Obstetra }\end{array}$ & 0,751758 \\
\hline 6 & $\begin{array}{l}\text { Médico em Radiologia e } \\
\text { Diagnostico Por Imagem }\end{array}$ & 10,507 & 6 & Médico Neurologista & 0,710298 \\
\hline 7 & Médico Oncologista Clínico & 9,887 & 7 & Médico Infectologista & 0,701076 \\
\hline 8 & Diretor e Serviços de Saúde & 9,675 & 8 & Médico Oftalmologista & 0,696749 \\
\hline 9 & Médico Cardiologista & 9,157 & 9 & Médico Cirurgião Geral & 0,656981 \\
\hline 10 & $\begin{array}{lll}\text { Médico } & \text { Ginecologista } & \text { e } \\
\text { Obstetra } & & \end{array}$ & 7,438 & 10 & Médico Residente & 0,649548 \\
\hline 11 & $\begin{array}{l}\text { Médico } \\
\text { Cardiovascular }\end{array}$ & 6,991 & 11 & $\begin{array}{l}\text { Médico em Radiologia e } \\
\text { Diagnostico por Imagem }\end{array}$ & 0,644153 \\
\hline 12 & Médico Legista & 6,564 & 12 & Médico Anestesiologista & 0,64351 \\
\hline 13 & Médico Hematologista & 6,308 & 13 & Médico Otorrinolaringologista & 0,567812 \\
\hline 14 & Médico em Cirurgia Vascular & 6,307 & 14 & $\begin{array}{l}\text { Médico em } \\
\text { Intensiva }\end{array}$ & 0,550393 \\
\hline 15 & Médico do Trabalho & 6,241 & 15 & Médico em Medicina Nuclear & 0,54786 \\
\hline
\end{tabular}

Nesta seção mapeou-se a rede de ocupação dos médicos que atendem o SUS e extraiu-se algumas medidas gerais da rede com o auxilio do Software NetMiner3, além disso, foram utilizadas as ferramentas de estatísticas básicas descritivas (média e correlação).

A rede envolveu 65 ocupações profissionais dos médicos que atendem o SUS. Assim, a média da quantidade de ocupações por profissionais médicos é de 2. Foi feita a análise estatística da média da carga horária semanal por ocupação dos médicos e, essa análise demonstrou as cinco ocupações com maior quantidade de horas, conforme demonstra o Gráfico 6. Sendo: (1) Médicos Residentes (51 horas) atuam em Hospitais, Pronto Socorro e Samu (Média Complexidade e Alta Complexidade), Médicos Radioterapeuta (40 horas) 
atuam em hospitais, centros de radioterapia e clínicas (média complexidade e alta complexidade), Médicos da Estratégia de Saúde da Família (39 horas) atuam em Unidades Básicas de Saúde e Centros de Saúde (Nível de Atenção Básica) Assistente Administrativo (30 horas) um médico que atua em Policlínica Estadual e Médicos Legista (27 horas) que atuam em Pronto Socorro e Centro de Saúde. Em contrapartida, as cinco ocupações com menores quantidades de horas são: Gerente de Serviços de Saúde (2 horas), Médico Generalista (3 horas), Diretor Administrativo (5 horas), Médico Angiologista (5 horas) e Médico Cirurgião da Mão (5 horas).

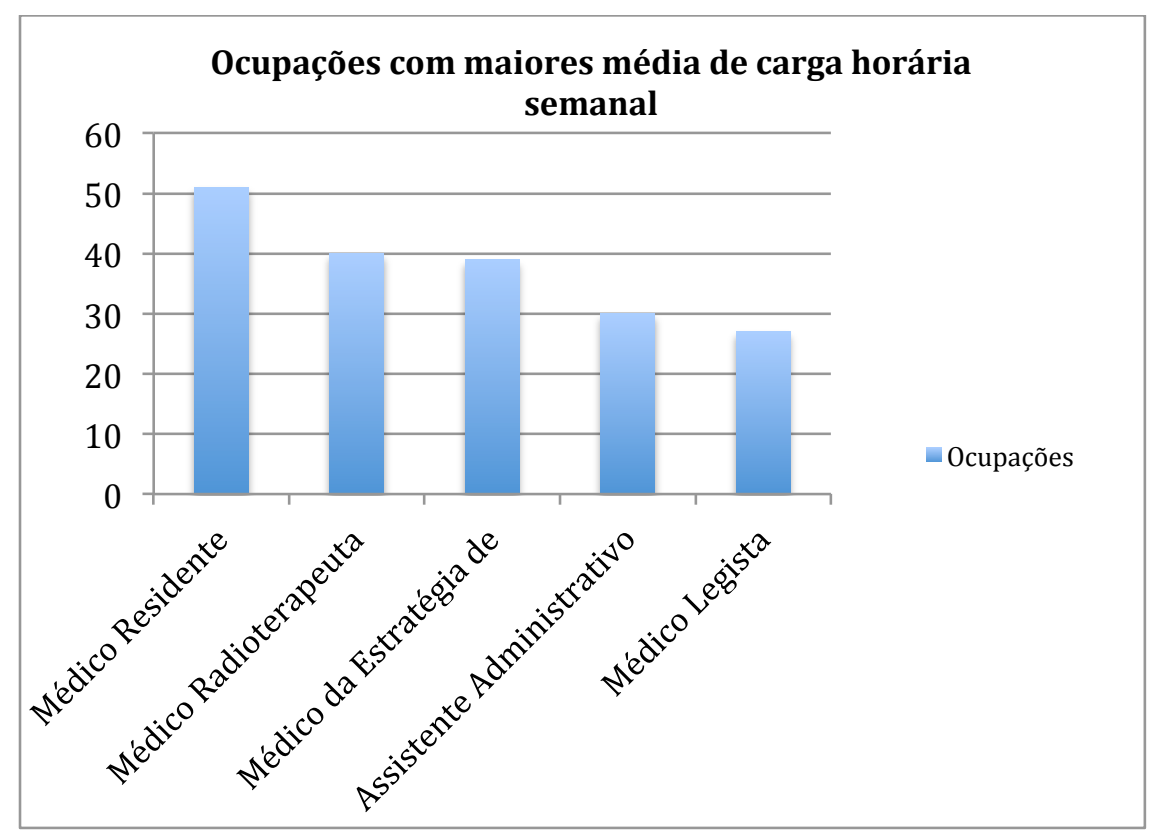

Gráfico 6 - Ocupações com maiores média de carga horaria semanal

Desse modo, a análise estatística das relações entre as variáveis são:

(1) Carga horária total semanal e a quantidade de ocupações dos médicos, a análise demostrou se há correlação entre essas variáveis e, o resultado foi uma correlação positiva de 0,17 , porém baixa;

(2) Quantidade de ocupação dos médicos e quantidade de vínculos profissionais dos médicos, o resultado foi a existência de uma correlação linear positiva, 0,35, mas é uma correlação baixa.

Portanto, pode-se afirmar que existe correlação positiva entre as variáveis acima mencionadas, porém baixa. 
Tendo concluída esta fase de análise (ocupações), o Quadro 17, traz as principais discussões sobre as medidas da rede e os principais achados no nível de análise das ocupações dos médicos.

\begin{tabular}{|c|c|c|}
\hline \multicolumn{2}{|r|}{ NÍVEL DE ANÁLISE: OCUPAÇÕES } & \multirow[b]{2}{*}{ Autores } \\
\hline $\begin{array}{l}\text { Medidas da } \\
\text { rede }\end{array}$ & Principais achados & \\
\hline $\begin{array}{l}\text { Degree } \\
\text { Centrality }\end{array}$ & $\begin{array}{l}\text { O índice de centralização da rede é } 73,68 \% \text {, alto grau de centralização } \\
\text { dos atores na rede. Os cinco atores com maior centralidade na rede } \\
\text { varia de } 36 \% \text { e } 84 \% \text {. As } 65 \text { ocupações dos médicos possuem algum } \\
\text { grau de centralidade na rede. Contudo, o índice do grau de centralidade } \\
\text { dos atores na rede está entre } 0,84 \text { (o mais central) e } 0,001 \text { (o menos } \\
\text { central). Esse posicionamento na rede permite acessar novos } \\
\text { conhecimentos e medir o envolvimento de um ator na rede. } \\
\text { As cinco ocupações com maior centralidade na rede são ocupações } \\
\text { mais generalistas, tais como: médico clínico, cirurgião geral, } \\
\text { anestesiologista. Por outro lado, as menos centrais são mais } \\
\text { específicas, tais como: Médico Broncoesofalogista, Médico } \\
\text { Radioterapeuta, Médico em Medicina Nuclear, entre outros e, esses } \\
\text { estão na periferia da rede com baixo grau de centralidade. }\end{array}$ & $\begin{array}{l}\text { (Wasserm } \\
\text { an e Faust, } \\
\text { 1994). }\end{array}$ \\
\hline Coreness & $\begin{array}{l}\text { O índice de Coreness é 8. Assim, } 14 \text { atores representam o maior } \\
\text { Coreness (grau de centralização de cada membro da rede) estão } \\
\text { representados no centro da rede. O médico clínico está no centro do } \\
\text { mapa, já as ocupações de Médico Residente, Médico Endocrinologista, } \\
\text { Médico Fisiatra, entre outros, estão localizados na periferia da rede. } \\
\text { Portanto, os atores com maior Coreness (esses 14) estão colaborando } \\
\text { especialmente dentro do núcleo central. }\end{array}$ & $\begin{array}{l}\text { Batagelj e } \\
\text { zaversnik, } \\
2002\end{array}$ \\
\hline Closeness & $\begin{array}{l}\text { O índice de Closeness é } 0,748 \% \text {. No entanto, as ocupações mais } \\
\text { centrais em relação a proximidade são: o Médico Clínico, o Médico } \\
\text { Cirurgião Geral e o Médico Anestesiologista. Assim, esses atores estão } \\
\text { posicionados no núcleo da rede e estão conectados a relacionamentos } \\
\text { mais densos e, essa posição permite eles serem menos dependente dos } \\
\text { atores intermediários. Portanto, o Médico Clínico é o ator mais central } \\
\text { e o Médico Residente e o Médico Radioterapeuta são os menos } \\
\text { centrais, ou seja, estão localizados na periferia da rede. }\end{array}$ & $\begin{array}{l}\text { Tasseli, } \\
2015 ; \\
\text { Powell, } \\
\text { Koput e } \\
\text { Doerr, } \\
1996\end{array}$ \\
\hline Betweenness & $\begin{array}{l}\text { O índice de Betweenness é 0,508\%. Os resultados do Betweenness } \\
\text { node é de cada ator na rede, além disso, esses resultados permitem } \\
\text { descobrir qual ocupação serve como mediador entre os outros atores } \\
\text { conectados. Dessa forma, a ocupação dos médicos com maior grau de } \\
\text { Betweenness é Médico Clínico em seguida: Médico Cirurgião Geral e } \\
\text { Médico Pediatra. Esses atores aparecem como os três maiores } \\
\text { intermediários da rede, ou seja, determina qual ocupação dos médicos } \\
\text { que tem o caminho mais curto entre qualquer par de nós. } \\
\text { Particularmente, esse resultado indica pelo fato de qualquer unidade de } \\
\text { saúde possuir pelo menos um médico clínico. }\end{array}$ & $\begin{array}{l}\text { Iñiguez et } \\
\text { al, } 2014\end{array}$ \\
\hline
\end{tabular}




\begin{tabular}{|c|c|c|}
\hline Density & $\begin{array}{l}\text { O índice de densidade da rede é } 0,118 \text {. Tal índice de densidade tem } \\
\text { como significado que } 12 \% \text { das relações possíveis dentro da rede se } \\
\text { efetivam. A rede é densa, composta por } 65 \text { ocupações e, com alto grau } \\
\text { de conectividade entre os atores. } \\
\text { Observa-se que as quatro ocupações com maior índice de centralidade, } \\
\text { são: Médico Clínico, Médico Cirurgião Geral, Médico Pediatra e } \\
\text { Médico Anestesiologista, pois possuem maior interação por meio dos } \\
\text { vínculos profissionais dos médicos, tende maior afinidade entre as } \\
\text { ocupações e tendem a localizar-se em redes mais densas. }\end{array}$ & $\begin{array}{l}\text { Gnyawali } \\
\text { e } \\
\text { Madhavan } \\
, 2001\end{array}$ \\
\hline Inclusiveness & $\begin{array}{l}\text { O índice de inclusão dos atores da rede é } 98,85 \% \text {, ou seja, o número de } \\
\text { nós conectados (ocupações dos médicos) expressas como uma } \\
\text { proporção do número total de nós. Portanto, os nós são altamente } \\
\text { conectados. }\end{array}$ & $\begin{array}{l}\text { Zoppi, } \\
2012\end{array}$ \\
\hline Egonet & $\begin{array}{l}\text { As três ocupações dos médicos que representam o maior número de } \\
\text { ligações do nó focal são: Médico Clínico, Médico Cirurgião Geral e } \\
\text { Médico Anestesiologista. Isso indica que os médicos que possuem uma } \\
\text { dessas três ocupações (atores ego), provavelmente se tornarão mais } \\
\text { bem informados comparado com as demais ocupações da rede }\end{array}$ & $\begin{array}{l}\text { Reagans e } \\
\text { Zuckerma } \\
\text { n, } 2008\end{array}$ \\
\hline Structural Hole & $\begin{array}{l}\text { A análise contempla } 65 \text { ocupações dos médicos (nós), Os três atores } \\
\text { com maior índice de limitação agregada são: Médico em Medicina } \\
\text { Nuclear , Médico Psiquiatra e Médico da Estratégia de Saúde da } \\
\text { Família estão melhores posicionados para acessar informações ou } \\
\text { explorar potencias buracos estruturais em sua rede. Esses atores } \\
\text { apresentam baixa centralidade na rede e estão localizados na periferia. } \\
\text { Já na medida de Eficiência as ocupações com maior índice são: Médico } \\
\text { Residente, Médico Clínico e Médico Pediatra, isso implica que essas } \\
\text { ocupações dos médicos são caracterizados como os nós mais eficientes } \\
\text { da rede, pois maximizaram o número de contatos não redundantes e } \\
\text { reduziram o número de contatos redundantes na rede, dessa forma, } \\
\text { permite o acesso a novas informações. } \\
\text { As três ocupações dos médicos com maior índice de Tamanho Eficaz, } \\
\text { são: Médico Clínico, Médico Cirurgião Geral e Médico } \\
\text { Anestesiologista. Entretanto, esses índices mostram somente o número } \\
\text { de ocupações dos médicos que estão conectadas a ego. } \\
\text { Já na medida de hierarquia, as três ocupações com maior índice são: } \\
\text { Médico Clínico, Médico da Estratégia de Saúde da Família e Médico } \\
\text { Psiquiatra, contudo, essas ocupações comprovam ligação somente com } \\
\text { um alter. É uma rede hierárquica. }\end{array}$ & Burt, 1992 \\
\hline
\end{tabular}

Quadro 17 da de hierarqdiscussõs discussas medidas da rede no nuia, as três ocupações com

\subsection{A análise do grau de Hubiness de unidades de saúde}

A segunda fase de análise, trata-se do cálculo das Unidades de Saúde $H u b$ (USH), o modelo hub-and-spoke foi utilizado por analogia na rede de médicos com vínculos profissionais em unidades de saúde públicas e privadas. Assim, a fórmula foi adaptada do Hub and spoke proposta originalmente para a área de logística por Derudder et al. (2007) para avaliar o grau de Hubiness das unidades de saúde. 
A Figura 45 apresenta as fórmulas para a análise de Hubs de saúde, assim essa figura é composta por quatro fórmulas, divididas em duas técnicas: Técnica A e Técnica B.

$\mathrm{Na}$ Técnica A a Fórmula 1 simplesmente examina a intensidade do Hub Absoluto (HA) dos nós da rede, ou seja, os Hubs são identificados em termos do número total de médicos que utilizam o nó para fazer uma conexão em diante. Desse modo, foram considerados os médicos que possuem três vínculos profissionais ou mais, assim entende-se que esse médico utiliza o nó para fazer conexões. A Fórmula 2 verifica a intensidade do $H u b$ Relativo (HR) dos nós da rede, e é calculado dividindo-se o número de médicos do hub por todos os médicos que utilizam o nó, ou seja, todos os médicos vinculados profissionalmente naquele $H u b$. Então, se $H R=0$ a Unidade de Saúde funciona como um nó origem/destino e, se $\mathrm{HR}=1$, então o nó funciona exclusivamente como um intermediário no fluxo de médicos (adaptado de DERUDDER et al., 2007).

$\mathrm{Na}$ Técnica $\mathrm{B}$, tanto a fórmula 3 quanto a 4 analisa o número de unidades de saúde que fazem o uso intenso de uma Unidade de Saúde $H u b$ (USH). N é o número total de nós na rede, $\mathrm{Cj}=1$ se os médicos da Unidade de Saúde j empregar a Unidade de Saúde como um $H u b$, e $\mathrm{Cj}=0$, se este não é o caso. Essa medida, por sua vez, reconhece que os $H u b s$ não somente conectam os médicos, mas também um número de unidades de saúde. Assim, em vez de as duas medidas anteriores, que incidem sobre o número total de médicos conectados, essa medida foca para o número de Unidades de Saúde que fazem uso intenso de um $H u b$, ou seja, Conectividade do $H u b(\mathrm{CH})$ (adaptado de DERUDDER et al., 2007).

Segundo Derudder et al. (2007) esta medida pode ser enganosa se negligenciar a intensidade das conexões entre as diferentes Unidades de Saúde. Portanto, nesta tese a análise, Cj só é atribuído "1" se a Unidade de Saúde possuir 10 médicos ou mais que usam a Unidade de Saúde j como um Hub e, os médicos que possuem 3 vínculos ou mais. Um valor maior da $\mathrm{CH}$ sugere que um nó age como um ponto de comutação para um grande número unidades de saúde diferentes, um valor menor sugere que os médicos $H u b$ se originam de poucas unidades de saúde.

No entanto, pode-se esperar que os resultados desta medida será influenciada pelo número total de médicos do $H u b$ (HA), e uma interpretação correta dos resultados $\mathrm{CH}$, portanto, exige um confronto com os resultados HA. Em resumo, uma posição mais elevada no ranking $\mathrm{CH}$ do que no ranking $\mathrm{HA}$ sugere que, em média, os médicos do hub são originários de um maior número de diferentes nós da rede. Para tal finalidade, planeja-se utilizar as Técnicas A e B (Figura 45) e, suas respectivas fórmulas. 


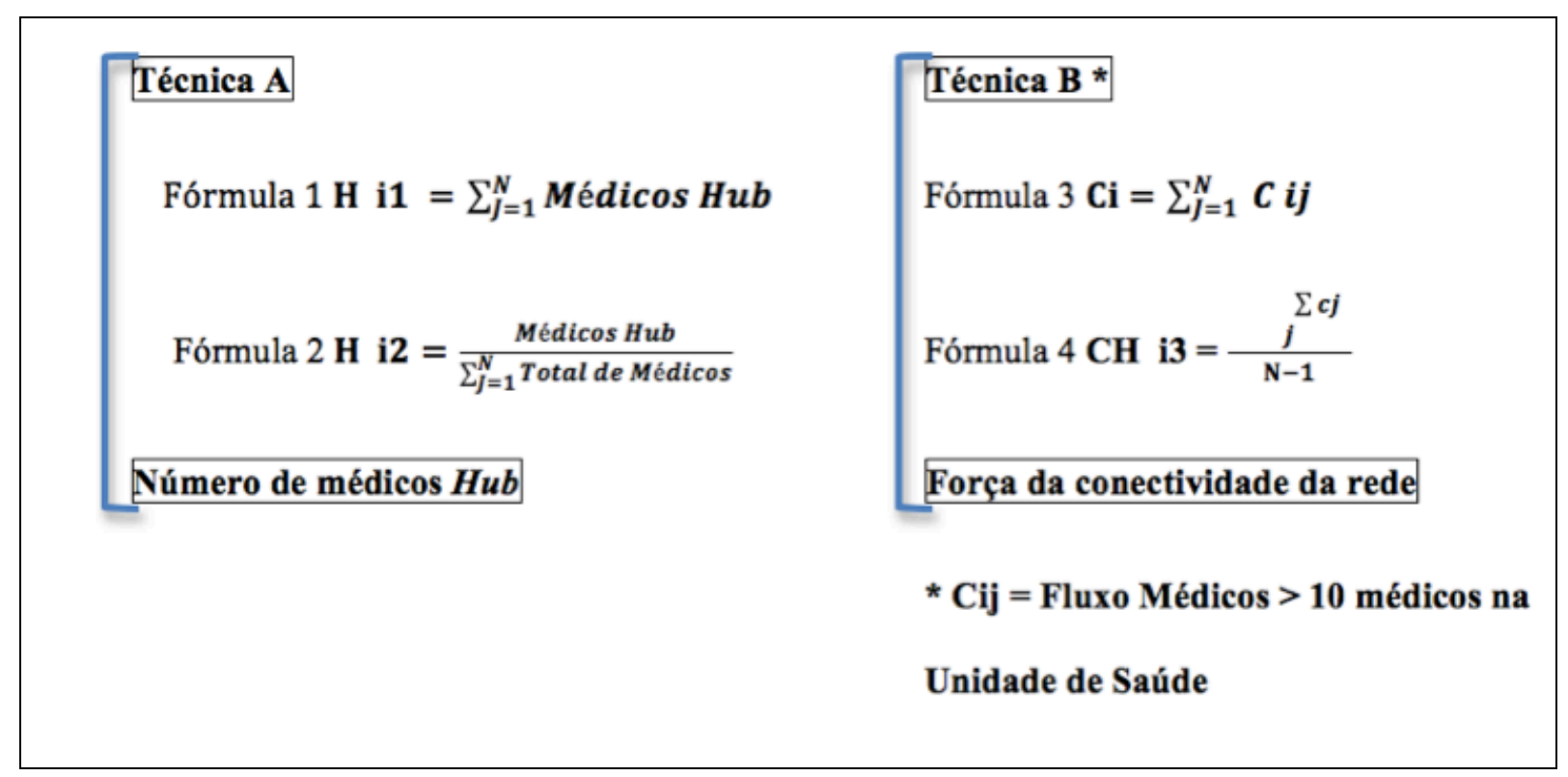

Figura 45 - Análise de Hubs de Saúde

Fonte: Adaptado de Derudder et al. (2007)

O município de Bauru conta com 65 unidades de saúde que atendem o SUS, mas para o mapeamento da rede foram excluídas 4 unidades de saúde (USF Vila Dutra, USF Vila Santa Edwirges, Base Central de regulação USA II, UFS Nove de Julho Fortunato Rocha Lima). Essas unidades de saúde foram excluídas da amostra, pois os médicos possuem vínculos somente com essas unidades. Desse modo, seguiu-se o mesmo critério do mapeamento da rede, para a análise dos Hubs de saúde. Além disso, foram consideradas somente as unidades de saúde em que os médicos possuem 3 vínculos profissionais ou mais. Assim, foram excluídas mais 5 unidades de saúde (Base Central e Regulação USA III, Centro de Detenção Provisória de Bauru, Penitenciaria Dr Eduardo de Oliveira Vianna de Bauru II, USF Nova Bauru e USF Vila São Paulo) por possuírem, cada uma, menos de 3 vínculos profissionais.

A Tabela 56 apresenta os dados calculados por meio da Fórmula 1 (Figura 45) e nela estão representadas as 15 unidades de saúde de maior importância em termos de Hubs absoluto (HA). Nessa análise foram consideradas as unidades de saúde com mais de 10 médicos e os médicos que fazem o uso da unidade de saúde como $H u b$, ou seja, os médicos que possuem 3 vínculos ou mais. Essa Tabela está em ordem decrescente de importância. 
Tabela 56 - Unidades de saúde hubs em termos absoluto

\begin{tabular}{clc}
\hline & \multicolumn{1}{c}{ Hub } & HA \\
\hline 1 & Hospital Estadual Bauru & 203 \\
2 & Hospital de Base de Bauru & 97 \\
3 & AME Ambulatório Médico de Especialidades Bauru & 74 \\
4 & Maternidade Santa Isabel & 72 \\
5 & Pronto Socorro Central de Bauru & 58 \\
6 & Hospital de Reabilitação de Anomalias Craniofaciais Bauru & 27 \\
7 & Instituto Lauro de Souza Lima Bauru & 18 \\
8 & Upa Geisel & 18 \\
9 & Upa Mary Dota & 18 \\
10 & Upa Bela Vista & 13 \\
11 & Upa Ipiranga & 13 \\
12 & Núcleo de Saúde Centro de Bauru & 12 \\
13 & Serviço de Orientação e Prevenção do Câncer & 12 \\
14 & Hospital Manoel de Abreu Bauru & 10 \\
15 & Central de Regulação Médica de Urgências & 10
\end{tabular}

A medida HA incide sobre o número total de médicos que fazem o uso do nó (Unidade de Saúde) como um ponto de comutação. Essa medida revela que os três principais nós da rede também funcionam como grandes Hubs de conexões entre os médicos, sendo: (1) o Hospital Estadual de Bauru (203 médicos); (2) Hospital de Base (97 médicos e (3) AME (74 médicos) essa quantidade de médicos mencionada são aqueles que possuem acima de três vínculos profissionais, assim dentro desses $\mathrm{Hubs}$, além dos fluxos dos médicos, dos pacientes passam também os fluxos de conhecimento e de informações que é importante para a inovação tanto na prestação de serviços nos cuidados com os pacientes quanto no sistema todo de saúde, o SUS.

Nota-se que os Hubs mais importantes em termos absolutos são os Hospitais e Centros de Especialidade, cujo o nível de atendimento é de Alta e Média Complexidade. Além disso, identificam-se dois tipos de Hubs: os locais e os regionais. Os Hubs locais, conectam com as unidades de saúde locais, tais como: UPA Geisel, UPA Mary Dota, etc. Os Hubs regionais, conectam com as unidades de saúde locais e regionais, por meio dos vínculos profissionais dos médicos, conforme demonstra as Figuras 29, 30 e 31 (Visualização dos vizinhos do ator na rede). 
A Tabela 57 demonstra a medida do $H u b$ Relativo (HR) e, refere-se a Fórmula 2, então, essa medida é baseada na relação entre o número de médicos que utilizam o nó como um $H u b$ e o número total de médicos que utilizam este nó. Esta medida de "intermediação" apresenta um quadro um pouco diferente do que a "intensidade", unidades de saúde como: Serviço de Orientação e Prevenção do Câncer, Central de Regulação Médica de Urgências e AME Ambulatório Médico de Especialidades Bauru nessa medida apresentam como grandes $H u b s$, enquanto eles não são particularmente fortes $H u b s$ de conexões em termos absolutos (onde eles ocupam as $13^{\mathrm{a}}, 15^{\mathrm{a}}$ e $3^{\mathrm{a}}$ posições).

Tabela 57 - Unidades de saúde hubs em termos relativos

\begin{tabular}{|c|c|c|c|c|}
\hline & Hubs & $\begin{array}{c}\text { Número de } \\
\text { médicos } \\
\text { Hub }\end{array}$ & $\begin{array}{l}\text { Número } \\
\text { Total de } \\
\text { Médicos }\end{array}$ & HR \\
\hline 1 & Serviço de Orientação e Prevenção do Câncer & 12 & 12 & 1,00 \\
\hline 2 & Central de Regulação Médica de Urgências & 10 & 11 & 0,91 \\
\hline 3 & AME Ambulatório Médico de Especialidades Bauru & 74 & 85 & 0,87 \\
\hline 4 & Upa Ipiranga & 13 & 15 & 0,87 \\
\hline 5 & Upa Mary Dota & 18 & 22 & 0,82 \\
\hline 6 & Upa Bela Vista & 13 & 16 & 0,81 \\
\hline 7 & Pronto Socorro Central de Bauru & 58 & 72 & 0,81 \\
\hline 8 & Upa Geisel & 18 & 23 & 0,78 \\
\hline 9 & Maternidade Santa Isabel & 72 & 97 & 0,74 \\
\hline 10 & Hospital de Base de Bauru & 97 & 135 & 0,72 \\
\hline 11 & Hospital Manoel de Abreu Bauru & 10 & 14 & 0,71 \\
\hline 12 & Hospital Estadual Bauru & 203 & 334 & 0,61 \\
\hline 13 & Núcleo de Saúde Centro de Bauru & 12 & 20 & 0,60 \\
\hline 14 & $\begin{array}{l}\text { Hospital de Reabilitação de Anomalias Craniofaciais } \\
\text { Bauru }\end{array}$ & 27 & 62 & 0,44 \\
\hline 15 & Instituto Lauro de Souza Lima Bauru & 18 & 50 & 0,36 \\
\hline
\end{tabular}

O resultado da Fórmula 3, é: $\mathrm{N}=655$, ou seja, o número total de nós da rede (unidades de saúde).

A Tabela 58 foca no número de unidades de saúde (em vez do número de médicos) ligado por um nó de rede, assim uma unidade de saúde é considerada como um Hub importante se ela se conecta com um grande número de unidades de saúde. Dessa forma, observa-se que as quatro unidades de saúde com maior índice de $H u b$ e maior conexão são: Hospital Estadual (707 conexões), Hospital de Base de Bauru (421 conexões), Maternidade Santa Isabel (263 conexões) e AME (280 conexões). 
Tabela 58 - Hubs de saúde mais importante em termos unidades de saúde conectadas

\begin{tabular}{llrr}
\hline & \multicolumn{1}{c}{ Hubs } & $\begin{array}{r}\text { Número de } \\
\text { Conexões }\end{array}$ & H \\
\hline $\mathbf{1}$ & Hospital Estadual Bauru & 707 & 0,020 \\
$\mathbf{2}$ & Hospital de Base de Bauru & 421 & 0,014 \\
$\mathbf{3}$ & Maternidade Santa Isabel & 263 & 0,009 \\
$\mathbf{4}$ & AME Ambulatório Médico de Especialidades Bauru & 280 & 0,006 \\
$\mathbf{5}$ & Pronto Socorro Central de Bauru & 248 & 0,006 \\
$\mathbf{6}$ & Serviço de Orientação e Prevenção do Câncer & 67 & 0,003 \\
$\mathbf{7}$ & Hospital de Reabilitação de Anomalias Craniofaciais Bauru & 59 & 0,002 \\
$\mathbf{8}$ & Central de Regulação Médica de Urgências & 36 & 0,002 \\
$\mathbf{9}$ & UPA Bela Vista & 35 & 0,002 \\
$\mathbf{1 0}$ & UPA Ipiranga & 32 & 0,002 \\
\hline
\end{tabular}

\subsection{Discussões dos resultados obtidos}

Esta terceira fase é dedicada a analisar e explicar, conforme indícios da literatura, os dados apresentados nas seções anteriores.

O mapeamento da rede de médicos com vínculos profissionais em unidades de saúde públicas e privadas permitiu entender a configuração atual da rede por meio do software de análise de redes e, a literatura auxiliou na interpretação e na análise dos resultados, inseridos no Capítulo 4, seções 4.1 e 4.2 .

Para tanto, o mapeamento da rede de médicos envolveu três níveis de análise:

1. Unidades de Saúde (organização) - onde médicos possuem os vínculos profissionais;

2. Médicos (pessoas) - vínculos dos médicos com outros médicos por meio de seus vínculos profissionais;

3. Ocupações (cargos) - vínculos das ocupações dos médicos por meio de seus vínculos profissionais.

Embora os três níveis de análise da rede de médicos seja sob a óptica dos vínculos profissionais em unidades de saúde públicas e privadas, esses apresentam algumas características comuns e outras distintas. Por esse fato, tanto o uso das ferramentas quantitativas (software de análise de redes, estatística básica e adaptação da fórmula do modelo Hub and Spoke) quanto a análise das redes sociais foram apropriados para o desenvolvimento deste estudo. A análise da rede em estudo considera aspectos estruturais e relacionais (GRANOVETER, 1985; BURT, 1992; WASSERMAN e FAUST, 1994; 
ROWLEY et al., 2000; SACOMANO NETO, 2004; MASQUEFA, 2008; BORGATTI, 2009).

Segundo Sacomano Neto (2004) o tamanho da rede é essencial para compreender as posições estruturais dos atores. Nesse sentido, o tamanho da rede e o número de ligações tanto no nível de análise das unidades de saúde (655 nós) quanto no nível de análise dos médicos (789 nós) apresentam a estrutura de uma rede grande que representa a forma de relações entre os atores (WAARDEN, 1992), composta por 2.582 ligações por meio dos vínculos profissionais dos médicos. Por outro lado, a estrutura da rede de ocupações é menor com cerca de 65 nós relacionando-se entre si.

Com relação aos aspectos relacionais, há indícios da presença de laços fortes e maior inclusão nas redes de médicos e na rede de ocupações, ambas as redes apresentam $98 \%$ dos nós conectados. Isso favorece a confiança e o intercâmbio de informações entre os médicos da rede (UZZI,1997; GRANOVETTER, 1973). Em contrapartida, na rede de unidades de saúde os laços são fracos na rede (40,30\% dos nós estão conectados), mas o núcleo dessa rede apresenta laços fortes com maior densidade, pois os atores centrais estão altamente conectados (tais como: Hospital Estadual de Bauru e Hospital de Base). De modo geral, as unidades de saúde que apresentam laços fracos nos relacionamentos estão propensas a acessar novas informações, e o seu acesso acontece por meio dos laços indiretos (GRANOVETTER, 1973).

O Quadro 18 descreve os principais resultados sobre os aspectos gerais da rede e os três níveis de análise, sendo: unidades de saúde, médicos e ocupações. Nesse sentido, destacase alguns aspectos comuns e outros distintos desses níveis de análises. Embora esse Quadro envolva todas as medidas de centralidade a discussão a seguir será somente sobre os aspectos mais relevantes encontrados.

- Centralidade na rede - a rede de médicos e a rede de ocupações possuem maior índice de centralização na rede, praticamente todos os atores envolvidos em ambas as redes possuem algum grau de centralidade na rede. Já as unidades de saúde o índice de centralização é menor e, somente $40 \%$ dos atores possuem algum grau de centralidade, os demais estão localizados na periferia da rede.

- Densidade na rede - o índice de densidade é alto tanto na rede de médicos quanto na rede de ocupações, caracterizando como uma rede densa. Na rede de unidades de 
saúde a densidade é mais baixa, caracterizando como uma rede difusa, porém, o núcleo é denso e a interconectividade entre esses atores é maior.

- Rede Ego - todas as redes apresentam redes egos (que representam o maior número de ligações do nó focal) e os atores egos são os atores centrais na rede. assumem o papel de ator focal na rede ego e se tornam mais bem informados (REAGANS E ZUCKERMAN, 2008)

- Buraco Estrutural - os três níveis de análise apresentaram a presença de buraco estrutural e, os atores que se destacaram foram os localizados na periferia da rede. Esses atores estão melhores posicionados para acessar informações ou explorar potencias buracos estruturais em sua rede (BURT, 1992)

\begin{tabular}{|c|c|c|c|}
\hline $\begin{array}{l}\text { Medidas da } \\
\text { rede }\end{array}$ & Unidades de Saúde & Médicos & Ocupações \\
\hline $\begin{array}{l}\text { Degree } \\
\text { Centrality }\end{array}$ & $\begin{array}{l}\text { O índice é } 23,468 \% \text { - } \\
\text { Cinco atores com maior } \\
\text { grau de centralidade e, Das } \\
655 \text { unidades de saúde, } 265 \\
\text { possuem algum grau de } \\
\text { centralidade na rede, mas a } \\
\text { maioria dos atores } \\
\text { encontram-se na periferia } \\
\text { da rede. }\end{array}$ & $\begin{array}{l}\text { O índice é } 55,029 \%-\text { o } \\
\text { núcleo da rede é composto } \\
\text { por muitos atores. Dos } 789 \\
\text { médicos, } 781 \text { médicos } \\
\text { possuem algum grau de } \\
\text { centralidade na rede. }\end{array}$ & $\begin{array}{l}\text { O índice de centralização da } \\
\text { rede é } 73,68 \% \text {, } \\
\text { relativamente alto. As três } \\
\text { ocupações com maior } \\
\text { centralidade na rede são } \\
\text { ocupações mais generalistas, } \\
\text { tais como: médico clínico, } \\
\text { médicos cirurgião geral e } \\
\text { anestesiologista }\end{array}$ \\
\hline Coreness & $\begin{array}{l}\text { O índice é } 9-44 \text { unidades } \\
\text { de saúde que atendem os } \\
\text { níveis de AC e MC }\end{array}$ & $\begin{array}{l}\text { O índice é } 122 \text { - } 148 \text { atores } \\
\text { apresentaram uma posição } \\
\text { mais central na rede }\end{array}$ & $\begin{array}{l}\text { O índice de Coreness é } 8 \text { - } \\
14 \text { atores representam o } \\
\text { maior Coreness. }\end{array}$ \\
\hline Closeness & $\begin{array}{l}\text { O índice é } 0,09-\text { Hospital } \\
\text { de Base, Hospital Estadual } \\
\text { Bauru e Pronto Socorro } \\
\text { Central atendem os níveis } \\
\text { de AC e MC }\end{array}$ & $\begin{array}{l}\text { O índice é } 0,49 \% \text {. Os três } \\
\text { médicos com maior grau de } \\
\text { closeness não são os que } \\
\text { apresentam maior carga } \\
\text { horária semanal de trabalho, } \\
\text { porém eles estão acima da } \\
\text { média (42 horas) }\end{array}$ & $\begin{array}{l}\text { O índice é } 0,748 \% \text {. As } \\
\text { ocupações mais centrais em } \\
\text { relação a proximidade são: o } \\
\text { Médico Clínico, o Médico } \\
\text { Cirurgião Geral e o Médico } \\
\text { Anestesiologista. }\end{array}$ \\
\hline Betweenness & 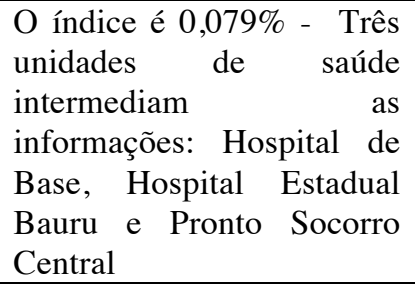 & $\begin{array}{l}\text { O índice é } 0,091 \% \text {. Os três } \\
\text { atores com maior } \\
\text { Betweenness atuam a maior } \\
\text { parte de sua carga horária } \\
\text { em hospitais e, seus vínculos } \\
\text { profissionais são públicos e } \\
\text { privados }\end{array}$ & $\begin{array}{l}\text { O índice é } 0,508 \% \text {. A } \\
\text { ocupação dos médicos com } \\
\text { maior grau de Betweenness } \\
\text { é Médico Clínico em } \\
\text { seguida: Médico Cirurgião } \\
\text { Geral e Médico Pediatra. }\end{array}$ \\
\hline Density & $\begin{array}{l}\text { O índice é } 0,4 \% \text { - Rede } \\
\text { difusa/núcleo denso }\end{array}$ & O índice é $11 \%$ - Rede densa & O índice é $12 \%$ - Rede densa \\
\hline Inclusiveness & $\begin{array}{l}\text { Cerca de } 40,30 \% \text { dos nós } \\
\text { estão conectados (mais no } \\
\text { núcleo da rede) }\end{array}$ & $\begin{array}{l}\text { Cerca de } 98,859 \% \text { dos nós } \\
\text { estão conectados na rede }\end{array}$ & $\begin{array}{l}\text { Cerca de } 98,85 \% \text { dos nós } \\
\text { estão conectados na rede }\end{array}$ \\
\hline Rede Ego & $\begin{array}{l}3 \text { unidades de saúde que } \\
\text { representam o maior } \\
\text { número de ligações do nó } \\
\text { focal são: Hospital de Base, } \\
\text { Hospital Estadual Bauru e } \\
\text { Pronto Socorro Central }\end{array}$ & $\begin{array}{l}3 \text { médicos que representam o } \\
\text { maior número de ligações do } \\
\text { nó focal }\end{array}$ & $\begin{array}{l}\text { As três ocupações dos } \\
\text { médicos que representam o } \\
\text { maior número de ligações do } \\
\text { nó focal são: Médico } \\
\text { Clínico, Médico } \\
\text { Geral Cirurgião } \\
\text { Anestesiologista }\end{array}$ \\
\hline
\end{tabular}




\begin{tabular}{|c|c|c|c|}
\hline $\begin{array}{l}\text { Buraco } \\
\text { Estrutural }\end{array}$ & $\begin{array}{lcc}\text { Presença } & \text { de } & \text { Buraco } \\
\text { Estrutural } & \text { cerca } & \text { de } 72 \\
\text { unidades } & \text { de } & \text { saúde } \\
\text { apresentam o maior índice }\end{array}$ & \begin{tabular}{llr} 
Presença & de & \multicolumn{2}{c}{ Buraco } \\
Estrutural cerca & de & 15 \\
médicos estão & melhores \\
posicionados para & acessar \\
novas informações &
\end{tabular} & $\begin{array}{l}\text { Presença de } r \text { Buraco } \\
\text { Estrutural, sendo } 3 \text { atores } \\
\text { (Médico em } \text { Medicina } \\
\text { Nuclear, Médico Psiquiatra } \\
\text { e Médico da Estratégia de } \\
\text { Saúde da Família) } \\
\text { apresentam maior índice }\end{array}$ \\
\hline
\end{tabular}

Quadro 18 - Quadro descritivo dos principais resultados sobre as medidas globais da rede e os três níveis de análise

Outra questão relevante a ser ressaltada é a identificação dos principais $H u b s$ de saúde no município de Bauru. Para tanto, foi utilizado o modelo Hub and Spoke (HS) proposto originalmente para a área de logística por Derudder et al. (2007). As fórmulas desse modelo foram adaptadas para avaliar o grau de Hubiness das unidades de saúde. As cinco unidades Hubs do município de Bauru em termos de conexão são: Hospital Estadual Bauru (707 conexões), Hospital de Base de Bauru (421 conexões), Maternidade Santa Isabel (263 conexões), AME (280 conexões) e o Pronto Socorro Central (248 conexões). Embora o software NetMiner3 tenha gerado a medida de Betweenness (indermediação), achou-se mais apropriado a utilização do HS, pois essa medida está relacionada a centralidade da intermediação.

Contudo, na medida de Betweenness as cinco unidades de saúde com maior índice são as mesmas do modelo HS, porém em diferentes posições, como exemplo: o Hospital de Base está posicionado em primeira posição no Betweenness, mas no modelo HS está em segunda posição, sendo o primeiro o Hospital Estadual de Bauru que se destaca tanto em termos de unidades de saúde conectada quanto no número total de médicos que fazem o uso do nó (Unidade de Saúde) como um ponto de comutação.

Com base nas discussões anteriores, propõe-se um esquema conceitual de análise da rede de médicos do SUS que será discutido na próxima seção.

\subsection{Proposta de um esquema conceitual de análise da rede de médicos no SUS}

A Figura 46 ilustra a proposta de um esquema conceitual de análise da rede de médicos no âmbito do SUS. Para analisar a configuração da rede de médicos com vínculos profissionais em unidades de saúde do SUS.

A pirâmide sintetiza os três níveis de atendimento no contexto do SUS. A integração ativa de médicos e unidades de saúde envolve progressiva força de laços e conectividade na 
rede, para o atendimento de pacientes nos diferentes níveis de complexidade. A unidades de saúde devem adquirir recursos e capacidades na medida em que se movem para cima na "Pirâmide" dos níveis de atendimento do SUS. Cada um dos níveis representa diferentes níveis de atendimento aos pacientes que buscam cuidados de saúde no SUS.

O nível de atenção básica é a base da pirâmide e a primeira dimensão (layer), ela indica o primeiro nível de atendimento aos pacientes que buscam cuidados no SUS. A segunda dimensão (layer) é o nível de média complexidade, ou seja, o encaminhamento dos pacientes para um atendimento específico, conforme o diagnóstico feito pelo médico da atenção básica. Por fim, a dimensão (layer) o nível de alta complexidade, encontra-se no topo da pirâmide porque envolve o atendimento dos casos de alta complexidade, pois necessita de altos níveis tecnológicos e aplicação tanto de conhecimento existente quanto de novos conhecimentos por meio dos profissionais de saúde (exemplo: médicos).

O movimento para cima nos graus da Pirâmide significa que as unidades de saúde desenvolveram competências e adquiriram recursos necessários para executar a atividade especifica naquele nível de atendimento de saúde. Na parte esquerda do esquema conceitual estão os unidades de saúde tipicamente encontradas, enquanto na parte direita estão as ocupações tipicamente encontradas naquele nível de atendimento.

Em geral, a medida que as unidades de saúde se localizarem nos níveis mais altos da pirâmide, maior será a conectividade e a força de laços. Adicionalmente, o nível de esfera de gestão no SUS irá ser direcionado as esferas na hierarquia mais alta do setor público de saúde, em direção aos níveis federais e estaduais.

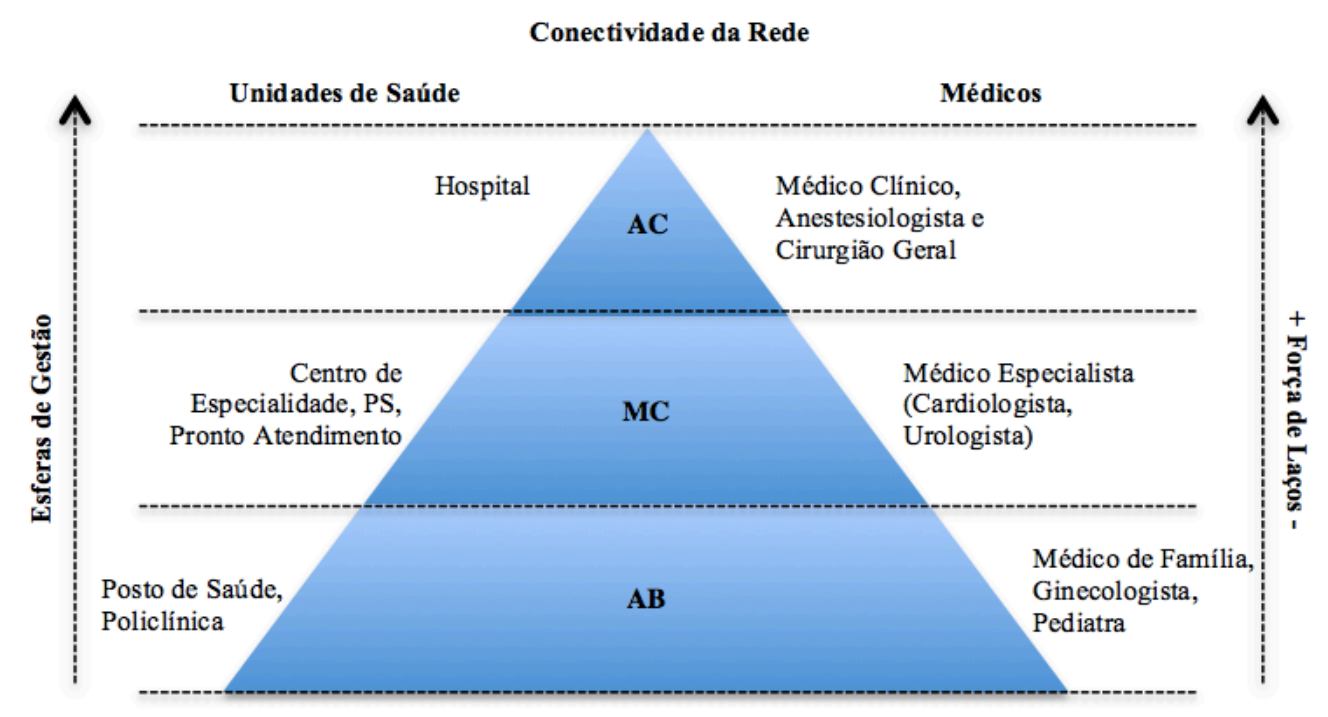

Figura 46 - Esquema conceitual de análise da rede de médicos no SUS 


\subsection{Implicações para a teoria}

Os resultados desta pesquisa podem contribuir para a teoria. As evidências do estudo empírico e o arcabouço teórico permitiu estabelecer questões de pesquisa descritivas para serem refinadas na forma de hipóteses para teste em pesquisas futuras. Portanto, uma boa hipótese deve ser baseada em uma questão de pesquisa.

O Quadro 19 ilustra os cinco atores com maior grau de centralidade nos três de níveis de análise de rede (Unidade de Saúde, Médicos e Ocupações). Observa-se que as unidades de saúde mais centrais são compostas por hospitais públicos. Na rede de médicos, as ocupações com maior grau de centralidade são anestesiologista e médico clínico (três médicos) e cirurgião geral (dois médicos) (Questão 1). Esses médicos possuem vínculos profissionais públicos e privados, sendo a maior carga horária em hospitais públicos. Corroborando, com os dados da rede de médicos, as três ocupações com maior grau de centralidade são: médicos clínico, cirurgião geral e anestesiologista. Outra questão relevante a ser ressaltada é que a análise de correlação entre o grau de centralidade dos médicos e a quantidade de ocupações, teve o resultado de uma correlação linear positiva de 0,39 (Questão 2).

As discussões e as evidências empíricas do mapeamento da rede nos permite tecer as primeiras questões de pesquisas (detalhes ver Capítulo 4, seção 4.1.2).

Questão de pesquisa 1: Quão frequentemente atores com ocupações de médico clínico, cirurgião geral ou anestesiologista em hospitais públicos aparecem entre os atores com maior grau de centralidade na rede de médicos?

Questão de pesquisa 2: Qual o número de ocupações declaradas no CNES, entre os médicos com o maior grau de centralidade na rede? 


\begin{tabular}{|l|l|l|}
\hline \multicolumn{4}{|c|}{$\begin{array}{c}\text { Atores com maior grau de centralidade } \\
\text { Nível de Análise }\end{array}$} \\
\hline \multicolumn{1}{|c|}{ Unidades de Saúde } & \multicolumn{1}{|c|}{ Médicos } & \multicolumn{1}{c|}{ Ocupações } \\
\hline Hospital Geral (AC) & $\begin{array}{l}\text { O ator A223 tem como ocupações declaradas: } \\
\text { médico clínico, anestesiologista e ortopedista }\end{array}$ & Médico Clínico \\
\hline Hospital Geral (AC) & $\begin{array}{l}\text { O ator A204 tem a ocupação médico } \\
\text { anestesiologista }\end{array}$ & Médico Cirurgião Geral \\
\hline Pronto Socorro Geral (MC) & $\begin{array}{l}\text { O ator A251 possui as seguintes ocupações: } \\
\text { médico clínico, anestesiologista, médico } \\
\text { cirurgião geral e médico urologista }\end{array}$ & Médico Anestesiologista \\
\hline $\begin{array}{l}\text { Centro de Especialidade } \\
\text { (AC) }\end{array}$ & $\begin{array}{l}\text { O ator A172 tem como ocupações: médico } \\
\text { clínico, gastroentereologia, médico cirurgião } \\
\text { geral, urologista e radiologista. }\end{array}$ & Médico Pediatra \\
\hline Hospital Especializado (AC) & $\begin{array}{l}\text { O ator A197 possui a ocupação de médico } \\
\text { infectologista }\end{array}$ & $\begin{array}{l}\text { Médico em Medicina } \\
\text { Intensiva }\end{array}$ \\
\hline
\end{tabular}

Quadro 19 - Os cinco atores com maior grau de centralidade nos três de níveis de análise de rede

O Quadro 20 ilustra os cinco atores com maior grau de intermediação (Betweenness) nos três de níveis de análise de rede (Unidade de Saúde, Médicos e Ocupações). Nas unidades de saúde, nota-se que os atores com maior grau de intermediação são os hospitais públicos e a maioria atendem os níveis de AC (Questão 3). Na rede de médicos, os atores que intermediam informações na rede possuem a ocupação médico clínico (Questão 4). Já na rede de ocupações, o médico clínico possui o maior grau de intermediação na rede e, isso evidencia a análise da rede de médicos. Assim, essas evidências empíricas permite tecer a terceira e a quarta questão de pesquisas futuras.

Questão de pesquisa 3: Quão frequentemente unidades de saúde que atendem no nível de AC aparecem entre as unidades de saúde com maior grau de centralidade?

Questão de pesquisa 4: Quão frequentemente a ocupação de médico clínico em hospitais públicos aparece entre os atores com o grau de intermediação na rede de médicos?

\begin{tabular}{|l|l|l|}
\hline \multicolumn{4}{|c|}{ Atores com maior grau de intermediação (Betweenness) } \\
Nível de Análise
\end{tabular}

Quadro 20 - Os cinco atores com maior grau de Betweenness nos três de níveis de análise de rede 
O Quadro 21 apresenta os cinco atores com maior índice de buraco estrutural nos três níveis de análise de rede (Unidade de Saúde, Médicos e Ocupações). Nas unidades de saúde, verifica-se que os atores com maior índice de buraco estrutural são geralmente, unidades de saúde pequenas que atendem $\mathrm{AB}$ e MC, das 655 unidades de saúde da rede, 68 unidades de saúde apresentam o maior índice de buraco estrutural, dessas 68 unidades, 45 atendem MC e a maioria estão localizadas fora do município de Bauru.

$\mathrm{Na}$ rede de médicos, os atores que estão melhores posicionados para acessar informações ou explorar potencias buracos estruturais são os que declaram como ocupação de médico da estratégia de saúde da família (Questão 5) e atendem os níveis de $\mathrm{AB}$ e MC (Questão 6), os demais atores que apresentam índice elevado de buraco estrutural as ocupações são psiquiatra, médico em medicina nuclear, ortopedista, entre outros. Esses médicos apresentam baixa centralidade na rede e, estão localizados na periferia da rede médico da estratégia de saúde da família. Na rede de ocupações, as ocupações que apresentam buraco estrutural são as mesmas dos médicos que apresentam o maior índice de buraco estrutural.

Questão 5: Qual a frequência com que Médicos da estratégia de saúde da família se posicionam em potenciais buracos estruturais na rede de médicos?

Questão 6: Qual o percentual com que brokers aparecem entre as unidades de saúde que atendem os níveis de $A B, M C$ ou $A C$ ?

\begin{tabular}{|c|c|c|}
\hline \multicolumn{3}{|c|}{$\begin{array}{c}\text { Atores que apresentam Buraco Estrutural } \\
\text { Nível de Análise }\end{array}$} \\
\hline Unidades de Saúde & Médicos & Ocupação \\
\hline Agnaldo Miranda (AB) & $\begin{array}{l}\text { O ator A125 tem a ocupação de médico } \\
\text { da estratégia de saúde da família }\end{array}$ & Médico em Medicina Nuclear \\
\hline Alberto Segalla Junior (MC) & $\begin{array}{l}\text { O ator A126 possui a ocupação de } \\
\text { médico da estratégia de saúde da família }\end{array}$ & Médico Psiquiatra \\
\hline $\begin{array}{l}\text { Ambulatório Municipal de } \\
\text { Saúde Mental de Bauru } \\
\text { (MC) }\end{array}$ & $\begin{array}{l}\text { O ator A127 tem a ocupação de médico } \\
\text { da estratégia de saúde da família }\end{array}$ & $\begin{array}{l}\text { Médico da Estratégia de Saúde } \\
\text { da Família }\end{array}$ \\
\hline $\begin{array}{l}\text { Ame Itapeva Edison } \\
\text { Oliveira Martho (MC) }\end{array}$ & $\begin{array}{l}\mathrm{O} \text { ator A5 tem a ocupação declarada de } \\
\text { médico clínico }\end{array}$ & Médico Radioterapeuta \\
\hline $\begin{array}{l}\text { Base Central e Regulação } \\
\text { Usa III (AB) }\end{array}$ & $\begin{array}{l}\text { O A119 tem a ocupação de médico da } \\
\text { estratégia de saúde da família }\end{array}$ & $\begin{array}{l}\text { Médico Endocrinologista e } \\
\text { Metabologista }\end{array}$ \\
\hline
\end{tabular}

Por último, espera-se que haja mais competição entre os médicos pelos vínculos profissionais em hospitais gerais do que as demais unidades de saúde. Usualmente, os atores 
com maior grau de Hubiness são hospitais gerais. Nesta pesquisa, identificou-se o Hospital Estadual de Bauru e o Hospital de Base como atores na rede de médicos com maior grau de Hubiness, sendo esses hospitais gerais. Uma explicação provisória para isso é porque atores centrais obtém acesso a recursos, poder e informações do ator na rede (BALESTRIN E VERSCHOORE, 2008).

Portanto, propõe-se a seguinte questão de pesquisa:

Questão de Pesquisa 7 : Qual a diferença no nível de competição entre os médicos, por vínculos profissionais em hospitais gerais em relação as demais unidades de saúde?

\subsection{Implicações para a prática}

Este trabalho apresenta resultados relevantes, no que tange a aspectos da gestão de vínculos profissionais dos médico, da identificação dos principais Hubs de saúde no município de Bauru e da proposta de um esquema conceitual de análise da rede de médicos no SUS.

Foi destacado no Gráfico 5 (inserido no Capítulo 4), que a quantidade de vínculos profissionais dos médicos varia entre 1 e 27 vínculos. Percebe-se que algumas ações em relação a gestão dos vínculos profissionais médicos deveriam estar mais bem difundidas no sistema público de saúde. A média de vínculos profissionais dos médicos da rede é 3 , porém cerca de $33 \%$ dos médicos da rede declaram ter de 4 a 10 vínculos profissionais.

A multiplicidade de vínculos profissionais dos médicos causa ineficiência para a rede de saúde, tanto no que se refere, à maximização da utilização dos recursos humanos e financeiros nas unidades de saúde, quanto a ocorrência nos médicos da síndrome de burnout e deslocamento entre as unidades de saúde (MAGALHÃES et al., 2015). Os médicos buscam complementar os ganhos salariais com diversos vínculos profissionais (MACIEL et al., 2010). Consequente, a carga horária semanal de trabalho desses médicos, que acumulam diversos vínculos profissionais, são mais elevadas. Na rede de médicos em estudo, a média é de 42 horas semanais de trabalho, mas a amplitude varia entre 2 e 130 horas semanais de trabalho, o que gera uma produtividade decrescente, conforme o estudo de Pencavel (SMITH, 2015).

Outro fato relevante para a discussão é que a média da carga horária semanal por esfera de gestão é baixa, conforme discussão do Capítulo 4 (seção 4.1.1 - Análise geral da 
rede e síntese dos resultados), sendo a Esfera Estadual (12,91 horas/semanais), a Esfera Federal (26 horas/semanais), a Esfera Municipal (12,40 horas/semanais) e a Esfera Privada (9,33 horas/semanais). Isso evidencia a multiplicidade de vínculos profissionais dos médicos em diferentes esferas de gestão.

No entanto, estabelecer políticas de gestão dos vínculos profissionais dos médicos para melhorar a eficiência da rede e do sistema de saúde é importante. No caso dos médicos unificar a quantidade de vínculos profissionais e limitar a carga horária de trabalho semanal por esfera de gestão. Isso implicaria inclusive em uma redução de custos trabalhistas para o sistema. Como exemplo, o ator A251 declara 4 vínculos profissionais na esfera municipal, portanto esses custos relacionados a direitos trabalhistas (isto é, férias, décimo terceiro salário etc.) são quadruplicados para o município.

Foram identificadas as unidades de saúde que atuam como $H u b$ na rede em estudo, essas unidades estão melhores posicionadas de forma a concentrar recursos (médicos mais especializados, equipamentos que envolvem alta tecnologia). Alguns Hubs emergem porque ocupam posições de centralidade na rede por vantagens locacionais (DERUDDER et al, 2007). No calculo do HA, verificou-se a presença de dois tipos de Hubs, sendo os locais (como exemplo, Hospital de Base de Bauru) e os regionais (como exemplo, Hospital Estadual de Bauru). Conforme a discussão do Capítulo 4 (seção 4.2) e Tabelas 56 e 58. Entre os Hubs regionais identificados, verifica-se, que os dois com o maior índice de Hubiness são Hospitais Gerais e os Hubs locais quatro deles são Pronto Atendimento. Dessa forma, esses Hubs estão duplicando recursos no mesmo nível de atendimento e na mesma esfera de gestão. Assim, a identificação dos Hubs de saúde torna-se importante para verificar onde os recursos estão sendo aplicados e gerar ações de gestão na rede de saúde. Portanto, ações de desregulamentação poderiam auxiliar na formação dos $H u b s$ e a tendência seria a concentração de recursos para melhorar a eficiência na rede de saúde.

Finalmente, esta tese contribui para a prática com a proposta de um esquema conceitual de análise da rede de médicos no âmbito do SUS (Figura 46, seção 4.4). Esse esquema conceitual baseou-se nos três níveis de atendimento no contexto do SUS e, buscou identificar as unidades de saúde e as ocupações dos médicos tipicamente encontradas em cada nível. Isso é relacionado com o grau de conectividade da rede de médicos. Os resultados desta pesquisa pode auxiliar os gestores na tomada de decisão sobre os recursos necessários em cada nível de atendimento do SUS, por meio do entendimento do posicionamento dos atores na rede de médicos e unidades de saúde. 


\section{CONCLUSÕES}

Este capítulo busca discutir as principais conclusões no que tange ao alcance dos objetivos propostos, às tendências de pesquisas futuras e às limitações desse estudo.

O objetivo principal dessa pesquisa trata do desenvolvimento de uma análise da rede de médicos com vínculos profissionais em unidades de saúde públicas e privadas. Adicionalmente busca-se identificar os principais Hubs nas unidades de saúde no Município de Bauru e propor um esquema conceitual para análise da rede em estudo. Desse modo, convém retornar às questões chaves que guiaram a realização dessa pesquisa, para apresentar as principais conclusões a respeito dessa pesquisa.

Q1 Como analisar, por meio da teoria de redes, a rede de médicos com vínculos profissionais em unidades de saúde públicas e privadas de um município do Estado de São Paulo?

Q2 - Qual a configuração da rede de médicos com vínculos profissionais em unidades de saúde públicas e privadas, delimitada a partir de unidades de saúde vinculadas ao SUS (Município de Bauru)?

Este trabalho conseguiu alcançar os objetivos inicialmente propostos.

Para a realização do estudo, foi mapeada a rede de médicos e identificados os Hubs de saúde com maior conectividade na rede. A pesquisa foi realizada no âmbito do SUS e foi delimitada a partir do município sede do DRS - Bauru, sendo a principal base de dados utilizada - o sistema DATASUS/CNES, sendo esses dados públicos e atualizados mensalmente. $\mathrm{O}$ mapeamento da rede de médicos com vínculos profissionais em unidades de saúde públicas e privadas envolveu três níveis de análise: (1) Unidades de Saúde (organização); Médicos (pessoas) e Ocupações (cargos) por meio dos vínculos profissionais dos médicos que atendem ao SUS. Para mapear a rede foi utilizado um software de análise de redes que gerou medidas de centralidade, densidade, rede ego e buraco estrutural e, a literatura auxiliou na interpretação e na análise dos resultados (inseridos no Capítulo 4, seções 4.1 e 4.2$)$.

No nível de análise de unidades de saúde, a estrutura geral da rede é grande, sendo composta por 655 atores. A rede é tida como difusa, os laços são fracos e o índice de centralidade é de $23 \%$, sendo que a maioria dos atores está localizada na periferia da rede. A rede pode ser considerada como um sistema aberto (rede aberta) o que favorece a propagação de informações, beneficiando a busca por conhecimento e inovação nos diferentes níveis de atendimento, porém, o núcleo dessa rede é denso com laços fortes e altamente conectados. 
No nível de análise da rede de médicos, considera-se que o tamanho da rede é grande e envolve um significativo número de atores (789). Por outro lado, a rede de ocupações é pequena e composta por 65 nós que se relacionam entre si. Ambas as redes (de médicos e ocupações) apresenta a característica de uma rede densa e com presença de laços fortes, há grande interconectividade entre atores, pois cerca de $98 \%$ dos nós estão conectados. Essas estruturas, apresentam-se como um sistema fechado (rede fechada), focando no intercambio social, confiança, partilha conhecimentos e normas. Este tipo de rede beneficia a execução, devido à confiança e à troca de conhecimentos disseminada entre os atores da rede e, consequentemente, favorece a qualidade da prestação dos serviços de saúde aos pacientes que buscam por atendimento no SUS.

Os três níveis de análise apresentam a presença de buraco estrutural e, sendo que os atores que estão localizados na periferia da rede, estão melhor posicionados para acessar informações e inovar. No caso da rede de médicos e de ocupações, os atores periféricos são aqueles com especialidades especificas, tais como: Médico em Medicina Nuclear, Médico Psiquiatra e Médico da Estratégia de Saúde da Família.

A identificação dos Hubs de saúde foi feita por meio da formula do grau de Hubiness do modelo Hub and spoke, originalmente proposto para a área de logística por Derudder et al. (2007). Essa fórmula foi adaptada para avaliar o grau de Hubiness das unidades de saúde públicas e privadas. O cálculo do HA possibilitou identificar a presença de dois tipos de $H u b s$ na área de saúde, sendo os locais e os regionais. Na rede em estudo, os Hubs regionais, são tipicamente os hospitais gerais e os Hubs locais, as unidades de pronto atendimento.

A proposta de um esquema conceitual de análise da rede de médicos no SUS (Figura 46) auxiliou no entendimento da rede e ilustrou os atores tipicamente encontrados nos diferentes níveis de atendimento do SUS. Os Hubs tipicamente encontrados são atores que atuam nos níveis de $\mathrm{AC}$ e, são compostos pelos hospitais gerais. Os médicos que declaram as ocupações Médico da Estratégia de Saúde da Família, Ginecologista e Pediatra são aqueles atores típicos que atendem no nível $\mathrm{AB}$.

A literatura sugere que as redes difusas e os buracos estruturais permitem acessar informações não redundantes e inovar por meio de seus laços fracos de relacionamento, e dos atores que estão localizados na periferia da rede. Já nas redes densas os nós são altamente conectados e com alto índice de centralização, caracterizada como um laço forte. Esse trabalho corrobora, por meio dos dados empiricamente observados, o consenso na literatura.

O modelo $H u b$ and Spoke auxiliou a identificar a formação de $H u b s$, por meio da concentração de recursos no setor de saúde nos diferentes níveis de atendimento. Assim, as 
unidades de saúde (Hubs) concentram os equipamentos caros e de alta tecnologia e os médicos possuem maior nível de conhecimento e, as unidades de saúde mais básica (Spokes) concentram recursos de baixo valor e médicos mais generalistas. Nesse sentido, a existência de Hubs observados nesse município indicam que há uma melhor eficiência nas conexões da rede de saúde.

Os resultados desta pesquisa contribuem tanto para a teoria, com o estabelecimento de questões de pesquisa descritivas, quanto para a prática, com a proposição de um esquema conceitual de análise da rede de médicos no SUS. Adicionalmente, a adaptação da fórmula do grau de Hubiness do modelo Hub-and-Spoke serviu para identificar as unidades de saúde que atuam como $H u b$ e, finalmente, pela identificação da necessidade de políticas para a gestão dos vínculos profissionais médicos no SUS. Além disso, este estudo pode servir como um estudo pioneiro para os acadêmicos e profissionais que decidem adotar esse tipo de análise de redes.

Em razão da natureza do estudo estar baseada no contexto do SUS e delimitada em um município sede do DRS, surgem limitações de análise e coleta de dados. Uma limitação desse estudo foi o corte temporal na coleta de dados, dado que o sistema DATASUS/CNES é atualizado mensalmente. Os médicos que atuam no âmbito do programa "Mais Médicos" não estão inseridos no DATASUS/CNES, portanto não foram incluídos nessa pesquisa.

As pesquisas futuras devem envolver tanto um estudo quantitativo como qualitativo, utilizando estudos de caso, estudos etnográficos, instrumentos estatísticos, pesquisas de levantamento, gráficos e o aprofundamento no uso do softwares de análise de redes para grandes redes, além de softwares para simular e otimizar redes. Outra sugestão é a utilização das questões de pesquisa para estudos futuros. As questões de pesquisa podem ainda permitir o estabelecimento de hipóteses para teste empírico (Capítulo 4, seção 4.5) e aplicar o Esquema conceitual de análise da rede de médicos no SUS em outros municípios (Figura 46). 


\section{REFERENCIAS}

AHUJA, G. Collaboration Networks, Structural Holes, and Innovation: A Longitudinal Study, Administrative Science Quarterly, v. 45, n. 3, p. 425-455, 2000.

ALVAREZ, A.O.V e AGUILAR, N.G. (2005). Manual Introductorio al Análisis de Redes Sociales: Medidas de Centralidad, 2005. Disponível em: <http://revista-redes.rediris.es/webredes/talleres/manual_ars.pdf> Acesso em: 13 Set 2015.

ALEXANDER, J. A., S. D. LEE AND G. J. BAZZOLI. 'Governance forms in health systems and health networks', Health Care Management Review, v. 28, pp. 228-242, 2003.

ALMANSOORI, W.; GAO, S.; JARADA, T. N.; ELSHEIKH, A. M.; MURSHED, A. N.; JIDA, J.; REDA ALHAJJ; ROKNE, J. Link prediction and classification in social networks and its application in healthcare and systems biology. Network Modeling Analysis in Health Informatics and Bioinformatics, v.1, n. 1-2, p. 2736, 2012.

ANDERSON, U.; HOLM, D. B.; JOHANSON, M. Moving or doing? Knowledge flow, problem solving, and change in industrial networks. Journal of Business Research, n. 60, p. 32-40, 2007.

ANDRADE, L.O.M; BARRETO, I.C.H.C. Promoção da Saúde e o Sistema Nacional de Saúde no Brasil: um alinhamento conceitual necessário. Ciência \& Saúde Coletiva, v.9, n.3, p.530-543, 2004.

ARROYABE, M.F.; NIEVES, A; ARROYABE , J.C.F. R\&D partnerships: An exploratory approach to the role of structural variables in joint project performance. Technol. Forecast. Soc. Change, p. 1-11, 2014.

AUTRY, C.W. AND S.E. GRIFFIS. “A Social Anthropology of Logistics Research: Exploring Productivity and Collaboration in an Emerging Science,', Transportation Journal, v. 44:4, pp. 27-43, 2005,.

AUTRY, C.W.; GRIFFIS, S.E. Supply Chain Capital: The impact of structural and relational linkages on firm execution and innovation. Journal of Business Logistics, v. 29, n. 1, 2008.

BABIE, E. Métodos de pesquisas de Survey. Tradução: Guilherme Cezarino. Belo Horizonte: Ed. UFMG, 1999, 519p.

BALDI, M. A.;VIEIRA, M.F. Calçado do Vale: Imersão social e redes interorganizacionais. RAE n. 3 v. 46 , p. 16-27, 2006.

BALESTRIN, A.; VERSCHOORE, J. Redes de cooperação empresarial: estratégia de gestão na nova economia. São Paulo: Bookman, 2008.

BARABASI, A.L. ; JEONG, H.; NÉDA, Z.; RAVASZ, E.; SCHUBERT, A., VICSEK, T. Evolution of the social network of scientic collaborations. Physica A, v. 311, p. 590 - 614, 2002.

BARATA, L.R.B.; MENDES, J. D. V.; BITTAR, O.J.N.V. Hospitais de ensino e o sistema Único de saúde. RAS. v. 12, n. 46, 2010.

BARBEIRA, M.; FRANCO, M; HAASE, H. Knowledge sharing in networks within the healthcare sector: measuring knowledge management capabilities. 13th European Conference on Knowledge Management (ECKM), 2012, Spain. Proceedings of the 13th european conference on knowledge management, v. 1, p. 37-47, 2012.

BATAGElJ, V; ZAVERSNIK, M. An O(m) Algorithm for Cores Decomposition of Networks. Advances in Data Analysis and Classification, Volume 5, Number 2, 129-145, 2002. Disponível em: http://arxiv.org/pdf/cs/0310049v1.pdf. Acesso em: 12 dez. 2015

BAUM, J.A.C; COWAN, R. E JONARD, N. Network-Independent Partner Selection and the Evolution of Innovation Networks. Management Science, v.56(11), pp. 2094-2110, 2010. 
BERlingerio, M; COSCIA, M; GIANNOTTIA, F; ANNA MONREALE, A.; PEDRESCHI; D. The Pursuit of Hubbiness: Analysis of Hubs in Large Multidimensional Networks. Preprint submitted to Elsevier. May 11, 2011.

BITtAR, O. J. N; MAGAlHÃes, A. Hospitais de Ensino no Estado de São Paulo : seis anos de acompanhamento. RAS, especial, p. 155-213, 2010.

BITTAR, O. J . N. V; MENDES, J. D.V.; MAGALHÃES, A. Rede hospitalar no Estado de São Paulo: mapear para regular. São Paulo: SES/SP, 2011.

BOLZE, M.G; FISCHER, P.D.; MISOCZKY, M.C.A.; BORDIN, R. Vínculos Empregatícios de Médicos de Família e Comunidade no Brasil, 2004. Revista Brasileira de Educação Médica, 34 (3) : 406-411, 2010

BORGATTI, S.P; EVERETT , M.G. Models of Core/Periphery Structures. Social Networks, 21: 375-395, 1999.

BORGATTI, S.P; EVERETT, M.G; FREEMAN, L.C. UCINET 5 for Windows: Software for Social Network Analysis (USER'S GUIDE), 1999. Disponível em: <http://www.analytictech.com/ucinet6/Ucinet_Guide.doc>. Acesso em: 15 Nov 2015.

BORGATTI, S. P.; LI, X. On social network analysis in a supply chain context. Journal of Supply Chain Management,v. 45, n. 2, p. 5-22, 2009.

BORGATTI, S. $\quad$ P.; Centrality, 2005. Disponível $\quad$ em $<$ http://www.analytictech.com/essex/lectures/centrality.pdf> Acesso em: 13 out 2015.

BRAITHWAITE, J,;WESTBROOK, J.I.; RANMUTHUGALA, G., CUNNINGHAM, F., PLUMB, J., WILEY, J.; BALL, D.; HUCKSON, S.; HUGHES, C.; JOHNSTON, B.; CALLEN, J.; CRESWICK, N.; GEORGIOU, A.; MATIBET, L.B.; E DEBONO, D. The development, design, testing, refinement, simulation and application of an evaluation framework for communities of practice and social-professional networks. BMC Health Services Research, 9:162, 2009.

BRASIL, Lei n. 8.080, de 19 de setembro de 1990. (1990, 19 de setembro). Dispõe sobre as condições para a promoção, proteção e recuperação da saúde, a organização e o funcionamento, Brasília.

BRASIL. Atenção primária e promoção da saúde. Conselho Nacional de Secretários da Saúde. Brasília: CONASS, 2007.

BRASIL (2006). Decreto n. 51.433, de 28 de dezembro de 2006. (2006, 28 de dezembro). Cria unidade na Coordenadoria de Regiões de Saúde e dá providências correlatas. Diário Oficial Estado de São Paulo, Poder Executivo, Seção I

BRASIL. Portaria No 311, de 14 de Maio de 2007. Desativa automaticamente no Cadastro Nacional de Estabelecimentos de Saúde (SCNES) os Estabelecimentos de Saúde que estejam há mais de 6 (seis) meses sem atualização cadastral. Diário Oficial Estado de São Paulo, Poder Executivo, Seção I.

BRASIL. Ministério do Planejamento, Orçamento e Gestão. Instituto Brasileiro de Geografia e Estatística. Projeção da população do Brasil e das Unidades da Federação, 2014. Disponível em: <http://www.ibge.gov.br/apps/populacao/projecao/>. Acesso em: 06 Ago 2014.

BRASIL, Ministério da Saúde. Entendendo o SUS. Portal da Saúde, 2006. <Disponível em: http://portal.saude.gov.br/portal/saude/area.cfm?id_area=136> Acesso em: 22 Jan. 2014.

BRITTO, J. Redes de cooperação entre empresas. In: KUPFER, D. e HASENCLEVER, L. Economia Industrial: Fundamentos teóricos e práticas no Brasil. 9. ed. Rio de Janeiro, Editora Campus, 640p, 2002.

BURT, R.S. Structural Holes: The social structures of competition. Harvard University Press, England, 1992.

BURT, R. S. A Note on Social Capital and Network Content; Social Networks, 1997, v. 19(4), pp. 355-73, 1997. 
BURT, R. S. Brokerage and closure: An introduction to social capital. New York: Oxford University Press, 2005.

BURT, R. S.; MELTZER, D. O.; SEID, M.; BORGERT, A.; CHUNG, W.; COLLETTI, R. B.;DELLAL, G.; KAHN,S.A.; KAPLAN, H.C.; PETERSON, L.E.;MARGOLIS, P. What's in a name generator ? Choosing the right name generators for social network surveys in healthcare. BMJ Qual Saf, v. 21,p. 992-1000, 2014.

CAMPOS, G.W.S. Reflexões Temáticas sobre Equidade e Saúde: o caso do SUS. Saúde e Sociedade v.15, n.2, p.23-33, 2006.

CARRINGTON, P.; SCOTT, J.; WASSERMAN, S. Models and methods in social network analysis (1st ed.). Cambridge: Cambridge University Press, 2005.

CARSWELl, P.; MANNING, B.; LONG, J.; BRAITHWAITE, J.(2014). Building clinical networks: a developmental evaluation framework. BMJ Qual Saf, v. 23, n.5, p. 422-7.

CARTER, C. R.; LEUSCHNER, R.; ROGERS, D. S. A Social Network Analysis of the Journal of Supply Chain Management: Knowledge Generation, Knowledge Diffusion and Thought Leadership. The Journal of Supply Chain Management, v. 43, n.2, p. 15-28, 2007.

CERVO, A. L.; BERVIAN, P.A.; DA SILVA, R. Metodologia Científica. 6. ed. São Paulo: Pearson, 2006.

CESCONETTO, A.; LAPA, J.S.; MARINO, M.C. Avaliação da eficiência produtiva de hospitais do SUS de Santa Catarina. Cad. Saúde Pública, Rio de Janeiro, v.24, n.10, p. 2407-2417, 2008.

CHAMBERS, D.; WILSON, P.; THOMPSON, C.; HARDEN, M. Social network analysis in healthcare settings: a systematic scoping review. PloS One, v.7, n.8, 2012.

COELHO, P.S.; SILVA, R.N.S. Um Estudo Exploratório sobre as Metodologias Empregadas em Pesquisas na Área de Contabilidade no EnANPAD. Revista Contemporânea de Contabilidade, ano 04, v.1, n.8, p. 139-159, 2007.

COLEMAN, J.S. Social capital in the creation of human capital. American Journal of Economic Sociology, 94 (Supplement), p. 95-119, 1988.

COLEMAN, J. S. Foundations of social theory. Cambridge, MA: Harvard University Press, 1990.

CORNWALL, A.; SHANKLAND, A. Engaging citizens: lessons from building Brazil's national health system. Social Science \& Medicine , v.66, n.10, p. 2173-84, 2008.

CUNNINGHAM, F. C.; RANMUTHUGAlA, G.; PlUMB, J.; GEORGIOU, A.; WESTBROOK, J. I.; BRAITHWAITE, J. Health professional networks as a vector for improving healthcare quality and safety: a systematic review. BMJ Quality Safety, v.21, n.3, p. 239-49, 2011.

CUNNINGHAM, F. C.; RANMUTHUGALA, G.; WESTBROOK, J. I.; BRAITHWAITE, J. Net benefits: assessing the effectiveness of clinical networks in Australia through qualitative methods. Implementation Science, 7:108, 2012.

CYRAM. NetMiner 3.3.0.Seoul:Cyram Co., Ltd, 2008.

DEPARTAMENTO DE INFORMÁTICA DO SUS (DATASUS). Cadastro Nacional de Estabelecimentos de Saúde. Disponível em: < Http://cnes.datasus.gov.br> Acesso em: 24 Set. 2013 e 01 abr à 30 jun 2015.

DERUDDER, B.; LOMME DEVRIENDT, L.; FRANK WITLOX, F. FLYING. Where You Don't Want To Go: An Empirical Analysis Of Hubs In The Global Airline Network. Tijdschrift voor Economische en Sociale Geografie, Vol. 98, No. 3, pp. 307-324, 2007.

DEVARAKONDA, S. Hub and spoke model: making rural healthcare in India affordable, available and accessible. Rural Remote Health. Jan-Mar;16(1):3476. Epub, 2016. 
DIAZ, J.A.R. Networks and the future: A new methodological approach to envision and create the network society of tomorrow. Futures, v. 41, p. 490-501, 2009.

DOMINGOS, M.C. Managing healthcare through social networks. IEEE Computer Society. 0018-9162/10, p. 20-25, 2010.

DUNN, A. G.; WESTBROOK, J. I. Interpreting social network metrics in healthcare organisations: a review and guide to validating small networks. Social Science \& Medicine, v. 72, n. 7, p. 1064-8, 2011.

FALAVIGNA, A.; CANABARRO, C. T.; MEDEIROS, G. S. Health system and medical education in Brazil: history, principles, and organization. World Neurosurgery, v. 80, n.6, p. 723-7, 2013.

FERREIRA, M. P. Assistência à Saúde nos Departamentos Regionais de Saúde: um exercício metodológico sobre eficiência e acesso aos serviços de saúde. 2009. 140 f. Tese (Doutorado em Ciências) - Universidade de São Paulo. Faculdade de Medicina de São Paulo, São Paulo, 2009.

FLEMING, D.K.; Y. HAYUTH. Spatial Characteristics of Transportation Hubs: Centrality and Intermediacy. Journal of Transport Geography 2, pp. 3-18, 1994.

FREEMAN, L.C. Centrality in social networks conceptual clarification. Social Networks 1, 215-239, 1978.

GALASKIEWICZ, J. “Editorial: Has a Network Theory of Organizational Behaviour Lived Up to Its Promises?,’ Management and Organization Review, (3), pp. 1-18, 2007.

GALASKIEWICZ, J. Studying Supply Chains From a Social Network Perspective. Journal of Supply Chain Management, v. 47, n.1, p. 4-8, 2011.

GILSING, V.A.; DUYSTERS, G.M. Understanding novelty creation in exploration networks-Structural and relational embeddedness jointly considered. Technovation ,v.28, pp. 693-708, 2008.

GILSING, V.; NOOTEBOOM, B. Density and strength of ties in innovation networks: an analysis of multimedia and biotechnology. European Management Review, n.2, pp.179-197, 2005.

GILSING, V. A.; LEMMENS, C. E. A. V.; DUYSTERS, G. Strategic Alliance Networks and Innovation: A Deterministic and Voluntaristic View Combined, Technology Analysis \& Strategic Management, 19:2, p. 227-249, 2007.

GNYAWALI, D.R.; MADHAVAN, R. Cooperative networks and competitive dynamics: A structural embeddedness perspective. Academy of Management Review, v. 26, n. 3, p. 431-445, 2001.

GOBBO JUNIOR, J. A.; OLSSON, A. The transformation between exploration and exploitation applied to inventors of packaging innovations. Technovation, n. 30, p. 322-331, 2010.

GOBBO, S.C.O.; FUSCO, J.P.A.; GOBBO JUNIOR, J.A. An analysis of embeddedness in the value creation in interorganisational networks: an illustrative example in Brazil. Int. J. Advanced Operations Management, v. 6, n. 2, pp.178-198, 2014.

GOBBO, SCO. Uma análise do embeddedness na formação de valor em redes de empresas: um exemplo de aplicação em uma rede do setor metal-mecânico / 2010. 145 f. Dissertação (Mestrado em Engenharia de Produção) - Universidade Estadual Paulista, Campus Bauru. Bauru, São Paulo, 2010.

GOVINDARAJAN, V.; RAMAMURTI, R. Delivering world-class health care, affordably. Innovative hospitals in índia are pointing the way. Harvard Business Review, pp. 1-7, 2013.

GRANJA, G.F.; ZOBOLI, E.L.C.P.; LISLAINE APARECIDA FRACOLLI, L.A.F. O discurso dos gestores sobre a equidade: um desafio para o SUS. Ciência \& Saúde Coletiva, v.18, n.12, pp. 3759-3764, 2013.

GRANOVETTER, M.S. Economic Action and Social Structure: The problem of Embeddedness. The American Journal of Sociology. v. 91, $\mathrm{n}^{\circ} 2$, pp. 481-510, 1985. 
GRANOVETTER, M. S. The strength of weak ties. American Journal of Sociology, n. 78, p.1360-1380, 1973.

GRENIER, C. Structuring an integrated care system: interpreted through the enacted diversity of the actors involved - the case of a French healthcare network, International Journal of Integrated Care, v. 11, n. 16. pp. 1-15, 2011.

GRIFFITHS, F.; CAVE, J.; BOARDMAN, F.; REN, J.; PAWLIKOWSKA, T.; BALL, R; COHEN, A. Social networks-the future for health care delivery. Social Science \& Medicine, v. 75, pp. 2233-41, 2012.

GÜNTHER, H. Pesquisa qualitativa versus pesquisa quantitativa: esta é a questão? Psicologia: Teoria e Pesquisa, v. 22, n. 2, p. 201-210, 2006.

HANSEN, D.L., SHNEIDERMAN, B., SMITH, M.A.: Analysing social media networks with NodeXL: insights from a connected world. Morgan Kaufmann, Amsterdan. 284 p, 2011.

HEMSTROM, C.; SELEN, W. Building resource planning capability in clinical hospital networks using casemix : a conceptual framework. Proceedings of the 11th Annual Conference of Asia Pacific Decision Sciences Institute, Hong Kong, pp. 77-88, 2006.

HE, X.; HUA, E.; LIN, Y.; LIU, X. Computer, Informatics, Cybernetics and Applications: Proceedings of the CICA 2011, Springer Science \& Business Media, 1 de dez de 2011 - 1704 p., 2011.

HULT, G.T.M.; HURLEY,R.F.; GUINIPER L.C.; NICHOLS JR, E.L. Organizational Learning in Global Purchasing: A Model and Test of Internal Users and Corporate Buyers, Decision Sciences, v.31, n.2, pp. 293325, 2000.

HULT, G.T.M.; KETCHEN, D.J.; NICHOLS JR., E.L. Organizational Learning as a Strategic Resource in Supply Management, Journal of Operations Management, v.21, n.5, pp. 541-556, 2003.

IÑIGUEZ, T; PLUMED, M; MARTÍNEZ, M.P.L. Ryanair and Spain: Air connectivity and tourism from the perspective of complex networks. Tourism \& Management Studies, 10(1), 46-52, 2014.

JACK, S.L. The role, use and activation of strong and weak network ties: a qualitative analysis. Journal of Management Studies. v. 42, p. 1233-1259, 2005.

JAY, N.; KOHLER, F.; NAPOLI, A. Using formal concept analysis for mining and interpreting patient flows within a healthcare network, Springer-Verlag, Berling Heidelberg, p. 263-268, 2008.

JUNQUEIRA, L. A. P.; DAPUZZO, F. Gestão de redes: a estratégia de regionalização da política de saúde, História, Ciências, Saúde - Manguinhos, Rio de Janeiro, p. 545-547, 2010.

KAMADA, T. e KAWAI, S. (1989). An Algorithm for drawing general undirected graphs. Information Processing Letters, v. 31, pp. 7-15, 1989.

KOGUT, B. The network as knowledge: generative rules and the emergence of structure. Strategic Management Journal, v. 21, n.3, p.405-25, 2000.

KOVÁCS, G. e SPENS, K.M. Abdutive Reasoning in Logistics Research. International Journal of Physical Distribuition \& Logistics Management, 35:132-144, 2005.

KRZYWINSKI, M.; ALTMAN, N. Points of significance: visualizing samples with box plots. Nature Methods, v. 11, n. 2, p. 119-120, 2014.

LÄMSÄ, T.; SAVOLAINEN, T. Network Approach to Health Care Quality Improvement: the Case of a Finnish Hospital District, in E. Geisler, K. Krabbendam and R. Schuring (eds), Tecnology, health care, and management in the hospital of future, Praeger Publishers, Westport, pp. 3-12, 2003.

LARSSON, A.; WADELL, C.; PINEIRO, E.; RITZÉN,S. Collaborative healthcare innovation, Workbook, Departament of Machine Design, Royal Institute of Technology, Stockholm, Sweden, Product innovation engineering program (PIEp), (2012). Disponível em: <issuu .com/innoplant> Acesso em: 16 Set. 2013. 
LEMOS C, CHAVES L.D.P. Produção de internações hospitalares, no Sistema Único de Saúde, na região de Ribeirão Preto, Brasil. Rev Gaúcha Enferm., Porto Alegre (RS), v.32, n.4, pp.727-35, 2011.

LENZ, R.; BEYER, M.; KUHN, K. A. Semantic integration in healthcare networks. International Journal of Medical Informatics, v.76, n.2-3, pp. 201-7, 2007.

LIU, C.H. The effects of innovation alliance on network structure and density of cluster. Expert Systems with Applications, v. 38, pp. 299-305, 2011.

LONGARAY, A. A.; ENSSLIN, L. Uso da MCDA na identificação e mensuração da performance dos critérios para a certificação dos hospitais de ensino no âmbito do SUS. Production Journal, v.24, n.1, p.41-56, 2014.

MAGALHÃES, E; OLIVEIRA, A.C.M.S; CATIA SOUSA GOVÊIA; LADEIRA, L.C.A; QUEIROZ, D.M.; E VIEIRA, C.V. Prevalência de síndrome de burnout entre os anestesiologistas do Distrito Federal. Rev Bras Anestesiol., 65(2):104-110, 2015.

MACIEL, R.H.; SANTOS, J.B.F; SALES, T.B; ALVES, M.A.A; LUNA, A.P LEONARDO; FEITOSA, L.B. Multiplicidade de vínculos de médicos no Estado do Ceará. Rev Saúde Pública, 44 (5):950-6, 2010

MASCIA, D; CICCHETTI, A e DAMIANI,G. "Us and Them": a social network analysis of physicians'professional netwroks and their attitudes towards EBM. BMC Health Services Research, 13:429, 2013.

MARTELETO, R.M. Análise de redes sociais - aplicação nos estudos de transferência da informação. Ciência da Informação,v.30. no.1. Brasília. Jan./Apr.2001.

MASQUEFA, B. Top management adoption of a locally driven performance measurement and evaluation system: A social network perspective. Management Accounting Research. v.19, pp. 182-207, 2008.

MELLO, G.A.; IBAÑEZ,N.; VIANA, A.L.D. Um olhar histórico sobre a questão regional e os serviços básicos de saúde no Estado de São Paulo. Saúde Soc. São Paulo, v.20, n.4, p. 853-866, 2011.

MELTZER, D.; CHUNG, J.; KHALILI, P.; MARLOW, E.; ARORA, V.; SCHUMOCK, G.; BURT, R. Social Science \& Medicine Exploring the use of social network methods in designing healthcare quality improvement teams. Social Science \& Medicine, v.71, n.6, pp. 1119-1130, 2010.

MERIT IPA. Georgia's "Hub and Spoke" model for rural healthcare providers. Merit Independent Physician Association, 2015. Disponível em: <http://www.meritipa.com/georgias-hub-and-spoke-model-for-ruralhealthcare-providers/> .Acesso em: 11 Mai 2016.

MITRE, S.M.; ANDRADE, E.L.G.; MITRE, R.M. Avanços e desafios do acolhimento na operacionalização e qualificação do Sistema Único de Saúde na Atenção Primária: um resgate da produção bibliográfica do Brasil. Ciência \& Saúde Coletiva, v.17, n.8, pp. 2071-2085, 2012.

MORAIS, R. M; COSTA, A.L. Um modelo para avaliação de sistemas de informação do SUS de abrangência nacional: o processo de seleção e estruturação de indicadores. Rev. Adm. Pública, Rio de Janeiro, v. 48, n.3, pp. 767-793.

OLIVEIRA, E.X.G; CARVALHO, M.S.;TRAVASSOS, C. Territórios do Sistema Único de Saúde mapeamento das redes de atenção hospitalar. Cad. Saúde Pública, Rio de Janeiro, v. 20, n.2, p. 386-402, 2004.

PENG, T.-J. A.;BOURNE, M. The Coexistence of Competition and Cooperation between Networks: Implications from Two Taiwanese Healthcare Networks. British Journal of Management, v.20, n.3, pp. 377, 2009.

PEARCE, M.; GAMBRELL, D. This Chart Shows Who Marries CEOs, Doctors, Chefs and Janitors. Bloomberg, 2016. Disponível em: http://www.bloomberg.com/graphics/2016-who-marries-whom/. Acesso em: 16 de fev de 2016. 
PFEFFER, J. A.; SALANCIK, G. The external control of organizations: a resource dependence perspective. New York: Harper \& Row, 1982.

PINTO, N.R.S.; TANAKA, O.Y.T.; SPEDO, S.M. Política de saúde e gestão no processo de (re)construção do SUS em município de grande porte: um estudo de caso de São Paulo, Brasil. Cad. Saúde Pública, Rio de Janeiro, v. 25, n.4, pp. 927-938, 2009.

PINTO, N.R.S.; SPEDO, S.M.; TANAKA, O.Y. (Im)Possibilidades de Implementar uma Direção Única no SUS em Município de Grande Porte: o caso de São Paulo, Brasil. Saúde Soc. São Paulo, v.19, n.3, p.518-532, 2010.

POWELL, W. W., K. KOPUT, L. SMITH-DOERR. Interorganizational collaboration and the locus of innovation: Networks of learning in biotechnology. Admin. Sci. Quart. 41(1) 116-145, 1996.

PROVAN, K. G; KENIS, P. Modes of network governance: structure, management and effectiveness. J Publ Adm Res Theor, 18:229-252, 2008.

PUCCINI, P.T.; CORNETT, V.K.; SAHYOM, T.Z.; FUENTES, I.C.P.; BOTTA, L.M.G.; PUCCINI, R.F. Concepção de profissionais de saúde sobre o papel das unidades básicas nas redes de atenção do SUS/Brasil. Ciência \& Saúde Coletiva, v.17, n.11, pp. 2941-2952, 2012.

REAGANS, R.E; ZUCKERMAN, E.W. Why knowledge does not equal power: the network redundancy tradeoff. Industrial and Corporate Change, Volume 17, Number 5, pp. 903-944, 2008.

RONCHETTO, J.R.; HUTT, M.D.; REINGEN, P.H. “'Embedded Influence Patterns in Organizational Buying Systems”, Journal of Marketing, v.53, n.4, pp. 51-62, 1989.

ROWLEY, T.; BEHRENS, D.; KRACKHARDT, D. Redundant Governance Structures: An Analysis of Structural and Relational Embeddedness in the Steel and Semiconductor Industries, Strategic Management Journal, v. 21, n. 3, Special Issue: Strategic Networks, pp. 369-386, 2000.

SACOMANO NETO, M. Redes: Difusão de conhecimento e controle: Um estudo de caso na indústria Brasileira de caminhões. 2004. 259 f. Tese (Doutorado em Engenharia de Produção) - Universidade Federal de São Carlos. São Carlos, São Paulo, 2004.

SÁNCHEZ, P. M.; PÉREZ, M.E.G; VARELA, Y. A.; NÚÑEZ, J. V.; CARRAL, A.P.; SÁNCHEZ, E. Q. El análisis de las redes sociales. Un método para La mejora de La seguridad en las organizaciones sanitárias. Rev Esp Salud Pública, v. 87, pp. 209-219., 2013.

SCHICH, M.; SONG, C.; AHN, Y.Y.; MIRSKY, A.; MARTINO, M.; BARABÁSI, A.L.; HELBING, D. A network framework of cultural history .Science, v. 345, p. 558-562, 2014.

SCOTT, J. Social Network Analysis: A Handbook, 2nd ed., Sage Publications, Thousand Oaks, CA, 2000.

SEGATTO, C. Entrevista com GOVINDARAJAN, V. Por que a medicina pode levar você à falência. O lado oculto das contas de hospital. Época. 12 de maio de 2014. pp 80-83, 2014.

SHAW, S.-L. Hub Structures of Major US Passenger Airlines. Journal of Transport Geography 1, pp. 47-58, 1993.

SHIMIZU, H. E. Redes de Atenção à Saúde no Brasil. Physis Revista de Saúde Coletiva, Rio de Janeiro, v.23, n. 4, pp. 1101-1122, 2013.

SILVA, J.S. Métricas de análise de redes sociais e sua aplicação em redes de interação biológicas: metodologia de aplicação e estudos de caso. 2014. 171 f. Tese (Doutorado em Ciências) - Escola Politécnica da Universidade de São Paulo, São Paulo, 2014.

SKINKMAN, R (2015).Georgia will try hub-and-spoke model for rural hospitals. Fierce Healthcare. Finance. Feb 23, 2015. Disponível em: <http://www.fiercehealthcare.com/finance/georgia-will-try-hub-and-spoke-modelfor-rural-hospitals $>$ Acesso em: 11 Mai 2016. 
SMITH, N. Americans Already Work Plenty Hard, Jeb. US Economy. Bloomberg, 2015. Disponível em: $<$ http://www.bloombergview.com/articles/2015-07-13/jeb-bush-s-call-for-longer-work-hours-is-bush-leagueeconomics> Acesso em: 28 de agosto de 2015.

SPEDO, S.M.; TANAKA, O.Y.; PINTO, N.R.S. O desafio da descentralização do Sistema Único de Saúde em município de grande porte: o caso de São Paulo, Brasil. Cad. Saúde Pública, Rio de Janeiro, v.25, n.8, pp.1781$1790,2009$.

STERNBERG, R. Innovation Networks and Regional Development - Evidence from the European Regional Innovation Survey ( ERIS ): Theoretical Concepts , Methodological Approach, Empirical Basis and Introduction to the Theme Issue, 8(4), 2000.

STEWART, D. Socialized Medicine : How Personal Health Records and Social Networks Are Changing Healthcare, 2009. Disponível em: <http://www.econtentmag.com/Articles/ArticleReader.aspx? ArticleID=56166\&PageNum=1> Acesso em: 15 Mai 2014.

TASSELLI, S. Social Networks and Inter- professional Knowledge Transfer: The Case of Healthcare Professionals. Organization Studies, Vol. 36(7) 841-872, 2015.

TEIXEIRA, C.F. Promoção e vigilância da saúde no contexto da regionalização da assistência à saúde no SUS. Cad. Saúde Pública, Rio de Janeiro, 18(Suplemento), pp.153-162, 2002.

THRASHER, E. H.; CRAIGHEAD, C. W.; BYRD, T. A. An empirical investigation of integration in healthcare alliance networks. Decision Support Systems, v.50, n.1, pp.116-127, 2010.

TODEVA, E.; KNOKE, D. Strategic alliances and models of collaboration. Management Decision. v. 43, n. 1, pp. 123-148, 2005.

UZZI, B. The Sources and Consequences of Embeddedness for the Economic Performance of Organizations: The Network Effect, American Sociological Review, v. 61, n. 4, , pp. 674-698, 1996.

UZZI, B. Social structure and competition in interfirm networks: The paradox of embeddedness. Administrative Science Quarterly, n. 42, pp.35-67, 1997.

VICTORA, C.G.; BARRETO, M.L.; LEAL, M.C.; MONTEIRO, C.A.; SCHMIDT, M.I.; PAIM, J. F; BASTOS, F.I.; ALMEIDA, C.; BAHIA, L.; TRAVASSOS, C.; REICHENHEIM, M.; BARROS, F.C. Health conditions and health-policy innovations in Brazil: the way forward. v. 377, 2011. Disponível: www.thelancet.com Acesso em: 12 Mai 2015.

VIEGAS, S. M. F.; PENNA, C.M.M. O SUS é universal, mas vivemos de cotas. Ciência \& Saúde Coletiva, v.18, n.1, pp.181-190, 2013.

YIN, R.K. Estudo de caso: Planejamento e Métodos. Trad. Daniel Grassi. - 3. Ed. - Porto Alegre: Bookman, 212p, 2005.

WAARDEN, F.V. Dimensions and types of policy networks. European Journal of Political Research, v. 21, p.29-52, 1992.

WALKER, G., KOGUT, B.E.SHAN, W., Social capital, structural holes and the formation of an industry network. Organization Science, v. 8, p. 109-125, 1997.

WANG, G.X. A network approach for researching political feasibility of healthcare reform: the case of universal healthcare system in Taiwan. Social Science \& Medicine , v.75, n.12, pp.2337-44, 2012.

WASSERMAN, S.; FAUST, K. Social Network analysis. Cambridge University Press, 1994.

ZHAO, J.H.; ZHOU, H.J.; LIU,Y.Y. Inducing effect on the percolation transition in complex networks. Nature communications. v 4, p. 1-6, 2013. 
ZOPPI, L.G. Introdução ao NetMiner. Tree Branding. Apresentação ao Programa de Pós Graduação em Engenharia de Produção da UNESP -Campus de Bauru, Bauru, 24 Ago 2012.

ZUKIN, S., DIMAGGIO, P. Structures of Capital: The Social Organization of the Economy. Cambridge, MA: Cambridge University Press, 1990. 


\section{APÊNDICE A - Roteiro de entrevista utilizado no Estudo Piloto no DRS de Bauru}

Setor de Saúde:

Respondente:

Cargo:

1) Qual é a função do DRS no SUS? Para quem o DRS se reporta? Como é a hierarquia do SUS?

2) O sistema do SUS está divido em três níveis de atendimento: Rede de Atenção Básica, Rede de Média Complexidade e Rede de Alta Complexidade? Quais e quantas são as unidades de saúde que estão inseridas em cada rede? Existe algum relatório?

3) A quantidade de consultas ofertadas atende a demanda dos usuários do SUS?

4) Existem "filas de espera" de consultas em algum atendimento realizado pela Rede do SUS? Caso afirmativo, em qual rede existe essa "fila" e quais são especialidades de maior demanda?

5) Como funciona o encaminhamento de pacientes no SUS?

6) Para quem o DRS encaminha os pacientes? Qual é o critério de encaminhamento?

7) Existe algum sistema de informação integrado? (De todos os DRS com as Redes do SUS)

8) Na sua percepção, a rede do SUS está preocupada em criar novos conhecimentos com os pacientes? Informar por rede (AB, MC e AC).

9) $\mathrm{Na}$ sua percepção, a rede do SUS está preocupada em atender o maior número de pacientes? Informar por rede $(\mathrm{AB}, \mathrm{MC}$ e $\mathrm{AC})$ 